The Impact of Refugee Camps on the Process of Migration Towards Europe: An Assessment

Author: Sebastian Paul 


\title{
Department of International Relations
}

\author{
Dissertation Supervisor: András Tétényi, Ph.D.
}

\section{Declaration:}

I hereby declare that I am the sole author of the thesis entitled 'The Impact of Refugee Camps on the Process of Migration Towards Europe: An Assessment.' I duly marked out all quotations. The used literature and sources are stated in the attached list of references. 
Corvinus University of Budapest

International Relations Multidisciplinary Doctoral School

International and Security Studies

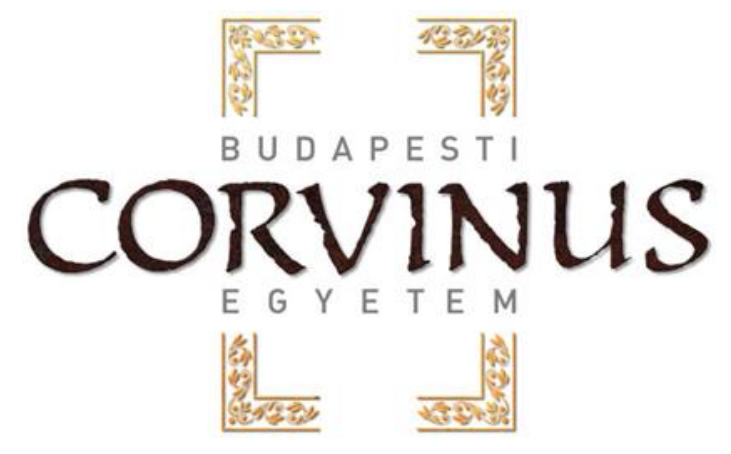

The Impact of Refugee Camps on the Process of Migration Towards Europe: An Assessment

Doctoral Dissertation

Author: Sebastian Paul

Place of Submission: Budapest

Year: 2021 
(20) 


\section{Table of Contents}

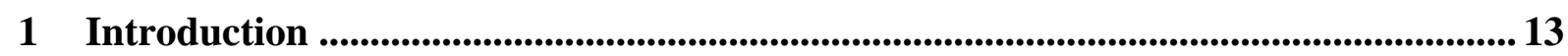

2 Methodology and Research Design ................................................................................ 18

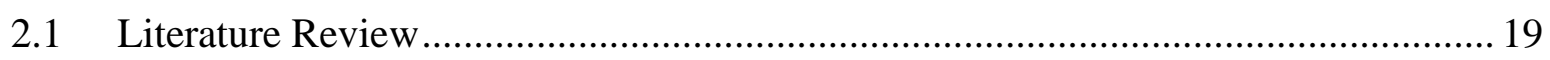

2.2 EU Migration Policies, Borders and Security, Policy Situation ............................. 21

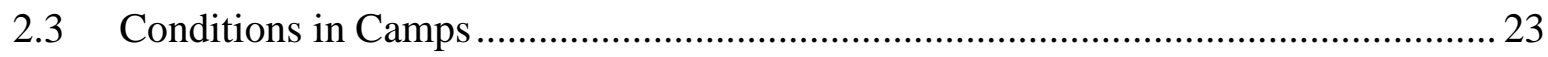

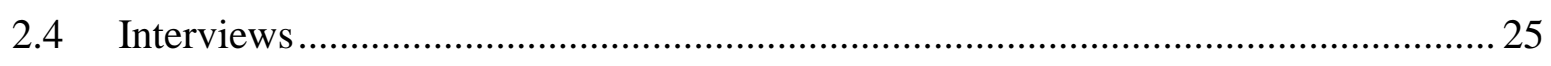

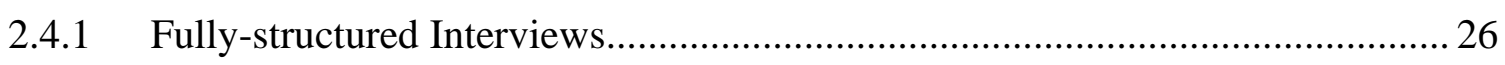

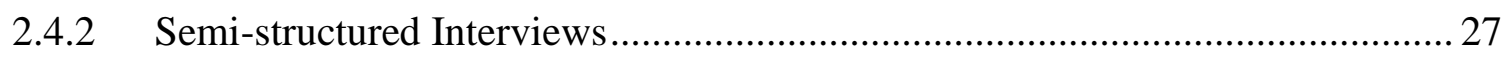

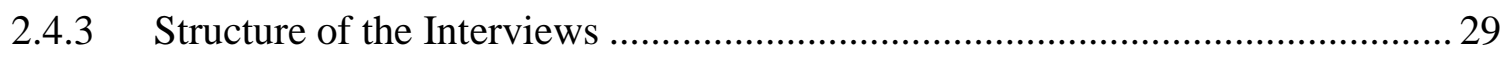

2.4.4 How do the Interviews answer the Research Question(s)? ............................... 30

2.4.5 Limitations and Weaknesses of the Research................................................... 31

2.4.6 Difficulties during the Conduction of the Interviews ....................................... 32

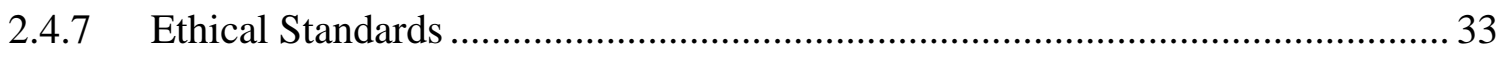

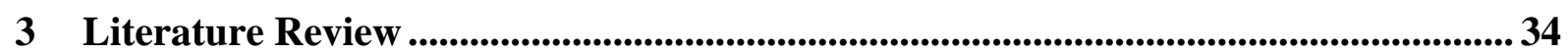

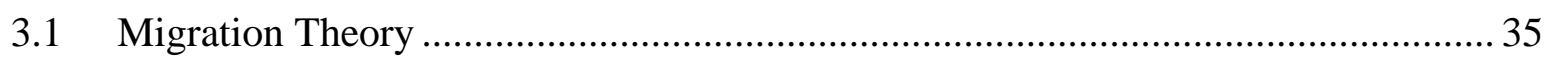

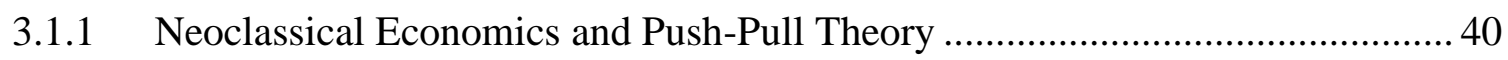

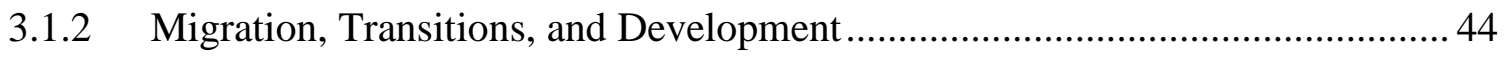

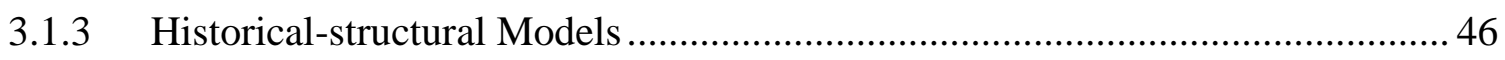

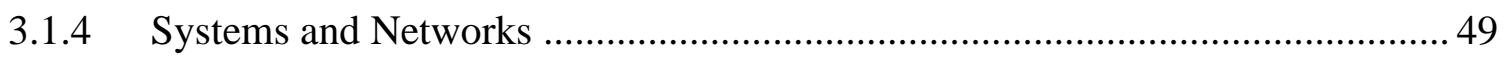

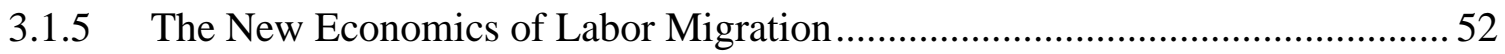

3.1.6 Aspiration and Ability Model / Drivers of Migration ....................................... 54

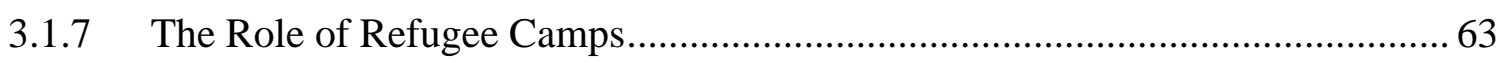

3.2 Current Status of Migration Studies...................................................................... 71

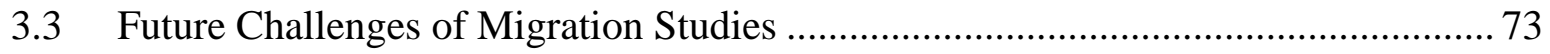

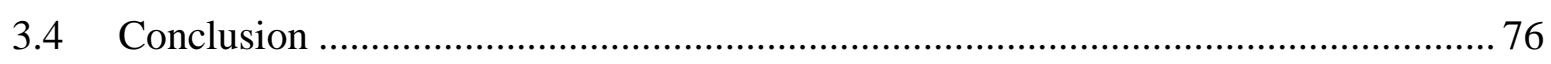

4 EU Migration Policies, Borders and Security, Policy Situation ................................ 78

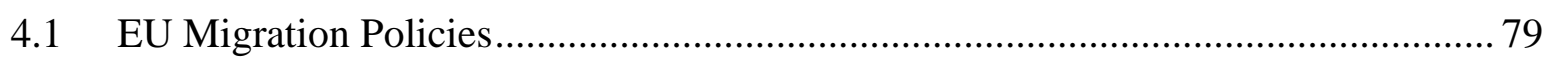

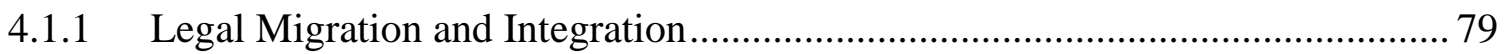

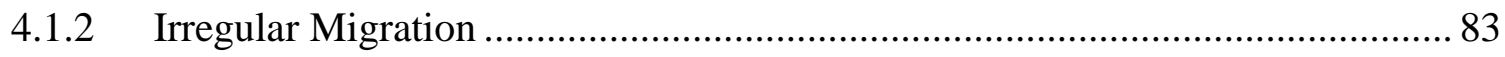

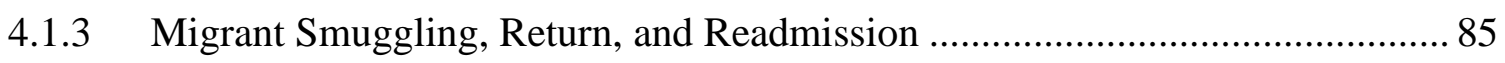

4.1.4 Common European Asylum System (CEAS) ................................................. 88

4.1.5 The country responsible for Asylum Application (Dublin)................................ 89

4.1.6 Reception Conditions and Asylum Procedures .............................................. 91 
4.1.7 Who qualifies for International Protection and Temporary Protection .............. 93

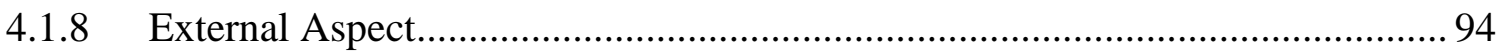

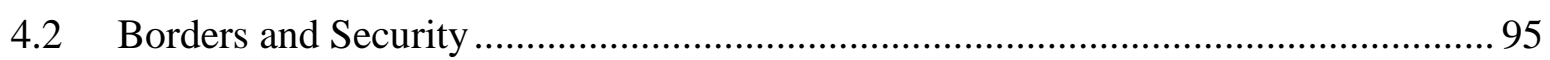

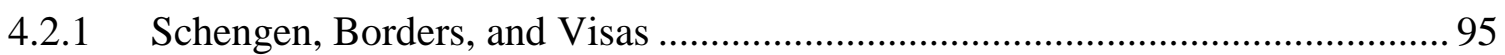

4.2.2 Counter-Terrorism and Radicalization ....................................................... 97

4.2.3 Organized Crime and Human Trafficking ......................................................... 99

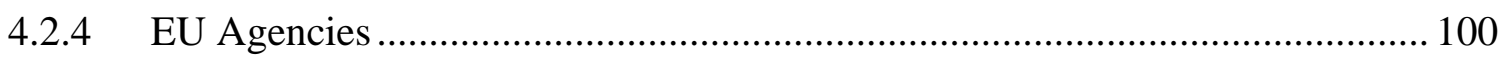

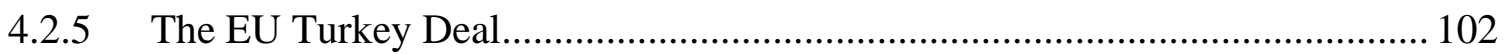

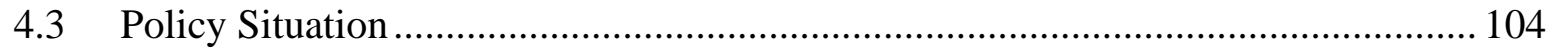

4.3.1 Growing Populism and Human Rights ...................................................... 104

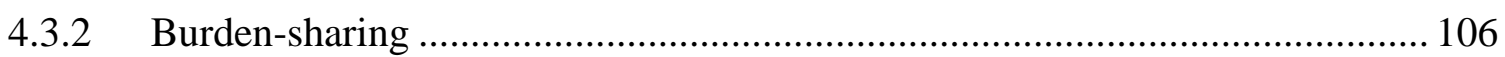

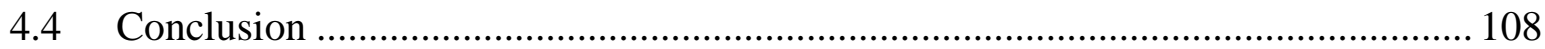

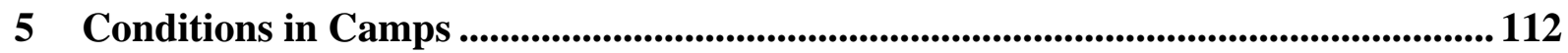

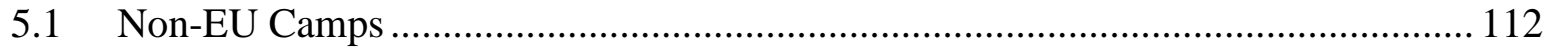

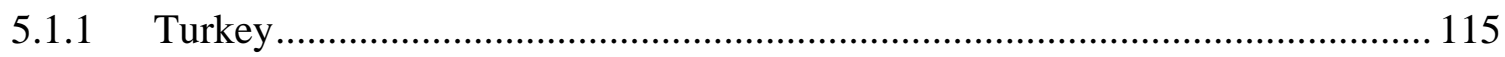

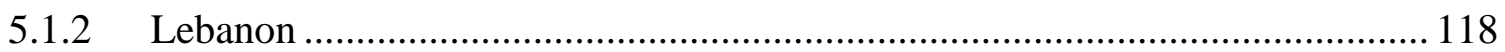

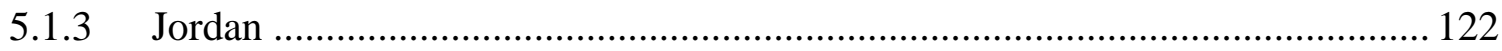

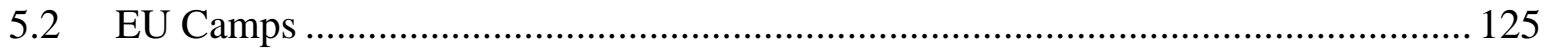

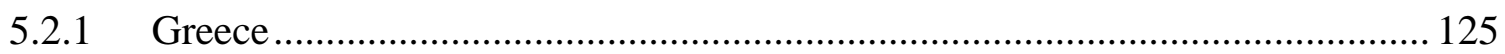

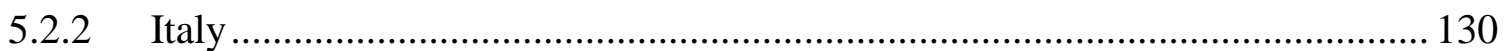

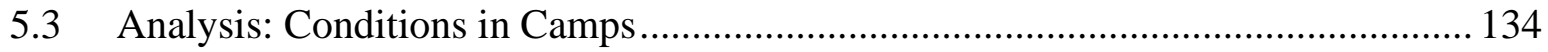

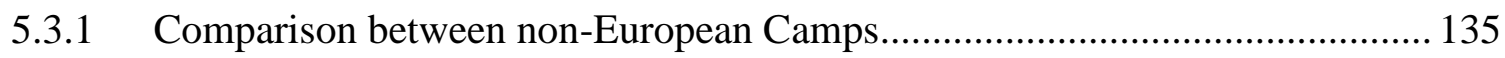

5.3.2 Comparison between Camps in the EU ........................................................ 136

5.3.3 Comparison between non-European and EU Camps ..................................... 137

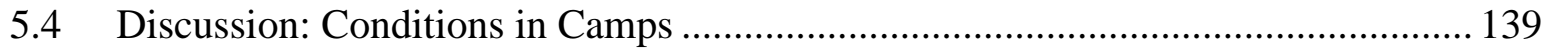

5.4.1 The Connection between Aid and Conditions in Camps................................. 139

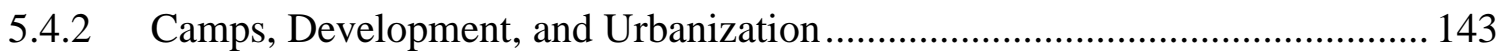

5.4.3 Improving Conditions in Camps: Solutions and Recommendations ................ 147

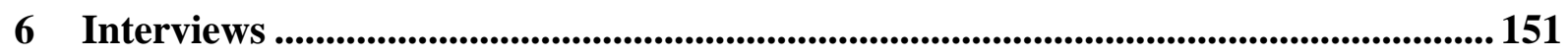

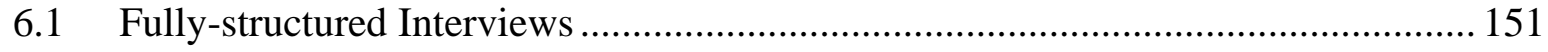

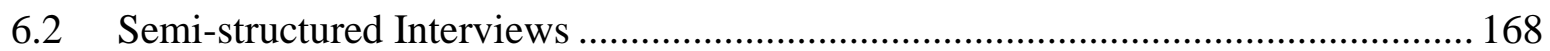

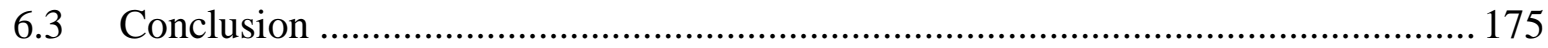

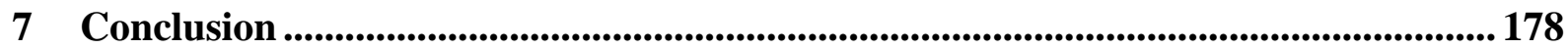

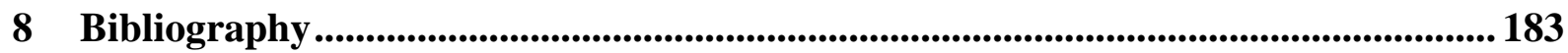




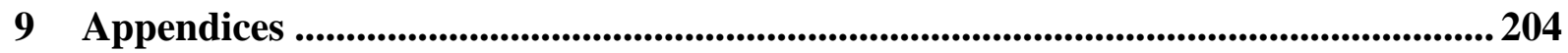

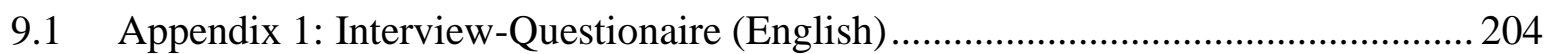

9.2 Appendix 2: Interview-Questionaire (German) ............................................... 210

9.3 List of the Semi-structured Interviews and Notes................................................. 216 


\section{Abbreviations}

\begin{tabular}{|c|c|}
\hline AMIF & The Asylum, Migration, and Integration Fund \\
\hline BAMF & Bundesamt für Migration und Flüchtlinge \\
\hline BPB & Bundeszentrale für politische Bildung \\
\hline CEAS & Common European Asylum System \\
\hline CEPOL & Collège Européen de Police \\
\hline CSDP & Common Security Defence System \\
\hline EASO & European Asylum Support Office \\
\hline $\mathrm{EC}$ & European Commission \\
\hline ECTC & European Counter Terrorism Centre \\
\hline ENP & European Neighborhood Policy \\
\hline EMF & European Migration Forum \\
\hline EMN & European Migration Network \\
\hline EMSA & European Maritime Safety Agency \\
\hline EU & European Union \\
\hline EUR & Euro \\
\hline EURODAC & European Dactyloscopy \\
\hline EUROSUR & European Border Surveillance System \\
\hline FAO & Food and Agriculture Organization of the United Nations \\
\hline FRA & Fundamental Rights Agency \\
\hline FRONTEX & Frontières Extérieures \\
\hline GAMM & Global Approach to Migration \& Mobility \\
\hline IDP & Internally Displaced Person \\
\hline IOM & International Organization for Migration \\
\hline $\mathrm{MoU}$ & Memoranda of Understanding (MoU) \\
\hline IR & International Relations \\
\hline IS & Islamic State (Terror Organization) \\
\hline ISF & The Internal Security Fund \\
\hline NAFTA & North American Free Trade Agreement \\
\hline NELM & New Economics of Labor Migration \\
\hline NIDL & New International Division of Labor \\
\hline RAN & Radicalization Awareness Network \\
\hline TFEU & Treaty on the Functioning of the EU \\
\hline $\mathrm{UN}$ & United Nations \\
\hline
\end{tabular}




\begin{tabular}{|l|l|}
\hline UNDP & United Nations Development Programme \\
\hline UNFPA & United Nations Population Fund \\
\hline UNHCR & Office of the United Nations High Commissioner for Refugees \\
\hline UNICEF & United Nations Children's Fund \\
\hline USD & US Dollar \\
\hline WFP & World Food Programme \\
\hline WWI & World War I \\
\hline WWII & World War II \\
\hline
\end{tabular}




\section{List of Tables}

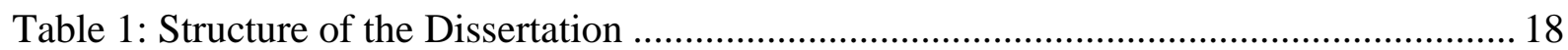

Table 2: EU Migration Policies, Borders and Security, and Policy Situation ........................ 22

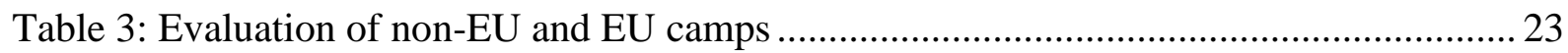

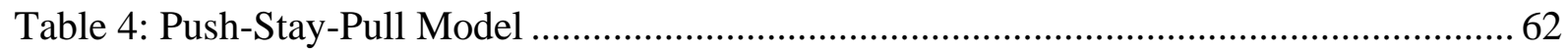

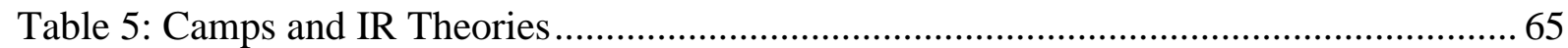

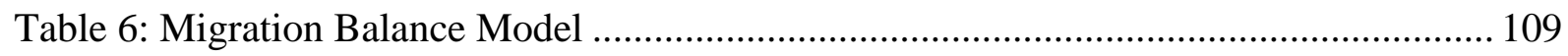

Table 7: Asylum Seekers and Refugees Allocation Model................................................... 110

Table 8: Evaluation of the Characteristics of the Participants ............................................. 151

Table 9: Evaluation of Question 1 \& Question 2 of the Interviews ...................................... 153

Table 10: Evaluation of Question 3 and Question 4 of the Interviews ............................... 154

Table 11: Evaluation of Question 5 and Question 6 of the Interviews ................................ 155

Table 12: Evaluation of Question 7 and Question 8 of the Interviews ................................. 156

Table 13: Evaluation of Question 9 and Question 10 of the Interviews .............................. 158

Table 14: Evaluation of Question 11 and Question 12 of the Interviews ............................. 159

Table 15: Evaluation of Question 13 and Question 14 of the Interviews ............................. 161

Table 16: Evaluation of Question 15 and Question 16 of the Interviews ............................. 162

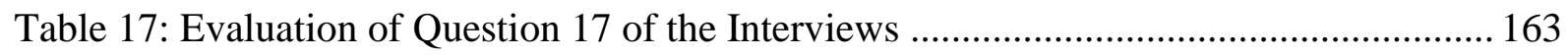

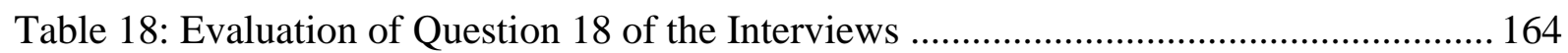

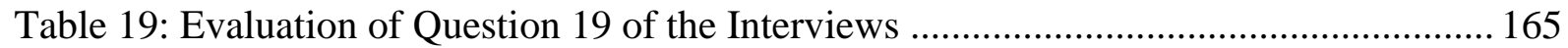

Table 20: Evaluation of Question 20 of the Interviews ...................................................... 166

Table 21: Evaluation of Question 21 and Question 22 of the Interviews ............................. 167

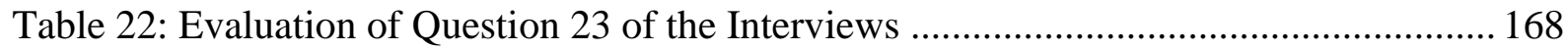

Table 23: Characteristics of Participants (Qualitative Research)....................................... 168

Table 24: Questions and Themes for Qualitative Research .............................................. 169 


\section{Acknowledgment}

First of all, I would like to thank my mother, who has supported me my whole life and made this dissertation possible. I am confident that without her sacrifices on many levels - not only during the duration of my Ph.D. studies but also during my Bachelor's and Master's degree -, I would have never been able to obtain a Ph.D. The same applies to Joseph Kennedy, who has supported me and helped me with the correction and editing of this dissertation. I am very grateful and fortunate to have a family that went through this process with me.

Of course, I also want to thank all my friends and the Corvinus International Relations Multidisciplinary Doctoral School. There are just too many people to mention them all. However, I appreciate, specifically, the hard work of the doctoral office and everyone else who made this Ph.D. program possible.

Moreover, I thank Beata Paragi and Péter Stepper for their comprehensive reviews and comments in 2020 and Prof. Dr. Nelu Bradean-Ebinger for his support during the first two years of the program.

Last but not least, I would like to thank Andras Tétényi for being a great supervisor. His guidance, assistance, and experience improved the quality of the dissertation significantly.

I will always remember the amazing time that I had in Budapest and at Corvinus University.

Once again, I thank everyone for the tremendous support over the past years. 


\begin{abstract}
In recent years, migration studies focused very much on forced displacement, especially after the influx of migrants to Europe in 2015. Some European countries accept immigrants from non-EU regions. Others blame migrants for taking advantage of Europe's social systems and follow restrictive policy measures. The EU is as divided as never before in its history, and the process of migration to Europe has become more critical. In this context, the characteristics, fleeing reasons, and refugees' and asylum seekers' journeys are relevant. This dissertation looks at these factors in the framework of refugee camps. Even though refugee camps are frequently an essential part of the journey of asylum seekers and refugees on their way to Europe, there is only limited literature in this field. Thus, the research aims to analyze migration and refugee movements as a consequence of the miserable and inhumane conditions in refugee camps and identifies indicators for (mass) migration to Europe. For this purpose, and since everyone speaks about migrants, but not with migrants, I conducted quantitative and qualitative research in 192 fully-structured and 17 semi-structured interviews. The research provides a comprehensive comparison of the living conditions in non-EU and EU refugee camps, analyses their role in the process of migration to Europe, and emphasizes the differences between different camps.
\end{abstract}

Furthermore, the characteristics of asylum seekers and refugees and their motives for coming to Europe were examined. The findings of the study show who these people are and from where they originate. There is evidence for the hypothesis that the majority of people flee because of severe danger (e.g., armed conflicts) and are not 'economic migrants' despite the claims of nationalistic governments in the EU. However, there is evidence for the hypothesis that improved living conditions in camps could reduce mass migration movements to Europe. The dissertation enhances the discussion of refugee camps in migration studies, provides new perspectives and insights about the journey of asylum seekers and refugees to Europe, and people's characteristics leaving their country of origin. 


\section{Introduction}

The influx of millions of immigrants from the Middle East and the African continent in 2015 was a turning point in EU migration policies. Since then, migration has become a highly controversial topic in civil societies and policy-makers, politics, and migration studies. The topic divided and polarized the EU into countries that are willing to accept asylum seekers and refugees and the member states that are not. Consequently, the conflict can stop the European integration process, which itself is already damaged after the Eurozone crisis (Manners and Murray 2016). Other authors even see the Brexit ${ }^{1}$ movement as a consequence of anti-immigration agitation in British media (Goodman and Kirkwood 2019). The process of migration to Europe has become a significant challenge for the EU.

Thus, to contain and control refugee movements ${ }^{2}$ to Europe, EU member states are building fences and walls, border controls are standard again, and Frontex intensifies its surveillance. However, these measures can never solve the problem. Military conflicts in the Arabic world will probably continue in the next decades, and many refugees try to escape the danger. Many are coming who are not directly affected by war but by poverty. More and more people from these third-world countries attempt to find a better life in EU countries that provide residents with financial benefits. Besides, global warming, droughts, and other climatic changes will produce more refugees than ever before. It is not reasonable to believe that walls and fences will permanently stop refugees from coming to Europe. All these developments lead to the conclusion that the current migration movements are just the beginning and have, without a doubt, the potential to end the integration process in Europe. The EU is facing a significant challenge to integrate millions of non-Europeans into European society, a society which itself is far from being homogenous and cohesive.

However, many people talk about asylum seekers and refugees, but only a few talk with them. Who are these people? Where do they come from? Moreover, what were their motives for coming to Europe? What are the characteristics of those coming to Europe, and are they economic migrants or refugees? The background and journey of migrants coming to

\footnotetext{
${ }^{1}$ The 'Brexit' stands for the United Kingdom leaving the EU.

${ }^{2}$ Movement in the sense of migration (movement of people; not political movements).
} 
Europe is of extraordinary importance if we want to understand the process of migration in the year 2020. In this context, refugee camps play a vital role as a safeguard for asylum seekers and refugees. Many migrants have had to live or are still living in refugee camps. Due to their location, the Mediterranean Sea countries are profoundly affected by the influx of fleeing persons. Outside of the EU, the neighboring countries of (civil) war zones (e.g., Syria) are the primary destination for refugees. Greece and Italy, as EU countries, and Turkey, Lebanon, and Jordan, as non-EU countries, are essential transit countries and the 'new home' for a large number of migrants. Unfortunately, many of these people end up in improvised shelters or camps with inadequate nutrition, health care, security, and other factors. Devastating conditions in camps harm asylum seekers and refugees and do not provide incentives for staying; in actuality, they increase the probability that people will continue their journey to other destinations.

The consequences are constant inflows of fleeing persons from crisis regions, which are, understandably, continuing their journey until their basic needs get satisfied, or until their living conditions improve considerably. Camps have the potential to soften (mass) migration, or, at least, to regulate and manage movement since providing livable conditions to people in camps can improve their situation. In some cases, they may even eliminate the reasons for leaving.

Nevertheless, camps' importance is often undervalued, and the situation in camps after 2015 is only barely covered by the literature in migration studies. The following authors are rare exceptions: As early as 1998, Crisp and Jacobsen criticized the lack of international standards for refugee camps. Authors such as Milton et al. (2013) focused on the security aspect of camps in terms of radicalization; others, such as Berti (2015), elaborated on the scarce resources in the camps and the burden for the host countries. In total, the health care, nutrition, and educational situations are very often insufficient (see Toole et al. 1988; Paardekooper et al. 1999; Sharara and Kanji 2014; Sirin and Sirin 2015; Acarturk et al. 2015). Even though migration studies' focus has slightly shifted to asylum seekers and refugees in recent years, the camps' role has not been adequately considered. This dissertation's groundbreaking character is its in-depth research regarding camps by interviewing a significant number of asylum seekers and refugees with camp experience. Thus, I contribute to migration and asylum seekers and refugees studies by investigating camps in the EU, the Middle East, and Turkey. Whereas the authors mentioned earlier, for instance, focused only on certain aspects of the debate (e.g., health care or security), I follow a different approach, 
aiming to capture the whole complexity of the topic by providing a comprehensive and coherent approach in terms of camps, covering multiple dimensions of the discussion. The dissertation's universal character differentiates it from previous research in this field and makes it stand out. In this context, the dissertation provides explanations and insights for living conditions in camps, the characteristics of camps' inhabitants, their journey to the camps, and their motives for leaving the camps and continuing their journey to the EU.

Therefore, this dissertation hypothesizes that reasonable living conditions in refugee camps in the EU and outside of the EU could reduce (mass) migration movements. The research aims to analyze migration and refugee movements as a consequence of the miserable and inhumane conditions in refugee camps. I try to identify indicators for (mass) migration to Europe, especially by analyzing refugee camps' situations. The following research questions will be investigated:

- How does the devastating situation in the perceived reality ${ }^{3}$ of asylum seekers and refugees in camps (including undernourishment, poverty, disease, et cetera) affect migration movements to Europe?

- How does the camp experience [experiences gained in camps] contribute to refugees' and asylum seekers' decision-making process in the context of migration to Europe?

For this purpose, the dissertation starts with a comprehensive literature review. Over 100 years of migration studies are covered in this part. It begins with the basic neoclassical approach, including push-pull models and the 'laws of migration.' After that, the literature review demonstrates how migration theories have developed and evolved in the past decades. A significant focus will be on the transformation process from classic push-pull factors (why people leave their country and why people migrate to others) to the more sophisticated aspiration and desire models, which also introduced other dimensions in the form of drivers of migration. Other vital theories covered in this chapter are transition and development, the historical-structure approach, systems and networks, and the new economics of labor

\footnotetext{
${ }^{3}$ Living conditions in camps are perceived very differently, depending on the duration of the stay, the (personal) circumstances, and other factors. What is for one person acceptable, could be for another one devastating. There is no universal standard for evaluating living conditions, which is why I use the term 'perceived reality' in this context.
} 
migration. The chapter concludes by reviewing works dealing with the issue of refugees in camps and what impact devastating conditions have had on their lives. Since refugee camps, as a consequence of the events of 2015 , are only barely covered by the literature, this dissertation provides its own 'push-stay-pull' model. Camps are supposed to be primarily short-term solutions for fleeing persons and often function, because of devasting conditions, only as transit zones on their way to the actual destination. The 'pull factors' cannot be fully applied here, and people do not go to camps because they see long-term prospects there for themselves or their families. In reality, they have simply no other choice and get stuck in 'no man's land,' since refugees cannot go back to their country of origin but are also incapable of reaching their destination. A new approach is needed.

After the literature review comes the contextual section, which starts with EU migration policies, borders and security, and policy situations. Firstly, I clarify the terms of legal and irregular migration. Secondly, I go deeper into the EU migration policy by focusing on the Common European Asylum System (CEAS). After that, the chapter deals with Schengen, borders, counter-terrorism and radicalization, organized crime and human trafficking, EU agencies, and the so-called 'EU-Turkey deal.' The last part of the chapter describes the EU's policy situation, the growing populism, and the human rights situation by mainly focusing on fair burden-sharing issues.

The next chapter is about the poor living conditions in refugee camps. Since most asylum seekers in 2015 came from Syria, the case studies concentrate on neighboring Syrian countries, like Turkey, Lebanon, and Jordan. Furthermore, the situation of camps in the EU, which are the leading destinations for arrivals (e.g., Greece and Italy), will be described, including all the relevant numbers, figures, and statistics. Thus, camps inside and outside of the EU become comparable, which builds the foundation for more in-depth analysis regarding the connection between aid and devastating conditions in camps in the following section. This part is intended to make the bridge between theory, detailed case studies, and context. The chapter should create a starting point for further discussions.

The last part of the dissertation is the interview section. In total, I conducted 192 fullystructured (quantitative research) and 17 semi-structured (qualitative research) interviews with asylum seekers and refugees in Germany about their characteristics, their experience in camps, and their journey. The research findings indicate that poor living conditions in refugee camps definitely affect migration movements to Europe and that people flee mainly because of severe threats to their life and health. Improvements in the situation in the camps could 
significantly reduce the crisis; the importance of satisfying basic human needs such as health care, nutrition, or security is stressed. Additionally, the political, economic, cultural, and environmental dimensions should also be evaluated when investigating refugee movements from camps.

For the most part, camps since 2015 have been a 'blindspot' in migration studies. This dissertation attempts to fill this gap and, hopefully, helps to shift the attention of (future) researchers to the unique role of camps in the process of migration to Europe or elsewhere. 


\section{Methodology and Research Design}

The dissertation tries to answer this question: 'How does the devastating situation in the perceived reality of asylum seekers and refugees in camps (including undernourishment, poverty, disease, et cetera) affect migration movements to Europe?' In other words: 'How does the camp experience [experiences gained in camps] contribute to refugees' and asylum seekers' decision-making process in the context of migration to Europe?'. The dissertation aims to analyze migration and refugee movements as a consequence of the miserable and inhumane conditions in refugee camps. The hypothesis is that reasonable living conditions in refugee camps in the EU and outside of the EU have the potential to reduce (mass) migration movements. The dissertation aims to identify indicators for (mass) migration to Europe, especially by analyzing people's situations in refugee camps.

To achieve this goal, I started with a literature review in migration studies, which establishes the niche of camps. The next chapter focuses on EU policies and their implications for asylum seekers and refugees. After that, I analyzed the conditions in non-EU and EU camps. This last part is the interview section, where I conducted quantitative and qualitative research. Thus, each chapter builds on the one before, and everything follows a clear structure. The different chapters interact and complement each other.

Table 1: Structure of the Dissertation

\begin{tabular}{|l|l|l|}
\hline Literature Review & $\begin{array}{l}\text { This chapter covers migration } \\
\text { studies, asylum seekers, and } \\
\text { refugee studies and establishes } \\
\text { the niches of refugee camps. }\end{array}$ & Conceptual framework \\
\hline BU Migration Policies, & $\begin{array}{l}\text { This chapter explains EU } \\
\text { migration policies (including } \\
\text { Policy Situation }\end{array}$ & $\begin{array}{l}\text { Context and conceptual } \\
\text { the legal framework and their } \\
\text { implications for asylum seekers } \\
\text { and refugees. The debate of } \\
\text { camps can only be fully } \\
\text { understood in the context of } \\
\text { burden-sharing, weak policy } \\
\text { measures, and the union's }\end{array}$ \\
\hline
\end{tabular}




\begin{tabular}{|c|c|c|}
\hline & internal dividedness. & \\
\hline Conditions in Camps & $\begin{array}{l}\text { Based on the previous chapters, } \\
\text { the conditions in camps outside } \\
\text { and inside the EU can be } \\
\text { evaluated. The literature review } \\
\text { and the policy chapter provide } \\
\text { the conceptual framework for } \\
\text { the analysis of conditions in } \\
\text { camps. }\end{array}$ & Case studies and context \\
\hline Interviews & $\begin{array}{l}\text { The interviews provide an in- } \\
\text { depth perspective on the } \\
\text { conditions in camps. For this } \\
\text { purpose, I conducted } \\
\text { quantitative and qualitative } \\
\text { research, which builds on the } \\
\text { previous chapters and provides } \\
\text { some new insights and } \\
\text { findings. }\end{array}$ & $\begin{array}{l}\text { Quantitative and } \\
\text { qualitative research }\end{array}$ \\
\hline
\end{tabular}

The research findings indicate that poor living conditions in refugee camps definitely affect migration movements to Europe and that people flee mainly because of severe threats to their life and health. Many different aspects and push factors in the camps are considered, including nutrition, health care, education, job opportunities, income, security, political participation, and spare time activities. The improvement of the situation in the camps could significantly diminish the crisis. Overall, the research provides a comprehensive overview of asylum seekers' and refugees' experiences in camps, their characteristics, and their journey.

\subsection{Literature Review}

The literature review covers migration theories and some asylum or EU policy-making implications (EU policy-making and asylum will only play a minor role in this section 
because the whole complex is covered in an extra chapter). ${ }^{4}$ The goal is to provide a comprehensive overview of the essential theories in over 100 years of migration studies. In general, the literature review focuses on the questions 'Why do people move?', 'Why and where do asylum seekers move?', and 'What is the role of refugee camps?'. It is important to note that the literature will always be reviewed with a strong focus on people in camps and their living conditions. Indeed, not all, but many arguments will follow this direction.

The essential question in migration studies is 'Why do people move?'. There is no one universal answer to this question since there are countless reasons and different circumstances, which influence individuals and their decision-making processes in terms of migration. The following sections include the most important theories that are aiming to approach this field. The neoclassical model, transitions and development, historical-structural models, systems and networks, and The New Economics of Labor Migration provide the best answer to this question since all these models have a substantial focus on the push factors (why do people move) of migration and economics. Notably, early scholars like Ravenstein (1885; 1889) or Lee (1966) emphasized their research on these factors and the macro dimension. Later works in this field build upon their foundation, and newer approaches provide more comprehensive answers to more complex questions (e.g., aspiration and ability model or drivers of migration).

Compared to earlier works in migration studies, the case of asylum seekers, refugees, and IDPs has gained more attention and importance in the last 20-30 years. The framework of the aspiration and ability model (Carling 2002) allows a more detailed look. Many researchers have approached this field by asking the question 'Why and where do asylum seekers move?'. Thus, the works of Davenport et al. (2003), Melander and Öberg (2007), Neumayer (2004, 2005), Moore and Shellman (2004), Tétényi et al. (2018), and others will be covered in this section by evaluating the micro-level of the debate.

Both the micro and macro dimensions build the foundation for the discussion about refugee camps, their unique position as a safeguard, and their role as a fleeing destination in the context of migration decision-making processes. I emphasize the different approaches regarding camps in the framework of IR Theories and elaborate on contributions from

\footnotetext{
${ }^{4}$ See chapter four of this dissertation.
} 
scholars like Berti (2015), Sirin and Sirin (2015), Crisp and Jacobsen (1988), or Chatty (2009; 2010; 2017), which explain the devastating conditions in camps, whereas other researchers stress the cultural, social, and historical complexity of the topic. Overall, the literature review establishes the role of camps in the conceptual framework of migration studies. The chapter concludes with the 'Push-Stay-Pull Model,' an approach I developed and designed, which illustrates the camps' role in this context and (possible) future migration studies trends.

\subsection{EU Migration Policies, Borders and Security, Policy Situation}

The EU aims to apply humane asylum procedures but struggles to define and establish universal standards throughout Europe. Whereas the Mediterranean sea countries and Northern EU states are most affected by migration inflows, other EU states such as Hungary are unwilling to accept any asylum seeker (Tétényi et al. 2018). Thus, the EU asylum system is operating inefficiently and burdens member states unfairly. This chapter examines the analytical framework behind EU policy measures on asylum seekers and refugees. It emphasizes the deficits in terms of legal and irregular migration, the EU asylum system approach, and the Schengen and Dublin regimes. I argue that these EU policy measures have become more restrictive and are continuously undermining human rights; I critically reflect on the ongoing and current debates in EU policies regarding migration to Europe.

This chapter considers all these different aspects of the discussion and provides a coherent review of the current EU policy implications and the continuing academic criticism. Policy measures are insufficient, and a common approach concerning asylum seekers cannot be established since the relocation and allocation of refugees among EU member states cannot be realized. Most EU members are following their own agendas, which leads to dysfunctional burden-sharing and solidarity procedures. Restrictive policy measures and human rights violations are the consequences.

This chapter provides the contextual framework for the following chapters, which focus on camps. The situation of camps is only plausible in the discussion of (EU) policies. It explains the dividedness of the EU and its inconsistent and insufficient asylum policies. Hence, I address three major categories that demonstrate the dilemma in terms of inconsistency: EU migration policies, borders and security, and policy situations. Each variable is tested by its efficiency, and I elaborate on different aspects of the discussion in asylum seekers' and refugees' policies. The table below gives an overview of the chapter. 
Table 2: EU Migration Policies, Borders and Security, and Policy Situation

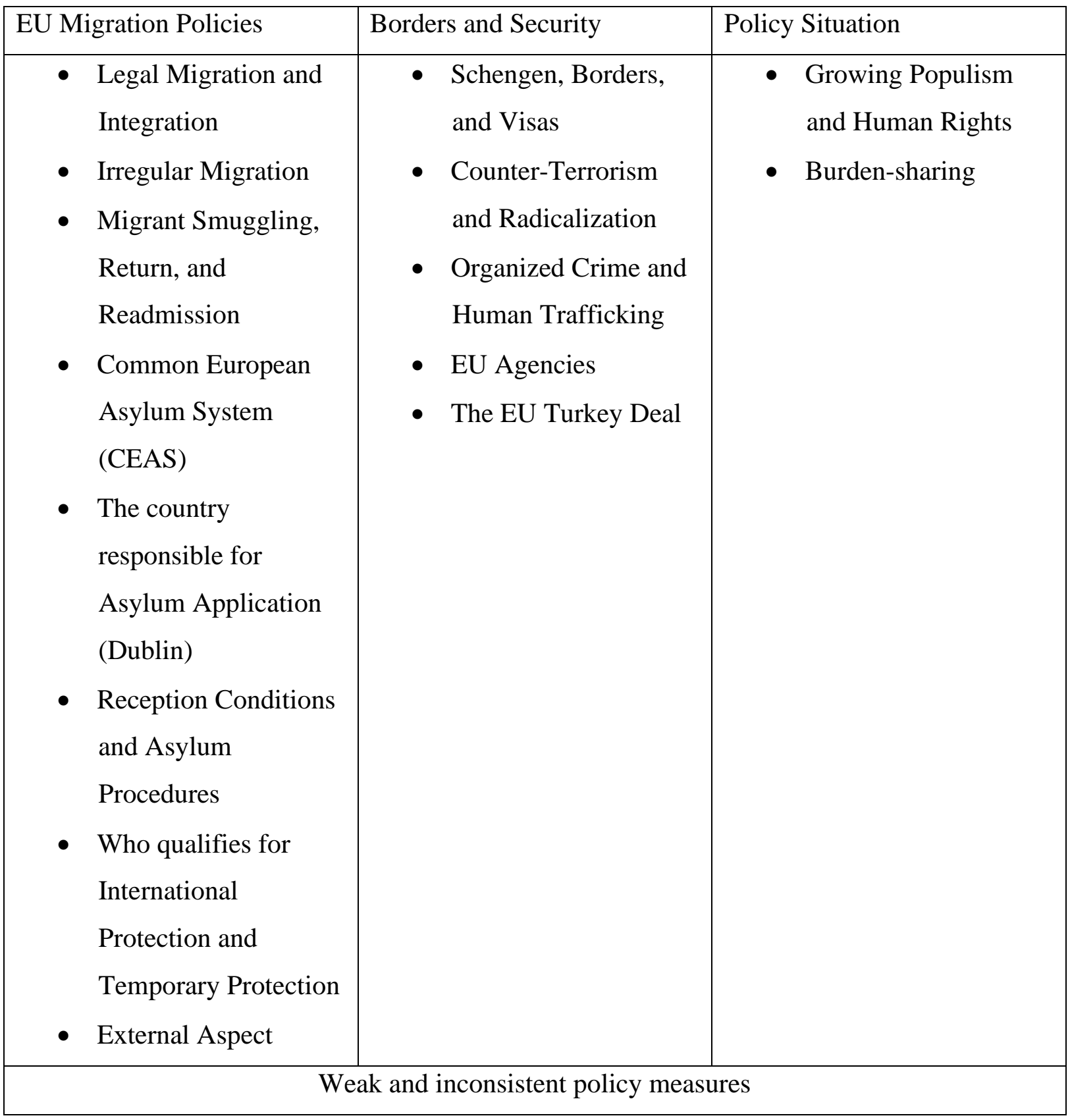

Consequently, the EU is in an identity crisis and incapable of responding adequately to significant challenges like the influx of migrants from the Middle East. Inconsistent policy measures and non-uniform approaches to migration weaken the stability of the EU significantly. Burden-sharing and security issues due to growing populism divide the union, hurt the EU-Turkey Statement, and lead to its failure from an EU perspective. There is still a need for a common approach regarding asylum seekers and refugees. 


\subsection{Conditions in Camps}

This chapter describes the conditions of refugee camps inside and outside of the EU by completing the contextual framework necessary for understanding the interview section in the next chapter. Due to financial and time limitations, I was unable to visit any of these camps myself. A proper field study could not be conducted during the COVID-19 pandemic. $^{5}$ Therefore, I used mainly official information from aid organizations like the UHNCR.

The idea behind the case selection was to pick some of the current refugee hotspots inside and outside of the EU and make them, to a certain extent, comparable. Many refugees flee to geographically close countries. Turkey, Lebanon, and Jordan are all countries neighboring Syria, which was and still is one of the primary sources for asylum seeker flows. On the other hand, Greece and Italy are, because of their access to the Mediterranean sea, usually one of the first arrival destinations for refugees in the EU. According to the Dublin system (see chapter 4.1.5), this is also where people have to apply for refugee status to get asylum. The location of the country and the EU policy implications make these cases significant.

This section aims to identify the differences between camps in these countries. For this purpose, I applied an analytical framework based on UNHCR data, insights of the European Commission, and coverage from credible reporters and media. The evaluation results allow conclusions that emphasize the importance of living conditions in camps in the context of migration to Europe. The table below explains the evaluation criteria.

Table 3: Evaluation of non-EU and EU camps

\begin{tabular}{|l|l|l|l|l|}
\hline $\begin{array}{l}\text { Evaluation of living } \\
\text { conditions in camps }\end{array}$ & Turkey Lebanon & Jordan & Greece & Italy \\
\hline $\begin{array}{l}\text { Figures, Numbers, and } \\
\text { Statistics }\end{array}$ & $\begin{array}{l}\text { The first section provides essential data regarding asylum seekers } \\
\text { and refugees in Greece and Italy, including the number of migrants } \\
\text { and their countries of origin. Additionally, the data shows the }\end{array}$ \\
\hline
\end{tabular}

\footnotetext{
${ }^{5}$ I finished this dissertation during the outbreak of the COVID-19 pandemic, which was, of course, a significant event. However, since most of this work was already written in the pre-pandemic era, this topic is only barely covered in my work.
} 


\begin{tabular}{|l|l|}
\hline Funding & current trend of migration movements to these countries. \\
\hline $\begin{array}{l}\text { The Situation in the } \\
\text { Camps }\end{array}$ & $\begin{array}{l}\text { Usually, refugee camps are dependent on funding from international } \\
\text { organizations, states, or private donors. Whether the camps fulfill } \\
\text { their funding requirements or not says something about the camps' } \\
\text { situation and the living conditions provided. } \\
\text { conditions using insights from media, NGOs, and other researchers. } \\
\text { The focus is on satisfying basic human needs such as nutrition, } \\
\text { health care, education, and housing conditions. }\end{array}$ \\
\hline
\end{tabular}

Of course, the work also has some limitations and weaknesses. The following points are legitimate criticism:

- Subjective evaluation: The evaluation of 'living conditions' is, indeed, very subjective. There is no universal formula for it since many of these findings base on personal opinions and impressions. Everyone experiences' living conditions' differently. What one person might consider as 'reasonable' is for another devastating. The research is dependent on sources from international organizations and state institutions and field studies from reliable media outlets. According to the World Bank (2018a), almost half of the world's population could not meet basic needs. They live on less than 1.90 USD per day.

- Selection bias: The camps' living conditions can vary significantly from camp to camp since it is nearly impossible to get an overview of every single camp. Thus, the 'extreme case' (negative and positive) may get the most attention in media coverage (e.g., camps on Greek islands). It is often hard to make generalized statements, which fairly reflect the situation in the whole country.

- False information: Some of the next section's information could be basically wrong based on insufficient research and field studies.

- Manipulation/Political Agenda: The migration topic has become highly controversial in recent years. There are many different interests, and not everyone might want to describe the actual situation but instead follow a political agenda to accomplish specific goals. 
- State Propaganda: This point is related to the previous one. The state, or more precisely the government of a state, might use its power to influence various aspects of the discussion in its favor.

The precaution that I have undertaken to avoid these biases were short conversations before every interview. I tried to get an overview of who each person is and if she or he was seriously interested and serious about the interviews. It does not eliminate every bias, but it significantly limits them. The goal was always to get comprehensive, coherent, and uncensored responses from authentic people.

The chapter concludes with a comparison between refugee camps in the EU and refugee camps in non-EU countries. The main objective is to determine how people's lives in camps can be improved, but it is also significant what differences there are between camps in EU or non-EU countries. What are the impacts on migration flows? Can they be interrupted, and push or pull factors be reduced? The basic approach is "if people are not satisfied with their situation in camps in non-EU countries, why should they be happy with their stay in camps in the EU, especially if the conditions are here devastating as well?" Keeping people in no man's land and preventing them from leaving the camps can be a sustainable long-term solution neither from a human rights perspective nor from a development perspective. There is still much research that needs to be done in this field.

Some data regarding figures, numbers, and statistics or funding is more straightforward and easier to compare than the situation in the camps, which can be perceived very differently and is, of course, subjective. Nonetheless, the chapter provides some valuable findings. It is a high starting point for further discussions before going into the last section of the dissertation, which contains some unique firsthand information from people who have experienced refugee camps during their journey to Europe.

The investigations of refugee camps will produce some new findings and enrich the discussion in the field of migration studies.

\subsection{Interviews}

The interview section consists of two parts: fully structured interviews (quantitative research) and semi-structured interviews (qualitative research). First, I conducted 192 fully-structured interviews with asylum seekers and refugees in Germany. After that, I also had the opportunity to conduct 17 semi-structured interviews to get a more in-depth look at camp conditions. Thus, qualitative research builds on quantitative research. 


\subsubsection{Fully-structured Interviews}

The research is quantitative and based on interview questionnaires with asylum seekers and refugees in Germany who migrated to Germany in 2015 or later. The study was conducted in Germany's Bavarian region that receives the second most asylum applications of all Bundesländer in Germany (Statista 2020b; 2020c). Regarding the sample size, I used the snowball method. My mother, a certified teacher for German as a foreign language, works with asylum seekers and refugees in Germany and organized contact with some of her students. Thus, the only other person who was involved in the interview process is my mother. Without her contacts, the whole research probably would not have been possible, and it is one of the reasons why the research was conducted in Germany. The other reasons are the high number of refugees and asylum seekers in Germany and, of course, the country origin of the dissertation's author. From this point, participants of the research project recruited friends and community members for further interviews. The only prerequisites were that participants had to be of legal age and a legitimate asylum seeker or refugee in Germany, making the preselection process homogenous. However, these were the only restrictions that existed in terms of sample size. In general, I followed a maximum variation/heterogeneous approach.

The interviews were fully structured, consisted of 23 closed-ended questions, and every participant received the same questions. The questionnaires are attached in appendix number one (English version) and appendix number two (German version). Overall, 103 interviews were conducted in person and orally in German or English (pre-pandemic). Another 89 interviews were conducted over Skype due to the worldwide pandemic but followed the same approach. Usually, the interviews took place in small groups (e.g., with families) and in private spaces (e.g., the flat of an asylum seeker). Because of language barriers that existed in many cases, various people from the same country as the respondents helped with translation during the face-to-face interviews. I asked the questions and filled in the questionnaire. In total, I conducted 192 interviews with asylum seekers and refugees from spring 2019 until the end of summer 2020. There were no financial incentives for the interviews, and every participant was at least 18 years old. The results of the research are 100 percent anonymous and kept confidential.

The objective was to analyze and understand refugee movements due to poor living conditions in camps in the Middle East and Mediterranean countries. At this point, a primary goal is to conduct as many interviews as possible with people who had that experience and are willing to share this information to get a deeper understanding of their journey and the 
conditions in camps. At the end of the research, we should identify indicators for (mass) migration to Europe, at least these indicators related to camps (e.g., poverty, hunger, limited resources, et cetera). Since I used standardized questionnaires to make the results comparable, the research should also allow some comparisons between camps (for instance, living conditions of camps in the EU compared to living conditions of camps in non-European countries).

However, not all participants of the interviews spent time in camps. Their answers, for two reasons, are included in this section:

- People who were not in camps are of importance as well. It tells us still something about their experience and journey to Europe. Thus, the information that people have not been in camps is valuable.

- 2.) Some questions are not camp-specific. The questionnaires are structured so that answers from people with no camp experience can be integrated into the research. Again, these people have something to say, and it would be a missed opportunity not to take note of their unique experiences.

\subsubsection{Semi-structured Interviews}

After the quantitative research, I also had the opportunity to conduct 17 semi-structured interviews with asylum seekers and refugees from the same sample as in the previous section. This was a unique opportunity to get a more in-depth look at the topic. The semi-structured interviews were built on the fully structured interviews and aim to provide a more comprehensive overview of conditions in camps, migration decisions, and the journey to Europe. Despite that, quantitative research does not necessarily capture the topic's whole complexity because of its limitations in research design. In order to fill in this gap, I extended the research by qualitative research. Because I had already conducted a significant number of interviews, I knew which topics and sections I would like to cover comprehensively. In general, I followed a similar approach since all the participants had already participated in fully structured interviews.

The semi-structured interviews took place between May and August 2020. Because of the ongoing pandemic, all the interviews were conducted online via Skype. I followed a purposeful sampling approach in the framework of criterion-i (Patton 2002; Marshall et al. 2008). The focus group was people who stayed in both non-EU and EU camps during their journey to Europe. Again, people had to be asylum seekers or refugees in Germany, and the 
minimum age for participating was 18 years. However, all 17 participants came from Syria and fled to Germany in 2015 or after due to the civil war outbreak in Syria. The interviews were conducted individually, and all the participants came from the same asylum-seekers' hostel in Bavaria. Every interview lasted about 25 to 45 minutes, and the same Syrian translator accompanied each interview partner. Thus, the interviews were conducted orally and in German (every participant had studied German). If necessary, the translator helped with the translation. All the data were coded, analyzed, and categorized. However, sometimes a language barrier existed. Neither the interview partners nor the translator spoke perfect German. Therefore, I had to edit occasional sentences to the degree that they sound fluent and smooth in German. After that, I translated my German notes into English. ${ }^{6}$

Unfortunately, I did not have permission to record and transcribe the interviews, even though I have anonymized the interviews' results. ${ }^{7}$ Therefore, I took notes during and after the interviews. After each interview, I reviewed the material and showed it to the participant for permission purposes. Some interview partners feared state authorities and negative consequences for themselves. Obviously, this is a highly sensitive topic. Since I promised not to record the interviews through my webcam, I could only make notes. The whole COVID-19 situation was, in this context, not helpful either. In real meetings, full transcriptions might have been provided and authorized.

I informed all the participants about their rights, including withdrawing from the interviews at any time they want. Every interview was entirely voluntary, and I made sure everyone understood the purpose of the research. The recruiting process was a mix of snowball and network methods since all the participants had already participated in the quantitative analyses.

Overall, it was my goal to let the participants speak freely without interruption. I had only minimum involvement in this process by asking the questions and clarifying misunderstandings. The notes of the interviews are attached in the appendices of this dissertation.

\footnotetext{
${ }^{6}$ The interviews were in German language. Due to time and practical reasons, my notes were also in German before I translated them.
} 


\subsubsection{Structure of the Interviews}

The fully-structured interviews start with general information, including age, gender, citizenship, and profession. It aims to answer the question of who these people are. This question's importance is to determine if certain groups or demographics are more likely to be part of migration movements than others. The first four questions are to clarify if and where the person was in a refugee camp. The whole questionnaire is conceptualized in a way to distinguish between camps in the EU and non-European countries. Hence, if people stayed in an EU camp, they follow one path of questions. However, if they stayed in a non-European camp during their journey, they follow the other route of questions. Indeed, people who stayed in both are supposed to follow both and will be able to provide the most useful data. From question five on, the camp-specific questions start. Some questions allow 'circle all that apply' answers, and others ask more precisely about the real experience in the camps. For example, question number five is: 'Why did you choose a camp in the countries from Q2 \& Q4? Please circle all that apply.' The possible answers are 'Security,' 'Accessibility of the country,' 'I was sent to the camp,' 'Higher living standard,' and 'Others.' This is a question where people can circle multiple answers.

On the contrary, question number six asks: 'For how long did you stay in the refugee camp(s) named in Q2 \& Q4?'. Of course, there is only one answer possible. The questionnaire continues in this fashion until question number 17, which marks the camp evaluation section's end. From question number 18 to question number 23, which is the end of the interview, there is no camp experience required, and these questions can be answered by other asylum seekers and refugees who have not been in camps. These questions are journey-specific and address the topic of where and how people entered the EU. This section focuses on the Mediterranean Sea countries of the EU due to their proximity to the Middle East and the African continent. Entering the EU by crossing the dangerous Mediterranean Sea and paying smugglers are indicators of genuine fleeing reasons. Economic migrants are considered less likely to risk their lives on high seas. They often do not have the financial capabilities to pay smugglers. Other questions ask about fleeing reasons and why people chose the EU as their destination. Finally, the fully-structured interviews conclude by asking the question of people's intention of going back to their country of origin (holidays and short-term visits not included).

In general, the questions are supposed to be comfortable and understandable. The only thing that might be confusing is the distinction between EU camps and non-European camps. However, since all these interviews were face-to-face with the interviewer, who did the job of 
circling the right answers and navigated through the procedure, it was not an issue. All interviews were conducted in a reasonable amount of time (approximately 5 to 20 minutes each).

Concerning the semi-structured interviews, I asked six open-end questions about conditions in non-EU camps, conditions in EU camps, the journey to Europe, the reasons for leaving their country of origin, the reasons for coming to Germany/Europe, and the stay factors in the camps. These are also the six themes for the qualitative research section.

\subsubsection{How do the Interviews answer the Research Question(s)?}

The research is building around the questions 'How does the devastating situation in the perceived reality of asylum seekers and refugees in camps (including undernourishment, poverty, disease, et cetera) affect migration movements to Europe?' and 'How does the camp experience [experiences gained in camps] contribute to refugees' and asylum seekers' decision-making process in the context of migration to Europe?'. The dissertation hypothesizes that reasonable living conditions in refugee camps in the EU and outside of the EU have the potential to reduce (mass) migration movements.

The first part of the fully-structured interviews provides some personal information about asylum seekers and refugees, including their gender, age, citizenship, and profession. It gives us an idea of who the people are that migrate and what their origin is. The next questions are supposed to determine if people have been living in refugee camps during their journey to Europe or not. If yes, was it in Europe, outside of Europe, or even both? Questions Q5 to Q17 evaluate the camps' situation and distinguish between EU camps and camps in non-EU countries. The distinction is necessary to assess if or not conditions in camps have different effects on migration decisions. Interview partners were allowed to say their genuine opinion and rate the conditions in the camps based on their own experience. Overwhelmingly negative responses would confirm the hypothesis that devastating conditions influenced asylum seekers' decision not to stay in the camps and move forward. Simultaneously, an overwhelmingly positive evaluation would disprove the theory since people would have found proper living conditions but still decided to continue their journey. Thus, camps' adverse conditions equal higher push factors and increase the probability of mass migration to Europe. At the end of the conducted study, we should make some strong statements on the connection between asylum seeker movements and refugee camps' support. The questions Q18 to Q23 provide some additional information on asylum seekers regarding their 
background, motive, aspiration moving to Europe, and plans. Therefore, the research also allows us to make some further conclusions.

Furthermore, I extended the research through qualitative interviews. This section's results build on the last part and provide a more comprehensive perspective on camps' conditions. These questions do not correspond to new research questions but rather complement and enhance the fully-structured interviews' quality.

\subsubsection{Limitations and Weaknesses of the Research}

The research has, of course, also some limitations and weaknesses. Because of the snowball method that I used, all the interviews were conducted only in Germany's region (Bavaria). Likewise, no classification by specific demographic groups was made (e.g., 50 percent interviews with males, 50 percent with females, or grouping by age, origin, time in camps, et cetera), which makes the study not wholly representative. Other possible limitations and weaknesses of the work are:

- Language Barrier: Since a translator was sometimes needed, some parts could be gotten 'lost in translation' based on misunderstandings or wrong translations.

- Lack of interest or motivation: Some people might have been just not interested in the interviews and did not care about their answers.

- Sabotage: This case is similar to the previous one. We cannot exclude that people lied on purpose to sabotage the results of the research.

- Uncomfortable atmosphere: Some people could have felt uncomfortable during the interviews by answering private questions.

- Politically or culturally motivated answers: Due to personal preferences, some answers could be exaggerating positively and negatively (being extreme bias). For example, one person does not want to talk badly about another country (cultural reasons), or one person dislikes individual governments' political views (political reasons). In both cases, the answers could tremendously differentiate from the 'truth.'

However, the last points are pure speculation and are just possible factors that could have influenced the interviews' results. In general, I aimed to create a comfortable atmosphere for the interview partners and let them speak freely without any restrictions. If somebody gave obviously preposterous or wrong answers, I would have filtered out the responses (for instance, 'Assad is the Chancellor of Germany'), but this has never happened over the 
occasion of the interviews. Hopefully, soon, further research with more financial and personal backing will be conducted in this field.

\subsubsection{Difficulties during the Conduction of the Interviews}

Unfortunately, some problems occurred during the process of conducting the interviews. Some of the main issues are explained in the following:

- The first problem is pretty much self-explanatory. The interviews were conducted in Germany over one year, but I studied in Budapest, Hungary. The organization was challenging in many ways and required weeks of planning in advance, including much traveling. As described in the previous section, these simple geographic circumstances limited the sample size of possible interview partners significantly.

- In some cases, interview partners were unreliable and did not come to the interview. In one particular case, the potential interview partner did not show up for four consecutive appointments.

- The language barrier made communication sometimes complicated. A translator was often needed since not all the interview partners spoke sufficient English or German. However, sometimes the interaction with the translator was also not accessible, but in the end, everything worked out.

- Sometimes, people refused to give interviews due to a lack of trust or unsubstantiated fears. Several people had the impression the interviewer would work together with German state authorities to initiate their deportation. Occasionally, some people even feared higher state authorities from their origin could become in possession of the interview information and take advantage of it. In cases like this, explanations and assurances did not help.

- The main problem was probably the lack of cooperation with institutions, schools, and other organizations in Germany. In theory, it would have been easy to interview a whole school class of asylum seekers, who are learning the German language, but all attempts to improve the interviews' sample size failed. Most requests remained unanswered or got denied. The managers of refugee accommodations in Germany had the most restrictive policy. Even individual discussions in private meetings were not allowed there, including security checks at the entrance (the questionnaires did not pass that obstacle). Thus, the only way to conduct the interviews was outside of public buildings (e.g., schools) in individual, private meetings. 
- A new problem that occurred during the dissertation's finalization process was the spread of the worldwide pandemic Covid-19. Countries shut entirely down, borders were closed, and no social interaction with other people was allowed, which harmed the dissertation's interviews. Without Covid-19, a higher number of participants would have been possible. Nonetheless, I continued the interview process online, and I was able to increase the number of participants.

\subsubsection{Ethical Standards}

The first section of the fully-structured interviews includes the following paragraph: 'All of the answers you provide in this survey will be kept confidential. No identifying information will be provided to the Corvinus University of Budapest or any other institution. The survey data will be reported in a summary fashion only. They will not identify any person.' Every participant was informed about the survey standards, and none of them was younger than 18 years old. The data is kept 100 percent confidential. Even for the dissertation's author, it is impossible to identify any person based on the interviews since the questionnaires do not include identity-specific questions and were shuffled afterward. After the interviews were conducted, I kept the responses in a closed cupboard, and they have never left the room. None of the information was shared with anybody. All the interviews were voluntary, and nobody was coerced. Each participant could withdraw from the interviews at any time or refuse to answer specific questions.

Furthermore, I made no payments or other financial commitments, except for offering some drinks or snacks to the interview partners. If some drinks or snacks were offered to me, I accepted them due to cultural reasons and politeness. For instance, refusing offers like this could be considered as impolite or disrespectful in some cultures.

Since the semi-structured interviews build on the fully-structured, they follow the same ethical principles. However, I informed every participant about their rights again. 


\section{Literature Review}

This literature review reflects the situation of migrants, refugees, internally displaced people, and asylum seekers. The topic's complexity and emotionality often do not make it very easy to distinguish between these terms since migration has become one of the most controversial issues among EU member states in recent years. Consequently, before going deeper into the literature, I start with the definition and differentiation of those terms to be as precise as possible.

The discussion for finding a universal definition for the term 'migrant' is not new. In 1966, researcher Lee (1966) struggled to find a proper explanation. Lee's definition of migration is very inclusive. Migration can be short-term or long-term. It can be from one continent to another or even moving from one apartment to another in the same building. Until this day, there is no uniform legal definition for the term 'migrant' on the international level. Many countries and organizations use the word as an umbrella term, encompassing both migrants and refugees. Another common form is the term' international migrant', which also includes refugees or asylum seekers. This circumstance can often lead to confusion because migration can also occur voluntarily, while 'forced migration's is the opposite. Therefore, the UNHCR separates between the terms' migrant' and 'refugee' (UNHCR 2018). In this dissertation, we will rely on Lee's widely broad definition but also distinguish between migrants and refugees.

Compared to the term 'migrant,' the terms' refugee,' 'internally displaced person' (IDP), and 'asylum seeker' are very well-defined. According to the UNHCR, a refugee is 'someone unable or unwilling to return to their country of origin owing to a well-founded fear of being persecuted for reasons of race, religion, nationality, membership of a particular social group, or political opinion' (UNHCR 1951; 1967: 16).$^{9}$ IDPs are those who 'stay within their own country and remain under the protection of its government, even if that government is the reason for their displacement. They often move to areas where it is difficult for us to deliver

\footnotetext{
${ }^{8}$ There is also no general definition for the term 'forced migration' since the term has been used in the past for many different types of displacement such as natural disasters, conflicts, or famine (UNHCR 2018).

${ }^{9}$ This is the short definition of the term 'refugee'. The actual definition is much longer and can be accessed at the website of the UNHCR (UHNCR 1951, 1967). For reasons of space I do not quote the whole definition here.
} 
humanitarian assistance. As a result, these people are among the most vulnerable in the world' (UNHCR 2019a), and 'an asylum-seeker is someone whose request for sanctuary has yet to be processed. (...) However, during mass movements of refugees, usually due to conflict or violence, it is not always possible or necessary to conduct individual interviews with every asylum seeker who crosses a border. These groups are often called 'prima facie' refugees' (UNHCR 2019b).

Overall, except for the term 'migrant,' the UNHCR defines the terms correctly, and these are the definitions used in this dissertation.

\subsection{Migration Theory}

Migration has always been an essential part of humanity, has, without a doubt, considerable implications in the present, and probably will continue to do so in the future (McNeil and Adams 1978). King (2012) argues that human motivation to move or migrate is, to a certain extent, intrinsic: 'the need to search for food, pasture, and resources; the desire to travel and explore; but also to conquer and possess' (2012: 4). Furthermore, migration is also an innovation driver since people moving from one area to another are distributing their inventions. However, the debate concerning immigration has changed in the last 30 years. Castles and Miller (1993; 2009) describe the actual era as 'The Age of Migration' and concluded that international migration 'has accelerated, globalized, feminized, diversified and become increasingly politicized' (2009: 10-12). Urry $(2000 ; 2007)$ wrote that Western societies' typical structures such as social class, static residence, and stable employment have been disrupted, and mobility has become more critical.

At the moment, there are approximately 272 million migrants worldwide (UN 2019a). Seventy-one million of them are categorized as 'forcibly displaced people' (IDRs ${ }^{10}$, refugees, and asylum seekers) (UNHCR 2020a), which means a total increase of 51 million migrants compared to 2010 (UN 2019a). ${ }^{11}$ Even though this figure is tremendously high, it is still

\footnotetext{
${ }^{10}$ Internally displaced persons.

${ }^{11}$ There are two notable issues with the numbers. 1.) Every countries has its own methods to capture 'migrants'. Someone, who is one country seen as a migrant, could be recognized and counted as a normal citizen (nonmigrant) in another country. 2.) 'Undocumented' or 'irregular' migration makes it impossible to capture the
} 
relatively small compared to the world population of 7.8 billion. Therefore, the vast majority of people worldwide do not migrate, even though many more of them should migrate according to push-pull models and economic circumstances (King 2012). Malmberg (1997: 21-22) calls this the 'immobility paradox.'

The immobility paradox leads to the question, "why so many people have never migrated (King 2012)?" Is it because of incapabilities, or are they basically not willing to? Is it their social and professional environment (family, friends, culture, et cetera) that holds them back? Or is the willingness extraordinarily high, but people do not have the resources (finances) to do so? Are politics such as immigration barriers a threshold that they cannot overcome? King (2012: 5) concludes that people have even lost their right to free movement in the last decades, while the mobility of goods, capital, entrepreneurship, and media has increased. King (2012) also points to another phenomenon in this context: "migration for some, but not for all.' Migration aspirations have a lot to do with origin and social status.

Wealthy persons from the EU or North America are perceived as 'good' immigrants. In contrast, immigration from impoverished regions (e.g., Africa or Latin America) and not wealthy persons are often stigmatized as 'bad' immigrants. Carling (2002) investigated countries that are traditionally outflow-migration countries. Based on this, he developed his famous 'aspiration/ability' model and stated that 'the age of migration' is for many people 'the age of involuntary immobility.'12

Indeed, migration changes and transforms countries, but it also polarizes societies. On the one hand, we have people who welcome migration and see these immigrants' value in contributing to a community with their labor force and cultural diversification. On the other hand, we have people who blame migrants for every problem a country might have (drugs, prostitution, unemployment, crime, religious extremism, et cetera). King (2012) criticizes this polarization and those people blaming mostly migrants for societies' problems and argues for a more objective, fact-based discussion.

Following Malmberg's approach (1997), migration operates in time and space and has to overcome the obstacles of distance and' time in migration' (Cwerner 2001). When

'real' number. Nevertheless, the numbers provided by UN or UNHCR are definitely the best statistics available.

${ }^{12}$ See chapter 3.1.6 for a comprehensive overview of the aspiration/ability model. 
speaking of international migration, a border needs to be crossed to migrate from one sovereign state to another (if there is no border-crossing, it is internal migration). Although this appears at first glance obvious, it is not. Borders are abstract concepts and have been determined by humans. There is no 'natural' or 'universal' law, which defines borders ${ }^{13}$. Thus, borders can suddenly change or disappear overnight. The examples of the former Soviet Union and the former Republic of Yugoslavia demonstrate how quickly these changes can happen. There are also vast differences regarding the permeability or density of borders, free movement in the Schengen Area, and closed external borders (King 2012). Concerning the time factor, a person usually needs to live at least one year in the host country to get recognized as an immigrant ${ }^{14}$. However, the range reaches from one year to ten years or a permanent settlement. Otherwise, temporary migration is very often connected with return migration to the country of origin, while permanent settlers only visit their original country (ir)regularly (King 2012: 7).

Furthermore, there is often the wrong perception that people can only migrate between two different countries (back and forth). Hence, cases where people move forward to a third country (or get stuck somewhere between) are often ignored. Nevertheless, this form of 'onward' migration becomes more significant and common since migrants spend a significant amount of time on their journey in countries that are not intended as their destination. Suter (2012), who investigated the routes of Sub-Saharan migrants, concluded that Morocco, Turkey, and Libya were nothing more than transit countries for most people on their way to Europe. Collyer (2007) came to similar results by tracing back the routes (first crossing the Sahara, then the Mediterranean Sea) of West African migrants to Europe. Another example is Somalian immigrants in the Netherlands (confirmed refugees), who moved on to the United Kingdom because of more prominent Somalian communities there (Liempt 2011).

Cohen (1996) and King (2002: 90-91) have elaborated on migration binaries, dichotomies, or dyads to provide additional typologies in terms of migration. Although the authors themselves say further research is needed, the dualities enrich the discussion. The following ones have already been covered in this literature review: internal vs. international,

\footnotetext{
${ }^{13}$ Natural barriers like rivers, mountains, or lakes back are historically "natural borders". However, this perspective seems to be out-dated since many borders were made randomly by humans (e.g., the Sykes-Picot agreement from 1916).

${ }^{14}$ See also Chapter number three for the definition of the term 'migrant'.
} 
temporary vs. permanent, and regular vs. irregular migration. A more complex one is the distinction between voluntary (e.g., 'economic' migrants) and forced migration (e.g., refugees) since classifications can change. Most migrants, for instance, are both: internal and international migrants (migration within the $\mathrm{EU}$ or other political/economic unions). Alternatively, migration, which is only supposed to be temporary, can become long-term and turn into a permanent settlement (e.g., the case of foreign guest workers in Germany and Switzerland during the 1960s) (Castles et al. 1984).

A second one is the distinction between regular and irregular migration. Irregular migrants can become regular (legal) through political processes, and, vice versa, regular migrants can become illegal through bureaucratic procedures (e.g., no extension of residence permit) (Fakiolas 2003). Finally, the last distinction between voluntary and forced migration often seems too simplistic (King 2012: 8). Sales (2007: 47) stresses that (armed) conflicts are a severe economic struggle factor and might result in a mass-outward migration. Thus, the collapse of state structures and infrastructure makes economic and political fleeing reasons very likely to occur during or after an armed conflict. However, this form of 'economic' migration is not covered by the 1951 UN Convention on Refugees ${ }^{15}$. A well-researched example of such 'economic' emigrant movements is the case of Albanians after 1990 due to political and economic state failure (Barjaba and King 2005).

Overall, migration studies cover a wide range of fields, from economics, politics to social sciences, et cetera, making the subject genuinely interdisciplinary ${ }^{16}$. In general, we can identify three dominant forms of migration: labor migrants, settler migrants, and refugees. (King 2012) This basic framework has been enriched during 'The Age of Migration' by new types of migration and international mobility (King 2002; King et al. 2010; Martiniello and Rath 2012). Thus, due to improved infrastructure and versatility, we can observe worldwide migration movements, which have no historical ties (Bangladeshi migration to Italy) (Knights and King 1998). Other new forms are local scale-cross-border shuttle migration (Engbersen 2001; Morawska 2001), residential tourism (e.g., extended holidays due to seasonal sports like skiing or surfing (Myklebost 1989), and business visits and work contract migration (Salt

\footnotetext{
${ }^{15}$ See chapter three for the definition of the term 'refugee' according to the UN Convention on Refugees.

${ }^{16}$ According to King (2012: 10) the terms 'cross-disciplinary', multidisciplinary and 'postdisciplinary' are snynonyms and are also often used in this context.
} 
1992). Nevertheless, there are many other forms of movement, including family reunion, marriage migration, student migration, highly-skilled migration and brain drain, environmental and climate change migration, and human trafficking and sexual exploitation (Martiniello and Rath 2012; King 2012). New conceptional frameworks such as 'mobility' (Urry 2007), 'transnationalism' (Glick Schiller et al. 1992), and 'diaspora' studies (Cohen 2008) make the field of migration studies more sophisticated. All of these different concepts introduce different approaches.

The discussion of an interdisciplinary approach to the field of migration is not new. Jansen (1969: 60) stressed that migration studies include many social science disciplines. According to King (2012), geographers, sociologists, and economists have the most lengthy history in this field. Still, many other researchers from other specializations such as social psychology, political science, anthropology, history, demography, law, the humanities, literary, media and cultural studies have tackled the field of migration over time. King criticizes these 'narrow disciplinary boundaries' and states that most universities are fragmented in discipline-based degrees and research programs (King 2012: 9-10). Many other scholars support this argument. Castles (2000: 15-25) emphasizes that disciplinary approaches are 'the enemy' in terms of analyzing human migration, and Arango (2004: 15) argues that single disciplines cannot fully cover the complexity of the topic and have limited the building of comprehensive theories. Thus, several researchers have stressed the importance of an interdisciplinary approach, such as Hammar et al. (1997), Favell (2008), King (2002; 2012), Bretell and Hollifield (2008), and Samers (2010).

It has become clear that migration studies cannot be treated as a single discipline, and a combination of various theories is crucial to developing a solid overview of migration theories; the next section is divided into several parts. Frankly, the massive amount of different models and theories does not allow us to cover them all. For example, highly skilled labor migration or retirement migration will only play a minor role in this literature overview since the dissertation's focus is mainly on refugees and asylum seekers. Therefore, the structure of this work follows similar approaches as other researchers such as Massey et al. (1993), as well as Arango (2004), Morawska (2007), de Haas (2010), Fussell (2012), and 
King (2012), who previously investigated migration from poor to rich countries. ${ }^{17}$ However, the dissertation is written in the context of the events of 2015 and other recent developments (e.g., climate change).

\subsubsection{Neoclassical Economics and Push-Pull Theory}

It is nearly impossible to find the genesis of migration studies since migration has always existed, but the Industrial Revolution raised awareness. Consequently, early work in migration theories was strongly influenced by predominately economic factors in the $18^{\text {th }}$ and $19^{\text {th }}$ centuries when landowners or farmers were forced to move from rural regions to cities to find work in factories. During this time, one key scholar was E.G. Ravenstein, who formulated his 'Laws of Migration' $(1885 ; 1889) .{ }^{18}$ According to Ravenstein's model, people prefer moving short distances and only rarely make exceptions to that rule. In compliance with the historical context, people moved to commerce centers and were employed by industries (I: 198-199). Rural regions that they left filled up with other migrants. Therefore, 'each main current of migration produces a compensating counter-current' (I: 199). Ravenstein further states that inhabitants from towns are less migratory than those from rural regions (I: 199), as are males compared to females (II: 288).

Furthermore, technological factors like the improvements in transportation or manufacturing and commerce affect the amount of migration (II: 288). In conclusion, economic reasons are the main factor for migration (II: 286). Ravenstein's work was written from a British perspective and focused on internal rather than international migration (King 2012). Samers (2010: 55-56) describes the 'Laws of Migration' as 'economically deterministic,' 'methodologically individualist,' and 'dreadfully antiquated.' Other scholars, especially geographers (Ravenstein himself was a cartographer at the British War Office), valued his model much higher. White and Woods (1980: 6) called his approach 'the cornerstone of geographical thought on migration,' and Boyle et al. (1998: 5) wrote Ravenstein's work 'provided the hypotheses upon which much future migration Research and theorization were built'.

\footnotetext{
17 The migration from poor to rich countries is probably the most dominant research topic in the field of migration studies and many theories build on that.

18 'I' refers to Ravenstein's paper from 1885 and 'II' to the 1889 paper.
} 
Although Ravenstein's works are over 100 years old, they are still current to a certain extent. The attractiveness of cities or centers has even increased and will continue to do so in the future (UN 2019b). The same applies to technological progress (e.g., the Silicon Valley region) and the importance of economic reasons. Nevertheless, Ravenstein's theories are, of course, in many ways, outdated. The main criticism here is that our perception of distance has changed. Economic factors are not predominant in mass migration from civil war countries like Syria in 2015 to Europe. In general, mobility has increased, and even long-distances are covered in a relatively reasonable amount of time for a fair price. ${ }^{19}$ Indeed, economic differences between origin and destination remain a significant issue. Still, it is evident that these articles reflect a completely different period (even before WWI and II) and neglect the consequences of armed conflicts.

The first attempts to develop a more generalized theory in migration studies that do not focus extensively on economic factors were decades later. In this context, one of the most groundbreaking papers is Lee's 'A Theory of Migration' (1966), which developed a completely different and more comprehensive approach with its 'Push-and-Pull' model ${ }^{20}$ Lee breaks it down to a comfortable and understandable formula, emphasizing the similarities that all migration movements have in common: origin, obstacles to overcome, and destination. In general, whether one decides to migrate or not is based on individual decisions and circumstances. Every area or country has its list of advantages ('+ factors') and disadvantages ('- factors'). In this model, push describes the causes of flight, while pull examines the destination's attractiveness by defined factors. Push factors are socio-economic (hunger, poverty, demographic issues, et cetera), political (war, dictatorship, discrimination, et cetera), and environmental (natural disasters, scarce resources, et cetera) based. Accordingly, pull factors include the following aspects: economy (booming economy, higher income, social welfare-system, et cetera), society (security, housing, education, et cetera), demography (sufficient space, social networks, infrastructure, et cetera), and politics (freedom, the rule of law, democracy, et cetera). Another important part of the model is the 'intervening obstacles'

\footnotetext{
19 The term 'fair' price is still relative, and many people cannot afford it (World Bank 2018a).

${ }^{20}$ Actually, Lee has never used the term 'Push-pull model' by himself (Passaris 1989), but his approach is commonly understood as 'Push-pull'. de Haas (2010: 4) criticizes this circumstance as 'undeserved'. Other scholars, such as Peterson (1958) have already used the term before.
} 
(e.g., distance or restrictive immigration laws), which every migrant has to overcome to reach the destination. Furthermore, Lee formulated a list of hypotheses concerning 'the volume of migration,' 'streams and counter-streams,' and 'the characteristics of migrants.'

In comparison to Ravenstein's model, the Push-and-Pull model is definitely a step forward and is, until now, a frequently cited work in the field of migration studies. However, earlier studies, which were much more focused on economic factors, remain noticeable. Other aspects, e.g., push factors such as armed conflicts, natural disasters, or political persecution, did not find any noteworthy mention in the paper, even though Lee's concept made a more comprehensive approach possible as previously described. In general, Lee's approach lacks in terms of not being specific enough. Of course, the idea was to formulate a generalized theory, but many aspects were vague and focused too much on the argument's economic issues. One could also argue that Lee is trying to describe the unexplainable. Not every decision is rational (Lee was aware of that), but in 1966, he could probably not predict the invention of the internet and smartphones. People are overstimulated continuously with information and tend to develop preferences for specific countries or areas they have never visited before or have limited knowledge about it.

Thus, especially in relatively well-developed countries, the phenomena can be observed that people make their migration decision based on cultural preferences or just the willingness to travel (having an adventure), but not on harsh life circumstances. The same applies to information networks and mobility. Distance is not a significant issue anymore, and high-speed internet connections make it easier to communicate globally. Overall, the Pushand-Pull model was still a significant starting point for discussion, and numerous scholars elaborated on specific aspects of the model. According to King (2012: 13), Push-pull models dominated the whole mid-twentieth century regarding migration theories and 'reflect the neoclassical economics paradigm, based on principles of utility maximization, rational choice, factor-price differentials between regions and countries, and labor mobility.'

Massey et al. (1998: 18-21) distinguished the neoclassical approach between the macro and micro levels. While the macro-level focuses on spatial differences between two regions in terms of economic power, labor, and capital, the micro-level focuses on individual decisions and evaluating the pros and cons made by 'rational actors.' Lewis (1954) elaborated on the macro-level of this framework. He developed his dual-sector development model, which says the industrial sector grows substantially by labor migration from the agricultural industry. Kindleberger (1967) used this approach to explain labor migration from the South- 
European and Mediterranean countries to the North-West-European countries. King et al. (1997) described the transformation process of the South-European countries from laborexporting countries to labor-importing countries after the 1970s based on Lewis' (1954) and Kindleberger's (1967) research. Other essential works in this field are from Todaro (1969) and Harris and Todaro (1970). They examined urban-rural migration, which also applies to international migration (Borjas 1989; Todaro and Maruszko 1987; de Haas 2010). On the other hand, the neoclassical model's micro-level aspect was assumed to be migration based on the return on investment in human capital (Sjaastad 1962; Bauer and Zimmermann 1998) and cumulated in the development of 'the international immigration market' model by Borjas (1989).

Although the criticism concerning Push-pull and neoclassical models is overwhelming, it is even not clear if these two approaches should be observed separately from each other or not. King (2012) treats the Push-pull model as a part of the neoclassical framework, while de Haas (2010) distinguishes between these two approaches, which shows the subject's diversity and complexity. However, there is some form of unity in the extensive formulation of criticism. Malmberg (1997: 29) criticizes the 'internal logic' and 'simplicity' of the theory. For Arango (2004: 19-20), the lack of explanation why only a minimal amount of people migrate, even though incentives are given, is the 'achilles heel' of the neoclassical approach. His second point is the theory's incapability to explain why countries with similar structural backgrounds and resources have different out-migration. The approach fails to consider socio-cultural factors, the political reality (e.g., migration barriers), colonial roots, and the world economy's structure. According to King (2012), these developments lead to a theoretical fragmentation in Marxist political economy, historical developmentalism, systems theory, and the 'new economics' of migration during the 1970s and 1980s.

On the other hand, de Haas (2010: 4), who distinguishes between Push-pull and neoclassical models, censures Push-pull and is more pleased by neoclassical theories. For de Haas, the model is too static and not specific enough. It does not measure the relative weight of migration decisions and does not consider the interaction with other factors affecting people's lives. In comparison, the neoclassical approach is more sophisticated and examines 'migrations as a function of geographical differences.' Overall, the neoclassical approach is more dynamic and can be understood as a process. de Haas explains that with the 'factor price equalization' (Heckscher-Ohlin theorem), which is supposed to create a convergence of 
wages and reduce migration (Harris and Todaro 1970; Lewis 1954; Ranis and Fei 1961; Schiff 1994; Todaro and Maruszko 1987).

Furthermore, de Haas stresses that both models derive from functionalist social theory, which says an equilibrium between rich and developing countries in terms of wages, for example, will decrease migration (2010: 5). In conclusion, he states that equilibrium-based models struggle to explain real-world migration because individuals do not have access to all information and do not operate under perfect market conditions. They cannot make independent decisions that are not affected by the framework of push-pull macro-level implications.

Overall, the neoclassical approach is fundamental in migration studies and builds the foundation for in-depth macro- and microanalysis. Even though many of these approaches seem to be 'outdated,' they provide a comprehensive set of primary migration reasons. Indeed, the focus is very much on the economic perspective, but other scholars such as Van Hear et al. (2018) were influenced by these theories and extended the basic model by considering new nuances (e.g., migration complexes in the framework of drivers of migration). Asylum seekers and refugees studies cannot be covered and understood without these essential contributions to the field.

\subsubsection{Migration, Transitions, and Development}

Zelinsky (1971) invented 'The Hypothesis of the Mobility Transition,' which is in sharp contrast to the rational decision-making contrast of the neoclassical approach. The author linked migration and mobility to different stages in the modernization process. His article's central message is that 'there are definite, patterned regularities in the growth of personal mobility through space-time during recent history, and these regularities comprise an essential component of the modernization trend' (Zelinsky 1971: 220-222). King (2012) compares Zelinsky's model with demographic transition theory and Rostow's (1960) 'growth' model stages. de Haas (2010: 6) emphasizes that Zelinsky suggested a 'Spatio-temporal' model 'by integrating demographic transition theory with the theory of the spatial diffusion of innovations.' He came up with the concept of 'vital transition,' which focuses not only on demographic factors but also on economic growth and modernization.

Thus, 'vital transition' can also be understood as 'development' or 'modernization.' Zelinsky's model is a five-stage model taking the individual phases of 'vital transition' into consideration: 
1. Pre-modern or traditional society: migration only occurs very rarely, high fertility and mortality, and mostly short-distance migration movements (e.g., marriage).

2. Early transitional society: mass rural-urban migration, a decline of mortality and population growth, and emigration to other countries for settlement or colonization.

3. Late transitional society: less rural-urban migration and emigration, lower fertility rates, and improved mobility (e.g., commuting).

4. Advanced society: rural-urban migration gets replaced by inter-urban migration, immigration from poor to rich countries (e.g., low-skill labor force), international migration of high-skill labor force and professionals, low fertility and mortality rates, and stable population-level.

5. Future 'super advanced' society: improving infrastructure and communication, less human circulation, labor-force migration from emerging countries, low fertility and mortality rates, and immigration control mechanisms.

Many researchers, such as Skeldon (1977), who initially investigated the urbanization process in Peru, were inspired by Zelinsky's work. The two following articles by Skeldon in this context $(1990 ; 1997)$ implemented the spatial dimension of transition theory in world migration: 'There is a relationship between the level of economic development, state formation and the patterns of population mobility. Very generally, we can say that where these are high, an integrated migration system exists consisting of global and local movements, whereas where they are low, the migration systems are not integrated and mainly local'. (Skeldon 1997: 52) de Haas (2010: 7) elaborated on this and called the new dimension 'structure' since Skeldon did not only focus on demographic and economic transition but also on nation-state formation in Europe, colonization, cultural and linguistic roots, and structural interdependencies and inequalities (e.g., migration from Africa to the UK or France). Massey (1988) followed the same argument by stressing the relationship between capitalist development and migration. He also argued that improved infrastructure and consistent differences in wages would increase movement among people who are seeking better living conditions elsewhere. Hatton and Willamson (1998) confirmed Massey's analysis from 1988.

In a later article, in 1983, Zelinsky addressed some of his critics and presented an updated version of his model by integrating the dependency theory, policies, decision-making of governments, and corporations in developed countries and their role in terms of migration patterns. Nevertheless, as King (2012: 15) stated, Zelinsky's research was, at least to a certain 
extent, visionary because he 'anticipated the current debate on migration and development,' which is, indeed, true. Almost 50 years later, many parts of his initial theory are still relevant. Zelinsky linked the concept of time and space with mobility and migration. Thus, he was one of the first scholars who knew what an important role technology, infrastructure, and communication would play in the future. Unfortunately, many other researchers ignore this aspect in their theories, which makes the criticism of the neoclassical approach legitimate. However, it is worth discussing if both arguments can easily co-exist. Zelinsky merely implemented this approach by introducing the concept of time and space. However, one of his work's shortcomings is that it is very much long-term oriented and does not address shortterm events such as conflicts, wars, or natural disasters. In this regard, push-pull models, for example, are superior.

\subsubsection{Historical-structural Models}

The 'historical-structural' models describe a set of related approaches and theories concerning migration. Many of these models are heavily influenced by Marxists and their interpretation of the capitalistic system. Therefore, inequality and the capitalistic system's exploitive nature play a significant role in international migration's genesis (Morawska 2012: 55). According to King (2012), the three most influential models in terms of structural theorization and reasons for international migration are dual and segmented labor markets, dependency theory, and world-systems theory.

Piore (1979) analyzed the labor market's structural framework in terms of migration and concluded that pull factors dominate over push factors in this situation. Especially in highly-developed, mostly Western societies, there is a high demand for a cheap and flexible labor force. This trend is the foundation for the 'dual labor market.' According to this theory,

the labor market is fragmented into two different labor markets. The first labor market is for the domestic population and offers well-paid jobs, security, and better jobs overall for its citizens. The other one is the secondary labor market. This labor market is primarily for poor migrant workers and offers low-wages, insecurity, and worse working conditions. In other words, migrants do the low-skilled and very often dangerous work that the local workforce is unwilling or unable to do. Of course, this separation of labor also has other implications. The cheap labor force's presence lowers the domestic population's wages as well, which causes tensions between citizens and migrants because doing badly-paid work is usually still better 
than what they left behind. Nieswand (2011) calls this 'the status paradox of migration.' The reputation of migrants in their home country is very high due to the constant financial support of family members; the migrant's status in the host country is usually very miserable.

Consequently, the secondary labor market becomes very 'segmented' due to race, nationality, religion, et cetera, and migrants take these jobs (Samers 2010: 65). The phenomena of the 'segmented' labor market are mainly observed in well-developed countries. The recruitment process also tends to be network-based since foreign recruiters prefer coworkers of their own ethnicity (Fussell 2012: 28). Sassen (1988; 1991) extended Piore's (1979) work and transformed his approach to the post-industrial era. Sassen analyzed the emergence and growth of megacities like New York or London and concluded that corporate headquarters, financial centers, and producer services played an essential role in the genesis of them. Global cities are full of extreme contrasts. The super-rich lives alongside the very poor. Therefore, the work that has been done by the rich people themselves previously is now done by immigrants, who are working in restaurants or hotels, cleaning offices, and healthcare, et cetera., so-called low-end jobs done by the 'precariat' (Standing 2011).

Piore (1979) and Sassen's $(1998 ; 1991)$ approach is related to another theory within the Marxist framework: the 'dependency school.' It is the complete opposite of the neoclassical approach. The neoclassical school assumes that migration is self-correcting, and migration balances out over a certain period, which leads to a new equilibrium. For example, wage-differences are supposed to diminish until they vanish entirely. On the other hand, neoMarxists argue that 'migration is self-perpetuating, reproducing inequality through the mechanism of cumulative causation' (Myrdal 1957; Petras 1981).

Compared to other scholars such as de Haas (2010), who negatively link migration and development, dependency theorists see migrants as part of the global labor force from the more impoverished regions of the world in the context of exploitation by the capitalistic system. (Morawska 2012: 60) King (2012: 17) concludes that dependency theorists reflect this process as something that makes millions of people homeless and forces them to leave their original countries. The dependency theory approach was very successful during the 1960s and 1970s in Latin America. Frank (1969, 1978), with his 'development of underdevelopment' claim, was one of the most influential researchers. Wise (2008), who investigated Mexican migration, is a more actual representative of this school.

The third and latest approach within the historical-structural models is the 'World Systems Theory.' It is similar to the previously mentioned approaches. However, the world- 
systems theory is supposed to be more comprehensive when considering the global capitalist system's success and influence from the $16^{\text {th }}$ century (Wallerstein 1974; 1979). At the beginning of the 20th century, the end of colonialism can be seen as the origin of the World Systems Theory. Even though decolonization dominated the post-war era, the links between former colonies and superpowers remained strong. So did the permanent circulation of people between these countries because of infrastructure, transportation, linguistic, and cultural connections (Morawska 2007: 3). Thus, Wallerstein (1974) distinguished countries by wealth and their economic power. According to this model, the dominant capitalist powers were North America, Europe, Japan, Australia, and New Zealand. These countries formed 'the core' and were surrounded by countries from 'the periphery.' Those periphery countries were highly dependent on the core in terms of trade, capital, and migration. Wallerstein's model also included 'semi-periphery' countries like Brazil, Argentina, Mexico, Turkey, or South Korea. ${ }^{21}$ However, all these countries were embedded in the framework of the 'new international division of labor' (NIDL) (Froebel et al. 1980). The NIDL derives from capitalist exploitation in rural regions and creates a considerable amount of available workforce ('reserve army'), which allows the core countries to use the underclass wherever and whenever they need them. In other words, the capitalistic system created a self-preserving source of low-wage and low-status people for the upper-class in the core countries to maintain their high living standards. Authors like Cohen (1987) or Potts (1990) elaborated on the endless hunger of the capitalistic system and its need for 'slave-like workers' (King 2012).

Reception to the Marxist approach has been widely mixed as well. Arango (2004: 27) criticizes that historical-structural models consider migrants as 'little more than passive pawns in the play of great powers and world processes presided over by the logic of capital accumulation.' He further criticizes historical determinism as 'univocal, reductionist interpretations of history in which all countries pass through... as if following a grand script' (Arango 2004: 27).

King (2012: 19) has three significant criticisms. First, he argues that migration flows do not always follow the money but often appear spontaneously as a reaction to specific

\footnotetext{
${ }^{21}$ The rise of new superpowers like China, India or Russia in recent years shows that this classification is, of course, not correct anymore.
} 
events or developments. Second, historical-structural approaches often do not recognize the successful examples of migration (e.g., immigrants in the U.S., who accumulate wealth) and pay attention only to capitalism's exploitatory aspect. Third, the role of the state is ignored by all, not only by Marxist theorists. The political economy dimension of immigration receiving countries needs to be considered in terms of 'quota and admission systems, regulations of entry, duration of stay, work permits, citizenship rights, etc.' (King 2012: 19).

According to Morawska (2007: 4) and her 'hegemonic stability' model, only a small group of political and militarily powerful nations dominate the global economy. Thus, these 'hegemonic receiver-states regulate global trade, finance, and international migration' (King 2012: 19). Castles and Miller have already linked global migration to the political economy framework in 1993 and explained it in later works with transformational changes (Castles 2010) or massive shifts in the global economy, political, and military power dynamics (Castles and Miller 2009: 54). However, Castles and Miller also recognize the disruptive character of international migration and 'transnational societies' in the context of hegemony (2009: 12).

Regarding asylum seeker and refugee movements, historical-structural models add a new dimension to the debate by emphasizing the role of inequality and armed conflicts in migration decisions. They supplement the classic push-pull theories and provide a coherent explanation of why specific destinations attract people.

\subsubsection{Systems and Networks}

Systems theory may be the most flexible approach among migration studies since it delivers an analytical framework for structure, linkage, and migration (King 2012). Thus, the systems approach covers a wide range of different topics due to its adjustable and its less stringent character of the model in terms of ideology: village migration systems (Mabogunje 1970), inter-urban migration (Poot 1986), the European labor migration system (White and Woods 1980: 49-55), the global migration system (Kritz et al. 1992), or the world systems theory of Wallerstein (1979) can be all categorized as a part of systems theory. Faist (1997: 193) emphasizes the advantage of the systems approach compared to the linear Push-pull models as 'circular, multi-causal, and interdependent,' which makes specific changes of systems traceable.

King (2012: 20) summarizes systems as self-feeding (like chain migration), selfregulating (correcting themselves in response to a 'shock' to the system), or self-modifying 
(e.g., shifting to a different destination when one is blocked off).' Mabogunje's (1970), who investigated the rural-urban migration situation in West Africa, developed the following model:

1. The environment: all critical parameters for a person to include living standards, culture, politics, economics, et cetera.

2. The migrant: the capability of a migrant to move.

3. Control subsystems: determining the volume of migration by decision-making processes.

4. Adjustment mechanisms: social, economic, and political forces, which react to the departure and arrival of migrants.

5. Feedback loops: positive and negative feedbacks of the destination decide if the migration flows continue or stop.

Mabogunje's work has received mixed reactions. While Kritz et al. (1992) stressed the model's flexibility and argued for an adaptation to international migration studies, other researchers reviewed his 1970 article negatively. Boyle et al. (1998: 77-79) criticized that Mabogunje's systems approach failed to explain several systems such as 'apartheid migration system' or the 'Gulf migration system.' According to King (2012), Mabogunje's systems approach lacks research design and data availability, making it easy for critics to point to the theory's mechanical and positivist character. Nevertheless, systems and networks have been established in the field of migration studies. Thus, a great deal of research has been done in the meanwhile. Arango (2004: 28) calls networks 'one of the most important factors for migration.'

Massey et al. (1998: 42-43) argue that networks lower the costs and risks for migration since networks consist of migrants, former migrants, or future migrants who operate in the same social environment and connect through individual ties like friendship or family. Therefore, these groups provide and share information concerning migration and movement. Tilly (1990) came up with the following statement in this context: 'it is not people who migrate but networks' (1990: 79). Faist (1997) and Goss and Lindquist (1995) see networks as the 'bridge' between individuals and socio-structure, which makes them, in their opinion, superior to Push-pull or gravity models. Fussell (2012) has identified three more relevant contributions to the systems-network approach: First, they differentiate migration by dynamics. Second, they can predict future migration streams or developments. Third, they distinguish between causes of migration and its perpetuation and its diffusion in time and 
space. This approach's historical roots date back to Thomas and Znaniecki (1918-1920), and they also play a significant role in the development of chain migration theories (MacDonald and MacDonald 1964).

Most of the emphasis has been on investigating family networks because the common understanding and perception is that those ties are the strongest. However, Granovetter's research from 1973 showed that also 'weak ties' can promote migration. Such weak relationships can be derived from common culture or values, same race or ethnicity, or even just loose friendships, et cetera. All these factors and circumstances can be enough to build up trust and establish a network-related movement (Tilly 2007). Liempt (2011), who researched Somalian migration to the United Kingdom, is an excellent example. Boyd and Nowak (2012: 79-83) differentiate between three significant network styles: family and personal networks, labor networks, and illegal migrant networks. The authors also added gender to the topic by stressing women's importance in establishing and maintaining such networks (2012: 83-86). King (2012: 22) states that migration networks are overwhelmingly reviewed positively in the literature from a migrant's perspective. These networks provide information, guidance, financial assistance, housing and help them with everything else that new migrants have to deal with at their destination. Arango (2004: 28) attributes a multiplier effect to networks and assumes they perpetuate migration movements. However, King stresses that these network effects are not endless and cannot continue forever due to natural limitations (2012: 22). Samers (2010: 87-93) addressed the issues of smuggling, human trafficking, and other criminal activities in the context of networks, which shows that networks do not have only positive effects for migrants but can also harm them.

The latest effort in the field of networks and systems comes from Barthel and Neumayer (2015). The authors argue that network effects increase asylum seekers' numbers since other migrants from the same origin can provide information and assistance. These network effects extend borders and also affect other geographically proximate source countries. A common language has the same indications, but the implications are relatively small. On the other hand, the authors could not find evidence for network effects for countries with the same colonial history.

These findings contradict some of Neumayer's earlier research results (2004), where Neumayer found that asylum seekers often come from former colony countries and prefer destinations with the same language or one close to their origins. However, restrictive immigration laws and other anti-migration measures lead to more asylum migrants in 
neighboring destination countries. Indeed, the opposite effect is observed if a destination country lowers its entry barriers. Their research shows that once a destination has become popular among migrants from a specific origin, it will last for quite a while due to network effects. This is similar to Neumayer's earlier findings. He was able to confirm 'network effects' (a high share of asylum seekers from a particular country means a higher level of attractiveness of other asylum seekers from the same origin) (Neumayer 2004). Thus, a 'raceto-the-bottom' is likely to appear between destination countries by lowering migrants' standards.

The study of networks is of extraordinary importance for this dissertation. Chapter six will show evidence for the theory that actual asylum seekers and refugees in Europe are influenced by networks of families, friends, or communities of the same origin.

\subsubsection{The New Economics of Labor Migration}

The New Economics of Labor Migration (NELM) emerged during the 1980s and connects the neoclassical approach with family decision-making. The most influential representative of this theory was Oded Stark (1991; Lucas and Stark 1985; Stark and Bloom 1985). This theory permanently added two meaningful aspects to the discussion of migration. First, the migration decision-making process should not be observed separately but preferably seen in the context of close family members and relatives. Usually, these decisions are made in groups and depend on who goes, for how long, to which place, et cetera. Massey et al. (1998: 21) also extends the group of family members to include (close) friends and other persons significant to the individual making a migration decision. Second, decision-making processes in terms of migration are not only about finances and making more profit by receiving higher wages or generating a higher income in general; it is also about 'income diversification' and 'risk aversion.' The need for risk reduction is given primarily in developing countries, which cannot adequately handle natural disasters like droughts or floods due to a lack of financial resources.

King (2012: 23) concludes that the NELM perspective is a diversification of risks by considering both significant aspects of the theory. Families, households, or communities take control over the finances and resources by sending group members where they are needed and generating the most value for everyone. Therefore, for instance, it can be beneficial for some family members to stay. In contrast, other family members could be more 'valuable' at other places, including internal migration, as well as an international movement. One of the 
significant advantages of this 'diversification strategy' in allocating family members is that those successful abroad, respectively, at their destination, can support family members left behind. Besides the positive effect of risk aversion, it also helps to cover the costs of daily life (nutrition, accommodation, clothing, et cetera) and to invest in future projects (property, businesses, investments, et cetera) (2012: 23).

The main difference between the NELM theory and the neoclassical approach is, for King (2012), the perception of 'return migration.' In the neoclassical framework returning to the origin means 'failure' because of miscalculation or other events. Nonetheless, cases of return migration are not covered at all. On the other hand, in NELM theory, return migration is perceived as something positive or right and not a failure. People who return to their origins have been successful and achieved their goals. Thus, they are coming back with more than they possessed (Cassarino 2004).

One of the critics concerning NELM comes from Arango (2004: 23), who argues that the theory is very much dependent on the supply side of labor and works best in rural regions (e.g., Mexico or Botswana). Kings (2012: 23) further criticizes that families are treated as a 'black box.' NELM does not say anything about the tensions, conflicts, or other problems, which some families might have and influenced their decision-making process. NELM models expect 'harmony' within families but do not pay enough attention to the other side of the coin. Finally, NELM can explain why individual family members migrate but cannot describe the situation when the whole family decides to leave their origin, which is often the case.

A new aspect was recently added to the debate by introducing refugee studies to NELM, networks, and world-systems theory. FitzGerald and Arar (2018) explained in their research the development of the sociology of international migration. They emphasized the lack of refugee studies, which has become a relatively new field in academics. The field sociology of migration emerged during a period of relatively free immigration, and refugee studies developed during a period of high selectivity. The recognition as a refugee helped in cases of resettlement or restraining deportation. Therefore, according to the authors, it is essential to understand this evolution to fully grasp the current debates about the so-called 'refugee crisis' and policy responses. FitzGerald and Arar refer to realistic approaches and elaborate on how models like the new economic labor migration provide a framework for refugees' decisions. The same applies to the world-systems theory concerning mass hosting, asylum, transit, and resettlement. 


\subsubsection{Aspiration and Ability Model / Drivers of Migration}

This section of the dissertation shows how migration studies have developed and evolved. While theorists such as Ravenstein $(1885 ; 1889)$ or Lee (1966) tried to formulate some universal theories about migration, the reality showed the limitations of their approach. They are often criticized as too 'static' or 'mechanic.' The aspiration and ability model attempts to overcome these limitations by introducing a more comprehensive, nuanced, and flexible approach. One could argue it tries to combine the rational neoclassical with the flexibility of the NELM and systems theory to resolve migration's complexity. The concept of 'drivers of migration' illustrates this since it is not supposed to follow only a simple push-pull pattern but tries to conceive the whole complexity of 'migration complexes' (Van Hear et al. 2018).

Thus, later works, which examined the Push-and-Pull model, instead analyzed certain aspects of the theory rather than developing new generalized models. Davenport et al. (2003) criticized earlier works in migration studies for ignoring internally displaced people in the context of forced migration and not considering the situation of people at home and in other countries in terms of 'push' and 'pull' factors. In general, the authors argue that there is too much emphasis on the 'push' aspects and aimed to develop a micro-foundations theory. The difference between this approach and prior studies is that people choose to stay or leave and are not just the outcome of a 'stimulus-response mechanism.' The empirical research conducted shows evidence for political threats as a flight reason, while the authors could not find support for other factors such as economic threats.

The contrast to previous works is distinct. Davenport et al. investigated IDPs' situation by conducting empirical research and focused primarily on political threats as a reason to flee. The authors developed a new concept by distinguishing between 'state violence,' 'dissident violence,' and 'state-dissident violence' (Davenport et al. 2003: 32). This approach describes the actors in an armed conflict or (more precisely) in a civil war. In comparison to earlier studies, economic reasons were not the main fleeing reasons anymore. Davenport et al. do not deny the importance of economic factors but emphasize that political threats have a much more significant influence on migration movements. Even though the study focuses mostly on IDPs, the implications for the migration movements to Europe since 2015 are still current since most refugees came from civil war countries (e.g., Syria).

However, it is also essential to keep in mind that people are more flexible because of the enormous infrastructure and communication possibilities. In the past, many people from emerging countries were not fully aware of the living conditions in the Western world, and 
not everyone is simply satisfied by getting geographically away from the conflict zone but are seeking a better life elsewhere. This observation also applies to refugee camps. Poor living conditions might not be enough anymore to prevent people from leaving for more developed countries ( e.g., the EU).

Furthermore, this study tells us also something about life in Western societies. The rise of autocratic and populistic movements can be observed everywhere in Europe. Without a doubt, we are leaving in times of turmoil. Climate change, digitalization, mass migration, et cetera affect the lives of many people. State violence and violence from dissidents are also phenomena, which can be experienced in the EU, like, for example, the 'Yellow-vest' protests in France recently. Indeed, we are far from a civil war situation in the EU, but the first signs are already alarming.

A similar approach was made by Melander and Öberg, who investigated in their study 'The Threat of Violence and Forced Migration: Geographical Scope Trumps Intensity of Fighting' (2007) the relationship between forced migration and any form of violence (e.g., civil wars) by applying new indicators. Similarly, Davenport et al. (2003) focused more on human rights. Thus, the authors examined 'the geographical scope of fighting' and the 'intensity' of conflicts. For that purpose, the authors analyzed refugees' empirical data and internally displaced people affected by civil wars or armed conflicts. The results of their work showed no evidence that the intensity of conflict increases the number of displaced people significantly. Hence, the authors concluded that it is more critical where the battle takes place and not how intense it is. According to their findings, Melander and Öberg state, 'the larger the fighting's geographical scope, the higher the number of forced migrants' (Melander and Öberg: 168-169).

The results of this empirical study might be surprising. Still, since we are talking mostly about IDPs again, people probably do not have the financial capabilities to go anywhere they want. People who do not have financial resources cannot simply leave, whether or not the conflict is very intense. In this case, it is very likely not relevant. The more interesting question here would be: where would people go without significant financial constraints? The authors also struggle to explain the term 'intensity' adequately. It remains unclear where the tipping point is or where the line between a very intense and less intense conflict is. It might even be impossible to measure 'intensity' because everyone perceives a conflict differently; this is very subjective. However, we should also consider that new forms of warfare and radicalism have occurred in the meanwhile. For example, the U.S. drone 
program might not be the most 'intense' one but is a constant threat. On the other hand, the Islamic State has brought extremism to a whole new level. This aspect of the study might not be current anymore and needs reexamination.

While previous studies focused primarily on push factors, Neumayer elaborated with his article 'Asylum Destination Choice: What Makes Some West European Countries More Attractive Than Others?' (2004) on the question of which particular preferences asylum seekers have concerning their destination (pull factors). His findings show that richer countries receive a higher per capita share of asylum seekers, and economic factors such as growth rate or unemployment rate do not significantly affect attractiveness. Neumayer's results showed evidence that countries with left-wing governments are, according to their recognition rate, more migration-friendly than right-wing governments, which are perceived to be more restrictive.

The rise of new populistic movements (usually right-wing) raises the question of how relevant the classic 'right-left' pattern still is. After 2015, Angela Merkel (chancellor of Germany) was perceived as a liberal person for her refugee policy. However, she is still part of Germany's conservative party, which has a long tradition of being migration-skeptical. In fact, in 2015 , there were initially plans to close the border when the significant migration movement reached German territory. The only reason for not taking any action was the fear of bad publicity by shutting down the borders and violence against helpless children, women, and men. The Brexit, President Trump election, and other successful right-wing movements in Europe have shifted the debate tremendously into the populist corner. In general, left-wing governments might still be more open regarding migration, but it is hard to test this hypothesis in 2019 because there are almost none left.

Furthermore, we can say that 2015 had nothing to do with language and geography. Germany barely has any historical ties with Syria and is also several thousand kilometers away. There are also no similarities between the main languages, but translation apps make the language barrier easier to overcome. However, network effects played a role after the first refugees arrived in Germany. Many new immigrants tried to bring their family members left behind in the original country into the EU. An open question remains if network effects might also exist in transit-zones or refugee camps. The last aspect of Neumayer's research is the implication on EU policy. Neumayer argues that some countries will always be more attractive than others (especially for migrants). His findings also seem to support Davenport et al.. (2003) empirical study concerning economic factors since economic performance, such as 
unemployment rate or growth rate, has no significance in the decision-making process of migrants. This might be, to a certain extent, definitely true, but, again, migration decisions are based on personal preferences, and these can be very subjective and change over time. Even though Germany might be, for instance, an attractive destination for asylum-seekers at the moment, it does not mean this circumstance cannot change rapidly.

Neumayer (2005) analyzed the reasons for asylum seekers going to Western Europe and addressed the policies required to reduce migration inflows. Neumayer used a more comprehensive approach to determine if the political regime and violent political conflict are relevant or not in terms of asylum migration. Neumayer's findings show that countries of origin's economic conditions are relevant factors for asylum seekers coming to Western Europe. The same applies to the political regime, threats to personal integrity like human rights abuses, dissident political violence, civil/ethnic warfare, state failure, and external conflict. According to his variables, the lack of democracy in the country of origin also increases asylum migration. On the other hand, he could not find any evidence for the socalled 'migration hump.'

Overall, Neumayer's findings meet the expectations. However, he states that his variables for genocide/politicide, famine, and natural disaster turned out to be insignificant because of the events' short-term character. In 2019, due to the climate change debate, it might be questionable if natural disasters can still be classified as 'short-term' since climate change played a role as a 'multiplier' in the Syrian civil war (Selby et al., 2017).

The so-called migration hump is an ongoing discussion in the field of migration studies like de Haas (2010: 11) elaborated on. The original theory dates back to the time when NAFTA passed. The expectation was that trade liberalization would reduce migration from Mexico to the U.S. (Martin 1993); Martin and Taylor (1996) argued that trade and immigration could be complements. Thus, in the short or medium run, migration flows might even increase. Neumayer's findings could not confirm the migration hump. Still, the original theory focused on international trade and migration, which often go hand in hand with liberalization on the labor market (e.g., EU expansion 2007). In other words: two competitive economies agree on a trade agreement, not on sustainable and structural development for the weaker partner. The balance of power should also be kept in mind since the stronger negotiating partner is very often able to determine the conditions of such deals. This factor makes a huge difference because these deals are not prepared to create an equilibrium between two partners and increase profits (mainly for multi-national enterprises). Neumayer, 
on the other hand, argues more from a long-term perspective. His approach was to find structural terms, which cause migration.

Moore and Shellman (2007) also asked if refugees are 'bogus' or not by providing the first global analysis of refugees' destinations. Their findings show evidence that fear of persecution, wages, culture, and relocation costs do, indeed, play a role in migration decisionmaking processes. According to the authors, refugees do not decide on the level of violence concerning their destination (except for genocides). They also do not flee primarily to countries supporting (political) freedom or offering significant economic opportunities. However, some examples, like the U.S. or Germany, are always among the top fleeing destinations. Moore and Shellman conclude that refugees mainly seek asylum in neighboring countries, especially if their origin is affected by war or civil war, and refugees fleeing to other countries follow their colonial ties.

Moore and Shellman made one of the most prominent studies concerning refugees' destinations by analyzing pull factors. The main difference to Neumayer's findings (2004) is the greater data-set that the authors used. They conclude that most refugees are incapable of realizing their preferences (e.g., higher wages or political freedom) because the relocation costs are too difficult to overcome. Nevertheless, one could argue that the analysis is too expansive and not precise enough since it took all refugee movements on a global scale in the past into consideration over a substantial period (from 1965-1995).

Again, times have changed radically since this study. The technological progress regarding communication, infrastructure, mobility, et cetera. is tremendous. That is also why this research cannot be compared to 2019 (or only allows a few derivations to the present). It is also questionable if global trends are relevant for migration flows to the EU. Every in- and out-migration has its reasons and purposes. A generalization seems to be inappropriate here.

Apart from that, Moore and Shellman's suggestions fit into the narrative that refugees are in the overwhelming majority, not 'bogus.' Neumayer (2005) came to a similar conclusion. The vast majority of people are fleeing from severe threats concerning life and freedom. Even though there are some exceptions for destination countries such as Germany or following colonial ties, they stay in the region mostly caring about their well-being and not about any financial benefits. Unfortunately, many policymakers and rising populistic movements within the EU ignore these findings.

Tétényi et al. (2018) analyzed why Hungary was the most popular destination for entering the Central and Eastern European countries between 2002 and 2016. Further, the 
authors tested the Hungarian government's claims that refugees are not refugees but rather economic migrants. Their findings show clearly that the main reason is Hungary's recognition rate and Hungary's geographical position, and its role as a transit country of the so-called 'Balkan route.' Other factors, such as unemployment, trade, aid, or Hungary's harsh border policy, did not play a significant role. Thus, Tétényi et al. conclude that the government's claims are false, and people entering Hungary are, indeed, fleeing as victims of violent conflicts from their country of origin. As long as these conflicts continue, refugees will continue applying for asylum in Hungary.

Tétényi et al.'s (2018) findings fit in the framework of the other conclusions, such as Neumayer $(2004 ; 2005)$ or Moore and Shellman (2007). While the other studies covered a wide range of various countries, Tétényi et al. focused only on one country (Hungary), which played an extraordinary role during the refugee crisis from 2015. Since Hungary is now known for its restrictive immigration laws, the country remains embedded in the EU policy framework, respectively, the Dublin system (people have to apply for asylum, where they first touch EU ground).

However, Hungary has never been the leading destination for asylum seekers or refugees, and people preferred to move on to the North (e.g., Germany or Sweden). Thus, the high number of asylum applications has very much to do with the country's geographical position and EU legislation, rules, and regulations and the lack of knowledge about the EU from asylum-seekers who were very likely not aware of them. It is also unclear how many people might have already sought asylum in other countries located more closely to their origin (e.g., Greece or Bulgaria). In 2015, the Dublin system did not function well.

Nevertheless, the most interesting open question remains: 'Under which circumstances would people have preferred to stay in Hungary?'. Tétényi et al. could not find any evidence for the claims of the Hungarian government. Still, the research also does not answer whether better living conditions or higher living standards in Hungary might have motivated people to stay and not move on to other countries like Germany.

Carling and Collins (2017) provide one of the most sophisticated literature reviews in migration studies by analyzing the terms 'aspiration', 'desire,' and 'drivers of migration' over time and how they have emerged. While aspiration and desire are synonyms, drivers of migration are an analytical framework that describes the world.

Nonetheless, all three terms explain how migration is 'initiated, experienced, and represented.' On the other hand, 'determinants of migration' and 'causes of migration' have 
declined consistently in academic publications and been replaced by the relatively new term 'drivers of migration.' Carling and Collins conclude that their selection of articles in migration studies show conceptual promise of re-engaging drivers of migration, building on long-standing criticisms, and responding to social sciences interest in the future. Carling and Schewel (2018) analyzed the aspiration/ability model from Carling (2002) and its implications for migration studies since then. Many researchers have adapted this basic framework by using a 'two-step approach,' which argues that aspiration is the desire to migrate and ability describes the capability to migrate. However, aspiration can vary between 'choice' and 'coercion.' Thus, this approach distinguishes between 'involuntary nonmigrants' and 'voluntary non-migrants.'

Consequently, the two-step approach explains migration and immobility in terms of preferences to stay or the inability to do so. Furthermore, the model was used in many surveys, such as the GWP $(2008)^{22}$ poll, to describe migration aspirations. This empirical approach makes it more challenging to develop a universal theory in an already fragmented field. In general, the aspiration/ability model is not supposed to be superior compared to other approaches but rather complementary.

The latest approach for inventing a more generalized theory, which refers to the neoclassical approach by Lee (1966), was made by Van Hear et al. (2018). They invented the 'Push-pull plus' model based on existing frameworks and models in migration theories. It is supposed to be a more comprehensive and nuanced model than Lee's approach. Push-pull plus presents an analytical framework that describes the factors that influence people's migration and decisions. These factors - often appearing in various combinations - are described as drivers. These drivers and dimensions shape migration complexes or configurations. Therefore, the authors introduce a new framework for analyzing drivers and implement the 'concept of driver complexes.' Drivers of migration should never be analyzed relationless but rather in combination with several factors. According to the authors, migration flows can be understood by considering the following categories: predisposing (structural disparities between origin and destination on the bases of macro-politicaleconomy), proximate (effects bearing directly on migration, e.g., down- or upturn in economic), precipitating (outbreak of war, natural disasters, the collapse of social welfare

\footnotetext{
${ }^{22}$ Gallup (2008). World Poll Questions. Washington, DC: Gallup.
} 
systems, et cetera) and mediating drivers (presence or absence of infrastructure, communication, information). Whether one person decides to leave or to stay depends on the combination and the real importance of these factors. The complexity of this model is to distinguish and evaluate relevant and less critical circumstances.

Nevertheless, the authors conclude that proximate and mediating drivers show more significant potential for intervention than structural and precipitating spheres. Thus, the authors identified some other dimensions of drivers, like locality (e.g., demographic or environmental pressures), scale (different social and geographical scales), duration or timeframe (different timescales from sudden to acute to chronic), and depth of tractability (drivers on the surface of society and hidden drivers). Again, the combination of these drivers is crucial in determining if migration happens or not. These factors should not be considered in isolation but rather in context (Van Hear et al. 2018).

In comparison to Lee (1966), Van Hear et al. recognize the complexity and different dynamics of migration flow by introducing the concept of inward migration, outward migration, and the journey (driver complexes). While Lee's approach was still very static and basic, Van Hear et al. developed a more flexible model by including other push factors like undernourishment, natural disasters, or human rights violation into their model. Lee's original thoughts were still very much influenced by economic push factors and authors like Ravenstein $(1885 ; 1889)$. This development shows how the Push-and-Pull model has shifted over time from a strictly neoclassical approach to a more generalized theory, recognizing various fields and disciplines.

Overall, the push-pull (plus) theory is probably the most comprehensive approach in migration studies (Paul 2019). However, the argument is focused more on a permanent settlement, or long-term migration, while refugee camps are supposed to be a short-term solution. Indeed, Lee (1966), who came up first with this model, has included 'obstacles for migration' in his theory. Still, he is not dealing with the issue of people who are forced to flee for serious reasons (e.g., war) and cannot overcome these obstacles to migrate to another country, nor can they go back to their country of origin. The pull factor does not exist here since the only appealing reason for fleeing is security. Of course, safety is the primary human demand, but it does not satisfy any other basic human needs. Therefore, the push factor remains tremendously high while security is the only pull factor; a factor which should not be taken into consideration at all if it is the only reason for leaving an area since it is natural that no rational (civilian) person wants to risk its life in armed conflicts. In this case, people are 
locked in no-man's-land, respectively, in camps or transit zones. Consequently, people are pushed farther, or in other words, people will continuously seek alternative living and survival situations. The theory is based on the thinking that people are migrating from one country to another, which is initially valid.

However, the reality is that people are mostly fleeing from one country to camps or transit zones, which makes a big difference (Paul 2019). While states are following migration policies and trying to control the in- and out-flow of migrants and citizens, camps are improvised solutions, often run by international institutions. Furthermore, although camps are mainly outside of the country where the armed conflict takes place, they are, in fact, small complex socio-microeconomics in themselves and often referred to as "a state in a state." In particular, the examples of refugee camps in Lebanon and Jordan (see chapter 5) show that these countries are entirely overwhelmed by significant refugee movements from Syria and can no longer control their borders. Thus, local governments in these neighboring countries are incapable of adequately dealing with this situation, while camps are developing their infrastructure and identity. Extended versions of the push and pull model are now considering more migration drivers, but the issues remain the same.

Therefore, a more profound approach is required, which considers short-term settlement, i.e., camps and transit zones, as an identifiable entity in the model. Additionally, this approach offers new opportunities in spatial planning as a part of urbanization processes. It can transform short-term into long-term sustainable solutions by satisfying basic needs (nutrition, fresh water, security, et cetera) and making cultural, political, and economic participation for its inhabitants possible.

Hence, I took the existing shortcomings in terms of camps and developed and designed an approach that considers camps' unique situation. The classic push-pull model could be added to by the factor 'stay,' which is supposed to reduce flight causes. The following table illustrates this model:

Table 4: Push-Stay-Pull Model (Paul 2019)

\begin{tabular}{|l|l|l|l|}
\hline & Push Factors & Stay Factors & Pull Factors \\
\hline Push, Stay, & Socio-economic & The satisfaction of Basic Human Needs & Economy \\
and Pull & Political & Development Program / Urbanization & Society \\
Factors & Environmental & Process & Demography \\
& & Cultural, Political, and Economic & Politics \\
& & Participation & \\
\hline
\end{tabular}




\begin{tabular}{|l|l|l|l|}
\hline & & Employment & \\
& & & \\
\hline Area & Country A & Transit-zone / Refugee Camp & \\
\hline Timeframe & $\begin{array}{l}\text { Long-term / } \\
\text { Short-term }\end{array}$ & Temporary with the Outlook for long-term & Long-term \\
\hline \multirow{2}{*}{$\begin{array}{l}\text { Direction of } \\
\text { Migration }\end{array}$} & $\rightarrow$ & With Obstacle $(\downarrow ; \rightarrow)$ & $\downarrow$ \\
\cline { 2 - 5 } & $\rightarrow$ & Without Obstacle $(\rightarrow)$ & $\downarrow$ \\
\hline
\end{tabular}

The suggested 'Push-Stay-Pull' model is another attempt to connect neoclassical approaches with drivers of migration theory to create a more comprehensive model by addressing people in refugee camps.

The interviews in chapter six will reflect on this model based on the elaborations in this section. The qualitative and quantitative research findings show that people might see opportunities in camps if they provide sufficient living conditions.

\subsubsection{The Role of Refugee Camps}

The unique role of camps requires a different approach, which cannot be fully understood by only covering migration studies. For that reason, different disciplines with different models are relevant. Specifically, International Relations (IR) Theories provide coherent analytical models since camps have to be seen in a global context and are often the result of international cooperation or solo-national efforts.

The refugee camps' role can be considered from three different IR theories perspectives: the (neo)realist perspective, the (neo)liberalist perspective, and the constructivist perspective, ${ }^{23}$ which are also the most dominant and influential IR theories. Since the UNHCR and other international organizations run many refugee camps, camps result from international cooperation. Thus, the camps that we can see in the media (for example, in Lebanon or Jordan) are a (neo)liberalist idea and embedded in the framework of theorists such

\footnotetext{
${ }^{23}$ IR Theories is a whole discipline in itself. This dissertation only provides a basic overview on the debate of refugee camps in IR Theories since the focus is on migration studies and camps.
} 
as Keohane (1984), Nye (1971), Krasner (1985), or Kindleberger (1973). The liberalist approach regarding camps can be understood as international burden-sharing. The hosting of refugees and asylum seekers becomes the international community's task, supporting states affected by the influx of fleeing persons with resources. ${ }^{24}$ The ideology's basic idea is that states gain more benefits from cooperation than from opposing each other, even though the world base is an anarchical structure. International organizations such as the UNHCR are the vehicle to accomplish this goal.

However, not all camps result from international cooperation, as the Turkish state demonstrates (see chapter 5). Many refugee camps run by the UNHCR are continually underfunded, making Turkey establish its camp infrastructure without aid organizations' adequate support. Compared to states such as Lebanon or Jordan, Turkey is relatively wealthy and can finance refugees' and asylum seekers' accommodations. Whereas poorer states are dependent on international funding and follow a neoliberal approach, more prosperous states can operate in the framework of realism. ${ }^{25}$

The presidency of U.S. President Trump illustrates another form of realism in the debate of camps. Because of his 'America First' policy, President Trump significantly reduced (financial) support for refugees (Shear and Kanno-Youngs 2019) and withdrew from several international agreements, such as the Paris Climate Agreement, the Trans-Pacific Partnership, the UNESCO, the Iran Nuclear Deal, and the UN Human Rights Council (CNN 2019). These actions are in line with classical realist theorists' approaches, such as Morgenthau's 'Politics among Nations' (Hilz 2007), Carr's 'The Twenty Years Crisis' (1939), and Waltz's 'Man, the State, War' (1959). ${ }^{26}$ Trump's (foreign) politics builds on power and dominance, which Ettinger (2019) describes as 'populist sovereignty.' This nationstate-oriented approach affects the debate about the camps because some states are not willing (or are unable) to fulfill their obligations in the international community, which is, from a realist perspective, a desirable goal.

\footnotetext{
${ }^{24}$ In reality, also UNHCR camps that are results of international funding are constantly struggling financially (see chapter 5).

${ }^{25}$ One could argue the EU-Turkey Statement is a form of international cooperation. However, despite the fact that the agreement is already suspended, the deal was never truly cooperative since both sides tried to take advantage of the other.

${ }^{26}$ Indeed, Trump's current politics are difficult to classify. The times have drastically changed in the meanwhile and cannot fully compared to Morgenthau's or Waltz's works.
} 
The third perspective is the constructivist approach, which also considers sociology and identity factors. The most prominent advocate of this discipline is Alexander Wendt $(1992 ; 1999)$. Wendt (1999: 1) himself described constructivism as: 'that the structures of human association are determined primarily by shared ideas rather than material forces, and that the identities and interests of purposive actors are constructed by these shared ideas rather than given by nature.' For constructivists, the world cannot only described by anarchy, hierarchy, or struggle for power and (economic) interdependency between states. IR theories are 'socially constructed' in terms of constructivism. Thus, authors such as Finnemore (1996) or Katzenstein (2005) focus their research on the study of culture, religion, identity, and regionalism.

In terms of camps, Chatty $(2009 ; 2010 ; 2017)$, Farah (2006), and White et al. (2013) can be seen as constructivists since they are also applying social, cultural, and historical aspects in their works about asylum seekers, refugees, and camps (see below in this chapter).

The following table sums the different camp approaches in IR Theories up.

Table 5: Camps and IR Theories

\begin{tabular}{|c|c|c|}
\hline \multicolumn{3}{|c|}{ Dominating IR Theories } \\
\hline Liberalist approach & Realist approach & Constructivist approach \\
\hline $\begin{array}{l}\text { Camps are the result of } \\
\text { international cooperation, } \\
\text { including the work of } \\
\text { organizations such as the } \\
\text { UNHCR }\end{array}$ & $\begin{array}{l}\text { Camps are the result of single } \\
\text { national efforts; only minimal } \\
\text { support from international } \\
\text { organizations }\end{array}$ & $\begin{array}{l}\text { Camps are the result of } \\
\text { social, cultural, and historical } \\
\text { characteristics }\end{array}$ \\
\hline $\begin{array}{l}\text { - Anarchy is a key } \\
\text { element of the theory } \\
\text { - International } \\
\text { institutionalism } \\
\text { (UNHCR) and } \\
\text { (economic) } \\
\text { interdependency } \\
\text { between states } \\
\text { (funding of camps) }\end{array}$ & $\begin{array}{l}\text { - Anarchy is a key } \\
\text { element of the theory } \\
\text { - Struggle for power } \\
\text { and materialism } \\
\text { (limited international } \\
\text { cooperation and } \\
\text { funding for UNHCR } \\
\text { camps) }\end{array}$ & $\begin{array}{l}\text { - Social identity is a } \\
\text { key element of the } \\
\text { theory } \\
\text { - The world is socially } \\
\text { constructed (factors of } \\
\text { identity determine the } \\
\text { design, success, and } \\
\text { establishment of } \\
\text { camps) }\end{array}$ \\
\hline
\end{tabular}


In general, refugee camps are essential destinations for refugees and are supposed to function as a safe place by providing security, health care, and nutrition. In many cases, refugee camps become the 'new home' for several months or even years for their inhabitants. Thus, camps become complex socio-economic environments, including infrastructure, housing, small businesses, and markets. Nonetheless, camps are supposed to be an immediate short-term solution for fleeing persons and often function, because of devasting conditions, only as transit zones on their way to the actual destination. People do not go to camps because they see a long-term future there for themselves are their families. In reality, they have simply no other choice and get stuck in 'no man's land' since refugees cannot go back to their origin country but are also incapable of reaching their destination. The question is if camps can become a long-term solution by providing sufficient living conditions? Even though migration studies' focus has slightly shifted to asylum seekers and refugees in recent years, the literature regarding camps is still lacking.

The literature regarding refugee camps deals with questions of security, health, and living conditions. Milton et al. (2013) elaborated on whether refugee flows contribute to terrorism in the host state. The authors focused primarily on people in refugee camps and found statistical evidence that terrorism can originate from refugee populations. Milton et al. argue that poor living conditions and isolation in camps make any form of radicalization more likely to occur. The fight over scarce resources with the domestic population in deprived regions raises conflicts, and the lack of prospects causes frustration. Furthermore, refugee camps are usually located in transnational areas or even in war zones, making it easier for terrorists to recruit new members. However, it does not mean that all people in refugee camps automatically radicalize and stress that further research is required to learn the exact reasons for this phenomenon.

The authors tackle a highly sensitive topic. The exact reason for this form of radicalization remains unknown. Indeed, poor living conditions and frustration might be, in theory, the perfect hotbed for terrorism, but what we do not know is at what point in time this radicalization happened? Did it happen during the time in camps or even before? Fleeing people have usually experienced hardship many times already. The research also says very little about the radicalized persons' mindset, and there is no information about their religion, political views, social status, family background, et cetera. Since radicalization does not happen overnight, it seems to be a simplification to correlate refugee camps (or refugee populations) and terrorism. 
Since the war in Syria started - and therefore, the 'European Refugee Crisis' emerged the attention of migration theories has also shifted to this issue. The neighboring countries of Syria are still the most affected countries by asylum-seekers - not Europe. This development is also reflected in recent literature by considering people in refugee camps fleeing from armed conflicts in Syria. According to Berti (2015), the critical areas of refugee camps' intervention include protection, shelter, health and education, and employment. Those needs have to be sufficiently satisfied to provide a proper standard of living. However, the situation is problematic for the people in refugee camps and is also a burden for the hosting country. The refugee crisis negatively affects social services and labor markets, housing, electricity, sanitation, and water resources.

Consequently, many developing countries suffer a fiscal deficit, international trade decrease, and loss of tourism income. Overall, the whole infrastructure and welfare system (if one exists) is put under extreme pressure. These economic and political tensions lead to social tensions within society since distribution battles become common. Another result is cultural conflicts, especially between groups that support different sides in the Syrian civil war. Therefore, massive refugee movements lead to economic, political, environmental, and security (food, health care, rising conflicts) instability (Berti 2015).

The debate concerning refugee camps is not new in the field of academics. In 1998, Crisp and Jacobsen already gave some mentionable-worthy input for the discussion by identifying constraints on implementing international standards in refugee camps. These limitations are environmental constraints (inhabitable living space), social constraints (refugees usually settle down close to their ethnic, cultural, and linguistic preferences), political constraints (the government has the final decision over its refugee policy), and logistical and financial constraints (limited capacity and resources). Nevertheless, the authors argue that refugee camps are necessary to protect people from armed conflicts. Governments have to apply a more liberal asylum policy. Humanitarian agencies like the UHNCR need more financial support to provide the highest possible supply of nutrition, necessary materials, and security (Crisp and Jacobsen 1998). Regardless, even when all these requirements are fulfilled, it is unlikely that camps will suddenly be abolished. Refugee camps are complex socio-economical structures that develop their urban infrastructure, character, and identity. Thus, because of self-sustainability, market towns will develop, and refugees could refuse to go back to their country of origin by becoming permanent settlers (de Montlocs and Kagwanja 2000). 
Newer studies in this field of research mainly focus on the mental health and educational situation in camps. The Sirin and Sirin (2015) study 'The Educational and Mental Health Needs of Syrian Refugee Children' stresses children's extremely terrible refugee camp conditions. According to their study, Syrian refugee camps are at considerable risk for mental health problems, which might affect their development negatively. Another issue is the inadequate and insufficient supply of high-quality education for these children. Both mental health care and education are essential parts of successful integration, but many host countries' funding problems make it nearly impossible to meet these requirements (Sirin and Sirin 2015).

The study from Paardekooper, de Jong, and Hermanns (1999), which analyzed South Sudanese children's situation in refugee camps in Northern Uganda, came to a similar conclusion. The vast majority of South Sudanese refugee children showed depressive symptoms and behavioral problems. In general, refugees have mental health issues more often than the host community and other groups of migrants (Acarturk et al. 2015). The Syrian civil war has demolished every health care system in the country and lead to the spread of infections and epidemics like poliomyelitis, measles, and cutaneous leishmaniasis - not only in Syria but also in its neighboring countries (especially in camps), because of the high vulnerability of the Syrian population during the crisis (Sharara and Kanji 2014).

Consequently, it is not very likely or reasonable that people would prefer to stay in areas where they are denied health care since most camps' situation remains devastating. Therefore, the push factors are increasing significantly, and people are more likely to leave.

According to Toole et al. (1988), who investigated in their article 'The Association Between Inadequate Rations, Undernutrition Prevalence, and Mortality in Refugee Camps: Case Studies of Refugee Populations in Eastern Thailand, 1979-1980, and Eastern Sudan, 1984-1985' the situation of Tigrayan refugees in Eastern Sudan and Cambodian refugees in Thailand, pointed out the importance of nutrition in refugee camps. While the mortality rate for Cambodian refugees in camps has declined significantly, the mortality rate for Tigrayan refugees in camps remained extraordinarily high. Specifically, young children (less than five years old) suffered from undernourishment. Furthermore, international relief agencies failed to distribute a sufficient amount of food to starving people. Thus, the authors concluded that anticipation of refugee movements is necessary to procure and organize enough nutrition.

Another dimension in the discussion of camps is the cultural aspect. The Middle East countries have been affected by the phenomenon of mass migration movements for over 100 
years (Watenpaugh 2016) and call the concept of hospitality 'Karam' in Arabic. (Chatty 2017). If people decide to go or stay in a camp is very much influenced by the person's cultural background. Karam is challenging to understand from a Western perspective, but it describes the Arab world's attitude to treat guests as friendly as possible. Even though people do not possess much, they are willing to share with strangers. Chatty $(2009 ; 2010 ; 2017)$, who investigated the influx of Iraqi and Syrian refugees into other Middle East countries, states the UNHCR and other aid organizations did not anticipate that people would refuse their camps and prefer living as self-settled refugees in the host communities. Many people consider seeking asylum in a camp disgraceful. The refugees clearly denied the 'separation' approach (separating 'hosts' from 'guests'). White et al. (2013) stress the issue of aid organizations, often ignoring people's needs outside the camps, and promote an approach that considers the Middle East's unique history. In this context, the Middle East's mass migration movements to Europe are also a consequence of 'the house is full' since states like Lebanon or Jordan were overwhelmed with the number of Syrian refugees in 2015. Nevertheless, asylum in the Middle East is hospitality, whereas UNHCR camps are emergency facilities. Chatty concludes:

'The international humanitarian aid regime's prioritizing of protection to a category of people who fit the legal definition of 'refugee' is a rigid, rights-based construction that leaves many gaps in its implementation. Those who do not wish to be categorised as legal refugees or who fail to meet the formal criteria fail to access international support. Local and regional Middle Eastern constructions of duty-based obligations to the guest, stranger, and person-in-need can, with strategic support, offer a wider range of people sanctuary and asylum sanctuary. A holistic approach that taps into the social and ethical norms of hospitality in local contexts can only improve and extend the delivery of rights-based asylum provided by international humanitarian organisations. '(Chatty 2017: 196)

Farah (2006), who investigated Palestine refugee camps, states that camps can also give people an identity since they see their 'origin' through the camps.

'Over time, the camp as a territorial unit became a space upon which the inhabitants mapped out a Palestinian identity. In the narratives of refugees, the camp is not a 'place for refugees' but is portrayed as an exiled fragment of Palestine, a temporary substitute universal village, and a suspension bridge from where Palestinians look simultaneously to the past and the future return, or to 'here' and 'there.' The village of origin looms as 'neighbourly' when contrasted with relationships in the camp; in turn, the inhabitants boast of a culture of sharing instead of the 
'colder' relationships that characterize the wider Jordanian society. In the narratives, the camp is demarcated as a place for 'peasants,' and often refugees would refer to Jordanians as 'bedouins,' representing national differences through modes of livelihood.' (Farah 2006: 243)

The latest approaches in discussing camps and asylum seekers and refugees studies create a 'Utopia' and envision 'a new transnational polity.' Van Hear and Cohen founded the so-called 'Refugia Project' in 2015 (Compas 2020). The authors criticize the insufficiency of current policy measures to address increasing refugee numbers worldwide. Thus, displacement cannot be solved by conventional methods such as repatriation of refugees, their local integration, or their resettlement (Cohen and Van Hear 2019). Although the concept of establishing new nations, city-states, regional initiatives, and free zones for refugees and asylum seekers is not novel, Van Hear and Cohen prefer a different approach:

'[...] Refugia: a confederal, transnational polity emerging from the connections built up by refugees, with the help of sympathizers. Unlike many of the proposals that we have reviewed, we do not envisage this as an island or other bounded territory. Rather, Refugia would be a linked set of territories and spaces connecting refugees into a polity that is neither a new nationstate nor simply an international organization, but has some characteristics of both: a new kind of transnational polity, governed by refugees and migrants themselves. There would be mobility among the constituent parts of Refugia, which would link refugee and migrant communities globally: moreover, the whole would be greater than the sum of its parts.' (Compas 2020)

In their opinion, the transnational polity regarding global mass migration movements is imperfectly prefigured:

'[...] Camps and communities in countries neighbouring conflicts, neighbourhoods in global cities, transnational political practices and money transfers, emergent communities in disparate locations en-route: all are fragments that taken separately do not seem to promise much. But cumulatively, they could add up to Refugia, imperfectly prefigured. Consolidating them into a common polity might prove to be a way out of the current impasse.' (Compas 2020)

Therefore, Van Hear and Cohen suggest a more comprehensive and coherent approach to the refugee question. In their vision, camps are part of a concept that entitles refugees and restores self-determination. However, Van Hear's and Cohen's conceptual framework has received a wide range of criticism, including 'Refugia Lets Nation States off the Hook,' 'Refugia Assumes a Commonality Among Refugees That Does Not Exist and Is Not Desirable,' 'Refugia Would Be a Mechanism of Containment: Another Nauru,' 'The Viability 
of Such a Transnational Polity Is Doubtful,' and 'Refugia Does Not Address Global Structural Imbalances and the Violence They Embody' (Van Hear 2018). Overall, the critics see the 'Refugia' approach as science-fiction and doubt the project's applicability in the current and intermediate-term.

\subsection{Current Status of Migration Studies}

The previous overview attempts to provide a comprehensive guideline through decades of migration studies and the various theories. King stresses that 'there is no single theory that captures the full complexity of migration, nor will there ever be' (2012: 24), which is true since there is no universal agreement about the classification and categorization of the certain sub-theories. Van Hear et al. (2018) and the concept of 'driver complexes' is one example of this because it refers to different authors and theories; the name of the argument 'Push-pull plus' is derived from Lee (1966), while the concept of the debate relates more to Carling (2002; Carling and Collins 2017; Carling and Schewel 2018). Ten different researchers will probably come ten to different conclusions or results. Van Hear (2010: 1535) stated that the importance of finding a generalized theoretical model in migration studies has decreased over time. Van Hear addresses migration as 'mixed migration,' which means there are different forms of migration streams. Every individual has his motivations for migrating, as seen by comparing students with workers or tourists with migrants, et cetera. (2010: 1535).

According to King (2012), Castles (2010), Faist (2010), and Portes (2010), there are currently two significant trends observable in migration studies. The first one is the approach of bringing migration studies out of isolation and integrating them into the field of social change and social transformation. Thus, migration is part of national and global social change. However, there is a certain level of disagreement regarding the depth of these changes. While Portes argues these changes exist, the impact of migration on the host country's social structure and its society is relatively small (2010: 1556). Castles emphasizes that movement transforms social structures, institutions, and the whole global economy. Therefore, Castles argues for deeper integration of migration studies into social sciences by demanding an interdisciplinary approach since migration affects 'all dimensions of human experience' (2010: 1596; see also chapter 3.1). The second trend goes in a similar direction. King (2012) states that migration theories were very much influenced by qualitative sociology, anthropology, human geography, and cultural studies beginning in the early 1990s and has shifted 'from quantitatively inclined population geography to qualitatively-minded cultural 
geography' (2012: 24, Blunt 2007) This development did not focus so intensely on the migration reasons anymore, but rather on the migration 'experience' (King 2012: 25).

In general, in the last 20 to 30 years, migration studies have developed a 'transnational' perspective. The two most influential works following the transnational narrative are probably 'Towards a Transnational Perspective on Migration' (Glick Schiller et al. 1992) and 'Nations Unbound' (Basch et al. 1994). Other valuable research was conducted by Portes (1999; also Portes et al. 1999) and Vertovec (1999, 2004). Portes' (1999) wellrecognized definition for transnationalism is 'that migration takes place on a recurrent basis across national borders and that requires a regular and significant commitment of time by participants... These activities are not limited to economic enterprises [such as sending and receiving remittances, or setting up a business 'back home'] but include political, cultural, and religious activities as well.'

Nevertheless, transnationalism in terms of migration should not be overestimated since not every international migrant has a 'transnational life' or occupies 'transnational social space' (Faist 2000; King 2012). Portes (2003: 876) emphasizes that only a minority of migrants fit into the transnational approach and sees a bias for research, which focuses mainly on transnational migrants. King (2012) concludes that the transnational approach, which derives from networks (see also chapter 3.1.4), is a challenge for the push-pull model and criticizes the overwhelming amount of literature concerning integration and assimilation of migrants at their destination.

The conflict model of Sirkeci (2009) shows the complexity of the topic since economic migrants also have to be considered as a result of the conflict. Whereas Koser (2007) neglects the role of the refugees and asylum seekers in transnationalism studies, Sirkeci (2009) sees refugees and asylum seekers as 'the prime examples for development of a conflict-oriented model of transnational migration because these two groups exemplify few of the various conflict situations' (Sirkeci 2009: 5). Sirkeci's conflict model distinguishes between 'seeking human security' and 'avoiding human insecurity,' as well as between potential, latent, and violent conflicts. The transnational space (Rummell, 1976) is continuously influenced, changed, and restructured by certain factors regarding migration and conflicts. Thus, transnational mobility operates at macro, mezzo, and micro levels of conflict. In conclusion, 'migration is a search for (human) security' (Sirkeci 2009: 12).

Cohen and Sirkeci (2011) describe migration as fluid processes in a dynamic environment. The 'culture of migration' is the result of this conceptual framework. It 
considers economic and political aspects (e.g., social expectations, opportunities, conflicts, security, and insecurity), the dimension of space and time, and social-cultural influence. Local, transnational, and macro-level processes are at the center of conflicts. As the example of migration from Turkey to Germany illustrates, national and transnational conflicts, differences in socio-economic developments, ethnic conflicts, and socio-economic deprivation had a significant impact on migration decisions in the past decades (Cohen and Sirkeci 2012: 34). Consequently, migration between these two countries has transformed from a cooperative to a conflict-based approach (Cohen and Sirkeci 2012; Sirkeci 2009).

\subsection{Future Challenges of Migration Studies}

The previous chapters provided an overview of migration studies' essential theories over 100 years, respectively, from Ravenstein's 'law of migration' to the transnational approach. However, there are still many challenges for the future. First, Arango (2004: 30-34) changes the perspective and asks why so many people do not leave. He criticizes this 'black spot' in migration studies. He suggests adding 'retain' and 'repel' to the push-pull framework, which would have direct implications 'on the social, family and cultural structures of (non)migration at the micro and mesoscale, and on the (geo-)political dimensions of international relations and migration control on the macro-level' (King 2012). Except for the political economy, the state and politics are almost neglected in migration studies (Hollifield 2008). Indeed, it should consider this more, but without moving to other 'extreme' and covering international migration mainly from a nation-state perspective (Wimmer and Glick Schiller 2003).

Second, the availability and capability of mobility between social structures are crucial for migration; between countries and within countries. King (2012) sees the need for a stronger emphasis on wealth, status, or connections in migration studies research. Kaufmann et al. (2004) describe a person's mobility to move in geographic and social spheres as 'mobility capital.' According to King (2012), 'mobility capital,' including possibilities to travel, migrate, circulate, and return, will become a more critical factor in the field of migration studies (see also networks in chapter 3.1.4).

Third, the vast majority of migration theories dealt with labor migration in the past. Hence, it has been the dominant topic in the field of migration studies for decades. However, this narrow perspective ignores other forms of migration, such as a family reunion, marriage migration, student migration, brain drain, lifestyle migration, and 'mixed-mode' migrations 
(King 2012: 26). Researchers have barely covered these migration types, even though they have some important implications, on network migration, for example. There is also a need for more specialized theorization regarding refugees (Kunz 1981, Richmond, 1988). In this regard, King (2012) suggests more comparative migration studies (point four).

The fourth point is gender: another much-ignored topic in the field of migration studies. Even though Ravenstein wrote about the differences between men and women regarding migration over 100 years ago, it has not been a very well covered field since then at least not to the extent required. For the last 40 years, the main emphasis has been on patriarchial family structures and their influence on migration (Mahler and Pessar 2003; 2006). One famous quote comes from Bjerén (1997: 226): 'the mobility of men will be misunderstood if not seen in relation to the [im]mobility of women,' which fits into the narrative of 'men migrate, and women stay behind.' Other noteworthy scholars who researched this field are, for example, Morokvasic (1984) or Silvey (2006). King (2012) argues that women and men are usually migrating for different reasons and under different conditions. He also stresses that it is crucial to understand to what degree and how gender relations change over time due to the migration process; for instance, migration can empower women (King 2012: 27). Overall, Mahler and Pessar (2006), who have conducted several studies in this field, noticed remarkable progress in 'bringing gender into the core of migration studies.' However, there is still much work needed (e.g., the role of masculinity in migration) (King 2012: 27).

The fifth is another change of perspective challenge for the future. The recognition of anthropological and cultural studies in the context of migration 'experience,' which has been mostly underappreciated or overlooked so far, becomes crucial. Researchers such as Ahmed et al. (2003), Chambers (1994), Papastergiadis (2000), and Rapport and Dawson (1998), as well as cultural geographers such as Blunt (2007), are well-known representatives of this school. Fielding (1992), another cultural geographer, suggests two primary cultures of migration: the 'stairway to heaven' (migration as freedom, new beginnings, going places, opting-out, et cetera); and the 'rootlessness and sadness of migration' (migration as an exile, displacement, rupture, sacrifice, failure, et cetera) (King 2012: 27). Hage (2005: 471) describes the mindset of people who are willing to migrate as follows: "it is when people feel that they are existentially "going too slowly" or "going nowhere," that they are somewhat "stuck" on the "highway of life," that they begin contemplating the necessity of physically "going somewhere."' 
Here is an abstract of the currently ongoing debates in the field of migration theories. In my opinion, it is hard to ignore the actual 'climate debate' in 2020, which brought millions of (young) demonstrators onto the streets worldwide (Paul 2018). The consequences of climate change will be devastating, and migration theories need to focus on that. The latest prediction comes from the World Bank (2018b). According to their report, 'Groundswell: Preparing for Internal Climate Migration,' there will be, in the worst case, 143 million climate refugees (around 86 million from Sub-Saharan Africa, 40 million from South Asia, and 17 million) from Latin America by the year 2050.

Nevertheless, the World Bank has also made some more optimistic scenarios. In the 'more inclusive development' scenario, the figures vary from 65 to 105 million refugees, and the 'more climate-friendly' scenario predicts between 31 and 72 million refugees. However, in all cases, the regions that will be mainly affected by climate change and its connected implications are Sub-Saharan Africa, South Asia, and Latin America. Therefore, 55 percent of the developing world's population is under threat of forced displacement in the next decades. This is due to reduced water availability and crop productivity in areas that will become inhabitable because of rising sea levels and storm surges. Consequently, climate-sensitive sectors and infrastructure will be hit hardest by climate change, as well as the most inferior part of the population (World Bank 2018b: 9-10).

The study from Greenpeace and the University of Hamburg 'Klimaflüchtlinge - die verleugnete Katastrophe' made by Jakobeit and Methmann concluded already in the year 2007 that the number of refugees who have had to flee because of climate change has already surpassed the amount of 'official refugees,' meaning those who are seeking asylum for political reasons, or who have had to flee from war. The leading indicators of climate change are, according to the study, droughts and limited access to water in Africa, and the rising sea level, especially in the Pacific Ocean. Furthermore, the authors conclude that not only less developed regions are affected by climate change, but also highly developed areas, as the example of Hurricane Katrina in the southern United States demonstrates (Jakob and Methmann 2007: 26-27). The United Nations Office for Disaster Risk Reduction (2015) reported that an average of 21.7 million persons had been displaced because of weatherrelated issues every year from 1995 to 2015. Unfortunately, a database documenting forced migration caused by climate change does not currently exist. Thus, the real problem remains, to a certain extent, unclear (EFJ 2017: 14). If climate change cannot be stopped, two billion refugees could be the consequence by the year 2100 (Hadlock 2017). 
Climate change intensifies political, economic, social, and demographic problems (Burke et al. 2015; Scheffran 2012). Thus, the tensions within society and the distribution battle for scarce resources, food supply, access to freshwater, et cetera will increase and could lead to the outbreak of new conflicts, some even with the potential for civil wars (PCC 2014; Norwegian Refugee Council 2008). According to Harris et al. (2013), natural disasters accelerate existing conflicts. The research paper from Schleussner (2016) found a coincidence rate of 9 percent between armed conflicts and disasters (like heatwaves or droughts) between 1980 and 2010. In ethnically fractionalized countries, the figure was 23 percent higher. Almost two-thirds of all armed conflicts since 1946 have been along ethnic lines (Schleussner et al., 2016). In 2008, the increase in food prices led to riots and violence in 48 countries (FRPI 2014). Therefore, North and Central Africa are potential hotspots for armed conflicts in the future since most countries in this area will suffer from climate change and are strongly fractionated into different ethnic, religious, and social groups. (EFJ 2017: 29) A study from Burke (2009) concluded that climate change and armed conflicts in the Sub-Saharan region are highly correlated. Especially in warm years, the probability of wars increases significantly. The research paper predicts an increase in armed conflicts of more than 50 percent by 2030. Werrell and Femina (2015), who have analyzed the Syrian conflict, pointed out the importance of climate change in this conflict. Indeed, climate change did not trigger the conflict since it is a complex political, economic, and geopolitical battleground, but it definitely had some implications and influence (Werrell and Femina 2015). Therefore, the main challenge for migration theories in the future is going to be to anticipate all these developments and to find sustainable solutions on how to manage all these mass migration movements, (armed) conflicts, refugee streams, integration efforts, and the situation of people in camps, et cetera.

\subsection{Conclusion}

The most influential migration theories are probably the neoclassical approach, networkssystems, NELM, and the aspiration-ability model. The neoclassical approach built the foundation for future discussions, and many other theories appear based on this method. Networks-systems and NELM can be understood as a reaction to the basic neoclassical model to describe a more nuanced and flexible approach. Although all these models still have their influence today, the aspiration-ability model is very likely the most significant theory at the moment, which is also why it got the most coverage in the literature review. 
However, it is still astonishing to see how little attention has been given to refugee camps in the literature since 2015. Overall, the amount of research is minimal, and the few studies conducted focused on specific aspects of the living conditions in camps. However, they did not discuss 'if' or 'how' these could sustainably be improved. Indeed, all these models can explain 'why' (push) people want to flee from there and 'why' (pull) they wish to go somewhere else, but none of them sees refugee camps as 'no man's land.' The case of people who are unable to leave a particular area or territory has even more implications than it first seems. Higher mobility and improved infrastructure unquestionably had a significant impact on migration worldwide, including tourism. Still, the Coronavirus outbreak in China shows, once again, the 'dark side' of technological progress since worldwide flights helped to spread the virus all over the world. This development will not be the last case of people who need quarantined (another example of people who cannot go anywhere, even though they might want to) to stop such pandemics. The management of such stressful situations and the improvement of living conditions should remain a significant priority of future migration studies.

In conclusion, refugees are more recognized in the literature, and the topic has gained more relevance in recent years. Even so, their 'journey' and the ones who are 'stuck' do not get enough attention. The case of refugees, IDPs, and asylum-seekers remain in many ways uncovered in the field of migration studies. Notably, people in camps get little enough attention, specifically how their living conditions could be improved. Further research is needed. 


\section{EU Migration Policies, Borders and Security, Policy Situation}

The following section is about EU policies, borders and security, and policy situations. It provides the essential background for the dissertation in the context of migration, including some significant findings and results from researchers in this field.

The world is changing tremendously fast. Never before in the history of humankind could people travel from one region of the world to another in a reasonable time. Mobility is associated with modernity, freedom, and human rights (de Wenden 2020: 47). On the other hand, it is ironic that we also live in an era of borders and restrictive immigration laws. Foucher (2007) states that there have never been as many borders since the Iron Curtain's fall. It is a trend that started after the First World War (Zweig 1982). Compared to this point of view, other authors such as Debray (2010) describe frontiers as necessary for identification and identity in Europe. These two perspectives demonstrate the current disputes not only in Europe but globally. ${ }^{27}$

The 1968 Treaty of Rome and the 1992 Maastricht Treaty changed Europe significantly (de Wenden 2020). Borders lost their importance or disappeared, while Europeans gained the right to circulate freely in Europe (for employment, for example). Even non-European citizens benefited to a certain extent from this freedom and openness, but the refugee crisis of 2015 changed the tenor of the debate. De Wenden (2020: 48) sums it in the following way up: 'distinctions between refugees and migrants have become similarly complicated, as well as the relationships between emigration, transit and immigration countries at the border zones of Europe, and in the Maghreb ${ }^{28}$ and Turkey.'

Thus, regionalization ${ }^{29}$ in terms of migration is a global phenomenon (Tsapenko 2017) but affects mainly the Euro-Mediterranean region (de Wenden 2020). The Mediterranean EU countries are in the center of the massive migration movements from Syria, the Middle East, and other countries from the Mediterranean region outside the EU. In this context, Libya has

\footnotetext{
27 This reflects only the 'moderate' perspectives in the discussion. Unfortunately, extremist opinions and radicalization are also part of the ongoing discourse.

${ }^{28}$ The territories of Tunesia, Algeria, Morocco, and Western Sahara. Some definitions also include Libya and Mauritania.

${ }^{29}$ Migration from neighboring countries, areas, or regions.
} 
an extraordinary role as a transit country for refugees from the sub-Saharan area. These refugees are often alleged not to be 'real' refugees in the public discourse but are still regular asylum seekers (Schmoll et al. 2015).

Before going deeper into the actual situation, I start with an overview of the most important EU policies and migration agencies. ${ }^{30}$

\subsection{EU Migration Policies}

The EU, specifically the European Commission (EC), has a comprehensive set of rules, laws, and regulations for migration-related topics. ${ }^{31}$ The EC deals with regular and irregular migration (including integration, readmission, and return), as well as with asylum procedures (CEAS). Furthermore, border security, the fight against crime and human trafficking, terrorism, et cetera. are high priorities. The EU also cooperates with non-European countries regarding these questions.

\subsubsection{Legal Migration and Integration}

The EU is seeking a 'balanced, comprehensive, and common migration policy.' This approach's cornerstones are 'responsibility' and 'solidarity.' However, this policy section is still under development. In the long-run, the EU is hoping for economic progress through legal migration and successful integration. The aim is to establish a functional framework for legal immigration by considering the need for integration in the host countries. The EU classifies migrants into specific categories to achieve this goal, such as highly skilled workers ('EU blue card directive'), students, and researchers. Family reunification and long-term residents are also considered in this initiative. In recent years, the EU has started to focus on providing information by launching several websites for potential migrants (e.g., the EU immigration Portal). Other directives strengthened the rights of non-European workers (e.g.,

\footnotetext{
${ }^{30}$ Migration policies is a huge discipline itself. Due to the limitations of the work, the whole spectrum cannot be fully covered. Thus, this dissertation will only focus on the most important points in EU policy regarding migration.

${ }^{31}$ All the tasks of the Migration and Home Affairs department of the EC (actual version) can be accessed at the website of the EC under: ec.europa.eu/home-affairs/what-we-do/policies_en (accessed February 2020), which is also the primary source in this section if not otherwise mentioned.
} 
the EU Single Permit Directive). Since 2011 the EU is intensifying its dialogue with origin and transit countries (Global Approach to migration and mobility).

The most important and conventional ways of legal migration to the EU are explained in the following paragraph:

- Work ${ }^{32}$ : The EU sees labor immigration as crucial in terms of economic development, competitiveness, and upcoming demographic challenges. The main focus is on highly qualified workers, seasonal workers, and intra-corporate transferees. For that purpose, it provides the 'EU Blue Card,' which was intended to make residence and working permit procedures easier for skilled labor force from non-European countries. However, the Blue Card approach was not successful. The EU is currently working on a new version of the Blue Card by introducing 'more inclusive and flexible admission conditions, faster and more flexible procedures, improved rights, and enhanced facilitation of intra-EU mobility.' Furthermore, the EU wants to strengthen the rights of seasonal workers and promote the intra-corporate exchange.

- Family reunification ${ }^{33}$ : The EU considers family reunification one of the main factors for successful integration in the host country. The 'Directive on the right to family reunification' attempts to establish a standard set of family reunification rules. This directive gets support from 25 EU member states, excluding the United Kingdom, Ireland, and Denmark. Nonetheless, the directive on the right for family reunification is supposed to make the procedure more comfortable; every EU member state is still

32 15/05/2014 - Directive 2014/66/EU of the European Parliament and of the Council of 15 May 2014 on the conditions of entry and residence of third-country nationals in the framework of an intra-corporate transfer; 26/02/2014 - Directive 2014/36/EU of the European Parliament and of the Council of 26 February 2014 on the conditions of entry and stay of third-country nationals for the purpose of employment as seasonal workers; 13/12/2011 - Directive 2011/98/EU of the European Parliament and of the Council of 13 December 2011 on a single application procedure for a single permit for third-country nationals to reside and work in the territory of a Member State and on a common set of rights for third-country workers legally residing in a Member State; 25/05/2009 - Council Directive 2009/50/EC of 25 May 2009 on the conditions of entry and residence of thirdcountry nationals for the purposes of highly qualified employment.

${ }^{33}$ 29/04/2004 - Directive 2004/38/EC of the European Parliament and of the Council of 29 April 2004 on the right of citizens of the Union and their family members to move and reside freely within the territory of the Member States amending Regulation (EEC) No 1612/68 and repealing Directives 64/221/EEC, 68/360/EEC, 72/194/EEC, 73/148/EEC, 75/34/EEC, 75/35/EEC, 90/364/EEC, 90/365/EEC and 93/96/EEC; 22/09/2003 Council Directive 2003/86/EC of 22 September 2003 on the right to family reunification. 
allowed to determine some of its own rules. Thus, the whole process remains very bureaucratic and complicated. Even though the vast majority of the EU members supported the directive, many countries still have not implemented it to its full degree.

- Study and Research ${ }^{34}$ : Education is the key to innovation, prosperity, and future economic growth. Consequently, the EU wants to promote the European educational system to get the most exceptional talents worldwide. The directive, which regulates the standard rules for admission of non-European students, is the 'Directive on the conditions of entry and residence of non-EU nationals for the purposes of research, studies, training, voluntary service, pupil exchange, schemes or educational projects and au pairing.' There are some requirements concerning the admission procedure and country-specific rules, but, overall, this is probably the sector with the most prominent unity among member states. The EU also welcomes non-European researchers by making their stay less complicated and allows them (students as well) to stay for nine more months in the EU if they are looking for a job or trying to establish a business.

- Integration ${ }^{35}:$ In a nutshell, the capabilities of the EU are limited on this point. Of course, the EU recognizes the need for inclusion for economic, social, and cultural development. Still, the integration process remains pretty much in the member states' hands and how they define 'successful integration.' Nevertheless, the EU contributes

${ }^{34}$ 12/10/2005 - Council Recommendation 2005/762/EC of 12 October 2005 to facilitate the admission of thirdcountry nationals to carry out scientific research in the European Community; 12/10/2005 - Council Directive 2005/71/EC OF 12 October 2005 on a specific procedure for admitting third-country nationals for the purposes of scientific research; 28/09/2005 - Recommendation 2005/761/EC of the European Parliament and of the Council of 28 September 2005 to facilitate the issue by the Member States of uniform short-stay visas for researchers from third countries travelling within the Community for the purpose of carrying out scientific research; 13/12/2004 - Council Directive 2004/114/EC of 13 December 2004 on the conditions of admission of third-country nationals for the purposes of studies, pupil exchange, unremunerated training or voluntary service.

35 05/03/2008 - Commission Decision 2008/457/EC of 5 March 2008 laying down the rules for the implementation of Council Decision 2007/435/EC establishing the European Fund for the integration of thirdcountry nationals the period 2007 to 2013 as part of the General programme "Solidarity and Management of Migration Flows" as regards Member States' management and control systems, the rules for administrative and financial management and the eligibility of expenditure on projects co-financed by the Fund; 25/06/2007 Council Decision 2007/435/EC of 25 June 2007 establishing the European Fund for the Integration of thirdcountry nationals for the period 2007 to 2013 as part of the General programme "Solidarity and Management of Migration Flows"; 25/11/2003 - Council Directive 2003/109/EC of 25 November 2003 concerning the status of third-country nationals who are long-term residents. 
by 'supporting national and local policies with policy coordination, exchange of knowledge, and financial resources.'

- Long-term residents ${ }^{36}$ : The EU aims to benefit long-term (legal) non-European residents, who integrate themselves into society and contribute to economic and social development by granting status and rights similar to EU citizens. This part is regulated in the 'Directive on the status of non-EU nationals who are long-term residents.' It provides long-term residence permits to migrants who have lived at least five consecutive years in the EU and also fulfill other requirements (e.g., regular income or health insurance; is not a threat to the public security). After fulfilling these requirements, long-term residents get access to employment and self-employed activity, education and vocational training, social protection and assistance (at least core benefits), access to goods and services, et cetera. They are also allowed to move under certain conditions from one EU state to another. The United Kingdom, Denmark, and Ireland are an exception to this regulation since they apply their own policies.

There is a wide range of criticism concerning EU migration policy. Reslow (2010) describes the dilemma between migration policy and development policy by identifying the 'Global Approach to Migration,' the 'Policy Plan on Legal Migration,' the 'thematic program for the cooperation with third countries in the areas of migration and asylum,' and the 'Mobility Partnerships' as insufficient in terms of building a bridge between these two policies. The policies' main goal is to reduce irregular migration, and inconsistency between different policies does not allow a comprehensive approach. Eisele and Wiesbrock (2011), who have investigated the European Neighborhood Policy (ENP) from 2004 by examining mobility partnerships with Georgia and Moldova, argue similarly that EU policies on regular migration are not beneficial for non-EU countries. The analysis shows that the top priority of the EU is on limiting movement and strengthening border controls. Legal migration opportunities remain an issue for migrants. Even though the EU has emphasized its goal of negotiating mutual agreements based on partnership, the authors conclude that EU interests

${ }^{36}$ 25/11/2003 - Council Directive 2003/109/EC of 25 November 2003 concerning the status of third-country nationals who are long-term residents. 
are overwhelmingly represented in the signed agreements, and cooperation is just a sidenote. Reslow (2012) states that EU members see migration as their responsibility even though EU institutions become increasingly more supranational organizations. Hence, EU member states usually cooperate if it is beneficial for them. In terms of mobility partnerships, the Commission plays only a minor role, and the Parliament and Court of Justice are completely not involved in the decision-making process.

As a consequence, some EU members are willing to participate, some others not. In recent years, the EU has even started external government initiatives to implement foreign migration policy, for example, in Ukraine or Morocco (Wunderlich 2012). Andrade (2013) emphasizes that the EU aims for such partnerships, but the 'Global Approach to Migration and Mobility' is underdeveloped due to resistance among member states. She identifies instruments of association, improving coordination between EU members, and external action as a key for a more comprehensive and useful approach. Thus, Scipioni (2018) concludes that a lack of solidarity and weak centralized institutions were major factors during 2015 and after.

In the last 20 years, labor migration from non-EU countries has become a crucial growth strategy to improve competitiveness (Paul 2013). The current EU migration policy focuses on the economic needs of the domestic labor market. Martin and Venturini (2015) state that highly-qualified, intra-corporate transferees, seasonal workers or students, and nonremunerated trainees and researchers are the primary targets for migration from third world countries. Asylum seekers or family reunifications are not on the agenda of the Commission. Therefore, the EU migration policy is still focused on the economic aspects since the strategy builds on the receiving state's financial benefits and how exploitable people are in the labor market. In general, we can say the highly-skilled labor force is welcome, but the rest not. Migration in the $21^{\text {st }}$ century is a fight for the most valuable talents. Similar trends can also be observed among EU member states, including migration from the South or the East to the North or the West of Europe. The 'lack of solidarity' (Scipioni 2018) applies to third-world countries and other EU member states.

\subsubsection{Irregular Migration}

The volume of irregular migration peaked in 2015 and remained high in the following years. According to EU member states, many of these new irregular migrations flows from Africa, Asia, and especially from the Middle East were assisted by smuggling networks. The EU classifies smuggling as highly criminal and dangerous. Every year, thousands of people are 
forced to take unsafe routes (mostly over the Mediterranean Sea) and consequently lose their lives during their journey to the EU. Thus, in the form of the European Agenda on Migration and the European Agenda on Security, the EU actively fights this trend. The goal is to reduce irregular migration incentives and stop migrants' exploitation by making the smuggling business as unprofitable and risky as possible.

In many cases, migrants remain dependent on their smugglers because they are the ones who can provide them false documents and fake IDs. These practices make irregular migrants more vulnerable. The same applies to human trafficking, which is also a major crime. Violaters face sanctions, not only for the human traffickers but also for employers who hire these immigrants. Therefore, the external borders of the EU have become more significant. In particular, people arriving by the Mediterranean Sea risk their lives. For that purpose, the EU state's coastguards and the European Border and Coast Guard Agency (FRONTEX) have increased their efforts to protect lives. This is supposed to happen by using new technologies like information technology (like the Visa Information System) and biometric features (e.g., fingerprints) for identification since one observation is that many arrivals are legal because of short-stay visas, however people stay long-term because of economic reasons. These agencies and technologies are supposed to stop this trend. However, EU states are still obliged to control their borders to build trust in the European migration system and respect fundamental human rights. The council and the European Parliament have formulated their objectives as follows: '1.) Strengthening the mandate of FRONTEX so that it can act more effectively at the external border. 2.) Establishing an evaluation mechanism to verify the correct application of the Schengen rules. 3.) Intensifying coordination between border surveillance authorities (through the European Border Surveillance System EUROSUR) and considering the feasibility of creating a European system of border guards.

4.) Establishing rules for the surveillance of the external sea borders in the context of operational cooperation coordinated by FRONTEX.'

According to Vollmer (2011), irregular migration has been an issue for decades in EU policies. The discussion started in the 1970s, intensified in the 1980s, and continued during the 1990s. Nowadays, it is one of the top priorities in EU policies, which also fits into the analytical framework of Reslow (2010, 2012) and Eisele and Wiesbrock (2011), who describe EU policies as a tool to reduce migration with restrictive policy measures. The two dominating topics in this field are 'threat and criminalization' and 'the number games.' Vollmer criticizes the populistic character of the discussion and argues that decision-makers 
and politicians are taking advantage of the ongoing debates by demonstrating strength and control. Other authors, such as Provera (2015) or Bosworth and Turnbull (2015), criticize 'the criminalization of irregular migrants.' Düvell (2011) states that EU policies' political and legal framework is not functional and often has a contradictory effect; instead of preventing irregular migration, some policy measures lay the foundation for illegal movements and promote them. Triandafyllidou (2010) emphasizes that EU policies' character limits legal entry opportunities and leads to irregularity.

In general, irregular migration is a highly fragmented field in EU policies. Every European country is following its interests (Wunderlich 2012), and the geographic position of some countries makes them more susceptible to irregular movements or illegal border crossing. Notably, the states in the South or South-East are mostly affected by irregular migration. In contrast, other members such as Hungary function as transit zones, and the Northern states are usually the destination. These circumstances are also reflected in the literature since many analytical frameworks elaborate on specific country cases, such as Kraler and Hollomey (2010) about Austria, Drbohlav and Medová (2010) about the Czech Republic, de Wenden (2010) about France, Futo (2010) about Hungary, Fasani (2010) about Italy, or González-Enríquez (2010) about Spain. A common approach in terms of EU policies does still not exist, and the events of 2015 divided the EU member states even more.

\subsubsection{Migrant Smuggling, Return, and Readmission}

In terms of irregular migration, migrant smuggling is of extraordinary importance. According to the EU, the smuggling business makes several billion Euros in revenue every year, making it very lucrative and profitable. These smuggling networks are responsible for massive human rights violations and thousands of deaths every year. Furthermore, they are often well connected to other dangerous criminal organizations profiting from terrorism, human trafficking, and money laundering.

Therefore, the fight against migrant smuggling has the highest priority for the EU, and the EC elaborated on the 'EU Action Plan against Smuggling' from 2015 to 2020. The plan includes: 'enhanced police and judicial response, improved gathering and sharing of information, enhanced prevention of smuggling and assistance to vulnerable migrant, and stronger cooperation with third countries.' In total, a variety of different agencies and measurements are in force. Europol, the EU law enforcement agency, has set up the 'European Migrant Smuggling Centre' and supports member states with its operations and 
investigations. The Common Security Defence System (CSDP) EUNAVFORMED Operation SOPHIA is active in the Mediterranean Sea. It intends to destroy the business model of smugglers by collaborating with the Libyan coastguard and navy. The same applies to FRONTEX, which has since 2016 permission to operate outside of the EU. Other supportive agencies are CEPOL, Eurojust, the European Asylum Support Office (EASO), the Fundamental Rights Agency (FRA), and the European Maritime Safety Agency (EMSA).

The EU cooperates with third countries and tries to fight against smuggling at its origin by providing financial and technical assistance. The partnership's objectives are: 'assistance in developing anti-smuggling strategies and legislation; building the capacity of law enforcement and judicial bodies to investigate and prosecute smugglers; and increasing the effectiveness of migration flows and border controls.' The EU is working together with third world countries and several international organizations, host country authorities, and networks to achieve these goals. Information campaigns, which are supposed to raise awareness for the smuggling issue in origin and transit countries, complement the partnership framework. Hence, the EU has established standard rules and directives. 'Directive 2002/90/EC' from 2002 defines unauthorized entry, transit, and residence, and 'Framework Decision 2002/964/JHA' is a sanction catalog for violating the directive (humanitarian reasons excluded). Finally, the EU signed the UN Protocol against the Smuggling of Migrants by Land, Air, and Sea and the United Nations Convention against Transnational Organized Crime in 2006.

Since the outbreak of the civil wars in Syria and Libya at the beginning of the last decade, migrant smuggling has gained more attention from the European public. Millions of people decided to flee to Europe and paid smugglers to bring them to the European mainland. Unfortunately, thousands of people died in the Mediterranean Sea due to adverse conditions on the sea, and smugglers, who took advantage of people, did a lucrative business. Reitano (2015) calls the Mediterranean Sea crossing 'the most dangerous border outside active conflict zones.' According to his research, the more restrictive (border) controls get, the more likely criminal smugglers get involved. Reitano suggests a more open asylum policy by allowing 'economic migrants' to enter the EU and improve cooperation in the crisis regions. Triandafyllidou (2018) follows a similar argument by stating that restrictive policies have increased the smuggling business. Other side-effects include disrupted cross-border flows and transformed economies. 
A different approach is made by Zhang et al. (2018). The authors conducted a field study on smuggling networks and shed light on a new perspective in the debate. Indeed, smuggling organizations are often profit-orientated and operate illegally. However, smugglers are, in some cases, family members or friends of fleeing persons. Achilli (2018), who investigated Syrians' smugglers, came to the same results and even concluded smugglers should not be villainized, at least not all of them. He could not confirm the narrative that smugglers' only goal is to make a profit and describes the relationship between smugglers and refugees as 'rich in solidarity.' Maher (2018) follows the same narrative after a field study in Senegal, and Mengiste (2018) describes smuggling even as 'socially embedded.'

The latest research findings in smuggling networks and the relationship between smugglers and refugees enrich the discussion. ${ }^{37}$ The topic is more complex and nuanced than it seems at first look. On the other hand, EU policy still does not recognize these research results and continues to 'criminalize' smugglers. Thus, EU policies should start considering these findings.

Nevertheless, according to the EU, every year, 400,000 to 500,000 people are obliged to return from the EU to their country of origin due to their irregular status. However, only 40 percent of the cases get completed. The EU does not see a contradiction between open migration policy and the return of irregular migrants. The 'Return Directive' from 2008, which all member states signed and even found its way into most countries' national law, is a standard set of rules for managing irregular migrants' returns using reasonable measurements in compliance with human rights protection. In 2014, the EC evaluated the success of the directive and came to a positive conclusion. However, the directive was also not able to send back all irregular migrants, as previously mentioned. In most cases, the reason for this is missing documents from non-EU countries, which makes the identification of persons problematic.

The return process can only be executed efficiently by cooperation among member states of the EU. Member states cooperate on 'assistance in cases of transit for removal by air, organization of joint flights for removals, mutual recognition of decisions on expulsion, and implementation of guidelines on forced return.' FRONTEX, once again, also plays a

\footnotetext{
${ }^{37}$ See also chapter six (semi-structured interviews), which confirms these findings.
} 
significant role in this context. Moreover, the cooperation is not limited to member states. It includes third-party countries as well. Therefore, the EU is actively working on readmission agreements of irregular migration with non-European countries.

Kruse and Trauner argued in 2008 that the EU is using readmission agreements as an instrument to force change in neighboring countries (e.g., Ukraine) by offering travel benefits in exchange. Hence, the EU policy on return and readmission is nationalized, and it is an essential geopolitical tool in terms of foreign policies. The EU aims to respect human rights. However, Dedja (2012), who observed the EU readmission policy to Albania, criticizes that the EU's primary goals are effectiveness and efficiency. Thus, safeguarding and human rights play only a minor role since EU member states do not control if returnees' treatment complies with EU standards. Carrera et al. (2016) can confirm these observations after analyzing the 'EU-Morocco Cooperation on Readmission' by stating the EU is ignoring human rights issues and trying to take advantage of such partnerships with third-party countries.

\subsubsection{Common European Asylum System (CEAS)}

The EU asylum system builds on the Geneva Convention from 1951 and guarantees refugees protection. All member states are supposed to share the same values and obligations, including fair and efficient procedures. Following this framework, EU member states agreed on establishing the Common European Asylum System (CEAS). The EU has to deal with different sizes of asylum streams. There are not constant and can vary significantly. In 2006, for example, the EU had only 200,000 applications from asylum seekers, which is small compared to the peak in 2015. Overall, the EU wants to establish common standards, and the outcome of the asylum decision should not be dependent on which country the application was examined in.

The initiative for a conventional asylum system dates back to 1999. Since then, plenty of new standards and directives have been adopted. The 'Temporary Protection Directive' deals with refugees who cannot go back to their origin, and the 'Family Reunification Directive' is another one specially meant for refugees. Meanwhile, the 'European Refugee Fund' was founded for the financial support of people in need. After a round of evaluation, the EC introduced the 'Policy Plan on Asylum' in 2008. The plan is supposed to harmonize protection standards, enhance cooperation, and increase solidarity among EU member states and non-EU countries.

Numerous new standards should treat asylum seekers equally and fair: 
- The revised Asylum Procedures Directive (Directive 2013/32/EU): more efficient and faster asylum decisions and more excellent protection of minorities.

- The revised Reception Conditions Directive (Directive 2013/33/EU): ensuring specific standards and humane conditions for asylum seekers in the EU.

- The revised Qualification Directive (2016/0222 (COD)): guaranteeing international protection and strengthening of asylum decisions.

- The revised Dublin Regulation (REGULATION (EU) No 604/2013): clarification, which state is responsible for asylum seekers.

- The revised EURODAC (Regulation REGULATION (EU) No 603/2013): law enforcement measures in terms of security threats (e.g., crime or terrorism).

The CEAS is mired in academic discussions. Lambert (2009), who analyzed the different approaches of the United Kingdom and France to the CEAS, discovered the absence of a coherent strategy in terms of 'transnational use of national jurisprudence on asylum between judges'; a problem that, after ten years, still occurs. Mitsilegas (2014) criticizes the lack of solidarity among EU members in the framework of the CEAS. National solo efforts are inadequate to address the challenge of rising asylum seekers numbers in the EU and do not respect human rights. Heijer et al. (2016) identified three major weaknesses of the current CEAS: 1.) Structural inflexibility. 2.) Unrealistic expectations regarding borders. 3.) The incorrect assessment that migration flows outside of the EU could be prevented.

In general, we can observe two different philosophies: 'more Europe' and 'less Europe.' Lavenex (2018) describes this as an ideological conflict within the EU. A 'Union of Values' is far from being realistic, which is also reflected in the CEAS. Thus, political actors and institutions, by not following the same vision, are not operating efficiently. Lavenex goes even one step further and calls these practices 'organized hypocrisy' since there is a contradiction in protecting asylum seekers' rights and converse policy measurements. However, according to Léonard and Kaunert (2019), the EU has adopted many policy instruments in recent years, despite member states' national solo efforts.

\subsubsection{The country responsible for Asylum Application (Dublin)}

The Dublin system is supposed to be a control and regulation mechanism for asylum seekers arriving in the EU. Every member state is obliged to register where and when the asylum seeker arrived and first stepped foot on EU ground. The objective is, of course, to make asylum decisions more efficient. It provides clarification to questions of responsibility 
regarding EU member states and urgency regarding asylum seekers. Both irregular and regular migration are included in the Dublin regulation.

Dublin III was established in 2013 and has important implications in terms of the efficiency of procedures and the protection of asylum seekers:

- Early warning system and crisis management.

- Protection of applicants by personal interviews, guarantees for underage, and reunification with family members.

- The right to appeal asylum-decisions, including the guarantee to remain in the territory until the court makes its final decision.

- Legal assistance by covering the costs.

- Under certain circumstances, state authorities are allowed to arrest asylum seekers.

- Improvement of procedures between member states. Dublin procedures should be completed within eleven months.

As a consequence of asylum seekers' mass arrivals in 2015, the EC is continuously working on further improvements. The events of 2015 showed clearly the weaknesses of the current CEAS and the Dublin regulations in particular. Thus, the EC proposed reforms in 2016 by renewing the CEAS and Dublin regulations (Dublin IV):

- Faster responsibility evaluation and time-limits for take-charge requests and transfers.

- A new allocation mechanism ensures fairness among member states and reduces pressure from profoundly affected areas or countries.

- Stricter policies for migrants without documents.

- More robust protection of asylum seekers rights', especially for minors and families.

In a nutshell, the EU still wants to make legal and safe immigration possible by guaranteeing Europe's pathways. Nevertheless, the EC concluded that the system was not fair enough in terms of burden-sharing in the past. The goal is to implement a 'fairness mechanism based on solidarity.' The new system would provide a clear, and more importantly, a more specified set of rules and standard regulations for asylum applications. Therefore, by taking the size and the wealth of a country into consideration, an individual reference number is set up. Suppose this reference number gets exceeded by over $150 \%$. In that case, an automatic mechanism is activated, and asylum seekers are sent to another EU country until the amount of asylum application goes back to 'normal.' The last part of this regulation includes financial incentives. Countries are allowed to not participate for a certain 
amount of time in this fairness mechanism by making financial contributions $(250,000$ EUR for each applicant) to the state that is relocating the asylum seeker.

The Dublin system's criticism is overwhelming, making it probably one of EU policy's most controversial topics. Raitio (2011) called the system, even before the events of 2015, 'unfair,' 'ineffective,' and 'intransparent.' Years later, the critics have not stopped, and the debate has been enlarged by nationalistic rhetoric (Lovec 2017). Notably, the burden-sharing aspect of the discussion is critical. The Mediterranian Sea countries in the South or SouthEast are usually the leading destinations for sea arrivals. According to the Dublin regulations, these member states have a geographical disadvantage because they have to deal with asylum applications. In the past, Greece and Italy, in particular, carried a disproportionate burden. Guild et al. (2015) see the EU's significant challenges in guaranteeing safe travel opportunities for asylum seekers and distributing these asylum seekers. The EU is facing an efficiency dilemma. In essence, the enforcement of the existing laws may overburden the southern states, but ignoring the Dublin rules may overburden the northern countries. (Trauner 2016). Kasparek (2016) illustrates the absurdity of the system by interviewing a Somalian refugee in Italy. In Italy, he was homeless and living on the streets. Thus, he applied in many other European states (e.g., the Netherlands and Sweden), but every asylum application got denied, and he ended up on the streets of Italy again.

The vast majority of EU members are not satisfied with the Dublin system. However, implementing a fair burden-sharing system seems also not realistic since right-wing nationalistic powers increase everywhere in Europe and gain more political momentum. The Dublin system's most promising alternative is a quota regulated approach, which could increase solidarity among member states.

\subsubsection{Reception Conditions and Asylum Procedures}

The EU has to provide specific standards and living conditions to asylum seekers awaiting their decision. These standards are defined in the Reception Conditions Directive from 2013, which aims to harmonize European standards concerning housing, food, clothing, health care, education for minors, and even access to the labor market. Underage people and other vulnerable persons (e.g., victims of torture) have the right to medical and psychological treatment. The directive also set up the rules for detention, which must be applied in full respect of human rights. 
The EC states that there is still some particular uncertainty regarding the definition of living standards and conditions. Thus, there are still significant differences among EU member states. The European Agenda on Migration is supposed to decrease these differences. There is an urgent need for clear reception conditions to improve the European asylum system and be better prepared for future crises. In 2016, the EC made a new proposal to revise the directive. The aim is more harmonization among member states, fewer incentives for secondary migration movements, and promoting migrants' integration.

The 'EASO guidance on reception conditions: operational standards and indicators' provides the most comprehensive version of existing European standards in asylum questions. EU member states are already following these standards and guidelines. It results from several organizations, institutions, and civil society organizations, such as the European Commission, the European Union Agency for Fundamental Rights (FRA), and the United Nations High Commissioner for Refugees (UNHCR). The objective was to develop a framework of specific standards for asylum seekers, which guarantees fundamental rights, protection, and appropriate living conditions.

Thornton's (2014) criticism is that the EU does not respect human rights, including limitations on freedom of movement, right to work, and denial of children's education. These practices are contrary to 'European values' and discriminate against asylum seekers unfairly. On the other hand, Zaun (2016) emphasizes the implementation of higher standards for asylum seekers over the past decades. The Northern states especially promoted such changes and were successful due to their dominant position in the EU. However, there is no convergence in terms of standards for asylum seekers, which corresponds to EU members' different economic powers. Therefore, harmonizing living conditions promotes European integration and provides higher standards for asylum seekers in the long-run.

To overcome some of these limitations, the EU has established asylum procedures, which are the framework for fair, efficient, and harmonized asylum procedures. People who are fleeing brutal situations are allowed to find international protection in the EU. The Asylum Procedures Directive is the principal regulator in this field and decides under which circumstances people are granted or denied asylum status:

- Clear rules for asylum application; everyone who would like to apply for asylum may do so.

- Time-limits for the application process (usually six months).

- Special treatment for people in need due to age, disabilities, illness, et cetera. 
- Clear rules for courts and tribunals regarding appeals.

In 2016, the EC made some new proposals to remove incentives for asylum shopping and secondary movements between member states. The aim is to establish 'a truly common international protection procedure within the EU' by removing dysfunctional procedures and replacing them with simple and more unambiguous systems; by guaranteeing the rights of applicants, giving them an interview, and providing free legal assistance, interpretation, and representation; by more attention for vulnerable persons; by stricter rules to prevent system abuse; by including a standard set of rules for safe third countries and the first country of asylum concept; by harmonizing rules on safe countries. The proposal and others are part of the CEAS reform package discussed by the European Parliament and council.

\subsubsection{Who qualifies for International Protection and Temporary Protection}

The requirement to get asylum in an EU member state is recognition as a refugee or a beneficiary of subsidiary protection. The Qualification Directive from 2011 is the regulation that defines third-country nationals and stateless people as refugees or persons who require international protection. The following aspects are included in the directive: protection from 'refoulement,' residence permits, travel documents, access to employment, access to education, social welfare, healthcare, access to accommodation, access to integration facilities, and specific provisions for children and vulnerable persons. The EU claims to treat people fleeing from war, persecution, and torture fairly and respectfully. To ensure that the EU clarifies ground for granting or withdrawing international protection, it improves the access of international protection beneficiaries to rights and integration measures. It considers the best interests of children and other gender-related aspects.

The EU has identified some weaknesses and shortcomings of the existing system and concluded that the results of asylum applications or the international protection of people could vary significantly among member states, so the EC has proposed reform packages based on solidarity responsibility to the CEAS. The new Qualification Regulation from 2016 attempts to reach convergence among member states regarding asylum decisions and international protection qualification. Again, the Parliament and Council did not have made any decision yet.

Concerning temporary protection, the Directive on temporary protection from 2001 was the direct response to the events of the 1990s when wars and conflicts caused mass 
migration to the EU. Specifically, the wars in the former Yugoslavia and Kosovo were the reason for these movements.

The EU defines temporary protection as follows: 'Temporary protection is an exceptional measure to provide displaced persons from non-EU countries and unable to return to their country of origin, with immediate and temporary protection.' In this context, the policies are supposed to reduce disparities and create an atmosphere of solidarity and burdensharing. The directive regulates a wide range of different topics, from residence permits for the entire duration of the protection (one to three years) to appropriate information on temporary protection. It addresses employment, accommodation or housing, social welfare, access to medical treatment, education for minors, and families' opportunities to reunite. It guarantees access to the regular asylum procedure. The other directive deals with returning, treating individuals with criminal records, and minor's situations. Solidarity among EU member states was not considered for nearly 20 years and has only recently become a sensitive topic.

\subsubsection{External Aspect}

The EU is working on agreements with non-EU countries and countries of the first asylum to anticipate migration flows and improve the country of origin's living conditions. Therefore, the EU has developed the 'EU Regional Protection Programmes' and 'Resettlement schemes.' Regional Protection Programmes are providing financial support to countries of origin and transit. The goal is to promote return, local integration, and resettlement. Hence, the protection of refugees gets improved by these benefits and actions. The programs result from cooperation between the Commission and the United Nations High Commissioner for Refugees, countries of origin, transit, and first asylum. Currently, the EU has Regional Protection Programmes with Belarus, the Republic of Moldova, Ukraine, Tanzania, Kenya, Yemen, Djibouti, Egypt, Libya, and Tunisia.

However, even though the EU has put much effort into establishing such programs, most member states still do not have any resettlement programs for refugees in the EU. In response to that, the EC founded a joint Resettlement Programme, which goes the other way, supporting refugees' settlement in the EU since Europe is still dealing with relatively low numbers of refugees compared to the rest of the world. Nevertheless, the program is voluntary. 


\subsection{Borders and Security}

\subsubsection{Schengen, Borders, and Visas}

The Schengen area ensures free and safe travel for EU citizens, non-Europeans, and others. Since 1985 internal borders between the EU member states and partners have been continuously demolished, making passing borders less time-consuming and beneficial for EU citizens, tourists and visitors. The focus of border controls has shifted from internal controls to common external border protection. Now, more than 400 million EU citizens have the right to work, travel, and move wherever they want in the EU. The Schengen area includes every EU member state except Bulgaria, Croatia, Cyprus, Ireland, Romania, and the United Kingdom (Bulgaria and Romania are in negotiations for joining). Non-EU members who are participating in the Schengen system are Iceland, Norway, Switzerland, and Liechtenstein. However, even though border checks for citizens are abolished, state authorities and police are, of course, still allowed to apply police checks at the border. Another exception is the case of severe threats to the internal security of a country. Under these circumstances, temporary border checks are also possible, but only for a limited time. Nevertheless, passports and visas are no longer required to pass a border within the EU for the most part.

The Schengen rules cover the following topics:

- A common set of regulations, including visa regulations and policies.

- Harmonization of the conditions of entry.

- International and cross-border cooperation between police.

- Document requirements for travelers in the EU.

Joining the Schengen area is a political decision. Still, some conditions have to be fulfilled, such as external border controls, cooperation with law enforcement agencies, or the application of common Schengen rules. Since 2015 there are regular Schengen evaluations every year to examine if member states are fulfilling their obligations. The temporary border controls are outlined in the Schengen Borders Code. These include foreseeable cases (articles 25 and 26; e.g., sports events), cases requiring immediate action (article 28; e.g., security threats), and cases where exceptional circumstances put the overall functioning of the Schengen area at risk (article 29; e.g., severe threats to several Schengen countries). Other essential parts of the Schengen system are:

- Border Crossing: The focus is very much on the external borders of the EU. The Schengen Borders code is a clear set of rules that explain who is allowed to stay in the 
EU and how long. The goal was to establish harmonized regulations for all EU member states. Overall, the emphasis is on solidarity and cooperation among member states. The EU Internal Security fund is supposed to support the costly investments at the external borders, and FRONTEX and EUROSUR (European Border Surveillance System) are other forms of cooperation.

- Smart Borders: In a nutshell, smart borders are a relatively new technology used at the external borders of the EU, but also at airports, for example. It is a computer-based entry/exit system for registered travelers. It makes border controls more efficient and helps in the fight against irregular migration. Initially, it was a pilot project, but more and more countries are adopting it.

- Visa Policy ${ }^{38}$ : The EU and the Schengen states have established a conventional visa system and policy. Visa requirements and exceptions depend, of course, on agreements with non-EU countries, respectively non-Schengen countries. In 2016, almost 14 million Schengen visas were approved.

At the beginning of the last decade, Monar (2010) described the Schengen as an 'Area of Freedom, Security, and Justice.' Furthermore, it was also the fastest-growing project in EU policies with a high differentiation level since the Schengen area seemed to be continually expanding. However, this process has come to an end. Today, the EU is more focused on keeping the union together instead of finding new Schengen areas. Börzel and Risse (2018) even speak of a 'Schengen crisis,' an identity crisis of the whole EU after the mass migration influx from 2015. In the fallout of these events, Eurosceptic actors and movements followed populistic approaches by demanding more border security to protect Europe.

Nevertheless, the abolition of borders for most European citizens is considered a great success for the Schengen area. Free movement allows people to cross borders without border controls, and economic accomplishments have been tremendous. Ademmer et al. (2015) even call Schengen a 'blessing' for Europe. Another advantage of the Schengen project is that it helped the EU promote European values outside of the Schengen area. Many non-EU countries have adopted EU policies and liberal norms. However, Ceccorulli (2018) sees a

\footnotetext{
${ }^{38}$ The number of visa applications is important since many refugee enter the EU on a regular way, but make the decision to stay after their visa has expired.
} 
significant dispute among member states because of the uncoordinated border actions during the migration crisis. While some countries followed a restrictive border policy, others left their borders open. In terms of security policies, Ceccorulli has a different standpoint and cannot find evidence that existing or planned migration policies were violated. Ademmer et al. (2015) conclude that the lack of solidarity during the refugee crisis undermined the advantages of no internal borders. Nation's migration policies should not diminish the last 30 years' accomplishments. Other authors, such as Guild et al. (2016), also praise the Schengen area and argue the border controls during the migration crisis complied with the legal framework. Schimmelfenning (2018) makes a comparison between the euro and the Schengen crisis. While the euro crisis has strengthened the unity of the EU, the Schengen area's plight had the contrary effect and divided Europe even more.

\subsubsection{Counter-Terrorism and Radicalization}

The EU aims to provide freedom, security, and justice to all its inhabitants. However, terrorism does not know any borders or restrictions and operates internationally. ${ }^{39}$ Thus, the EU considers the fight against terrorism as one of its priorities by enhancing cooperation and responsibility between member states. No state can be prosperous on its own when facing an international threat. For that purpose, the EU has developed the 'EU Counter-Terrorism Strategy' adopted by the European Council in 2005. The strategy consists of four cornerstones: prevent people from radicalization or joining terrorist groups, protect people from terrorist attacks, pursue international terrorism, and respond appropriately to terrorist acts. Another important initiative is the European Agenda on Security from 2015, which describes the fight against terrorism as follows: 'define and criminalize terrorist offenses, prevent radicalization and the spreading of terrorist propaganda, and to cut terrorists' access to the means to perpetrate attacks such as finance, firearms, explosives, etc.'

In 2017, all EU member states signed the 'Directive on combating terrorism.' The directive attempts to define and set specific standards in the fight against terrorism, including the financing of terrorism and the training of terrorists. Member states are obliged to cooperate and share their information. The directive also ensures that victims of terrorism and

\footnotetext{
${ }^{39}$ Unfortunately, international migration is also very often linked to terrorism or radicalization (see Milton et al. 2013 in the literature review).
} 
their families receive the support that they need. After the events of 2015 (the attack on Charlie Hebdo, in particular), the European Counter Terrorism Centre (ECTC) was founded, which can be understood as an extension of Europol and focuses on foreign terrorist fighters, explosives, firearms, financial intelligence, and online propaganda.

Regarding the prevention of radicalization, the EC reacted by establishing the Radicalization Awareness Network (RAN). The first approach to countering radicalization is the identification of propaganda material on the internet. A high-level Commission expert on radicalization proposed, in 2018, a regulation on preventing the dissemination of terrorist content online. Further measures in this field include protecting civil society and critical infrastructure, more security research by funding security projects, and cooperation with nonEuropean partners.

The main questions that arise are 'Why do people radicalize?' and 'Why do they become terrorists?'. The classic paper from Crenshaw (1981) distinguishes between root causes and trigger causes. Years later, Bjorgo (2005) built his analytical framework around these questions and identified four root causes for terrorism: structural causes, facilitating causes, motivational causes, and triggering cause. However, there is usually not one particular root for terrorism, but it is instead a mix of several reasons. After analyzing various government papers from different European states, Bakker (2015) sees nationalist-separatist and religious Islamist terrorism as the two dominant forms of terrorism right now. The EU focuses very much on network dynamics and, therefore, individual radicalization plays only a minor role, as well as the process of deradicalization. The purpose of psychology is undermined in EU policy. The EU's priority is the fight against radical Islam, while other terroristic streams do not get enough attention, such as right-wing or left-wing terrorism. Bossong (2014) evaluates these EU policies as inefficient, and Bakker describes the EU approach as 'incident driven,' but the EU has developed a more comprehensive approach in recent years. Other critical remarks were made by Sedgewick (2010): 'no universal definition for radicalization and terrorism,' Argomaniz (2015): 'online security versus privacy,' and Mattson et al. (2016): 'the war on terror decontextualize tensions in the society.'

Martins and Ziegler (2018) studied EU security measures after 2015 and agreed on Bakker's analysis. The EU is following a preventive strategy, which means counterradicalization equals counter-terrorism. Other EU policy trends are an externalization of knowledge production, a focus on the crime-terror nexus and prisons' role, more openness to the private sector, and an over-emphasis on Islamism. The authors conclude with a warning 
that 'the rise of nationalist rhetoric and policies sweeping over Europe will lead to tensions that may result in even more politically motivated violence' (349).

These findings illustrate the complexity of the topic, a very emotionally driven one. Notably, the focus on radical Islam gives European citizens the impression that 'all Muslims are terrorists.' Ironically, this form of exclusion might lead to radicalization, respectively, to tensions between nationalists (or citizens) and Muslims. Unfortunately, prejudices and xenophobic attitudes dominate the debate. Finally, the debate's privacy aspect is also very critical since governments tend to constrain fundamental rights (e.g., citizens' privacy) in the fight against terrorism.

\subsubsection{Organized Crime and Human Trafficking}

Human trafficking is a form of organized crime ${ }^{40}$ and a substantial violation of human rights, but unfortunately also a very lucrative business for human traffickers. The 'EU Charter of Fundamental Rights' (Article 5.3) prohibits it, and the TFEU (Treaty on the Functioning of the EU) defines it as a severe form of organized crime (Article 83). Human trafficking is related to immigration policy (Article 79). The relevant legal and policy framework is Directive 2011/36/EU on combating and preventing trafficking in human beings and protecting its victims and the EU strategy towards eradicating trafficking in human beings for the period 2012-2016. While Directive 2011/36/EU is the dominant framework for the victim's protection, assistance and support, and prosecution, the EU strategy is the basis. It shows the direction of the policy by providing regular reports, studies, and publications. The main goal was to strengthen victims' rights and destroy the business model of human traffickers by making it less profitable. The other two primary directives in this context are Directive 2004/81/EC and Directive 2012/29/EU, which set up some minimum standards for the treatment of victims and describes how to deal with non-European victims.

According to the Commission, human trafficking is often related to other organized crimes such as 'document fraud, drug trafficking, cybercrime, child pornography, migrant smuggling, and benefits fraud.' It is considered, therefore, to be a severe crime and is a

\footnotetext{
${ }^{40}$ This section will only focus on human trafficking, which is a part of EU policy on organized crime. Organized crime is, of course, a big topic and includes other serious crimes such as trafficking of firearms, sexual child abuse, drug dealing, et cetera.
} 
priority in the 'EU Policy on Organised and Serious International Crime 2014-2017', the 'EU Serious and Organised Crime Threat Assessment 2017', and the 'EU Policy Cycle on Organised and Serious International Crime 2018-2021'.

Indeed, human trafficking is related to migrant smuggling (see chapter 4.1.3.). However, according to Herkes (2018: 20-21), there are two crucial differences between these crimes: 1.) Human trafficking does not require crossing borders. Human smuggling does. Thus, a person can be trafficked without leaving the country. 2.) Human trafficking has an exploitive character, human smuggling, on the other hand, not necessarily since the primary goal is 'only' to cross one or several borders and to bring the migrant to its destination. The most common forms of human trafficking are forced labor, sexual exploitation, and child trafficking (Jones and Winterdyk 2018). Tallmadge and Gitter (2018) conducted a comprehensive study and determined the factors that affect the rate of human trafficking in a country. The findings show that a high percentage of immigrants make trafficking more likely. Other factors are access to the sea, low GDP per capita, and legalized prostitution.

Therefore, human trafficking depends very much on demographic, economic and legal, and geographic indicators. The location of EU members, of course, cannot be changed. However, the researchers' findings suggest that economic, demographic, and legal harmonization among member states might significantly reduce human trafficking. Further European integration and efficient asylum seeker allocation mechanisms seem to be a promising approach in the fight against human trafficking, as well as international organized crime. Thus, national solo efforts are not enough to stop the global exploitation of migrants. Unfortunately, the lack of solidarity among member states remains a considerable obstacle to overcome, and the implementation of such a policy is probably not going to happen any time soon.

\subsubsection{EU Agencies}

Numerous EU agencies are operating in the field of migration and policy-making. These agencies aim to support the EU member states by providing information and assisting in decision-making processes. The most important agencies are the following:

- FRONTEX: The European Border and Coast Guard Agency is the external border agency of the EU. Their main task is to anticipate and monitor migration flows, provide risk analysis, and make recommendations to member states on responding to possible threats or developments. 
- Europol: The European Union Agency for Law Enforcement Cooperation supports EU members in their fight against terrorism, drug trafficking, people smuggling, cybercrime, and other organized crime activities.

- CEPOL: The European Union Agency for Law Enforcement Training is a relatively new agency and is supposed to, as the title indicates, to provide training in questions of international crime and security issues.

- EASO: The European Asylum Support Office is a crucial part of the CEAS and supports member states to implement the CEAS obligations properly.

Apart from these, the EU has also established some networks for home affairs policies and their exchange. These networks consist of state authorities, NGOs, and individuals. The most critical networks in terms of migration are the European Migration Forum (EMF), the European Migration Network (EMN), and the Radicalisation Awareness Network (RAN).

One of the most important topics associated with the EU border and security policy is FRONTEX's role. Léonard (2009) contributed to the European Agency's activities and institutional issues for the Management of Operational Cooperation at the External Borders of the EU Member States (FRONTEX). According to the author and the EU, FRONTEX is the product of the power struggle within the EU. FRONTEX aims to establish 'institutional configurations for increasing cooperation on external border management.' The European Parliament has only limited control over FRONTEX since the agency is not embedded in the governmental framework. The primary control mechanism is the budget.

Consequently, human rights issues have no priority in FRONTEX's work, which causes much criticism from human rights organizations. Léonard (2010) also evaluated FRONTEX's activities regarding the securitization of asylum and migration in the EU. The author's findings show that 'all main activities of FRONTEX can be considered to be securitizing practices.' The two primary securitizing practices are 'extraordinary activities borders' (e.g., the coordination of joint surveillance and control operations at the external border; fits both categories) and 'activities that have been implemented to security threats' (e.g., training of national border guards). However, FRONTEX is financially highly dependent on the EU Parliament and cannot be considered 'a significant securitizing actor in its own right'.

Nevertheless, migration and borders have gained more and more by pieces of knowledge in recent years. Ambrosini et al. (2020) provided a conceptual framework across the policy and public spheres. Cinalli and Jacobsen (2020) explained the role of borders for politics and citizenship, de Winden (2020) described the fundamental contradictions between 
borders and migration, and Müller (2020) investigated the thesis that borders created 'solidarity crime' in France. Even restrictive immigration laws could not stop crime from spreading. Other works focused on solidarity in transit-regions (Giliberti and Palmas 2020) and the medical staff's experiences at border hotspots for migrants (Anderlini 2020). Further contributions in this field came from De Nuzzo (2020) 'The Two Dimensions of the Border: An Empirical Study France-Italy,' Ambrosini (2020) 'The Local Governance of Immigration and Asylum: Policies of Exclusion as a Battleground.' Additional resources include Bonizzoni (2020) 'The Border(s) Within Formal and Informal Processes of Status Production, Negotiation and Contestation in a Migratory Context,' Marchetti 'Cities of Exclusion: Are Local Authorities Refusing Asylum Seekers?', and Oomen and Leenders (2020) 'Symbolic Laws, Street-Level Actors: Everyday Bordering in Dutch Participation Declaration Workshops.'

\subsubsection{The EU Turkey Deal}

On March 18, 2016, the EU-Turkey Statement was signed to control and limit Syrian refugees' continuous inflow to the EU through Turkey (EU Parliament 2016). Turkey has always been an essential transit-country for people fleeing from conflict regions in the Middle-East to Europe. Since the outbreak of the civil war in Syria, Turkey's role as a geopolitical power in the region has accelerated. The agreement says that all new (irregular) arriving immigrants on Greek islands are sent back to Turkey. The same applies to asylum seekers who have been declared inadmissible. For every illegal migrant the EU accepts, they agree to resettle one Syrian legally.

Furthermore, the EU-Turkey statement includes the following aspects: sea and land surveillance for irregular migration, activation of a Voluntary Humanitarian Admission Scheme, further development of Customs Union, and improvement of the Humanitarian situation for people inside Syria. In exchange, the EU has agreed on substantial financial support and visa liberalization for Turkish citizens. Under the Facility for Refugees, the EU guaranteed Turkey three billion euros and a further three billion euros by 2018. Nevertheless, the Facility for Refugees is supposed to be for concrete projects, such as an 'Emergency Social Safety Net' for the most vulnerable refugees. Primarily women and children, mainly orphans, and religious minorities such as Christians and Yazidis benefit from these actions. Finally, Turkey has also agreed to take back all irregular immigrants from Turkish waters and 
everyone who does not require durable protection. Thus, NATO has increased its enforcement activity in the Aegean Sea, and smugglers are aggressively prosecuted.

One year after implementing the EU-Turkey Statement, the number of asylum seekers from Turkey had tremendously decreased. Still, questions regarding international law and the protection of refugees remained unanswered (Adam 2017). Adam criticizes the EU, which does not recognize its responsibilities in terms of human rights, and the EU-Turkey relationship has become significantly worse. According to Poon (2016), Turkey cannot be considered a safe third country for refugees, and the EU-Turkey deal is not in compliance with international law. Turkey is not obligated to EU law and violates the principle of nonrefoulement. Thus, access to fair asylum procedures for refugees in Turkey is minimal. Lehner (2018) sees the EU's externalization approach as a direct consequence of the failure of the CEAS in the summer of 2015. The deal itself is risky and morally questionable. Tunaboylu and Alpes (2017) state that refugees returning from Europe who get detained fear deportation, have only limited access to aid, and do not get guaranteed international protection. Following Kfir's (2017) argument, the EU is further undermining Turkish democracy in its efforts to build a barrier against migration flows from Turkey by legitimizing President Erdoğan's autocratic tendencies.

Heck and Hess (2017), who interviewed stranded refugees in Turkey, observed Turkey's migration movements' deceleration to the EU. The authors describe Syrian refugees' situation as being 'trapped' between Turkey and the EU since many people are still willing to move on and, at the same time, do not get treated well by the Turkish government. The security situation remains unclear for them. Martin (2019) argues that the liberal values of the EU are under stress but stay intact. However, the damage is done and compromises the EU's identity to a certain extent. Thus, European values are flexible and may cooperate with autocratic regimes under extreme (geopolitical) pressure. According to Smeets and Beach (2019), the EU-Turkey Statement results from 'effective inter-institutional collaboration,' which makes it the opposite of other initiatives such as the Dublin reform or relocation of asylum seekers fail because of a lack of solidarity and burden-sharing issues. In 2020, President Erdoğan opened the borders to Greece, which made the EU-Turkey Statement obsolete. There are various reasons for the failure, and both sides blame each other for breaking the deal. The Tagesschau (2020) concludes that the EU did not fulfill all of its obligations, for example, freezing the negotiations regarding a possible Turkey EU membership. However, all the financial commitments were fulfilled. 
Indeed, the relationship between the EU and Turkey has always been complicated. In its effort to regulate migration inflows from the Middle East, the EU seeks partnership programs with third countries. As one of the most important transit countries globally and the host country of over four million refugees, Turkey plays a crucial role in these deliberations. However, the human rights issue was ignored and, therefore, strengthened Turkey's autocratic tendencies by legitimizing the Turkish regime. The EU undermined its identity and values by its inconsistent approach to migration and human rights. One reason for that development is the rise of the new populistic anti-immigration movements, parties, and political actors in the EU. The increase of anti-immigration streams is reflected in EU policy decision-making processes. Thus, the EU does not apply humane return and readmission principles anymore since the primary objective is to decrease, under all circumstances, the influx of asylum seekers and refugees to Europe.

Besides growing populism, burden-sharing is still one of the biggest problems in the EU. The EU-Turkey Statement responded to inefficient and inappropriate policy measures, which burdens some countries and regions more than others (e.g., because of the Dublin system). There is no functional distribution and allocation mechanism for asylum seekers and refugees among EU member states today. Every country is following its unique approach, and the consequences are weak and unfair policies. Therefore, EU migration policies are reactionary, and standardized proactive measures are rare. The EU-Turkey Statement attempted to delegate internal responsibilities to external actors instead of implementing efficient regulations regarding migration. The EU has never spoken with 'one voice' and attempts to balance the different interests among member states.

The EU is in an identity crisis and incapable of responding adequately to significant challenges like the influx of migrants from the Middle East. Inconsistent policy measures and non-uniform approaches to migration weaken the stability of the EU significantly. Burdensharing and security issues due to growing populism divide the union, hurt the EU-Turkey Statement, and lead to its failure from an EU perspective. There is still a need for a common approach regarding asylum seekers and refugees.

\subsection{Policy Situation}

\subsubsection{Growing Populism and Human Rights}

The current situation in the EU is highly problematic. There are many different interests, and the EU is still struggling to find a joint agreement. De Winden (2020) describes the actual 
conflict lines between Southern and Northern European states, between Brussels and antiimmigration states, and among civil societies, which are also very divided on mass migration. This result is consistent with Neumayer's (2004) findings, who found that migrants' recognition rate is higher when left-leaning governments are in charge. The other one is the failure among member states to renew the Dublin system in terms of burden-sharing. The arrival of refugees over the Mediterranean Sea in the EU is not a new phenomenon. Still, discord in finding a common approach made it impossible to find a sustainable and fair solution. The consequence was thousands of people drowning in the Mediterranean Sea every year. Thus, the migrants themselves have become a factor and demonstrate how dysfunctional the EU is since right-wing movements across Europe mobilize and agitate against refugees. However, these movements do not always have to be rational. Tétényi (2020) identified economic insecurity as a major driving factor for populist demands within the EU (and elsewhere), respectively the anxiety of (economic) risk. The mobilization against asylum seekers and refugees becomes a catalyst to express these insecurities, often resulting in a simple ‘we against them' narrative.

Although right-wing governments are gaining more and more influence, they were not successful in implementing a more restrictive asylum policy. Kaunert and Léonard (2012) investigated the EU asylum policy in terms of 'venue-shopping.' While it is often commonly assumed that national asylum policymaking was 'outsourced' to the EU level to implement a more restrictive approach concerning asylum seekers and refugees, the authors came precisely to the opposite conclusion. The movement to the EU policy venue has increased the legal standards and made the system more liberal. Thus, the EU asylum policy is embedded in a broader framework (e.g., other treaties like the Lisbon Treaty), and the consequences are an increase of judicialization and communitarization. The advocates of a more restrictive asylum policy could not anticipate these changes and could not reply favorably.

A similar approach was made by Thielemann and Hobolth (2016), who described the human rights situation of migrants. The authors analyzed the 'numbers vs. rights' model in developed countries by elaborating on counter-veiling trade-off dynamics. They found that vast numbers of migrants are more likely to be affected by human rights restrictions, while smaller numbers of migrants are not and even enjoy more rights. However, the authors found little evidence for this hypothesis by looking at data sets from Yugoslavia and Iraq and cannot fully confirm such dynamics. In terms of asylum and refugee policies, the model has minimal explanatory power. In conclusion, Thielemann and Hobolth argue that the model does not 
include the importance of non-majoritarian institutions such as the European Commission, the European Union Court of Justice, and the European Asylum Support Office. They suggest further research in this field of policy decision-making.

The latest efforts in the field of human rights and asylum seekers have been made by Thielemann and Zaun (2018), who argue that developments since 2015 have not decreased refugees' rights in the EU, but rather 'safeguarded' and 'enhanced' the existing standards. The authors base their hypothesis on the principal-agent theory and back it up with empirical research. The delegation of tasks to the supranational level makes non-majoritarian institutions more resistant to nationalist or populistic movements by embedding them in EU policies' framework. Overall, non-majoritarian institutions' influence has increased, but member states remain in charge of implementing EU policies, leading to highly diverse outcomes. Nevertheless, these dynamics often tend to be the lowest standard denominator solution, which usually strengthens refugee rights instead of restricting them. Following this explanation, even the so-called 'EU-Turkey deal' fits into this argument since many member states delegated power to the supranational level. However, this development is not unproblematic as the rise of right-wing or eurosceptic movements in Europe shows, even though many of these far-right claims could not be confirmed (see the findings of Tétényi et al. (2018), Moore and Shellman (2007), or Neumayer (2004; 2005) for instance).

In general, the EU is still seeking a common approach in terms of migration. The implementation of the CEAS was one attempt to reach such an agreement, but it failed. The 'anti-migration,' respectively 'anti-asylum seekers' atmosphere in many EU member states do not follow a common approach. Therefore, the priority is for the central part to reduce refugee movements under all circumstances, including human rights violations.

\subsubsection{Burden-sharing}

The previous chapters on EU policies demonstrate that the EU struggles to find sustainable and fair solutions regarding burden-sharing. Even the Commission does not deny that, and more or less, all allocation efforts of migrants have been failures to this day. According to Hatton (2016), who studied a significant amount of asylum applications in the Western world, the primary reasons for people to flee are war, violence, human rights abuse, and adverse economic conditions. However, he also addresses the ongoing discussion on a too-liberal asylum policy that would automatically lead to uncontrolled mass migration and argues that improving the living conditions at origin would have little effect. Therefore, from an EU 
policy point of view, Hatton says that only 'draconian policies' like in Australia will tremendously reduce asylum applications. The EU needs to focus on poor host countries and should encourage resettlement programs from refugee camps. Nevertheless, the capacities for refugees in developed countries need to be increased. At the moment, the burden-sharing in the EU is insufficient and very unequally spread among member states. More cooperation is required.

In this context, Germany's migration policy illustrates the vast differences from other countries' policies. Thielemann (2018) refers to Germany's open border policy for Syrian refugees in 2015 and emphasizes that traditional approaches are struggling to explain this policy. Thus, Thielemann focuses on the public goods theory to elaborate on the events of 2015. He argues that the Dublin system is free-riding and burden-sharing insufficient, respectively, even undermining fair practice efforts. Some countries have to carry a more substantial burden than others.

Furthermore, the EU institutions could contribute to multi-level dimensions by offering, for example, financial incentives for burden-sharing initiatives. Weaker EU member states should not feel that more prosperous EU member states can easily buy themselves out from any obligations. Overall, the EU needs to strengthen its unity and solidarity by implementing a new EU asylum system based on 'real' cooperation among member states.

However, burden-sharing is not the only issue and is not limited to EU countries. The burden should be shared with non-EU or non-European countries. Hampshire (2016) emphasizes the asymmetrical character of negotiations between vibrant (destination) and weak (origin) countries. Thus, Hampshire analyzed the EU's Global Approach to Migration and Mobility (GAMM) and its impact on external and internal relations and international cooperation. Because of complex frameworks, many different institutions, and last but not least, endless diverse interests among EU member states, the EU struggles to reach satisfying and sustainable agreements with third countries. Three internal factors play a pivotal role in this context: 'contrasting approaches of the Commission and Council to the external dimension,' 'diversity of member states' interests in migration policy,' and 'different policy agendas of the European agencies' (572-573). As a result, many regulations are not enforced. Therefore, Hampshire calls the EU 'a less promising vehicle for international migration cooperation than bilateral interstate negotiations' (584).

Last but not least, international organizations and cooperation with them become more and more critical. Lavenex (2016) sheds light on the increasing importance of EU cooperation 
with international organizations such as the IOM or UNHCR in the context of multi-leveling migration policies. Both the IOM and UNHCR have become significant strategic partners over time, and the EU now cooperates with them daily concerning legal migration, irregular migration, and development. In general, the author distinguishes between three main strategies: 'counterweight, whereby international organizations act as independent complement or corrector to EU policy; subcontracting, referring to the outsourcing of EU project implementation to international organizations; and rule transmission, a process in which international organizations engage in transferring EU rules to third countries' (555556). Thus, the UNHCR and IOM are highly involved in EU migration policies by subcontracting and rule transmission.

\subsection{Conclusion}

Although some accomplishments, without a doubt, have been made since the implementation of the 'common' EU migration policy, many uncertainties remain. Several studies suggest that migrants' rights have improved in the EU (see chapter 4.3.1). Still, the recent trend of anti-immigration governments gaining more influence can also not be ignored. In general, the perception of migration is always very negative. Indeed, the EU is trying to fight for the best talents worldwide to increase its competitiveness globally. However, unqualified refugees or asylum seekers are very often not welcome.

An utterly blind spot in the EU migration policy is which role the EU and its member states play in the 'production' of migration flows. Global warming, armed conflicts, and poverty are neither new nor surprising developments. In many ways, the EU is even benefiting from that but is also unwilling to deal with the consequences. For example, the current economic growth rates and the living standard in the EU can only be sustained because of exploitation and waste of resources, which accelerate global warming. ${ }^{41}$ Moreover, the consequence of global warming is more and more migrants. As yet, the EU has not developed a plan for stopping this trend, and previous approaches to manage migration were not successful.

\footnotetext{
${ }^{41}$ Indeed, the EU growth rates have recently slowed down, and the EU is also investing a lot of resources in the implementation of renewable energies.
} 
Another surprising point is that the EU has not defined a response on the issue of demographic problems. While some rural regions are bleeding out, metropolitan areas continue to grow (Rink et al. 2014). The consequences are growing disparities and more tensions among civil society. On the one hand, in many EU countries, the population is shrinking. On the other hand, countries with a shrinking population like Poland deny migration from the Middle-East but promote movement from Asia or Ukraine to keep their living standards high. Even tourism has become a problem in certain regions since some popular holiday destinations are just overwhelmed by tourists and visitors, leading to many tensions with locals (The Guardian 2020a).

To begin, the whole EU, every single member state, should start to define goals in terms of population size for every country, every region, and every city. Based on this, the EU could start discussions for upcoming migration issues by developing a fair balance mechanism, considering both external and internal migration. By no means should people be 'forced' to move to different places - however, the EU can provide incentives and foster migration destinations.

The following 'Migration Balance Model' that I created explains this approach.

Table 6: Migration Balance Model

\begin{tabular}{|l|l|l|}
\hline \multicolumn{3}{|c|}{ EU Policy Measures } \\
\hline \multicolumn{1}{|c|}{ Burden-sharing } & \multicolumn{1}{|c|}{ Security } & \multicolumn{1}{|c|}{ Actual Policies } \\
\hline \multicolumn{1}{|c|}{ Burden-sharing, security, and actual policies lay the foundation for efficient, fair, and } \\
appropriate policy measures in terms of migration.
\end{tabular}


terms of in- and out-migration leads to stability and balances the internal migration system.

Migration Balance

After identifying the migration balance, the allocation process of asylum seekers and refugees comes into place. The next table explains how asylum seekers and refugee allocations build on the 'Migration Balance Model.' Firstly, states are supposed to identify poorly or overly populated regions. Based on this, the allocation process takes place, considering different hard and soft factors (see Migration Balance Model). Thus, fair and efficient burden-sharing measures can be established according to my Asylum Seekers and Refugees Allocation Model.

Table 7: Asylum Seekers and Refugees Allocation Model

\begin{tabular}{|l|l|l|}
$\begin{array}{l}\text { Countries, regions, and } \\
\text { places that are proportionally } \\
\text { over-affected by out- } \\
\text { migration. }\end{array}$ & $\begin{array}{l}\text { Number of Asylum Seekers } \\
\text { and Refugees }\end{array}$ & $\begin{array}{l}\text { Countries, regions, and } \\
\text { places that are proportionally } \\
\text { over-affected by in- } \\
\text { migration. }\end{array}$ \\
\hline $\begin{array}{l}\text { Allocation Mechanism based on economic power, life quality, and the ratio between in- and } \\
\text { out-migration (migration balance) }\end{array}$ \\
$\qquad \begin{array}{l}\downarrow \\
\text { On the EU-level: fostering and promoting the settlement of asylum seekers and refugees } \\
\text { based on fair quotas. }\end{array}$ \\
\hline \multicolumn{2}{|c|}{$\begin{array}{l}\downarrow \\
\text { Fair and efficient burden-sharing among member states }\end{array}$} \\
\hline
\end{tabular}

In general, this chapter analyzed the main EU policy measures and debates on asylum seekers and refugees, including legal and irregular migration, the CEAS, and the Schengen and Dublin regulations. The findings show that the EU's initial efforts promoted migration for the domestic labor market and reduced asylum seeker movements. Many member states approach migration as part of their sovereign rights and do not apply conventional European approaches. In the past 20 years, migration, both internal and external, has continuously been a significant issue among EU member states. Whereas some European countries benefit from well-educated, young, and skillful migrants, other member states are suffering from brain drain and intellectually 'bleed out.' Notably, the Southern and Eastern European nations are negatively affected by this migration. Hence, migration in the $21^{\text {st }}$ century is highly selective, 
and the competition is for the most exceptional talents in every discipline. Migrants are evaluated by their economic exploitability and their value on the domestic labor market.

On the other hand, asylum seekers and refugees are often 'not welcome,' and even EU member states with old demographics do not accept them because of cultural, religious, or economic reasons. Therefore, the EU is in the paradoxical situation that some parts of the EU are proportionally overburdened by migration influx from the Middle East and the African continent, while others desperately suffer from out-migration.

The EU aims for partnership programs with non-EU countries as an instrument to reduce migration movements significantly. These programs grant beneficial treatment in terms of economic advantages in exchange for agreements on migration issues. Partnership agreements have become crucial geopolitical tools and are one opportunity to influence foreign governments, decision-makers, and politicians. Regarding irregular migration, the EU focuses mainly on smuggling and human trafficking and seeks to destroy their business models. However, the smuggling business is not a black and white situation since many migrants have a close relationship with their smugglers.

Moreover, the EU consistently worsens asylum seekers' situation by implementing restrictive policy measures for entering the EU legally and pushing them into irregular migration. Some of these actions even have a contradictory effect and increase irregular migration instead of decreasing it. The consequences are human rights violations of asylum seekers and insufficient policy measures.

Consequently, the application of a functional CEAS does not exist. EU institutions and actors are not speaking with the same voice as member states, making the EU's approach to migration inconsistent. Nevertheless, authors like Zaun (2016) see some slow progress concerning human rights in the long-run, whereas others, e.g., Thornton (2014), emphasize the negative aspects of asylum seekers' treatment in the EU. Overall, the 'Schengen crisis' (Börzel and Risse 2018) and the inadequate Dublin regime need reforms towards more consistency, fair burden-sharing, and solidarity. 


\section{Conditions in Camps}

This chapter investigates the conditions in camps. To describe the situation in the camps, articles and reports from journalists, reporters, and others are referenced. Refugee camps from non-EU countries Turkey, Lebanon, and Jordan will be covered. Refugee camps from Greece and Italy (EU countries) will complete the coverage. Every country section starts with an overview of all the crucial data. It delivers numbers, figures, and statistics by explaining how many refugees currently live in the country and how many of them live in camps. Secondly, the funding of refugee camps is a priority. Refugee camps are continually struggling with funding and do not have enough resources to provide to living persons. The third part goes into more detail and aims to analyze the camps' living conditions. The relevant criteria are basic human needs. Thus, nutrition, freshwater supply, education, and security are germane factors.

Furthermore, it should be considered that notoriously shocking cases or extraordinarily positive cases enjoy more coverage in the media than the usual daily average life in the camps. A highly sensitive topic like this does not make it easy to find reliable sources, but existing constraints do not allow another procedure. However, I tried to describe the situation in the camps as fairly and objectively as possible. Last but not least, each country's sections end with a short conclusion. This chapter builds the foundation for chapter number six, which looks into camps' conditions by elaborating on conducted interviews.

The chapter concludes with a comparison between camps and further discussions, including some recommendations for improvement.

\subsection{Non-EU Camps}

Before I start with the analysis of living conditions in camps, it is important to note that refugees' and asylum seekers' legal status is diverse, which also has some implications regarding living conditions. Frangieh (2016) states that most Middle East countries have not signed the Refugee Convention (1951). He criticizes the lack of refugee protection and the legal framework's ineffectiveness regarding asylum policies. However, Middle East countries still conform to international human rights treaties. They operate in the bilateral Memoranda of Understanding (MoUs) framework, signed between the UNHCR and governments of states like Lebanon and Jordan. The MoUs includes and regulates mainly three aspects of asylum policies: 
- Non-refoulement: A refugee's status recognized by the UHNCR does not prevent people from being deported since Lebanon and Jordan constantly maintain the threat of refoulement. In 2012, Lebanon suspended the deportation of Syrian refugees. On the other hand, Jordan followed a more strict asylum policy and even deported children or injured people back to Syria.

- Legal status: Legal refugee status does not grant residency in the host country. Although refugees can obtain a temporary stay in both countries, their status remains precarious in practice. Refugees are under the constant threat of arrest for immigration law violations.

- Right to work: The UNHCR is responsible for providing aid for refugees in Lebanon and Jordan. Refugee's capacity to work is strictly limited due to labor market reasons (competition for cheap labor), which keeps them dependent on aid organizations. In reality, refugees often make their living through the black labor market, and they are at risk of getting arrested for working illegally.

The domestic legislation dealing with asylum seekers and refugees is the 'Law Regulating the Entry and Stay of Foreigners in Lebanon and their Exit from the Country' from 1962 in Lebanon, and 'Law No. 24 of 1973 concerning Residency and Foreigners' Affairs' in Jordan (Saliba 2016a; 2016b). International organizations criticize both Lebanon and Jordan for their asylum and refugee policies: 'Refugees enjoy few, if any, legal rights in Lebanon.' (UNHCR 2010)

Or:

'Jordanian law makes limited references to asylum seekers and refugees. Despite having the highest ratio of refugees to citizens in the world, Jordan has not signed the Refugee Convention of 1951 or its subsequent 1967 Protocol. Several concerns are usually cited over Jordan's non-signatory status, including the politically and socially complex-and yet unresolved-Palestinian refugee issue, popular sentiment against refugee integration, lack of resources and capacity to provide for refugees, and misinformation about the perceived social and economic burden of refugees and related questions of national security. [...] In practice, Jordan avoids the official recognition of refugees under its domestic laws and prefers to refer to Syrian refugees as 'visitors,' 'irregular guests,' 'Arab brothers' or simply 'guests,' which has no legal meaning under domestic laws, and was the same for Iraqi refugees under the MOU. This was further confirmed in an interview with the MOL [Ministry of Labour], Labour Inspection department.' (ILO 2015) 
Frangieh (2016: 43) concludes, 'The refusal of Jordan and Lebanon to assume long-term responsibility for refugees is the major obstacle against establishing a stable and favourable refugee protection regime.' The other major issue is, once again, burden-sharing between the host states and the international community. Lebanon and Jordan are willing to provide minimum living standards based on state-to-UN responsibility (MoU), but only if their responsibility ends at some point, and the international community shares this burden with them.

Regarding Turkey, the case is slightly different. Even though Turkey signed the Geneva Convention in 1951, the Turkish state did that with the limitation of only granting asylum status to European refugees (after World War II). According to Zeldin (2016), Turkey's migration policy focuses on Europeans and people with Turkish roots (Turkish Law No. 2510). Thus, current asylum seekers only get 'temporary protection' and usually are not allowed to apply for citizenship. After completing a successful interview with state authorities, asylum seekers are placed under 'temporary protection' for six months. The 'temporary protection' status is supposed to satisfy refugees' basic needs and provides social services, translation services, IDs, travel documents, access to primary and secondary education, and work permits. The state authorities decide whether and where applicants have to live in reception centers (camps), and people are obliged to report their location regularly. However, Zeldin also describes some of the interviews between asylum seekers and state authorities as 'misleading on purpose,' leading to the rejection of some asylum applications.

İçduygu (2016) criticizes the Turkish asylum and refugee policy as follows:

\footnotetext{
'Turkey allows the [...] (UNHCR) to operate and conduct refugee status determination [RSD] procedures whereby refugee status is jointly granted by the UNHCR and the Ministry of Interior with the underlying condition that accepted refugees do not locally integrate but instead resettle in a third country. Considering its geographical proximity to conflict-ridden states, Turkey's geographical limitation disqualifies a vast number of asylum seekers and refugees seeking permanent protection from the Turkish state.' (Zeldin 2016)
}

Finally, in the EU, the AMIF and ISF funds provide financial assistance for states hosting refugees and asylum seekers in camps. Furthermore, a comprehensive set of rules, laws, and migration policies manages migrants' inflow and status (see chapter 4). 


\subsubsection{Turkey}

\section{Figures, Numbers, and Statistics}

The number of registered Syrian refugees living in Turkey was 3,285,533 in 2017 (UNHCR 2017a). In comparison to 2015, with 1.7 million Syrian refugees, the number of refugees has almost doubled. From the nearly two million refugees in Turkey in 2015, 250,000 were living in one of the 25 refugee camps (the rest were spread across the country). The WFP provided food and clean water for 154,000 people in eleven camps (2015). In 2020 (January), there were 3,576,344 registered Syrian refugees (4.1 million refugees in total) in Turkey, which is a significant increase. The actual number of Syrian refugees living in South-East Turkey camps is approximately 65,000 people (UNHCR 2019c). Figures for the entire country are not available.

\section{Funding}

The reason for the relatively high standard of living in Turkish refugee camps is not due to the efforts of the UNHCR, but due to the Turkish state initiative. The Turkish government received guidelines (minimum distance between tents, et cetera) from the UNHCR and then designed the camps independently. This approach has the advantage that Turkey remains in control of every detail. This procedure is cost-intensive but also highly effective. While NGOs, who are usually running refugee camps, often have to deal with local bureaucracy, inefficient structures (many countries are involved), and insufficient funding, a relatively wealthy state can quickly fulfill the requirements (McClelland 2014). The actual figures concerning the UNHCR funding requirements in 2020 confirm this observation. The data available are currently for the years 2012 to 2018. The international community could not fulfill the funding requirements in this period, even though funding has increased tremendously in recent years. In 2018, Turkey received almost 1.5 billion USD, which was still not enough to close the gap (UNHCR 2020b).

\section{The Situation in the Camps}

According to the New York Times (McClelland), in 2014, Turkey's refugee camps were in pretty good condition. The Turkish government built container camps at record speed with at least minimum standards, including cleanliness, brand new brick paths, street-washing trucks, power lines, streetlights, housing maintenance, and playgrounds for children. Furthermore, 
the camp in Kilis provided education for 2,225 students, sometimes at a higher standard than in the school in Syria (McClelland 2014). However, the situation outside the camps remained devastating, and many people left the camps. Many of the refugees were living on the streets or in shanties.

In most cases, it is unknown where they lived. According to Onur Burçak Belli (2015), a reporter from the FAZ who observed the situation in Istanbul, Ankara, Adana, and other Turkish cities, most Syrian refugees' standard of living is much worse than in camps. She reported that children very often became the primary income source for families. Indeed, child labor is not a new phenomenon in Turkey, but the level of exploitation was exceptionally high since most Syrian children are traumatized and barely speak the Turkish language. Another issue was the rising tension within society because of the extraordinarily high number of immigrants (Topçu 2015).

Before Turkey's current situation, the Turkish government had anticipated the imminent crisis much better than other countries and was, respectively, far better prepared. While Jordan or Lebanon have had to struggle with epidemics, diseases, and other urgent health issues, Turkey managed to establish a well-functioning and highly-effective health care infrastructure to respond adequately to the mass migration from Syria. In fact, the Turkish state is economically much more robust when compared to Lebanon and Jordan. Therefore, the funding was not such a big issue as in other countries (Sahlool et al. 2012).

Although the Turkish state covers the basic needs of Syrian refugees in camps, there are also some criticisms like food poisoning, insufficient distribution of tents and essential goods (e.g., soap or toothpaste), and Turkish soldiers' insults, et cetera. In general, Özden (2013) believed that wealthier Syrians prefer to live outside the camps by renting apartments, while the not so wealthy stay in the camps. Consequently, especially in Southern Turkey (close to the Syrian border), the costs of living and unemployment have increased, which might lead to local conflicts between Syrians and Turks (Cagaptay 2014). Many Syrians live in extreme poverty or become homeless after running out of money in a short period. Nevertheless, compared to 2012, the Turkish government has intensified its cooperation with international help organizations, involving FAO, IOM, UNDP, UNFPA, UNHCR, and UNICEF to provide more assistance for a refugee living inside and outside the camps (Kirişc 2014).

Nevertheless, Turkey was overwhelmed by the inflow of Syrian refugees. At the beginning of the crisis, almost all refugees lived in camps. By the end of the year 2014, 
approximately 80 percent of Syrian refugees lived outside the camps, which shows that the Turkish government had distribution struggles before the refugee crisis in Europe had broken out. İçduygu (2015) stresses that Turkey should not be left alone to solve the crisis. Still, only sharing the international community's burden can significantly improve Turkey's Syrian refugees' situation.

In recent years, it has become much more difficult to find any new information about refugee camps since Turkey has drastically transformed under President Erdogan. However, Turkey's media are praising their camps' conditions as modern facilities with clinics, schools, libraries, mosques, football pitches, playgrounds, and protection centers for children, including quotes from satisfied inhabitants (Anadolu Agency 2019). However, the Turkish government followed the plan to send one million refugees back to Syria (Gall 2019). Even though some skepticism seems appropriate, the overall positive impression can be confirmed by Franck Düvell, a consultant of the EU Commission and the EU Parliament. In an interview with German state television, he said that Turkish Camps' conditions are much better than, for example, in Greece (ZDF 2020). In March 2020, the Turkish U.S. ambassador stated 'stopping the spread of the Coronavirus is mission impossible' and demanded help from the EU due to the Turkish state's limited resources (De Luce 2020).

\section{Conclusion}

In 2015, Baban et al. wrote that Turkey's Syrian refugees demanded more rights and even asked for citizenship and more participation in society. In December 2019, the BBC quoted the Turkish president Erdogan: 'If the violence towards the people of Idlib does not stop, this number [refugees] will increase even more. In that case, Turkey will not carry such a migrant burden on its own.' He continued: 'The negative effects of this pressure on us will be an issue felt by all European countries, especially Greece.'

Although Turkey anticipated the crisis very early and was well-prepared for the considerable migration inflow from Syria, the situation remains tense. It is not surprising that even a big state like Turkey has reached its limits. The camps' situation might be relatively okay, but Turkish state authorities still call Syrian migrants only 'guests.' Therefore, the integration in the labor market and other parts of society was not successful, which cannot be a long-term solution for anyone since the Middle East conflicts will not end shortly. Consequently, migration will not stop either, and Turkey needs to find a way to balance the situation. It is not very likely that Syrians will continue to accept their status quo. More new 
conflicts within society between the home population and the host population might occur as well. Erdogan's recent comments are politically motivated, addressing the Turkish community but also Brussels. The President wants to demonstrate strength to Brussels. The EU-Turkey deal opened the EU to blackmail. The threat of opening the Turkish borders is not new. However, it is still a useful tool to protect Turkish interests, and Europe cannot respond to Turkish military offenses against the Kurds. At the moment, Turkey is not sanctionable for its actions because Brussels authorities fear the EU could be once again overwhelmed with Syrian migration flows with unpredictable consequences.

In conclusion, refugees and asylum seekers have become a political issue used for political interests. Kelly Greenhill (2010) refers to these practices as 'Weapons of Mass Migration' in terms of forced displacement, coercion, and foreign policy. In an interview from 2015 (Cicero), Greenhill herself confirmed that Turkey uses methods and strategies described in her book; refugees as a 'weapon' to destabilize other countries or regions.

\subsubsection{Lebanon}

\section{Figures, Numbers, and Statistics}

According to the UNHCR, 1,001,051 registered Syrian refugees lived in Lebanon in 2017 (UNHCR 2017b). Compared to 2015, with 1,150,000 Syrian refugees, the number has not significantly decreased (Amnesty International 2015). However, the real number is probably tremendously higher. For instance, SPIEGEL ONLINE reported in 2015 that Lebanon is hosting approximately 2 million Syrian refugees in a country with a population of 4.5 million inhabitants (Salloum 2015). Every fifth person in Lebanon is a refugee, which makes Lebanon, per capita, the biggest host country for refugees in the world (Rainey 2015). In the meanwhile, the numbers have slightly decreased. There are still 914,648 registered Syrian refugees living in Lebanon (UNHCR 2019d). The hotspots for refugees are Bekaa (37 percent of the total population are refugees), North Lebanon (26.5 percent of the total population are refugees), Beirut (24.5 percent of the total population are refugees), and South Lebanon (11.4 percent of the total population are refugees) (UNHCR 2019d).

\section{Funding}

Private organizations and institutions like Women Now or Sawa for Syria have assumed the state's role and built their own refugee camps in Lebanon (Molter 2016). These organizations depend on donations, the same as the UHNCR does. Despite worldwide financial support, the 
funding of these help organizations is continuously wanting. For example, the UHNCR has only covered $30 \%$ of its 2 billion USD funding requirements (November 2017) (UHNCR 2017b).

Furthermore, most refugee camps are not official camps but are only tolerated by the Lebanon state. Private owners of the land are letting some of their ground for the establishment of refugee camps. One family's price per month is usually 100 USD - just for the allowance to set up a tent. For a family that has lost everything in war, this is a tremendous amount of money, and they still need nutrition and clean water (Molter 2016). The latest data available (2018) shows that the situation has become worse (UNHCR 2019d). Because the funding has remained more or less stable from 2015 to 2018, the gap has increased. The financing received in $2018 \mathrm{did}$ not even cover 50 percent of approximately 2.2 billion USD requirements. Thus, the biggest host country per capita of refugees is still tremendously underfunded.

\section{The Situation in the Camps}

The state of Lebanon changed its migration policy in the year 2015. Since then, the UHNCR is not allowed to register any Syrian refugees. Thus, the Lebanese state is incapable of hosting such a considerable amount of fleeing people and provide them sufficient food, water, health care, et cetera. The UN reported as early as December 2015 that some 70 percent of the over one million Syrian refugees in Lebanon now live below the Lebanese extreme poverty line“ (UN 2015).

Molter (2016) reported from Bekaa, where approximately one million Syrian refugees (temporarily) lived in refugee camps in 2016, that the camp administration can provide enough food and clean water. Nevertheless, the situation can change instantly, and everything else is in peril. For instance, only $30 \%$ of 400,000 Syrian refugee children can attend school because of limited classroom capacity. Many children have to work to support their families financially. Therefore, child labor is pretty standard, as is prostitution. The UHNCR can only provide 13 USD per month for one family, and because of funding issues, the trend is negative. Thus, the UN refugee organization is not a big help. Many of the help organizations themselves migrate to Turkey because their work registration is easier (Molter 2016).

Concerning health care, Lebanon did have proper infrastructure, including 165 hospitals, 158 primary health care centers, and well-educated employees in 2013 (El-Khtatik et al. 2013). Ammar et al. (2016) came even to the conclusion that the Lebanese health system 
did not even sustain its performance but even improved it. Overall, Lebanon's primary health system was functional but also costly before the crisis intensified in 2015. Regardless, the more prevalent, chronic, non-communicable health care needs made the country struggle. Lebanon was already over-allocated during that time since the country had to host Palestine refugees as well. One of the significant challenges is to provide long-term support, while after natural disasters, only emergency help is required (El-Khatib et al. 2013). Thus, Lebanon could not fulfill all these requirements anymore, and, consequently, the outbreak of leishmaniasis occurred in 2012. Saroufim (2014) concluded that "poverty, malnutrition, population displacement, weakened immunity, and inadequate housing are all risk factors for cutaneous leishmaniasis.'

Additionally, Lebanon has a long tradition of distribution battles between refugees (mostly from Palestine) and the hosting community. According to Halabi (2004), the camps' population competed for scarce resources, including employment and housing. Palestinian traders did not have access to markets surrounding the camp. The markets have been occupied mainly by Syrian traders and only offered outdated food products for Palestinians. Furthermore, the outbreak of other conflicts in the ' 60 s leads to a greater struggle over housing. The consequence was the establishment of illegal camps creating structures with high conflict potential (Halabi 2004). This problem has never been solved and shows some significant similarities to refugee camps' current Lebanon issues. The global community has ignored the demand for help from Lebanon for decades, and considerably underfunding of refugee camps still does.

Recently, the situation for Syrian refugees in Lebanon has even become worse. Foreign Policy reported in 2019 that the Lebanese government had intensified its repressive policy against Syrians, including demolishing buildings in- and outside of camps and crackdowns in Beirut. For example, in July 2019, the Lebanese army destroyed 20 Syrian shelters in the Arsal region (Human Rights Watch). The order affected around 3,500 to 3,600 people, who were not able to provide the necessary paperwork to prevent the destruction. Human Rights Watch also reported on repression by the army and arrests. Inhabitants of shelters claimed that actions were politically motivated.

Lebanon is struggling economically with high unemployment rates, but the tensions within society have also increased in terms of nationalism and xenophobia (Vohra 2019). These circumstances resulted in deportations back to Syria, where Syrians can expect, in the worst-case permanent arrest, torture, or death. The expulsion of refugees gets criticized by 
many NGOs. Nevertheless, more and more Lebanese citizens agree with these policy measures and practices since the country's already insufficient infrastructure has suffered more after the Syrians' influx. Lebanon feels still left alone with the crisis. President Michael Aoun said in 2019: 'The wave of Syrian displacement has produced negative repercussions that have impacted all Lebanese sectors,' as well as 'the return of refugees can't wait for a political solution to the Syrian crisis' (Human Rights Watch 2019). In 2020, Beech and Hubbard reported for the New York Times that camps in Lebanon are running out of soaps and other necessary hygienic materials, which makes adequate handwashing nearly impossible. Thus, thousands of people are defenseless in times of spreading pandemics.

\section{Conclusion}

Although no other country in the world has probably more experience with refugees and camps, Lebanon is, without a doubt, not able to manage the crisis by itself. Lebanon is too small and cannot provide proper accommodation, nutrition, and opportunities. Even the necessary funding requirements are not getting fulfilled by the international community. Thus, the economy and infrastructure are overwhelmed by the significant number of Syrian refugees in the country. Unfortunately, the war in Syria is not likely to stop in the next few years. Since the outbreak of the crisis, the number of refugees has only slightly decreased. However, the actual number even remains unknown because the Lebanon government has stopped cooperation with UNHCR to a certain extent.

Pictures and reports from refugee camps are devastating, which is not surprising, keeping in mind how bad the country's funding and overall situation is. It is not very likely that mass deportation back to Syria will occur. Nonetheless, the tensions within society are rising as well. Distribution battles over scarce resources are nothing new in Lebanon, but another conflict's potential is present. If the situation worsens, new migration waves to Turkey and Europe will be the consequence. Dionigi (2016), who analyzed the Lebanese situation, states that long-term strategies are needed for welfare programs for both Lebanese and Syrians. He concludes: 'Failing to appreciate the urgency of this issue will inevitably expose Lebanese governance to further strains and increase the precariousness of Syrian presence in Lebanon. This will have the effect of protracting the current crisis and potentially lead to even more regional instability' (Dionigi 2016: 33). 


\subsubsection{Jordan}

\section{Figures, Numbers, and Statistics}

Jordan is the third country in this case study that is profoundly affected by refugee movements. According to the UNHCR, there are were 654,877 Syrian refugees in Jordan in November 2017 (UNHCR 2017c). Compared to 2015, the number of refugees $(620,000 ; 84 \%$ in refugee camps) has slightly increased (Francis 2015). In 2020, the number of Syrian refugees in Jordan increased again $(655,435$ people in total) (UNHCR 2020c). The hotspots are the Amman Governorate (193,399), the Mafraq Governorate (162,317), the Irbid Governorate $(134,651)$, and the Zarqa Governorate $(94,809)$. One hundred twenty-three thousand six hundred fifty-one people live in refugee camps, and 531,784 people live outside of camps. Since 2014, the number of Syrian refugees in Jordan remains stable.

\section{Funding}

The UNHCR funding requirement for 2017 was approximately 1.2 billion USD, which was 42 percent covered (UNHCR 2017c). Thus, the coverage rate is, compared to Turkey and Lebanon, relatively high. However, considering the country's tremendously big problems, it is still just a drop in the ocean. In 2018, the latest data available, the funding situation has improved slightly since the requirements have also decreased (UNHCR 2020d). Overall, the situation since 2013 is tense, and no funding requirements have been fulfilled in recent years.

\section{The Situation in the Camps}

Similar to Lebanon, the Jordan state fails to provide sufficient security for the immigrants. Even before the crisis in Syria, Jordan was struggling with massive economic and political instability. Therefore, the situation has dramatically worsened since 2015 . The Jordan state cannot provide proper accommodation for refugees since most people live not in camps but rather in 'host communities' (Francis 2015). Since 2014, the Jordan government has highly restricted access to the country for Syrian refugees because the Hashemite Kingdom feared national instability due to the growing number of refugees and camps along the border with Syria. Thus, the tensions between the UNHCR and the Jordan regime have started to rise. Jordan's problematic situation makes it difficult for the UNHCR and other organizations to improve people's lives in refugee camps (Francis 2015). 
Jordan has a long history of almost six decades with refugee camps since it is one of Palestine's primary host countries. The unclear political situation makes it difficult, if not impossible, to implement a proper urbanization strategy for those camps. Nevertheless, due to the country's long hosting experience, some of these camps have developed the character of small cities or towns. Indeed, many buildings, streets, and housing opportunities have been improvised and do not provide proper accommodation, but there has undoubtedly been some development of some necessary infrastructure for inhabitants (Tawil 2006). However, the Syrian refugee crisis exceeded Jordan's financial ability to meet the requirements since Jordan was already incapable of managing the decades of refugee movements from Palestine. For instance, the Zaatari camp, the biggest Jordanian refugee camp for Syrians, had already struggled in 2011 to provide enough food, sanitation, and water. The registration process of Syrian refugees takes months (El-Khatib et al. 2013). As a consequence of these adverse conditions, some refugees went back to Syria or are living now in other (unregistered) improvised tenant camps spread over the country - without any access to nutrition or water (Achilli 2015).

Two years later, the dramatic situation in Jordan has not significantly changed. Musharbash (2017) claims that aid organizations have only limited access to the 'improvised" camps and are still incapable of providing enough support. Compared to Turkey and Lebanon, tens of thousands of people (mostly children and women) have no access to clean water and food. Furthermore, terrorist attacks happen regularly in the camps. There has been no support from help organizations since 2016.

Consequently, diseases and child mortality have spread through the camps because of the lack of health care. At the beginning of the year, there was some small success concerning these issues. However, the UNHCR is still many kilometers away, and most of the emergency supplies could not be delivered due to distribution problems and bad weather. In addition to domestic policy issues and inadequate infrastructure in Jordan, the camps' insecure situation is significant. Jordan estimates that ten percent of the refugee camps ${ }^{6}$ population are militant groups, including the IS. Another issue is a border dispute between Jordan and Syria, making it difficult to determine in which country the refugees are currently located (Musharbash 2017). UN officials call this region no-man's-land.

A report from the WFP from 2019 shows that the situation has not become significantly better. 40,000 Syrians are 'caught' between the border in Northeast Jordan and Syria. These people are highly dependent on aid organizations like UN agencies or other 
NGOs, which try to provide food and fresh water in an insecure environment. Many camps are hard to reach. In 2018, the WFP delivered essential aid to a camp in Rukban. Although this delivery saved many lives, aid organizations could not supply the region anymore, and an unknown number of children died due to preventable reasons. The Zaatari camp, just 16 kilometers from the Syrian border, has become the second-largest refugee camp in the world and the fourth biggest 'city.' In total, 78,000 Syrians live here in improvised shelters. 500,000 Syrian refugees (approximately half of them are children) in Jordan are dependent on cash and food vouchers from WFP (the WFP also provides bread to families in camps).

Nevertheless, some small accomplishments have occurred. The WFP has established a 'healthy food program' by using homegrown food for children and providing women jobs. Furthermore, the WFP has supported the Jordan economy with approximately 580 million USD since 2016.

Al Jazira made another interesting observation in 2018. The Zaatari camp has developed its own infrastructure and economy (Lee 2018). Life in the camp has become 'normal' to a certain extent. There are supermarkets, shops, cafes, and even restaurants. The NGOs' activities have also become part of their life, and the youngest members of the community have never experienced anything else. According to Lee (2018), there are 3,000 various shops and small businesses in the Zaatari market, which becomes even more remarkable by considering the inhabitants' average young age. Miller and Singh (2020) for CBS News quoted a humanitarian worker who has been working since 2012 in the camp, with the following words: 'None of us should ever be okay with calling this normal. But it's become an accepted reality for a lot of people.' Fafo (2019a; 2019b) concludes that Syrians' situation in Jordan has improved recently after analyzing factors of health, education, employment, and prospects for return. However, three in ten are still considering moving to Europe. In March 2020, the Jordan government placed the whole camp under lockdown to measure the fight against the Coronavirus (Cuthbert 2020), leading to distribution issues of essential products.

\section{Conclusion}

The situation in the refugee camps in Jordan is, in many aspects, extraordinary. First, the proximity of the Zaatari camp to Syria. The vast majority of other Syrian refugees preferred destinations that are farther away from their origin. Unfortunately, there is no research on motivation. However, one possible explanation could be that people originally only planned 
for a short-term stay and still hope Syria's conflict might end shortly. Another possibility is that people had no other choice and are now stuck in the region, as reports from the WFP (2019) suggest. Second, the extremely young average age of the inhabitants is unusual. Third, the socio-economic character of the Zaatari camp is unique.

Dalal (2015) investigated this socio-economic character of the urbanization of the Zaatari camp in Jordan. He came to the conclusion that camps tend to develop their character, and socio-economic dynamics are emerging. Thus, former empty spaces have transformed into markets, cafés, and shops in less than ten years. Or in other words, people have built up their own economy and infrastructure from scratch in a short period. Although there have even been some terror attacks in the past, social life has developed, too.

Nevertheless, although people have managed to arrange their presence there, the conditions are still appalling in many ways. Again, aid organizations are underfunded, and Jordan state does not have the resources to provide proper living conditions for everyone. On the surface, it might look like a sustainable solution for the future, but it is not.

The country of Jordan is another country overwhelmed by the number of Syrian refugees. The majority of the young Syrian population needs support from aid organizations, and there are only a few work permits for Syrians in Jordan. However, the case of the Zaatari camps remains especially exciting. If people cannot get integrated into the Jordanian society and will not get the opportunity to go back to the origin, independence movements could be the consequence.

\subsection{EU Camps}

\subsubsection{Greece}

\section{Figures, Numbers, and Statistics}

According to the UHNCR, there are currently 112,300 refugees or migrants in Greece, 71,200 on the mainland, and 41,100 on the islands (UHNCR 2019e). In 2019, the number of new arrivals increased significantly by 50 percent or 74,600 people compared to the previous year. Most of the new arrivals are families with children from Syria or Afghanistan. The camps on the islands are tremendously overcrowded because 36,400 people share the space in camps initially designed for only 5,400 people. In December 2019, the UHNCR had to provide cash assistance to 67,300 people and 25,500 relief items to people in need. In December of 2019 alone, the UHNCR contributed 8.7 million EUR. The organization also rents buildings and 
accommodation across the country. In 2019, the UHNCR was able to provide accommodation for 25,800 asylum seekers and refugees.

\section{Funding}

The biggest donor is by far the European Union and its member states (UNHCR 2020e). Two significant funds are responsible for the donations to Greece. The 'Asylum, Migration, and Integration Fund' (AMIF) and the 'Internal Security Fund' (ISF) (EC 2019a). The AMIF is intended to improve reception capacities, maintain the standards of asylum procedures, support the integration process of migrants, and improve return programs' effectiveness. On the other hand, the ISF is a support program to protect borders and fight international crime organizations. From 2014 to 2020, Greece received 328.3 million EUR from the AMIF and 285.2 EUR from the ISF (613.5 million EUR in total). However, this is not all. The EU also provides additional emergency assistance. Since 2015, the EU has contributed 816.4 million EUR to other international organizations and NGOs operating in Greece. They aim to lower the humanitarian crisis for refugees and asylum seekers. Under exceptional circumstances in crises, the Commission can apply the 'Emergency Support Instrument.' The mechanism is designed to support people in need, as well as member states, UN agencies, NGOs, and other international organizations that were cooperating with member states during major crises. Since 2016, the EC has contributed 643.6 million EUR via this mechanism.

The latest funding update is from February 2020. Currently, the UNHCR has received only five percent of its total funding requirements for 2020 (UNHCR 2020e), which means, by using statistical projection, the UHNCR would not be able to reach its requirements by a large margin.

\section{The Situation in the Camps}

Greece already has a long tradition of migration and refugee camps. Papadopoulou did (2004) research on Greece as an essential transit-country and its role in Western Europe's migration process. After the outbreak of the refugee crisis in 2015, several other scholars investigated the Greek situation. Sotiris and DeMond (2017) interviewed 50 volunteers in refugee camps. Kousoulis et al. (2016) concluded that the Greek health care system is dysfunctional, and the necessary medical care for Syrian refugees has been insufficient. Hermans et al. (2017) stated there is a crucial need for mental and dental health care in refugee camps, and Ben Farhat et 
al. (2018) examined the harsh conditions for refugees during their journey and stay in Greece in terms of violence and mental health.

In October 2019, the UHNCR published a situation report about dangerously overcrowded reception centers on Greek islands after the arrival of over 10,000 new asylum seekers and refugees. In addition, 30,000 people are living in inhumane conditions (UNHCR 2019f). The situation on Lesvos, Samos, and Kos was critical. The situation of the Moria center on Lesvos was especially alarming. Twelve thousand six hundred people lived in shelters, which were constructed for only 2,000 to 3,000 people. The report says 100 people had to share one toilet, and a fire in a container that killed a woman lead to riots and clashes with the local police. On Samos, another Greek island, 5,500 people lived in a space designed for only 700-800 people without access to proper nutrition or medical care. On Kos, 3,000 people had to stay in an area planned for 700. The UHNCR called this situation 'inadequate,' 'insecure,' and 'inhumane' and demanded that at least 5,000 people needed to be transferred from the islands to the mainland for further asylum procedures. New and more accommodation was asked for, too. Again, a long-term solution and a concept for the integration of refugees were completely missing. Four thousand four hundred unaccompanied children lived in these worrying conditions by considering that most of the shelters were not supposed to house children. Hundreds of children had no other choice than to live with strangers in a warehouse on Moria. On Samos, children even were forced to sleep on container roofs. The UHNCR describes this situation as 'extremely risky' and 'potentially abusive' for unaccompanied children in Greece and continued by criticizing the EU migration policy for not allowing these children to reunite with their families in the EU.

The Tagesschau (German State Television) reported in November 2019 that the Greek government had decided to shut down the camps on Lesvos, Samos, and Kos. The current reception centers would be replaced by new container facilities used as 'Identification and Departure Centers' with 5,000 people. These new facilities provide water, electricity, and sanitation. These spaces are designed for people who have no chance to get asylum status. The inhabitants of the containers will not be allowed to leave the new camps. The Greek government speaker said that the original concept was to send a message: people should not come to Greece after the country further restricted its immigration laws. At the same time, Greece wants to transfer at least 20,000 people from the islands to the mainland and accommodate them in apartments or former military facilities. 
Nevertheless, people continue arriving on the islands, and it is still not clear what should happen to them. Some smaller camps are planned on Greek islands, but the UNHCR is skeptical if the new plans comply with the UN charter. In December 2019, Caritas International reported in ZEIT ONLINE that the number of people in Moria Lesvos had increased to 15,000 (5,000 of them children). The migrants in camps are suffering more because of the cold winter. Many people are physically and psychologically sick due to inhumane conditions. The Commission was anxious about the situation, but other member states still refused to accept relocated people, even not the children. Thus, at the end of November, there was only space for 2,216 children, according to the National Center for Social Solidarity. Approximately 3,000 children were still without proper accommodation. Deutschlandfunk came to a similar assessment (Göbel 2019) in December 2019. Christos Christou from Medicins Sans Frontiers International compared Greece's situation with war zones and stated that EU-Turkey has failed. Critics claim that there is too much bureaucracy involved, and the asylum procedures are not efficient. The result is almost no readmission to the country of origin can be realized, but the migration flows from Turkey and other states continues.

The latest update is from February 2020. SPIEGEL ONLINE reported about demonstrations on Greek islands, Lesvos in particular, against EU and Greek policy (Christides and Lüdke 2020). The migrants claim that they are held hostage for months or years on the islands. There were again clashes with the Greek police. Footage showed children trying to escape teargas and several arrests of demonstrators.

Furthermore, Greek citizens from the island demonstrated against the situation on the island. The atmosphere is tense and described as 'everyone against everyone' since the number of migrants has increased to 42,000 on the islands (20,000 on Lesvos). The conservative Greek government has applied its new migration system, which says the asylum decision must be made within 25 days for new arrivals. The consequence is more deportations without sufficient examination of the cases.

On the other hand, people already on the island still have to wait for months or years until their asylum decision is made because of the Greek asylum procedures' changes. Since January, the UNHCR reports that people are getting arrested and immediately have to defend themselves in court without legal assistance. The goal of the government is to deport, every week, 200 people. There are currently nearly 100 new arrivals on Greek islands every day, which is an extraordinarily high number for February. The predictions are that this number 
will increase in the upcoming months when the weather gets warmer. Further escalation inand outside the camps is feared. Greece has still not the capacity to manage these substantial migration flows.

One year ago, The Time (magazine) reported that UNHCR called for 'emergency measures' and The Guardian (2020b) published an interview with Dr. Hana Pospisilova, who volunteers on Lesvos, with the following quotes:

'I am an experienced doctor. I have seen many patients in my life, but what I saw there had me crying. I saw many children I was worried about would die because they were suffering from malnutrition. I met a baby who smelled bad; his mother had not washed him for weeks because there was only cold water, and she was worried he would die.'

She concludes with a warning regarding the risk of disease outbreaks:

'People come and go to the medical facilities, they take antibiotics, they are still coughing, they still have a temperature. If you read about Spanish flu, it was exactly like this that is began to spread, in overcrowded facilities where people had a viral infection that became a bacterial infection that killed them.'

\section{Conclusion}

The situation in Greece remains disturbing. Since the refugee crisis outbreak in 2015, neither the EU nor Greece has developed the right strategies to deal with mass migration and asylum seekers in significant numbers. Even though the new conservative Greek government follows a more restrictive migration policy, the number of arrivals on Greek islands is still high. Some could also argue Greece has lost control over its islands. Demonstrations and confrontations with administration and Greek citizens have become daily events. The Greek example additionally leaves some doubts if the EU-Turkey statement is functioning. The bureaucratic obstacles for deportations back to Turkey or elsewhere are not easy and fast to overcome.

Meanwhile, thousands of people are locked in no man's land and do not have any prospects. Most of them are treated as criminals, and even children are no exception from these harsh policy measurements. Volunteers report catastrophic scenarios. Basic human needs are not satisfied (nutrition and freshwater supply), and disease outbreaks are not an unrealistic prediction.

In general, the whole Greek disaster also opens the discussion about funding and policy efficiency. Theoretically, Europe is one of the richest, maybe the wealthiest continent 
on the planet, but the conditions on the Greek islands are, at least to a certain extent, worse than in third-world countries despite all the funding, emergency mechanisms, and other policy measures like the EU-Turkey deal. None of them were successful or helped to improve the situation. Recently, the situation even has become, once again, worse. The latest reports warn about the consequences of a possible outbreak of the Coronavirus on the Greek islands (Grillmeier 2020; Pouplier 2020). Does the question remain how this is possible?

Moreover, what can be done about that? Indeed, Greece is a special case in itself. The debt crisis has never been overcome, and, therefore, the country still suffers from its austerity policy. Nevertheless, it does not explain why all the funding and financial support do not help change the camps' conditions. At the moment, it seems like further escalation is just a matter of time with unpredictable consequences for the whole European Union.

\subsubsection{Italy}

\section{Figures, Numbers, and Statistics}

Italy is another country that has a long tradition of migration, especially because of its Mediterranian location and proximity to the African continent. The most common way migrants arrive in Italy is by sea. Even before the outbreak of the European refugee crisis, Italy was one of the main destinations for refugees and asylum seekers. In 2014, 170,100 people arrived by sea, followed by 153,842 in $2015,181,436$ in $2016,119,360$ in 2017 , 23,370 in 2018, and 11,471 (UNHCR 2020e). Regarding the demographics, 70 percent are male, 10 percent female, and 20 percent children. In the same period, approximately 16,000 people died or are still missing in the Mediterranian Sea on their way to Europe.

In November 2019, there were 95,020 asylum seekers and refugees in Italy (UNHCR 2019g). They are accommodated across the country in reception facilities. Sixty-seven thousand nine hundred seventy-one people are in first-line reception facilities in Lombardy, Emilia-Romagna, and Piedmont. Another 24,568 people live in second-line facilities, which are primarily in Sicily and Latium. Four hundred eighty-one persons lived in so-called hotspots regions, in particular, Sicily. From January $1^{\text {st }}$ until the $30^{\text {th }}$ of October, Italy has received 29,526 new asylum applications. Thus, the number of asylum applications decreased by 38 percent compared to the previous year's same period $(47,475)$. By far, the largest group of asylum applicants comes from Pakistan (20 percent), followed by Nigeria ( 8 percent) and Bangladesh (6 percent), with Syria nowhere near the top. Lampedusa registers most sea 
arrivals. The latest numbers are from February 2020; there are already 2,072 sea arrivals since January $1^{\text {st }}($ UNHCR 2020e).

\section{Funding}

Italy benefits from the same EU funds as Greece. From 2015 until May 2019, Italy received EU support from AMIF and ISF (EC 2019b). The aim was to strengthen Italy's borders and to help Italian authorities to manage migration inflows. In total, Italy has received 950.8 million EUR. 519.9 million EUR came from the Asylum, Migration, and Integration Fund, and 434.9 million EUR from the Internal Security Fund. The vast majority of the money was awarded under the roof of EU long-term funding and national programs (724.4 million EUR). The funding is allocated at the beginning of each EU budget period (2014-2020) and is managed and implemented in compliance with the Commission. The other 226.4 million EUR are awarded as EU short-term funding in the framework of 'Emergency Assistance,' which can be requested by every EU member state under certain circumstances or urgent needs. The institutions and organizations that benefited most from EU funding are the Ministry of Interior, Coast Guard, Financial Police, Navy, and the Ministry of Defence Italian Navy.

\section{The Situation in the Camps}

Recent publications concerning refugee camps mainly focused on the outbreaks of disease. Ciervo et al. (2016) identified poor living conditions, famine, war, and refugee camps as 'major risk factors for epidemics' by analyzing cases of louseborne relapsing fever and its connection with asylum seekers who stayed for a while in camps in Africa and Sicily, Italy. Stefanelli et al. (2017) contributed similar research by investigating infection cases with serogroup X meningococci, another infectious disease. The spread of the disease was observed in Italian refugee camps, respectively, reception centers. The authors conclude that diseases like this are an 'emerging health threat for persons arriving from Africa.'

The Association for Juridical Studies on Immigration (ASGI), located in Italy, provided a comprehensive overview of the living conditions in refugee camps and reception centers in Italy on the Asylum Information Database $(2020)^{42}$ website. The general regulation

\footnotetext{
42 The Asylum Information Database website is financed by the EU AMIF fund.
} 
says people should be treated with respect regarding private life, gender, age, physical and mental health, family, and vulnerable persons. Nevertheless, the reception centers' conditions can vary significantly between reception centers, and unfortunately, annual reports about the circumstances in reception centers for Italy are not available. Asylum seekers usually have to stay for several months in one of the facilities. The system is divided into 'First Reception Centers' and 'Temporary Centers.' First reception centers are described as big, overcrowded, and isolated facilities with almost no connection to Italian urban centers or the outside world. Usually, these places do not have the same standards as smaller reception centers. Limitations of these centers are, for example, limited space, legal advice, and social life. The Italian NGO LasciateCIEntrare visited the first reception centers in Sant'Anna (Crotone, Calabria), Mineo (Catania, Sicily), Villa Sikania (Agrigento, Sicily), Cavarzerani (Udine, Friuli-Venezia Giulia), and Friuli (Udine, Friuli-Venezia Giulia) in 2016, 2017, 2018, and 2019. In Sant'Anna, doors could not be closed, and bathrooms had to be shared, unaccompanied children were treated as accompanied, and medication in the hospitals was insufficient. In Mineo, probably the most famous camp, people lived isolated entirely from the outside world, the sanitation was precarious, and infrastructure, in total, was ailing.

Furthermore, security was a big issue considering black markets, exploitation, prostitution, and drug trafficking. The camp in Cavarzerani was overcrowded, people even had to live in tents (no light and heating), and the hygienic conditions were critical. In 2018 an Afghan Dublin returnee committed suicide in the camp. The Friuli camp in Udine opened as a response to the adverse conditions in Cavarzerani.

Temporary centers should guarantee the same standards as the first reception centers. However, NGOs and reporters criticized the facilities' conditions, lack of hygiene, and insecure environment. In Enea (Rome, Lazio), 316 persons had to share three washing machines, and there was no hot water. In Roggiano Gravina (Cosenza, Calabria), everyone received the same medicine for different health issues. In Piano Torre di Isnello (Palermo, Sicily), the camp administration did not heat the buildings, and there were not enough clothes available for the cold winter months. In Telese (Campania), there were similar problems. Other temporary centers are located in Milan (Lombardy), Casotto (Veneto), Cona (Venezia, Veneto), and Montalto Uffugo (Calabria).

Moreover, in 2018, over 10,000 asylum seekers lived in makeshift camps and were not allowed to participate in the reception system. These camps are described as improvised and are spread across the country, including Piedmont, Lazio, Apulia, and Friuli-Venezia Giulia. 
Some of them had to close by the end of the year 2018. The inhabitants received the warning only two days before the evacuation, and it remained unclear if the people were transferred to other facilities or not.

In the summer of 2019, the Italian government announced the reception center's closure in Mineo, Sicily, which was once the largest refugee camp in Europe with over 4,000 people (UNHCR 2019h). Wallis (2019) called the camp on InfoMigrants.net ${ }^{43}$ a synonym for 'crime, overcrowded, and mismanagement.' Violence, rape, and murder happened in Mineo. Even crime gangs were operating from there. Some further reports suggest that the camp administrator has cut costs to make a profit from the camp (mishandling of EU funds). Human rights organizations criticized the camp's shutdown as another form of profit-maximation since the Italian state would save millions of Euros without the camp. Many people might have to stop their psychological or medical treatments because of the camp's shutdown. Despite all the criticism, the Italian government executed the shutdown.

A few months before these developments, a German reporter team from Monitor $(2019)^{44}$ (German state television) investigated Italy's situation. It showed the consequences of the shutdown of camps and how harsh the living conditions for refugees and asylum seekers in Italy are. The camp reported on in South Italy is called 'The Slum,' and approximately 1,000 people live there. There is no freshwater, and self-constructed improvised 'houses' even do not have functional toilets. The report says Italian state authorities are refusing to provide proper accommodation. Some people in camps complain the situation is worse than in Africa. People are living like homeless, and many of them are suffering because of Dublin regulations. Specifically, Dublin returnees often do not get any state benefits. The current Italian law states that people who have left their camps in Italy for unknown reasons might lose their accommodation. Or in other words, they become homeless in Italy. These actions forced tens of thousands of migrants to live on the streets.

\section{Conclusion}

\footnotetext{
${ }^{43}$ A parternship between France Médias Monde (France 24, Radio France International, Monte Carlo Doualiya), the German public broadcaster Deutsche Welle, and the Italian press agency ANSA. InfoMigrants is cofinanced by the European Union.

${ }^{44}$ Video footage is available on the Monitor website.
} 
Italy is another disturbing case of failures in the EU migration policy. Every year, the result is thousands of dead people in the Mediterranean Sea, and even though the Italian state is relatively wealthy, refugees and asylum seekers have to suffer from poor living conditions in camps. Under far-right Interior Minister Salvini, the former Italian government did not allow sea rescue boats filled with survivors to stop at Italian ports. Consequently, the conditions in the camps are getting worse, and people live in insecurity.

The Italian case also questions the Dublin system, just like the Greek example questions the EU-Turkey deal. It cannot be a sustainable solution that Dublin returnees end up being on Italy's street and become homeless. Again, no long-term strategy is applied. The contrary is the case. It seems like Italy is following a restrictive migration and asylum policy to make the living conditions as bad as possible for as many migrants as possible in the hope they voluntarily return to their country of origin. However, in the short-run, the mafia and other criminals take advantage of these people's situations. Furthermore, it also remains unclear if people would return to a place where they have to fear torture, arrestment, or worse in the long-run. Ironically, one could argue that the Italian migration and camp policy, in particular, has eliminated the poor living conditions in the camps by making the whole country a big open-air camp for refugees and asylum seekers.

The Italian migration policy creates dead people in the Mediterranean Sea, countless homeless people, and worsening living conditions in- and outside the camps. A situation where nobody wins.

\subsection{Analysis: Conditions in Camps}

The analysis starts with a comparison between non-European camps in Turkey, Lebanon, and Jordan. The second part compares the situation in camps in Italy and Greece, and the last section compares camps in the EU and camps in non-European countries. The analysis is based on the evaluation of the previous sections. Every comparison sets individual priorities and focuses on different aspects of the debate since the variables, circumstances, and situations are very diverse. In general, this part aims to find distinctions and diversities by making comparisons:

- Comparison between non-European Camps: Turkey, Lebanon, and Jordan are three completely different states, and this fact is reflected in the analysis of the situation in the refugee camps. The comparison emphasizes the financial, political, and socioeconomic differences by recognizing and highlighting the most important key aspects in discussing living conditions in these camps. 
- Comparison between Camps in the EU: This compares two EU member states, Greece and Italy. Both countries have access to the Mediterranean sea, struggled through recent economic crises, and are profoundly affected by migration flows. The chapter focuses on economic, geography, refugees' and asylum seekers' origin, and policy implications.

- Comparison between non-European and EU Camps: Obviously, the main difference is that Greece and Italy are members of the same political union, whereas Turkey, Lebanon, and Jordan are not. This circumstance has funding and policy implications and shows the different approaches in terms of camps. Nevertheless, comparisons are possible regarding the numbers of asylum seekers and refugees, the political situation, and security (including geopolitics).

\subsubsection{Comparison between non-European Camps}

The best camp conditions are in Turkey. The Turkish state anticipated the upcoming crisis in Syria very early and prepared for it properly. However, Turkey also had the financial resources to do so as one of the wealthiest countries in the region, which is probably the main advantage compared to Lebanon and Jordan. These countries are highly dependent on international organizations and funding, while Turkey is not, or only to a certain degree. Thus, the living conditions in the camps are on a relatively high level. There is enough nutrition and freshwater, children can attend schools, and there are some opportunities for free-time activities. By no means is living in a camp in Turkey a luxury lifestyle, but compared to Lebanon or Jordan, where it is often a daily fight for survival, at least some minimum standards are fulfilled in a secure environment. Starvation, diseases, and other disastrous developments are unknown in Turkish camps. The more significant issue is with refugees and asylum seekers outside of the camps. Many of them end up homeless on the streets, and exploitation, child labor, and prostitution are common. Finally, Turkey financially benefits from the EU Turkey deal, another advantage that the other countries do not have.

Lebanon, on the other hand, was utterly overwhelmed with the crisis. Although the state has a long tradition of hosting Palestinian refugees, the best experience and preparation do not help if 20 or 25 percent of the population are refugees. Even international aid organizations have given up and moved their activities to Turkey. Nevertheless, the supply of nutrition and freshwater in the camps is still highly dependent on their work. Only a minority of children can visit schools because the child labor force is needed to support their families. 
Another difference is the level of repression by state authorities. Undeniably, Turkey has changed the rhetoric and policy practices, but the camps' situation is not profoundly affected. At least for the moment, refugees and asylum seekers are safe in the camps. On the contrary, in Lebanon, Syrians fear state repression, rising xenophobia, and deportation back to Syria. The level of insecurity is tremendously high.

The most interesting case may be Jordan. It is hard or even impossible to say if the camps' situation is worse in Lebanon or Jordan. The situation for refugees and asylum seekers in- and outside camps is devastating. Nevertheless, it seems like the people in the camps have accommodated themselves to a certain extent in their situation. The Zaatari camp is an excellent example of that. In only a few years, a completely new 'city' has emerged. A city that was supposed to be an improvised camp with tents and shelters has developed its own infrastructure, market economy, and social life. Frankly, it is still far from being a perfect scenario since even terror attacks occur in the camp. However, it shows that people can transform the short-term problem into a long-term solution by improving the living conditions, of course, with aid organizations' help. Thus, the Zaatari camp is a unique case with a distinctive character. That is probably the main difference from other camps in the region, respectively, to camps in countries neighboring Syria: the temporary solution is no longer only a temporary solution.

\subsubsection{Comparison between Camps in the $\mathbf{E U}$}

The situation in Greece is alarming, and many riots have already occurred in Greek refugee camps. All camps are entirely overcrowded, the conditions are adverse, and doctors are even warning of the outbreak of diseases. Experts state that the conditions are worse than in Turkey (ZDF 2020). Only if people can make it to the Greek mainland can they improve their living standards. However, usually, people have to stay for months in the camps.

On the contrary, Italy's camp conditions are relatively high compared to Greece, but that does not mean they are sufficient. Although the conditions are on a deficient level, sometimes below that, there are at least no distribution battles over scarce resources. The Italian state has still not lost its control over the 'official' camps. The main issue in Italy is the situation of homeless refugees or asylum seekers who have lost their right to proper accommodation (due to Dublin regulations, for instance) and live in improvised camps. These persons' situation is as concerning as other people's situation, who have to live on Lesvos, for example. The differences that we can identify between camps in Greece and Italy are the following: 
- Economy: The Greek economy is still suffering from the austerity policy during and after the 'Euro crisis' (Kaplanoglou and Rapanos 2016; Petrova 2017; Perez and Matsaganis 2018). Debts are still high and harm the development of the country (Statista 2020a). Greece simply does not have the resources to manage the enormous migration inflows by itself and is highly dependent on EU funding. Italy, on the other, is one of the biggest economies and industries in the world. Indeed, Italy has suffered from the debt crisis in the past, and the overall condition of the economy is not good, but the country is still in tremendously better shape than Greece. Thus, it is not surprising that Italy can provide better living conditions in camps and reception centers.

- Geography: This is the apparent reason. Greece is located much closer to Turkey, and Turkey is a significant transit-country for many Syrians on their way to Europe. Therefore, Greece is more affected by the (armed) conflicts in the Middle East.

- Origin of refugees and asylum seekers: The composition of migration flows is entirely different between Italy and Greece. While most immigrants in Greece are coming from the Middle East, Italy is profoundly affected by migration flows from the African continent (many asylum seekers are also coming from Pakistan).

- Policy implications: Greece is the most important country in terms of applying the EU-Turkey deal. The EU has a keen interest in controlling, managing, and limiting migration through this agreement. Hence, this policy measure directly influences the situation in Greek camps. On the contrary, Italy is not affected by the EU-Turkey deal, but the country applies its domestic policies, including making many Dublin returnees homeless.

\subsubsection{Comparison between non-European and EU Camps}

In general, we can distinguish between Italy and Turkey on the one side, and Greece, Lebanon, and Jordan, on the other. Compared to the other case studies, Italy and Turkey provide the highest living conditions in refugee camps. As mentioned before, Turkey was well prepared for the crisis and invested a lot in managing and coordinating migration flows from Syria. Whereas Italy has always struggled with its role as a destination for migrants, Turkey showed political motivation to manage the crisis, at least at the beginning of the civil war in Syria. Italy, on the other hand-side, has never accepted its role. However, because of its economic power, Italy was still able to run sufficient camps and reception centers 
compared to other countries. Italy's and Turkey's situation is far from perfect, but at least people can survive there.

On the contrary, in Greece, Lebanon, and Jordan, it is a daily fight for survival. Maybe the most shocking finding here is that a member state of the EU is running refugee camps that are in the same condition. Some would even argue that they are worse than countries such as Lebanon or Jordan.

Nonetheless, there are some significant differences between non-European and EU camps. The differences are in the following areas:

- The number of asylum seekers and refugees: It often gets forgotten, but non-European countries are still hosting significantly more refugees and asylum seekers than EU countries. Turkey is currently worldwide, the number one host country, Lebanon is hosting the most people per capita, and the small state of Jordan is hosting over 650,000 refugees and asylum seekers.

- The political system: Turkey, Lebanon, and Jordan are autocratic regimes, while the EU is still, in most cases, democratic and provides liberal values, freedom, and protection. Indeed, this can be an advantage but also a disadvantage. The EU entails much bureaucracy, and the processes are slow since they usually have to pass many institutions. However, at the end of the day, the EU stands for stability. On the other hand, autocratic regimes can change overnight, and decisions are made quickly, which can cause immediate consequences for inhabitants of camps and reception centers, negative and positive.

- Security: Even though the perception of many countries and societies of the EU are different, terrorism and radicalization are the exceptions in Europe. Every single terroristic act is one too many, but they happen only very rarely. On the contrary, Turkey, Lebanon, and Jordan are all surrounded by war and conflict zones. It is more likely to become a victim of terrorism in these countries. The security situation is arguably better in Europe. Unfortunately, further escalation in European camps could change this fact. 


\subsection{Discussion: Conditions in Camps}

\subsubsection{The Connection between Aid and Conditions in Camps}

As mentioned above, the case studies emphasize the importance of satisfying basic human needs like health care, nutrition, education, et cetera. Additionally, the political, economic, cultural, and environmental situations should also be considered when analyzing refugee movements from camps, specifically why people do not stay there. Case studies show that providing livable conditions to people in camps can improve their situation or eliminate the push factors for leaving. In general, we can say that devastating conditions in refugee camps significantly increase the probability that people will continue to journey to other destinations. The 'push-stay-pull' model (see chapter 3.1.6) implements a new dimension in the discussion and tries to provide a coherent approach to stop mass migration by making life for people in refugee camps reasonably livable in the long-run. Fafo $(2019 \mathrm{a} ; 2019 \mathrm{~b})$ comes to a similar conclusion after analyzing Syrian refugees' situation in Jordan (camps). Improved living conditions reduced the push factors for moving to Europe.

The importance of refugee camps is a factor in the current - and still not solved European refugee crisis. The significant migration movement from Syria and its neighbor countries started when the UNHCR and WFP were running out of money and were no longer able to provide enough food, clean water, and security to the people outside the camps. In an interview with The Guardian newspaper in Britain, the UN high commissioner for refugees, Antonio Guterres, explained it in this way: 'The budgets cannot be compared with the growth in need. Our income in 2015 will be around 10\% less than in 2014. The global humanitarian community is not broken - as a whole, they are more effective than ever before. But we are financially broke' (The Guardian 2015). One of the major counter-arguments concerning this issue is that 'the poorest of the poor' usually do not migrate due to a lack of (financial) resources, which are obligatory for migration (UNDP 2009). Indeed, there has also been some discussion in the field of academics that development help may even have the contrary effect since financial support from development help is providing these resources (de Haas 2010). However, when analyzing the European refugee crisis, the issue is much more complicated. First of all, major studies in this field are from 10 to 20 years old and need reviewing.

In the meanwhile, the world has significantly changed. Now, we live in the digitalization era, and, therefore, the forms of communication have transformed completely. Even in vulnerable areas of the world, it is not rare for people to own mobile devices. When 
in 2015, Germany and other European countries opened their borders for asylum seekers, the message spread worldwide even to the most outlying regions in the world. The incentiveeffect of this message should not be underestimated. Infrastructure and mobility have made significant steps forward in recent years. Whereas in the 1990s and 2000s, traveling around the world was very costly, it is nowadays relatively affordable with the emergence of low-cost no-frills airlines. The more significant issue remains here: not if the 'poor of the poorest' can make it to Europe, but rather if they can get the right legal status and pay human traffickers to get them there.

The Dublin II agreement is the last part of what it makes so difficult and costly for migrants to reach their country of destination in Europe. The Dublin II agreement, which says people have to seek asylum in the country where they first enter European soil, is one of the reasons why it has always been so expensive to come to Europe since most asylum seekers prefer to go to Northern Europe (Germany, Benelux, Scandinavia, et cetera). When in latesummer 2015, the Dublin II agreement became obsolete, this obstacle did not exist anymore. Nevertheless, the situation concerning Syria remains very special. Before the outbreak of the civil war, the majority of the population had a relatively comfortable life. Thus, the country should not be considered as one of the 'poorest of the poor.' At the beginning of the civil war in 2011, most people might have still had the illusion that the war would end soon and did not intend to go to Europe. However, many people lost everything when they had to flee, but a significant number of people had some financial resources (Paul 2019).

A survey from 2016 by the IAB found out that most refugees who came to Germany financed their flight by savings (39\%) and by selling goods and property (34\%). The costs vary significantly from the country of origin, but in general, it was between 5,200 EUR (second half of the year 2015) and 7,300 EUR (2013) (IAB 2016). According to this study, we can say that the costs were not the biggest problem coming to Europe. At the same time, money is not always the means to have a good life, especially not in the crisis regions, since distribution battle and scarce resources are also an issue. If there is no food supply, money alone does not cover basic human needs like access to nutrition, food, and education. The work's limitation is that we cannot measure how much savings remain after fleeing to Europe.

Furthermore, it is also worth mentioning that the money's origin is not always clear, like an inside report from the German news journal SPIEGEL ONLINE demonstrates. According to the report, some refugees even sold organs (approximately 7,000 EUR for an organ on average) because of financial problems (Putz 2013). The amount of people who did 
this to flee to Europe remains unclear. Thus, further research is needed. The case studies show that proper accommodation and sufficient supplies (like in Turkey) can weaken the crisis if the funding requirements are fulfilled efficiently, and NGOs do not have to do the whole work alone.

It is conspicuous that the main focus of the EU was on Turkey (EU-Turkey deal) in the past. The actual short-term strategy is that Turkey functions as 'the bouncer' of the EU. The Turkish state is supposed to absorb all refugee and asylum seeker flows of the region and prevent them from moving to Europe by keeping the people in the country. In exchange for this service, the EU transfers billions of Euros to Turkey. Even though the deal is not sustainable, the EU is not cooperating with other states in the region to the same extent. The EU is merely following the approach to reduce migration in the first place, but not improving people's living conditions in- and outside of camps. International aid organizations in Lebanon and Jordan are underfunded continuously. The EU has the resources and the financial power to ameliorate the crisis in these countries. Not only are refugees and asylum seekers left alone, but the hosting states are also not receiving enough support to manage the emergency.

The EU migration policy is reactionary and mainly focuses on developing strategies after the crisis occurred. Development and foreign aid costs are still underestimated. In this context, the EU-Turkey statement is nothing more than a desperate attempt to diminish the crisis and is by far not enough. Even among EU member states, there is an ongoing discussion about burden-sharing and insufficient solidarity (see chapter 4.3.2). Greece has completely lost control over its islands. However, the approach is still the same: Greece should try to prevent people from going elsewhere in Europe instead of improving refugees and asylum seekers' living conditions. In a nutshell, the push factors increase due to adverse living conditions, and the pull factors of other EU countries, especially in the North, remain relatively stable. Hence, even if people make it to their destination country, people are sent back to Greece or any other state in the South due to Dublin regulations. Back in Greece, the situation has not changed in the meanwhile, maybe even has become worse, and Europe tries to push these refugees and asylum seekers back to Turkey. A neverending circulation of migration is the consequence without solving any of the problems.

Therefore, wealthy states have to share some of their wealth to support the crisis regions. Agreements like the 2016 Turkey deal or deals with other authoritarian regimes in the Middle-East and Africa are very risky because these countries' political and economic 
situation can change instantly. All in all, crisis management was a complete failure, and it could have been easily avoided by undertaking the right measures; a more reasonable and comprehensive policy concerning the European migration crisis is required, mainly providing a long-term strategy.

The improvement of living conditions in refugee camps around Syria is one possible approach. Taylor et al. (2016) analyzed refugees' economic impact in host countries by studying economic development in a 10-kilometer radius of three Congolese refugee camps in Rwanda. The research results indicate that cash aid to refugees in camps significantly boosts the whole economy of the region. The real income of businesses and households in the locality increased by 205 USD to 253 USD, and the trade of the local economy with the rest of Rwanda increased by 49 USD to 55 USD. The impact of food aid was lower than cash aid. Thus, the cooperation between aid organizations, states, and refugee camps can even support economic growth.

In conclusion, the European refugee crisis beginning in 2015 could have been avoided by the global community's earlier anticipation. The devastating conditions in refugee camps surrounding Syria were very well-known, but the cries for help were mostly ignored. To this day, the UNHCR is begging for funding. The amount requested is very moderate compared to the consequences of new possible mass migration movements from the Middle-East region to Europe. Certainly, funding is not everything but it is the basis for every other improvement. The international community, especially Europe, which is mainly affected by refugee movements from the Middle East, has to start providing guidance and assistance to give people local prospects. This can be done, even when taking soft factors like the human need for education, culture, or political participation into consideration. Scarce resources in refugee camps remains the biggest issue.

Nevertheless, this approach has some limitations. The whole European migration crisis is still a relatively new phenomenon. Many numbers and figures are hard to evaluate because most of the countries are involved in armed conflicts, the propaganda machinery is running, and none of these countries are democracies. Furthermore, the political situation can change overnight, as Turkey's failed coup a few years ago demonstrates. The recently published study about autocracy from Bertelsmann (2018) shows that Turkey and Lebanon and Jordan have left the path to democratization. Indeed, there is also the possibility that the civil war in Syria, respectively, a proxy war, might stop overnight, and refugees will start going back to their country of origin, but this option is not very realistic. The situation remains very fragile and 
can become worse if more countries get involved in this conflict. Since most hosting countries have already reached their limits concerning hosting refugees, there is also the threat that distribution battles for the scarce resources will escalate, and new conflicts between host communities and refugees will emerge. If that should happen, no international aid organization might be able to soften the crisis. However, providing sufficient and proper living conditions to asylum seekers and refugees and crisis hotspots is still the best crisis prevention.

\subsubsection{Camps, Development, and Urbanization}

Overall, the literature concerning migration theories does cover all relevant parts from forced migration to labor migration (see chapter 3), except for the unusual situation in refugee camps, which is only barely covered (see section 3.1.7). Refugee camps are relatively new phenomena that appeared in the time after the Second World War. Nevertheless, it is not extensively discussed in the field of migration theories (Paul 2019). There are almost no studies that analyze the process of urbanization from camps. Most of the new research in this field focuses on health care (epidemics, diseases, post-traumatic consequences, et cetera). A rare exception is 'Refugia', the work of Cohen and Van Hear (2019). The war in Syria shows that millions of refugees live outside their country of origin in temporary accommodations, and the hosting states fail to provide sufficient security, health care, and nourishment. Thus, private help organizations and institutions are replacing the functions of the actual states. Refugee camps are complex small to medium-size socio-economic systems. Some would even argue that refugee camps are even states within a state; or, taking the devastating situation for most of the people in those camps into consideration, the term 'failed' state seems also very reasonable.

A prevalent example for such a refugee camp is in the Gaza Strip in the West Bank, which is, in name, part of the autonomous region of Palestine, but is, in fact, under the control of the Israeli state since Israel controls the movement of people, telecommunication, water, and energy supply. Without a doubt, the Middle-East conflict is a very complex issue, and it will be not part of this dissertation. However, it illustrates a possible development in the future of other refugee camps in the region, even when excluding the religious tensions of the Middle-East conflict when a state - or other higher authority - is incapable of providing enough support. Despite these issues, for some inhabitants of Palestine camps, the camps have given them (a) an (new) identity (Farah 2006). Concerning refugee camps, there is a lack of 
literature in the field of migration studies. Thus, there is further need for research in this minor field regarding circumstances in which people prefer to stay in camps rather than fleeing to Europe.

Refugee camps in their current form are not a final solution (Paul 2019). Therefore, a new approach is needed. Migration theories, especially in the field of refugee camps, have to focus more on the aspect of how to give people prospects locally. Huge investments are required to build up a functional economy (including employment, trade, and infrastructure) and transform refugee camps into livable areas, providing housing, nutrition, water, et cetera. However, this transformation process can only be successful if the people's legal status is reconsidered, whether by integrating them in the host country, or by giving them a newly created citizenship, and people get the opportunity to participate in society politically and culturally. People need the right of self-determination about their lives and future. It is not very likely that people will ever integrate into a different society or start building up a new identity if they feel that other institutions or states are making decisions concerning them. In this context, self-empowerment is an essential factor that should not be underestimated. Consequently, refugee camps need to become self-sustaining systems that can be run, in the long term, independently from the financial help of international organizations or other states.

The discussion of urbanization in camps is not new, but it has gained more relevance in recent years. ${ }^{45}$ Lee (2018), who visited the Zaatari camp in Jordan, observed how the camp had developed its own infrastructure and market economy (see chapter 5.3.). It is naïve to think that people are not inventing their own creative solutions for a more reasonable life if they receive only limited support from the international community or the host country. The Zaatari camp emerged from scratch and occupied previously empty space without taking anything away from the domestic population (financial contribution from the Jordan state is not considered). By just allowing people to stay in the camp and the region, nobody was worse off. Or in other words: distribution battles over scarce resources with the domestic

\footnotetext{
${ }^{45}$ The science of urbanization is a whole discipline in itself. Nevertheless, it has also always been highly related to migration theories. The whole neoclassical approach in chapter three of this dissertation can be considered in this context, especially Ravenstein's 'laws of migration'. Due to the limitation of this work, I will only focus on urbanization in terms of refugee camps.
} 
population could be avoided. Indeed, an approach like this is not promoting integration practices, but, on the other hand, potential conflicts are also not very likely to occur.

Nonetheless, two essential requirements are necessary so that an urbanization process like this can begin. First of all, accepting the situation that the origin country is indefinitely not accessible, or even lost forever. Secondly, the host country's willingness to let development and urbanization like this happen by relinquishing some of its territory or giving individual camps or regions autonomy and the right of self-determination. In exchange, the host country could benefit from higher tax-income since many of the actual businesses in the camps are not 'official.' Any other forms of equalization payments, for instance, by involving the international community, are also conceivable after the successful implementation of an autonomous approach. The execution of this plan is, as shown in Palestine, very difficult. In Paestine, international law and agreements are violated almost daily.

At the moment, most camps are improvised constructions. The vast majority of people live in tents, shelters, or other inadequate buildings. Many camps are also isolated from the rest of the host country and do not have access to proper infrastructure (for example, the Lesvos camp in Greece). The urbanization process of camps should include the following aspects:

1. Accommodation: Proper housing conditions are crucial. As long as people have to live in tents, shelters, or other improvised buildings (e.g., some Favelas in Brazil), the urbanization process cannot be successful, or parallel societies might emerge. Even though the cases are hard to compare, China has built several mega-cities from scratch for its population in a reasonable amount of time in the past decades. The example demonstrates that a scenario like this is possible and realistic if funding requirements are fulfilled.

2. Security: The inhabitants' safety must be guaranteed, and in the long-run, the camp must get the opportunity to establish its own security standards. The international community or state authorities cannot protect the population if the goal is to build a self-sustainable system. Sooner or later, camp police forces are needed for reasons of trust alone.

3. Health care: Hospitals, doctors, and other medical facilities are another crucial point. People need the best possible care locally. The reason for that is self-explanatory.

4. Education: The population of the Zaatari camp in Jordan, for example, is very young. Thus, an adequate schooling system is needed. At the moment, many children in 
camps are excluded from education because parents need their children's labor force to make a living for the whole family. This state cannot be tolerated or accepted. In the long-run, the establishment of universities should be the objective. Respectively it should be at least taken advantage of new online opportunities, such as participating in online courses through high-speed internet.

5. Administration/Government: Coming back to self-determination, people must have a voice in which direction their new home should develop, either by allowing them to vote who should be their representative or deciding by referendum. If people do not have a voice regarding their future, the level of frustration rises again.

6. Functional (market) economy: The Zaatari camp is, once again, a perfect example of this. There are plenty of shops, cafes, restaurants, and many other small businesses. People should have opportunities to make a living and create income on a legal basis for themselves and their families. Establishing businesses and recruiting employees is the foundation for economic growth and long-term independence from aid organizations and funding from wealthy states. Moreover, it creates tax-income for the host country of the refugees and asylum seekers.

7. Guarantee of food and water: Sufficient food and water supplies are mandatory. Camp residents must produce food to build up a self-sustaining system, including efficient use of agriculture, farming, and fishing.

8. Infrastructure: Most of the camps are entirely isolated from the rest of the world. If people are allowed to leave the camps, they are often unable to visit the next town because of a lack of infrastructure. This obstacle needs to overcome by connecting camps with the rest of the world with streets, railways, train or bus stations, et cetera. A functional infrastructure network is also crucial for trade with other regions and countries.

9. Social life: The last aspect is probably the least important for people who have suffered from war, being displaced, and living under devastating conditions in camps. Nevertheless, this point should also be not underestimated. Humans are social characters and need activities for their free-time, including sports, access to the internet, and other forms of communication, books, films, et cetera. Therefore, camps must provide opportunities for people to structure their social life and free-time activities in terms of socializing and infrastructure (libraries, sports pitches and equipment, internet cafes, et cetera). 


\subsubsection{Improving Conditions in Camps: Solutions and Recommendations}

The role of refugee camps must be reconsidered (Paul 2019). The original plan that refugee camps should be temporary solutions does not work anymore. Indeed, the case of Palestine refugees raises the question if it has ever worked sufficiently. The civil war in Syria started in 2011 and is still far from being resolved. Thus, the forced migration from this region needs to stop to give the refugees local opportunites. Refugee camps around Syria can be the solution if the world community can implement public assistance, create jobs, and treat the camps as small micro-economies to allow them to trade with other countries and regions. To achieve this goal, multinational enterprises could start investing in this region by building plants to provide jobs to the local community. Tax reduction and a low-tariff policy for trading goods could be incentives to bring investors into the region. Since the sun and wind is nearly constant, this area is very attractive for regenerative energy producers building solar power plants and wind farms.

The key is the anticipation of future migration flows and responding appropriately and sustainably (Paul 2018). For instance, we know which regions will be most affected by climate change, and millions of people in Africa will lose their homes (see chapter 3.3). Approximately 86 million people in Africa will be forced to flee their country of origin in the coming decades (World Bank 2018). Of course, not all of them will want to come to Europe, but the actual amount depends hugely on the international community's decision-making process in the coming years. The refugee crisis of 2015 already showed that the relatively small number of one to two million refugees from the Middle-East overwhelmed European countries and the European Union as an entity. A significantly higher number has the potential to end the European integration process. The most crucial factor is time to identify, locate, and anticipate future refugee movements. Concerning Africa, the Sub-Saharan region will be affected very severely by climate change. Early prevention is the most effective way to stop mass migration.

One possible approach could be to rent territory for a certain period from other states, as the UNHCR does with renting refugee camps, but on a much bigger scale. The international community has to start an urbanization process in less developed and less populated North Africa regions to make permanent settlement from the Sub-Sahara possible.

In the first place, these new urban regions should provide sufficient nutrition, freshwater, health care, education, cultural and political participation, and security (including against climate change). As a result, new cities and urban regions will emerge without 
negatively affecting the hosting country's current infrastructure. Beyond that, cultural, religious, and political conflicts can be avoided by separating problematic groups from each other and supporting homogenous strategies for settlement. Indeed, these projects can only be successful if they allow people to determine their lives themselves. Thus, autonomous regions have to be created, which gives refugees a new perspective on the African continent, including employment and political participation. Otherwise, in the long-run, new political and economic problems will occur.

The migration process to Europe cannot be entirely stopped but can be tremendously reduced. However, Europe has to be prepared for a significant number of (climate) refugees from the African continent and the Middle East, even if all recommended measures are successful. It is impossible to predict the exact number of refugees and how Europe, in effect, the EU will change in the coming decades. Still, even when considering the most optimistic predictions, millions of people will likely make their way to Europe. The South-EastEuropean countries (Greece, Italy, and Spain) will be most affected by this influx of people. Thus, an allocation formula for the whole EU is still required because none of these countries can solve this problem without the solidarity of other EU states. In the long-run, if the rest of the EU still resists helping, fences and walls everywhere will be the consequence, and sooner or later, distribution battles will follow. The European integration process will end, and armed conflicts between EU states become a realistic scenario again since it is the only way to stop migration completely.

As a result, Europe and the European Union need 'controlled migration.' The legal status of refugees has to be clarified as soon as possible, as well as the terms for asylum. Indeed, human rights are not negotiable, but the distribution of natural resources can be. Therefore, massive funding and urbanization program are required to give people a viable alternative to migration. Furthermore, since not all refugees will stay in their country of origin, Europe must be prepared and start developing programs for controlled migration. One of the first steps has to be the clarification of the legal status of refugees. Hence, visa and migration centers should be established in Africa and the Middle East to find humanitarian solutions for asylum seekers without giving them the wrong incentives and false hopes. The worst-case scenarios will rapidly overwhelm Europe's capacities for integration. At the same time, it is also the responsibility of Europe to stop the deaths of tens of thousands of refugees every year in the Mediterranean Sea, especially by giving people the wrong incentives (e.g., denied asylum because of limited capacities). Thus, the establishment of 'visa/asylum centers' 
in North Africa and the Middle East could solve this problem. It is an unsustainable state of affairs that, in many cases, refugees have to flee to Europe before their legal status can be clarified. Again, a certain quota for how many people Europe can absorb appears to be reasonable. If there is no more capacity available for hosting refugees in Europe, people need a livable alternative elsewhere, which also guarantees their security. This policy would also end the brain drain-effects from other parts of the world to Europe. Indeed, migration flows as a consequence of armed conflicts and wars are more difficult to predict than making assumptions about the outcomes of global warming regarding migration since many conflicts occur overnight. Nevertheless, it is realistic that the Middle East region and certain parts of Africa will be, unfortunately, also suffering in the future from instability. Europe needs an entirely new approach and concept for the whole Mediterranean region. The strategy mentioned above is one possible way to soften the crisis of mass migration.

Furthermore, the world is at the edge of a new industrial revolution. Digitalization will change our understanding of work and labor significantly. According to the Oxford study, 'The Future of Employment: how susceptible are jobs to computerization?' (Frey and Osborne 2013), 50 percent of present jobs will vanish by 2030. An unconditional minimum income for everybody in the world is the only possible solution to treat that problem. The common fear of digitalization is that machines and computers will replace people. However, this point of view undermines the vast possibilities of digitalization. There are plenty of jobs, which will not be missed without a doubt; those jobs nobody likes to do. The digitalization process is the opportunity to get rid of those jobs and free certain parts of society from unnecessary labor. The perspective has to change. Instead of thinking that robots are replacing humans and only the owners of those machines benefit from this change, we have to restructure the organization of our economy and the distribution of wealth. Hence, the digitalization process is an excellent opportunity for the world's poorest people, if done in the right way, at least in the long-run. An unconditional minimum income could be provided to every refugee in the world. If it is high enough, people might stay in their region and start building up prospects in their home country or host country. Otherwise, the brain drain effect from the poorest regions in the world will never stop. Indeed, well-educated people are needed to establish a functional infrastructure and economy. It is not desirable to completely bleed the Middle-East by absorbing all young talented people to Europe while the rest are left behind. 
In any case, a more realistic scenario for the near future is to provide more funding for the crisis regions. For instance, Germany, which was one of the countries that took the most refugees in Europe, plans to increase its military expenditures by almost 50 percent in the next years (30 billion USD). Instead of investing in its defense, which is a very controversial topic within the German society, Germany alone could provide six times the funding for the refugee camps in Lebanon, Turkey, and Jordan. Consequently, the financial resources to solve the European refugee crisis already exist (without even talking about progressive taxation or taxation of financial transactions, et cetera), but they are just allocated in the wrong way or inefficiently. 


\section{Interviews}

\subsection{Fully-structured Interviews}

The evaluation of the results starts with the characteristics of the participants. The four main categories are 'Age,' 'Gender,' 'Citizenship,' and 'Profession.' Thus, the data tells us where asylum seekers and refugees come from and to which demographics they belong.

Table 8: Evaluation of the Characteristics of the Participants

\section{Characteristics of Participants}

\begin{tabular}{llllll}
\hline & $\mathrm{n}$ & $\%$ & & $\mathrm{n}$ & $\%$ \\
\hline Age & & & Gender & \\
\hline $18-29$ & 109 & 56.8 & Male & 119 & 62.0 \\
\hline $30-49$ & 49 & 25.5 & Female & 73 & 38.0 \\
\hline $50-64$ & 22 & 11.5 & & & \\
\hline $65<$ & 12 & 6.3 & & & \\
\hline Citizenship & & & Profession & & \\
\hline Syria & 79 & 41.1 & Unemployed & 52 & 27.1 \\
\hline Iraq & 41 & 21.4 & Ftudent & 79 & 61.1 \\
\hline Eritrea & 24 & 12.5 & Farmer & 13 & 6.3 \\
\hline Afghanistan & 9 & 4.7 & Housewife & 12 & 2.1 \\
\hline Palestine & 5 & 2.6 & Soldier & 4 & 2.1 \\
\hline Jordan & 10 & 5.2 & Construction & 4 & 2.1 \\
\hline Yemen & 12 & 6.3 & Salesperson & 4 & 12.5 \\
\hline Other & 12 & 6.3 & Other & 24 & \\
\hline & & & & \\
\hline
\end{tabular}

The first noticeable fact is that the vast majority of the migrants are very young. Over 50 percent are under 30 years of age, and 25.5 percent are between 30 and 49 years. People over 50 years are already migrating significantly less than the previous categories, and migration over 65 becomes very unlikely with under 7 percent. The trend shows that movement is an activity of the young, which is not surprising since immigrating to another country requires energy, resources, and health. The elderly interviewed in this section were part of family reunification processes and had relatively safe ways of entering the EU. Note that the young 
people took the dangerous paths on their journey to Europe (e.g., crossing the Mediterranean Sea).

The second important observation is that more migrants are male than female. Indeed, cultural or religious reasons might have played a role in selecting interview partners as well, but, in general, there were more men (62 percent) than women (38 percent) available. This could be because mainly young men are fleeing to Europe, who leave their families behind. They aim to reach Europe in insecure ways, and after the clarification of their asylum status, their families follow on safe routes (e.g., by airplane). These numbers are also consistent with findings of the 'Bundesamt für Migration und Flüchtlinge (BAMF)' and the 'Bundeszentrale für Politische Bildung (BPB)' (2020), who investigated the demographics of asylum seekers and refugees in Germany. As state institutions, they have, of course, more resources to conduct more sophisticated research in this field. According to their statistics, the ratio between men and women was approximately always between 60 percent (men) and 40 percent (women) in recent years. Concerning the age of migrants, the trend that 'migration is for the youth' is confirmed. The biggest group is between 0 and 15 years old (about 40 percent). ${ }^{46}$ The older the demographic gets, the fewer asylum seekers and refugees migrate to Europe and Germany.

The category 'Citizenship' is supposed to localize the origin of the migrants. It does not automatically mean that people come from the country where they originated from, but it should provide a basic overview. ${ }^{47}$ The biggest group in this category is by far people with Syrian citizenship (41.1 percent), followed by Iraq (21.4 percent) and Eritrea (12.5 percent). The other countries reflected in the interviews are Afghanistan, Palestine, Jordan, Yemen, and others. All of these countries suffered tremendously from war, conflicts, and political instability. The high number of Syrian asylum seekers are the direct consequence of the Syrian Civil War and mass migration movements to the EU since 2015. Again, the interview results are in line with the BAMF and the BPB statistics (2020). Syrians are currently, overall, the biggest group of asylum seekers in Germany. The interview results' main difference is that official German data also recognizes a relatively high number of asylum seekers from Europe

\footnotetext{
${ }^{46}$ A group that is not reflected in the interviews because every interview partner had to be at least 18 years old.

${ }^{47}$ Theoretically, somebody can be a Syrian citizen but live in a different country.
} 
(e.g., Russia or Moldova), countries with no priority in this research. Many interview participants were still students (41.1 percent), which derives from the interview partners' average young age. Overall, various jobs are represented, including farmers, homemakers, construction workers, soldiers, or salespersons. Nevertheless, the second biggest group are unemployed persons (27.1 percent), respectively, people with no real profession. Professions summarized under 'other' are, for example, barbers, tailors, policemen, and teachers.

The first two questions of the interviews deal with refugee camps outside of the EU, including a simple 'yes or no' and a 'circle all that apply' question, which should only be answered if people lived in a camp before moving to Europe.

Table 9: Evaluation of Question 1 \& Question 2 of the Interviews

\begin{tabular}{ll}
\hline Q1: Were you in a refugee camp before & Q2: In which country was the refugee \\
coming to the EU? & camp located where you lived before \\
& coming to the EU? Please circle all that \\
& apply. (only answer if Q1 is 'Yes')
\end{tabular}

\begin{tabular}{llllll}
\hline & $\mathrm{n}$ & $\%$ & & $\mathrm{n}$ & $\%$ \\
\hline Yes & 92 & 47.9 & Turkey & 39 & 42.4 \\
\hline No & 100 & 52.1 & Lebanon & 17 & 18.5 \\
\hline & & Jordan & 14 & 15.2 \\
\hline & & Syria & 1 & 1.1 \\
\hline & & Other countries & 21 & 22.8 \\
\hline
\end{tabular}

In total, 92 (47.9 percent) people lived in refugee camps before coming to the EU, and 100 (52.1 percent) did not. Thus, the majority of asylum seekers had no camp experience before coming to the EU. An explanation for this is that many people made it to their destination without getting interrupted (for example, during the summer of 2015), and family reunification played an important role. The primary target for people fleeing was Turkey, with 42.4 percent. Lebanon (18.5 percent) and Jordan (15.2 percent) were other important refugee camp destinations. All of these countries are neighboring countries of Syria. Therefore, the probability is very high that the ongoing conflict in Syria caused these movements. The reason for Turkey's 'popularity' among refugees is its proximity to Europe and the granting of relatively reasonable living conditions in comparison to Lebanon and Jordan. Nevertheless, number two in the rankings is 'other countries' with 22.8 percent, including African countries 
like Egypt or Libya. Another aspect is that, in recent years, migration from Eritrea has increased, and Eritreans had to live in camps on the African continent on their way to Europe.

The next two questions are very similar to the previous ones but focus on camps inside the EU. The first question asks if people stayed in a camp in the EU, and the second one (if the answer is 'yes'), in which country.

Table 10: Evaluation of Question 3 and Question 4 of the Interviews

\begin{tabular}{ll}
\hline Q3: Were you in a refugee camp after & Q4: In which country was the refugee \\
entering the EU? & camp located, where you lived after \\
& entering the EU? Please circle all that \\
& apply. (only answer if Q3 is 'Yes')
\end{tabular}

\begin{tabular}{llllll}
\hline & $\mathrm{n}$ & $\%$ & & $\mathrm{n}$ & $\%$ \\
\hline Yes & 91 & 47.4 & Greece & 55 & 60.4 \\
\hline No & 101 & 52.6 & Italy & 25 & 27.5 \\
\hline & & Spain & 3 & 3.3 \\
\hline & & Hungary & 0 & 0.0 \\
\hline & & Other countries & 8 & 8.8 \\
\hline
\end{tabular}

Compared to non-EU camps, the number of people who lived in EU camps is slightly lower, with 91 (47.4 percent). However, more people did not live in a camp in the EU (52.6 percent), which could be related to EU-Dublin asylum procedures. It is also essential to mention that some asylum seekers spent time in both camps: non-EU camps and EU camps. The main destinations for asylum seekers arriving in the EU are Greece and Italy. More than every second person (60.4 percent) enters the EU in Greece, and 27.5 percent end up in Italy. In total, both countries constitute over 85 percent of all first EU arrivals. The reason for that is, obviously, the Mediterranean location of both Greece and Italy. Spain plays only a minor role, Hungary functions mostly as a transit country, and the other camps are spread all over Europe (e.g., Bulgaria, France, or Cyprus). Countries like Germany (or other Northern EU states) are not 'classic camp countries' since these countries can provide at least minimum housing 
standards for asylum seekers. The correct term in this context would be 'refugee accommodation. $^{48}$

Question number five asks why people went to the camps in these countries and improves our understanding of the reasons for this selection. Question number six concerns the length of the stay in the camps.

Table 11: Evaluation of Question 5 and Question 6 of the Interviews

\begin{tabular}{|c|c|c|c|c|c|}
\hline \multicolumn{3}{|c|}{$\begin{array}{l}\text { Q5: Why did you choose a camp in the } \\
\text { countries from Q2 \& Q4? Please circle all } \\
\text { that apply. }\end{array}$} & \multicolumn{3}{|c|}{$\begin{array}{l}\text { Q6: For how long did you stay in the } \\
\text { refugee camp(s) named in Q2 \& Q4? }\end{array}$} \\
\hline & $\mathrm{n}$ & $\%$ & & $\mathrm{n}$ & $\%$ \\
\hline Q2: Non-EU country & & & Q2: Non-EU country & & \\
\hline Security & 59 & 47.2 & Less than one year & 56 & 60.9 \\
\hline Accessibility of the country & 31 & 24.8 & $\begin{array}{l}\text { More than one year, but less } \\
\text { than three years }\end{array}$ & 27 & 29.3 \\
\hline I was sent to the camp & 16 & 12.8 & Three years or more & 9 & 9.8 \\
\hline Higher living standard & 10 & 8 & & & \\
\hline Other & 9 & 7.2 & & & \\
\hline Q4: EU country & & & Q4: EU country & & \\
\hline Security & 88 & 42.3 & Less than one year & 58 & 63.7 \\
\hline Accessibility of the country & 52 & 25.0 & $\begin{array}{l}\text { More than one year, but less } \\
\text { than three years }\end{array}$ & 27 & 29.7 \\
\hline I was sent to the camp & 18 & 8.7 & Three years or more & 6 & 6.6 \\
\hline Higher living standard & 20 & 9.6 & & & \\
\hline Other & 30 & 14.4 & & & \\
\hline
\end{tabular}

For both non-EU camps (47.2 percent) and EU camps (42.3 percent), security was the dominant factor for choosing these countries and camps, followed by the accessibility of the

\footnotetext{
${ }^{48}$ Even during the events of summer 2015, asylum seekers lived in halls or other empty buildings in Germany. Usually, people were not forced to live in tents. 'Tent cities' like those in other countries never really existed. Thus, none of the interview participants reported such adverse living conditions in Germany.
} 
country. Hence, the numbers indicate refugees were, in the first place, concerned about their lives and were not seeking higher living standards elsewhere. The country's accessibility argues in the same way but tells us also that a significant number of people chose these camps only for reasons of proximity. Initially, they had different primary migration destinations, and their decisions were made out of extremity. Approximately eight to thirteen percent had no choice, and state authorities sent them to the camps after crossing a border during their journey. Other causes include, for example, migrants already had friends and family in one of those camps (network theory).

Regarding the length of the stay in the camps, the EU and non-EU camps' results are almost identical. In each case, more than 60 percent of interview partners stayed less than a year, over 29 percent remained over a year, but less than three years, and only a relatively small percentage of people lived longer than three years in a camp. Therefore, we find evidence for the hypothesis that camps are usually not more than a short-term solution. People do not see long-term prospects for them there and decide to move on. Thus, camps were not able to reduce the push factors significantly.

The next two questions are about personal experience and evaluation concerning nutrition supply and health care in the camps; obviously, two crucial factors in assessing the situation in the camps. The interview partners had the opportunity to choose from 'very good' to 'very bad.'

Table 12: Evaluation of Question 7 and Question 8 of the Interviews

\begin{tabular}{llllll}
\hline $\begin{array}{l}\text { Q7: How would you evaluate the nutrition } \\
\text { situation (food \& water supply) in the } \\
\text { camp(s) in Q2 \& Q4? }\end{array}$ & $\begin{array}{l}\text { Q8: How would you evaluate the health } \\
\text { care situation (medicine, doctors, } \\
\text { equipment, etc.) in the camp(s) in Q2 \& } \\
\text { Q4? }\end{array}$ \\
\hline n & $\%$ & & $n$ & $\%$ \\
\hline Q2: Non-EU country & & & Q2: Non-EU country & & \\
\hline Very good & 0 & 0.0 & Very good & 3.3 \\
\hline Good & 5 & 5.4 & Good & 4.3 \\
\hline Sufficient & 10 & 10.9 & Sufficient & 15.2 \\
\hline Insufficient & 28 & 30.4 & Insufficient & 26.3 \\
\hline Very bad & 49 & 53.3 & Very bad & 45 & 48.9 \\
\hline Q4: EU country & & & Q4: EU country & & \\
\hline
\end{tabular}




\begin{tabular}{llllll}
\hline Very good & 3 & 3.3 & Very good & 8 & 8.8 \\
\hline Good & 9 & 9.9 & Good & 17 & 18.7 \\
\hline Sufficient & 20 & 22.0 & Sufficient & 29 & 31.9 \\
\hline Insufficient & 23 & 25.3 & Insufficient & 21 & 23.1 \\
\hline Very bad & 36 & 39.6 & Very bad & 16 & 17.6 \\
\hline
\end{tabular}

The results of the interviews are slightly different between non-EU camps and EU camps. Overall, the impression of the non-EU camps was quite devastating. Fifty-three point three percent evaluated the nutrition situation as 'very bad' and another 30.4 percent as 'insufficient.' Only 10.9 percent rated it as 'sufficient.' Only five of the interview participants gave second-best grade. None of them gave the best grade, which is surprising since many of the asylum seekers spent some time in Turkish camps that usually get relatively high ratings from experts and aid workers. However, not all Turkish camps can provide the same high living standards, and the 'good' camps only have limited capacities. Camps from other countries than Turkey did not even once receive a 'sufficient' rating.

In comparison, camps in the EU provided better living conditions, but there are significant differences between Greece and Italy. While Italian camps got 'good' and 'very good' ratings, Greek camps were usually described as 'insufficient' or 'very bad.' Still, over 39 percent of the participants gave a 'very bad' evaluation. In general, the allocation of the ratings in EU camps is quite diverse, and they range between 3.3 percent 'very good' to 39.6 percent 'very bad' (sufficient and insufficient are almost equal).

In terms of health care, the perception was, in both cases, more positive. Nevertheless, the vast majority of people who lived in non-EU camps gave a negative evaluation (over 48 percent). Again, there were some differences between Turkey and other countries. A few asylum seekers even evaluated Turkish camps' health care situation as 'very good' or 'good.' Thus, these camps had more medicines and qualified doctors than, for example, in Jordan or Lebanon. This aspect could be explained by the Turkish state's economic power and the overall higher education level. In the EU camps, by contrast, we can almost see a normal distribution. Again, Italian camps received some positive evaluations ('very good' and 'good' equals 27.5 percent), whereas camps on the Greek islands got the worst ratings (over 40 percent of negative responses). The rest of the asylum seekers described the health care situation in EU camps as 'sufficient' (31.9 percent). The reason for that is the presence of aid organizations in the EU, a higher level of expertise, and more (financial) resources. 
The following section evaluates the educational situation in the camps and asks if there were schools for children or other educational institutions. As the interview participants' characteristics showed, the average age of asylum seekers and refugees is very young, and, therefore, education is a crucial category in this context.

Table 13: Evaluation of Question 9 and Question 10 of the Interviews

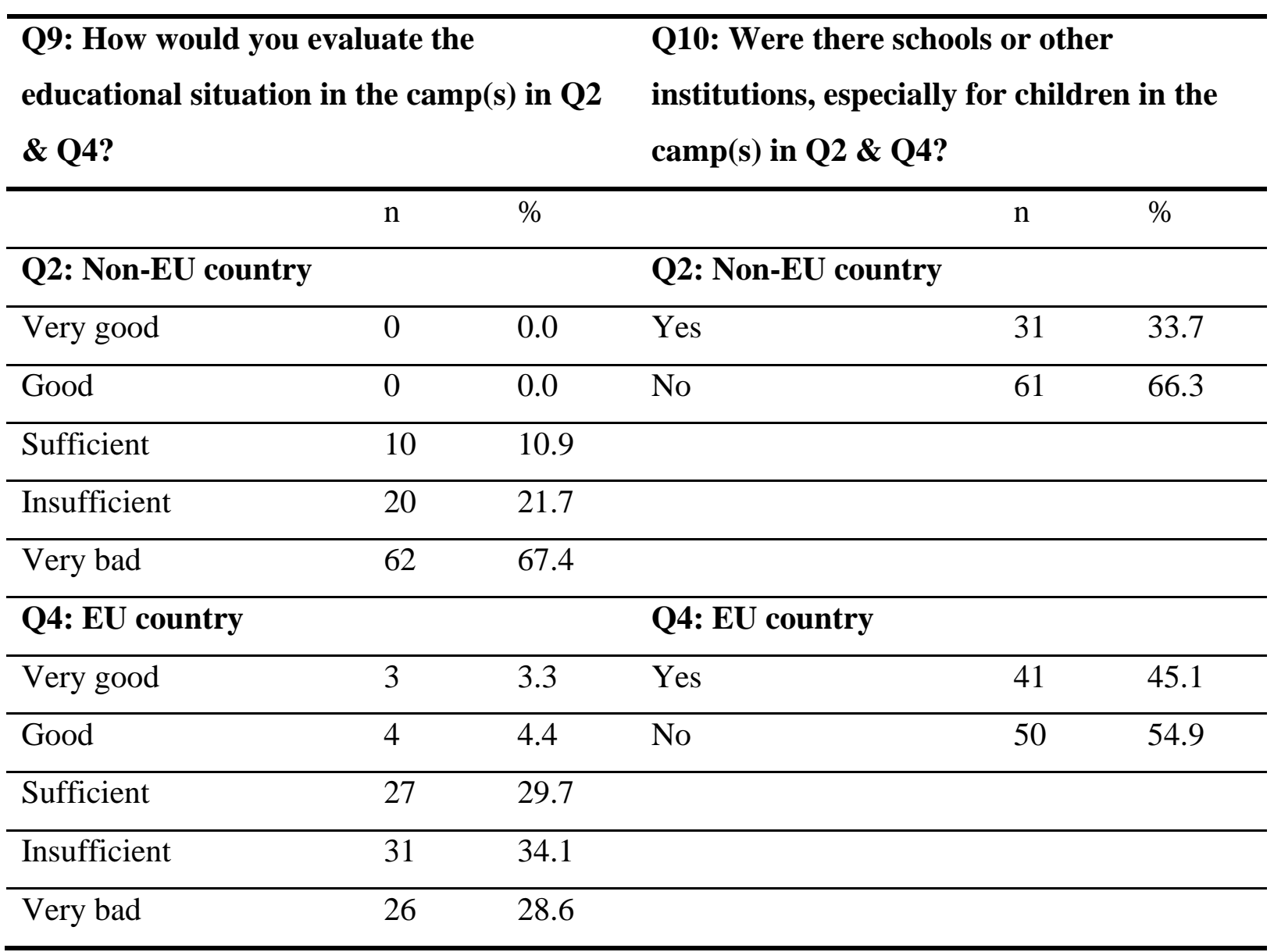

The figures show that non-EU and EU camps struggle to provide proper education to asylum seekers. In both cases, interview partners said schools and educational institutions were rare. The situation in the EU (45.1 to 54.9 percent) was better than in non-EU countries (33.7 to 66.3 percent). E-learning and other modern technologies did not exist, although this could be an approach to improve the situation. Thus, these facts are also reflected in the individual evaluations. The camps outside of the EU received almost 70 percent of 'very bad' and 21.7 percent of 'insufficient' ratings. Only ten point nine percent gave a 'sufficient' grade, and none of the participants answered the question positively. Particularly in the non-EU camps, child labor is a common problem, and, therefore, children do not have the time to go to school regularly. Even Turkey has some room for improvement in this regard. In the EU, child labor is, fortunately, less common. 
Consequently, the camps' educational situation is better, but there are still some significant differences between Italy and Greece. A majority of the negative responses (62.7 percent) came from people who experienced terrible living conditions in Greek camps due to a lack of capacities and educational staff. The rest of the asylum seekers had fewer bad experiences. Seven point seven percent gave positive evaluations, and 29.7 percent said the situation was at least 'sufficient' in the EU camps.

Questions number eleven and twelve focus on job opportunities and (regular) income, two fields that are usually related to each other. Creating jobs gives people prospects, and income is an incentive to stay. Thus, these topics are relevant to the research.

Table 14: Evaluation of Question 11 and Question 12 of the Interviews

\begin{tabular}{ll}
\hline Q11: Were there any job & Q12: Did you receive any income during your \\
opportunities in the camp(s) in Q2 & time in the camp(s) in Q2 \& Q4? If yes, how \\
\& Q4? & much?
\end{tabular}

\begin{tabular}{|c|c|c|c|c|c|}
\hline & $\mathrm{n}$ & $\%$ & & $\mathrm{n}$ & $\%$ \\
\hline Q2: Non-EU country & & & Q2: Non-EU country & & \\
\hline Yes & 24 & 26.1 & No income & 70 & 76.1 \\
\hline $\begin{array}{l}\text { Yes, but not in my } \\
\text { field }\end{array}$ & 13 & 14.1 & Less than 100 EUR per month & 14 & 15.2 \\
\hline \multirow[t]{5}{*}{ No } & 55 & 59.8 & $\begin{array}{l}\text { More than } 100 \text { EUR per month, } \\
\text { but less than } 200 \text { EUR per } \\
\text { month }\end{array}$ & 5 & 5.4 \\
\hline & & & $\begin{array}{l}\text { More than } 200 \text { EUR per month, } \\
\text { but less than } 300 \text { EUR per } \\
\text { month }\end{array}$ & 3 & 3.3 \\
\hline & & & $\begin{array}{l}\text { More than } 300 \text { EUR per month, } \\
\text { but less than } 400 \text { EUR per } \\
\text { month }\end{array}$ & 0 & 0.0 \\
\hline & & & $\begin{array}{l}\text { More than } 400 \text { EUR per month, } \\
\text { but less than } 500 \text { EUR per } \\
\text { month }\end{array}$ & 0 & 0.0 \\
\hline & & & More than 500 EUR per month & 0 & 0.0 \\
\hline Q4: EU country & & & Q4: EU country & & \\
\hline
\end{tabular}




\begin{tabular}{|c|c|c|c|c|c|}
\hline Yes & 27 & 30.0 & No income & 63 & 69.2 \\
\hline $\begin{array}{l}\text { Yes, but not in my } \\
\text { field }\end{array}$ & 11 & 12.2 & Less than 100 EUR per month & 16 & 17.6 \\
\hline \multirow[t]{5}{*}{ No } & 52 & 57.8 & $\begin{array}{l}\text { More than } 100 \text { EUR per month, } \\
\text { but less than } 200 \text { EUR per } \\
\text { month }\end{array}$ & 6 & 6.6 \\
\hline & & & $\begin{array}{l}\text { More than } 200 \text { EUR per month, } \\
\text { but less than } 300 \text { EUR per } \\
\text { month }\end{array}$ & 5 & 5.5 \\
\hline & & & $\begin{array}{l}\text { More than } 300 \text { EUR per month, } \\
\text { but less than } 400 \text { EUR per } \\
\text { month }\end{array}$ & 1 & 1.1 \\
\hline & & & $\begin{array}{l}\text { More than } 400 \text { EUR per month, } \\
\text { but less than } 500 \text { EUR per } \\
\text { month }\end{array}$ & 0 & 0.0 \\
\hline & & & More than 500 EUR per month & 0 & 0.0 \\
\hline
\end{tabular}

Concerning job opportunities or none, the results are almost identical for both non-EU and EU camps. In both cases, roughly 60 percent of the people did not have any job opportunities, between 12.2 to 14.1 percent had job opportunities but not in their field, and between 26.1 to 30 percent found job opportunities. On some rare occasions, people were even running their own businesses. However, there are some differences between EU and non-EU camps. Outside of the EU, a black labor market was expected. In the EU, there were more legal activities for asylum seekers, e.g., food and water distribution in cooperation with international organizations. It does not mean that EU camps were free from illegal activities, but state authorities were paying less attention to them in other parts of the world.

Nevertheless, most people had to live without any income, 76.1 percent in non-EU camps, and 69.2 percent in EU camps. Approximately 25 to 30 percent could generate a small income (in most cases, even less than 100 EUR per month). This is because refugees usually have to live from donations, coupons, vouchers, and job opportunities are, as mentioned before, minimal. Interview partners also reported some dubious businesses like dealing with drugs or prostitution, but these activities and their lucrative possibilities were not discussed. On the other hand, people often supported each other without making a profit from it. 
The subsequent questions deal with often underinvestigated issues in this field: free time opportunities and political participation. People are social beings and need more than just work to stimulate themselves, and civic engagement is a form of self-determination.

Table 15: Evaluation of Question 13 and Question 14 of the Interviews

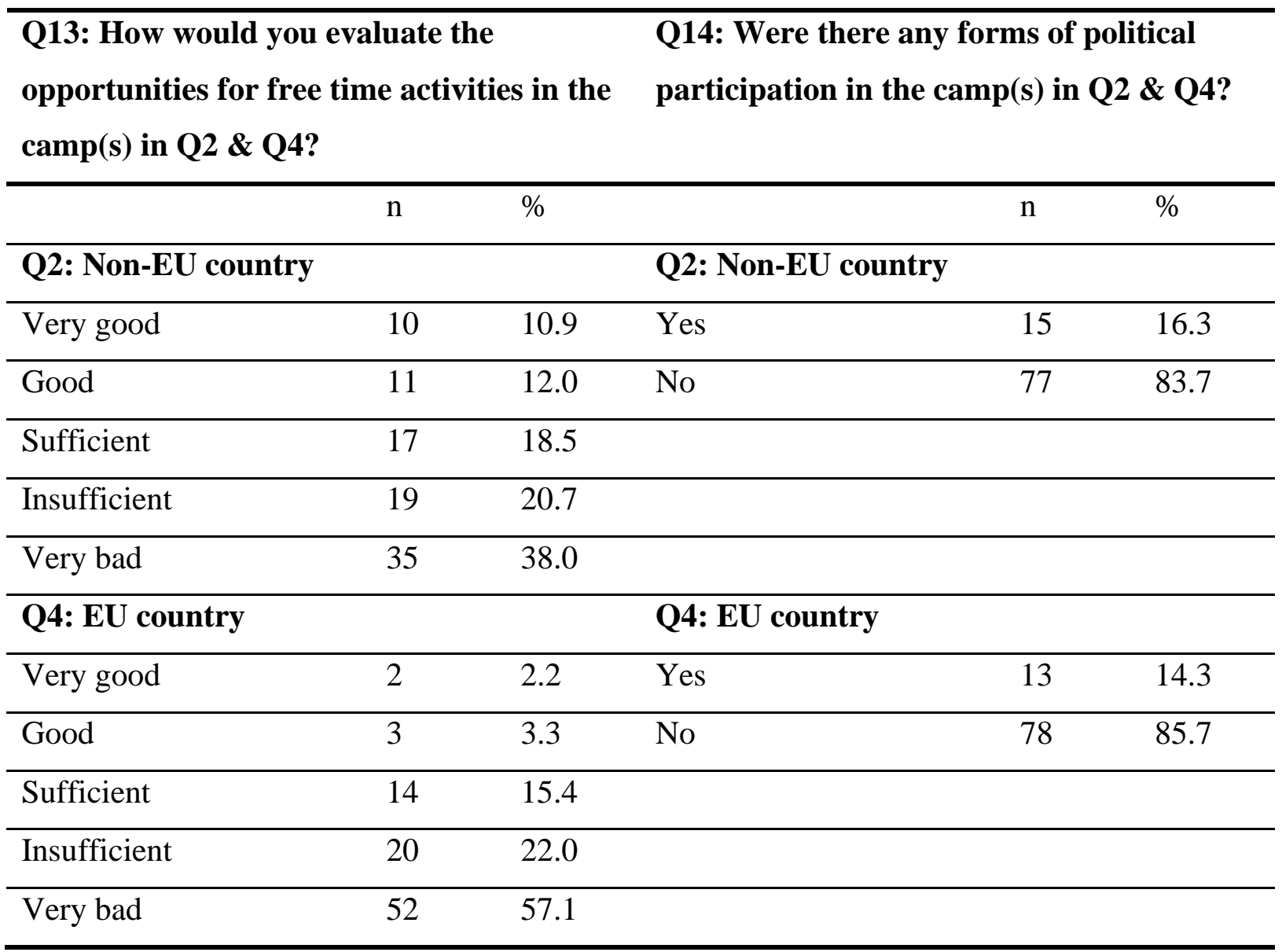

The free-time activities in non-EU camps received over 50 percent negative evaluations ('very bad' and 'insufficient'), 18.5 percent of the ratings were sufficient, and 22.9 percent positive ('very good' and 'good'). The allocation in the EU camps is similar, but there are some crucial differences. Seventy-nine point one percent see the free-activities negatively, and only 5.5 percent rate them positively. Thus, the overall perception is that free-time activities in non-EU camps are better than in EU camps. One possible explanation for this circumstance could be the duration of non-EU camps. Many of them had already existed before the significant mass migration movements to Europe started.

Consequently, some of them have established more long-term infrastructures, including appropriate opportunities for free-time activities. Another explanation is that in neighboring countries, the communities are more homogenous, which might improve social life, as well as spare-time activities. The same applies to questions of political participation. 
The civic involvement opportunities were slightly higher in non-EU camps (16.3 percent) than in EU camps (14.3 percent).

The next two questions evaluate the security situation in the camps and ask the critical question, 'Why did people leave the camp(s)?'. Thus, question number 15 evaluates another push factor, and question number 16 goes deeper into the decision-making process behind the choice leaving the camp(s).

Table 16: Evaluation of Question 15 and Question 16 of the Interviews

\begin{tabular}{|c|c|c|c|c|c|}
\hline \multicolumn{3}{|c|}{$\begin{array}{l}\text { Q15: How was the security situation (high } \\
\text { or low crime rate) in the camp(s) in Q2 \& } \\
\text { Q4? }\end{array}$} & \multicolumn{3}{|c|}{$\begin{array}{l}\text { Q16: Why did you leave the camp(s) in Q2 } \\
\text { \& Q4? Please circle all that apply. }\end{array}$} \\
\hline & $\mathrm{n}$ & $\%$ & & $\mathrm{n}$ & $\%$ \\
\hline Q2: Non-EU country & & & Q2: Non-EU country & & \\
\hline Very high crime rate & 10 & 10.9 & Poor living conditions & 49 & 43.0 \\
\hline High crime rate & 11 & 12.0 & $\begin{array}{l}\text { Seeking a better life in } \\
\text { the host country }\end{array}$ & 24 & 21.1 \\
\hline Normal crime rate & 46 & 50.0 & $\begin{array}{l}\text { Seeking a better life in } \\
\text { the EU }\end{array}$ & 36 & 31.6 \\
\hline Low crime rate & 13 & 14.1 & Other & 5 & 4.3 \\
\hline Very low crime rate & 12 & 13.0 & & & \\
\hline Q4: EU country & & & Q4: EU country & & \\
\hline Very high crime rate & 4 & 6.8 & Poor living conditions & 66 & 47.1 \\
\hline High crime rate & 4 & 6.8 & $\begin{array}{l}\text { Seeking a better life in } \\
\text { the host country }\end{array}$ & 24 & 17.1 \\
\hline Normal crime rate & 51 & 45.5 & $\begin{array}{l}\text { Seeking a better life in } \\
\text { the EU }\end{array}$ & 43 & 30.7 \\
\hline Low crime rate & 27 & 34.1 & Other & 7 & 5.0 \\
\hline Very low crime rate & 5 & 6.8 & & & \\
\hline
\end{tabular}

The ratio regarding the crime rate in non-EU camps is well-balanced between negative responses (22.9 percent; very high and high crime rate), normal crime rate (50 percent), and positive ratings (27.1 percent). Therefore, EU camps perform significantly better. Over 40 percent evaluated the crime rate as 'very low' or 'low,' 45.5 percent said the crime rate was 'normal,' and 13.6 percent perceived a 'very high' or 'high' crime rate. Indeed, the perception 
of such factors is personal and depends on personal experiences. However, the security standards in Europe are, to a certain extent, higher, and state authorities and politicians see asylum seekers very often as a threat. Consequently, they increase the security situation at the border and in camps, which also positively affects the crime rate. Non-EU countries, on the other hand, often do not have the necessary workforce and resources to act in the same way.

The results of why people decided to leave the camp(s) are pretty much identical between non-EU and EU countries. For approximately 43 to 47 percent of the answers, the dominant factor was 'poor living conditions,' followed by 'seeking for a better life in the EU' (about 30 percent), and 'seeking for a better life in the host country' (17 to 21 percent). Only four to five percent had other reasons. Of course, there is never the 'one' factor, but it is, instead, a mix of various reasons. Nevertheless, the trend is undeniable. Neither the non-EU camps nor the EU camps could reduce serious push factors by improving living conditions. In general, people had no reason to stay in the camps and sought different solutions elsewhere. The second observation is that the pull factors also remained high since a substantial number hoped to find a better life in the EU elsewhere, and staying in the host country was only an option for a relatively small number of people. The results suggest refugee camps failed to limit migration movements, externally and internally.

The upcoming question goes in the same direction and asks, not why people left the camp(s), but under which circumstances they might have stayed.

Table 17: Evaluation of Question 17 of the Interviews

Q17: Under which circumstances would you have stayed in the camp(s) in Q2 \& Q4? Please circle all that apply.

\begin{tabular}{lcclcc}
\hline & $\mathrm{n}$ & $\%$ & & $\mathrm{n}$ & $\%$ \\
\hline Q2: Non-EU country & & & Q4: EU country & & \\
\hline $\begin{array}{l}\text { Long-term prospects in } \\
\text { the country }\end{array}$ & 21 & 16.4 & $\begin{array}{l}\text { Long-term prospects in } \\
\text { the country }\end{array}$ & 40 & 29.4 \\
\hline $\begin{array}{l}\text { Higher satisfaction of } \\
\text { basic human needs } \\
\begin{array}{l}\text { water, food, medicine, } \\
\text { etc.) }\end{array}\end{array}$ & 33 & 25.8 & $\begin{array}{l}\text { Higher satisfaction of } \\
\text { basic human needs } \\
\text { (water, food, medicine, } \\
\text { etc.) }\end{array}$ & 24 & 17.6 \\
\hline $\begin{array}{l}\text { I would not have stayed } \\
\text { under any circumstances }\end{array}$ & 56 & 43.8 & $\begin{array}{l}\text { I would not have stayed } \\
\text { under any circumstances }\end{array}$ & 53 & 39.0 \\
\hline Other & 18 & 14.1 & Other & 19 & 14.0 \\
\hline
\end{tabular}

Again, the results are similar for both non-EU and EU camps. The biggest group of asylum seekers answered the question by stating they would not have stayed in the camps under any circumstances (43.8 percent and 39 percent). People had already made their decisions and 
followed their aspirations (e.g., if migrants aimed from the beginning to move to Germany, many of them did not change their mind). These answers reflect the substantial pull factors that, without a doubt, do exist, including economic reasons, free society, network effects, et cetera. At a certain point in the journey, 'staying' is no longer an option. However, the findings suggest that there are circumstances under which people might have changed their minds. People living in non-EU camps report 'higher satisfaction of basic human needs' (25.8 percent) and 'long-term prospects in the country' (16.4 percent). These factors are significant aspects of the debate. Inside the EU, the priorities slightly change, and 'long-term prospects in the country' (29.4 percent) becomes more important, whereas 'higher satisfaction of basic human needs' (17.6 percent) becomes less influential regarding decision-making. An indicator of these changes could be that the supply of food, water, and medicine are more limited in non-EU countries than in EU countries. In EU camps, asylum seekers already made it to Europe and, therefore, they seek long-term prospects, while camps in non-EU countries were just a stopover during their journey. Other circumstances were also popular answers (approximately 14 percent each). Usually, these arguments were related to financial and family reasons. In general, there is evidence that refugee camps could soften migration movements under the right circumstances.

The next question does not distinguish between non-EU and EU specific aspects and asks asylum seekers about the reasons for leaving their country of origin.

Table 18: Evaluation of Question 18 of the Interviews

\begin{tabular}{lll}
\hline $\begin{array}{l}\text { Q18: What was the (major) reason for you leaving the country of your origin? Please } \\
\text { circle all that apply. }\end{array}$ & $\mathrm{n}$ & $\%$ \\
\hline & 134 & 36.9 \\
\hline (Civil) War or Armed Conflict(s) & 77 & 21.2 \\
\hline Political Persecution & 29 & 8.0 \\
\hline Discrimination & 18 & 5.0 \\
\hline Natural Disasters & 34 & 9.4 \\
\hline Economic Reasons / Poverty & 7 & 1.9 \\
\hline Climate change-related reason & 30 & 8.3 \\
\hline Seeking a higher living standard in the EU & 34 & 9.4 \\
\hline Other & & \\
\hline
\end{tabular}

Unfortunately, wars and armed conflicts (36.9 percent) are, by far, the main reason for people leaving their country of origin. 134 out of 192 participants chose this option. Notably, many 
Syrian asylum seekers were profoundly affected by the (civil) war in Syria and decided to migrate to Europe. Still, almost from every country in the study, people suffered from violent conflicts, which is consistent with previous research (Davenport et al. 2003; Melander and Öberg 2007).

The second primary reason is political persecution (21.2 percent), which is often related to autocratic regimes and armed conflicts. 'Economic reasons and poverty' were the third most common response, together with 'other' (9.4 percent). Thus, the research shows that the vast majority had severe reasons for fleeing. The claims of nationalist governments in the EU, who refer to refugees as 'economic migrants,' are not valid. These findings are in line with research results from Neumayer (2004; 2005), Moore and Shellman (2007), and Tétényi et al. (2018). Indeed, there is never only 'one' reason to flee any situation, and various sets of different variables influence asylum seekers in their decision-making process regarding migration. There are other pull and push factors, as well. Wealthy and economically successful states are, of course, attractive destinations for migrants, but the dominant factors remain significant threats to the life and well-being of individuals. Natural disasters (5 percent) and climate change (1.9 percent) played only a minor role, as well as 'discrimination' (8 percent) and 'seeking a higher living standard in the EU' ( 8.3 percent). The other reasons included, for example, family or network-related answers.

Hence, it is also necessary to ask the question the other way around by identifying the main reasons for asylum seekers coming to Europe, respectively, to understand the pull factors behind the decision-making process.

Table 19: Evaluation of Question 19 of the Interviews

Q19: What was the main reason for you coming to the EU? Please circle all that apply.

\begin{tabular}{lll}
\hline & $\mathrm{n}$ & $\%$ \\
\hline Peaceful and secure environment & 113 & 31.5 \\
\hline Political stability & 62 & 17.3 \\
\hline Human rights (open and free society) & 65 & 18.1 \\
\hline Cultural aspects & 34 & 9.5 \\
\hline Higher living standard & 52 & 14.5 \\
\hline Other & 33 & 9.2 \\
\hline
\end{tabular}

Overall, as mentioned above, the question's responses correspond with the results of the previous section. Consequently, a 'peaceful and secure environment' dominates with 31.5 
percent of the total answers given, followed by 'political stability' (17.3 percent) and 'human rights' (18.1 percent). Since armed conflicts and political prosecution dominate the interviews' dominating flight factors, the answers meet the expectations. First and foremost, asylum seekers in the EU are seeking security. Luckily, the EU exists in a period of peace. Any form of military confrontation among Member states is unlikely, which increases the European Union's popularity tremendously as a destination for migrants suffering from war.

Moreover, the EU guarantees freedom, stability, and human rights. Political persecution is very unlikely. 'Higher living standard' (14.5 percent) is only of relatively small relevance in this context. Some of the interview partners even appreciate the cultural diversity in Europe (9.5 percent), and other reasons include, again, mostly family and networks.

According to the Dublin system, asylum seekers have to apply for asylum where they step foot for the first time in the EU. Therefore, the question of where people entered the EU is crucial.

Table 20: Evaluation of Question 20 of the Interviews

Q20: What was the country where you entered the EU for the first time?

\begin{tabular}{lll}
\hline & $\mathrm{n}$ & $\%$ \\
\hline Greece & 101 & 52.6 \\
\hline Italy & 58 & 30.2 \\
\hline Spain & 9 & 4.7 \\
\hline Bulgaria & 4 & 2.1 \\
\hline Hungary & 2 & 1.0 \\
\hline Other countries & 18 & 9.4 \\
\hline
\end{tabular}

The main destinations for asylum seekers are, not surprisingly, Greece (52.6 percent) and Italy (30.2 percent). Due to their Mediterranean Sea location, the accessibility of these countries makes them EU hotspots for asylum seekers' arrivals. Whereas Greece is attractive for refugees and migrants from the Middle East, Italy has always been a destination for Africa's migration movements. However, in recent years, Greece has been more affected by migration influx because of the civil war in Syria and other armed conflicts in the Middle East region. Spain (4.7 percent), Bulgaria (2.1 percent), and Hungary (1 percent) as destination countries only play minor roles in this regard. The relatively high number of other countries (9.4 percent) can be explained mainly by family reunification and people who entered the EU via tourist visas but decided to stay. 
Consequently, question number 21 asks how people come to the EU, and question number 22 tackles the issue of smuggling.

Table 21: Evaluation of Question 21 and Question 22 of the Interviews

\begin{tabular}{llllll}
\hline \multicolumn{2}{l}{ Q21: How did you arrive in the EU? } & \multicolumn{2}{l}{ Q22: Did you pay any smugglers to enter } \\
& $\mathrm{n}$ & $\%$ & & $\mathrm{n}$ & $\%$ \\
\hline By land & 38 & 19.8 & Yes & 123 & 65.8 \\
\hline By sea & 130 & 67.7 & No & 64 & 34.2 \\
\hline By airplane & 21 & 10.9 & & & \\
\hline Other & 3 & 1.6 & & & \\
\hline
\end{tabular}

The most common way of entering the EU is by sea (67.7 percent), followed by land (19.8 percent) and airplanes (10.9 percent). The Mediterranean countries are mostly affected by sea arrivals. Greece and Bulgaria are often entered by land due to their border with Turkey, even though the EU's external borders are highly protected. Entering the EU by flight is less common but still happens. Again, family reunification and tourist visas make this possible and allow people to enter their destination country without going through other EU states.

The majority (65.8 percent) paid smugglers to enter the EU and to reach their destination. The difference between smuggling and human trafficking is the exploitive character of human trafficking (Herkes 2018). Moreover, there is very often a misperception of smuggling. Whereas smuggling is often described as responsible for massive human rights violations (EC 2020), the reality is more complex and nuanced. Smugglers are often friends or family members of migrants who are not necessarily interested primarily in profitmaximization but rather try to help people during their journey (Zhang et al. 2018; Achilli, 2018; Maher 2018; Mengiste 2018). Many of the interview partners were able to confirm these impressions. People described the relationship with their smugglers as 'trustworthy' and 'friendly.' Unfortunately, black sheep do exist in this field. They were mostly concerned about their profit instead of focusing on safe entry opportunities for their clients. Orientation issues can explain the two answers in the category 'other.' Sometimes, people do not realize when, where, and how they cross a border. Uncertainty always remains, and, therefore, these people did not know if they entered the EU first by land or by sea since perfect border controls do not exist.

The last question asks asylum seekers if they intend to go back to their country of origin in the future. 
Table 22: Evaluation of Question 23 of the Interviews

Q23: Did/do you have any intention of going back to your country of origin?

\begin{tabular}{lll}
\hline & $\mathrm{n}$ & $\%$ \\
\hline Yes & 15 & 7.8 \\
\hline No & 158 & 82.3 \\
\hline I do not know yet & 19 & 9.9 \\
\hline
\end{tabular}

The response to this question was overwhelmingly negative ( 82.3 percent). Only a small minority of 7.8 percent intends to return to the country of origin, and 9.9 percent are undecided. Indeed, 'returning' means migrating back and not just visiting family or friends. Many more would like to return as visitors to their home country if the situation should significantly change one day. In general, once people have decided to immigrate, they are unwilling to go back, especially not after all they went through to build up a new life elsewhere. Asylum seekers and refugees want stability, security, and long-term prosperity, and these things cannot be guaranteed if they have to move every few years. 'Permanent settling' reduces mobility.

In many cases, migrants also establish new structures in their lives and find new communities. The children of migrants grow up in this European environment and are more likely to integrate themselves. Usually, after several years in Europe, the children of asylum seekers get the right to apply for European citizenship. Thus, even though the wars in Syria and other conflict regions might end in the future, migrants will not be willing to return to their original lands.

\subsection{Semi-structured Interviews}

I conducted 17 semi-structured interviews with asylum seekers and refugees in Germany. All of the participants also took part in the quantitative research in the previous section. The following table shows the characteristics of the participants.

Table 23: Characteristics of Participants (Qualitative Research)

\section{Characteristics of Participants}

\begin{tabular}{llllll}
\hline & $\mathrm{n}$ & $\%$ & & $\mathrm{n}$ & $\%$ \\
\hline Age & \multicolumn{5}{c}{ Gender } \\
\hline $18-29$ & 17 & 100 & Male & 14 & 82.4 \\
\hline
\end{tabular}




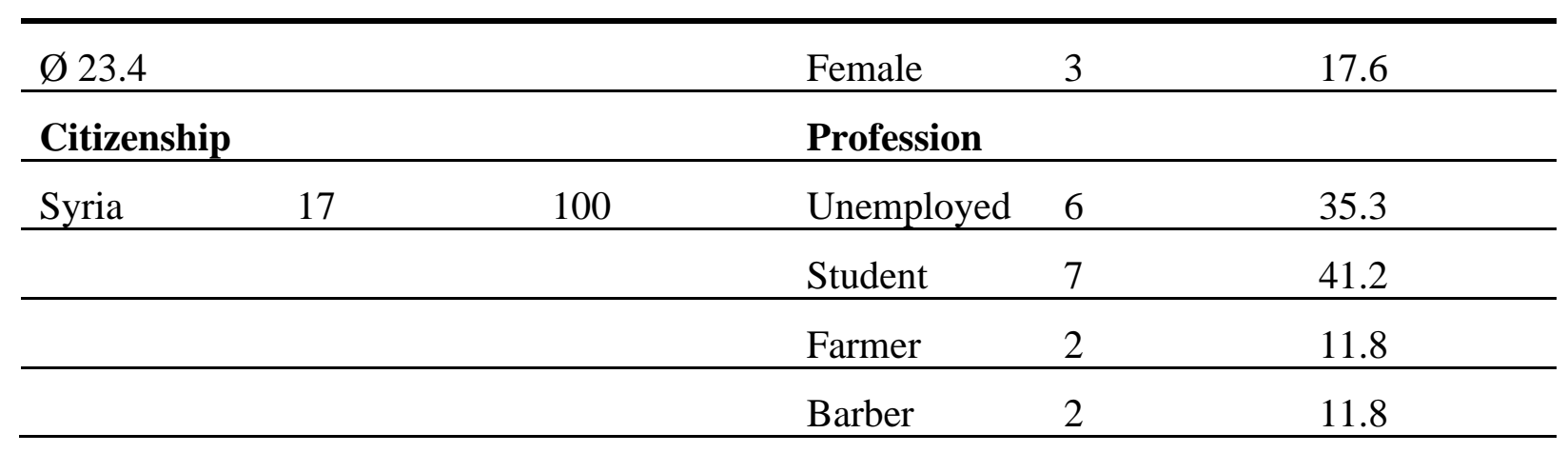

The sample size is in qualitative research, of course, much smaller with 17 participants. This section aimed to extend and complete the evaluation of living conditions in camps by getting an in-depth look into camps' analysis. All the participants have Syrian citizenship and are young (on average aged 23.4 years). Thus, over 40 percent of the interview partners are students. Another 35 percent are unemployed, and the rest of the participants worked as barbers or farmers. The vast majority of the participants were male (14 out of 17), and it is also important to note that people were even several years younger when they talk about their camp experiences. Since most of the big migration movements took place in 2015, many participants were still teenagers or children during that period.

In the process of evaluating the fully-structured interviews, I defined the following six themes for qualitative research.

Table 24: Questions and Themes for Qualitative Research

\section{Questions and Themes for Qualitative Research}

Conditions in non-EU camps

Conditions in EU camps

The Journey to Europe

Reasons for Leaving the Country of Origin/Syria

Reasons for Coming to Germany/Europe

Stay Factors in the Camps

\section{Conditions in non-EU camps}

Once again, we have to differentiate between Turkish camps and camps in Lebanon and Jordan. Whereas the Turkish camps provided reasonable living conditions for its inhabitants, Lebanon and Jordan were overwhelmed by people. One of the interview partners stated: 
"The life in the camps was ok. This is what you can expect when you live as a refugee in a different country. I was glad to be there. Outside of the camp, the conditions were way worse." $(\mathrm{P} 1,25$, male $)$

Indeed, the living conditions were still relatively low compared to European standards. For example, people had to share rooms with other refugees and strangers and used public toilets. Nonetheless, the camps had very often playgrounds for children, education facilities, sufficient health care, and adequate food and water. Overall, the camps were secure and safe places, and international aid organizations, as well as Turkish aid organizations, were present. However, not all Turkish camps fulfilled these high standards. P11 (27, female) draws a different picture from her camp experience:

"The conditions were unreasonable. There were no free time opportunities, no education for children, and only minimal health care. Even the food and water supply were insufficient. Sometimes I went to bed without a meal."

On the contrary, even though not all Turkish camps were 'perfect,' the situation in camps in Lebanon and Jordan can only be described as absolutely devastating. P3 (21, male), who lived for three months in 2015 in a Lebanese camp, reported no real accommodation, an insecure environment, almost no nutrition supply, and terrible living conditions (e.g., no health care and no schools). The person stated:

"I did not feel safe in the camp. Even some terrorists were trying to recruit people. I had to live in an improvised shelter since accommodation opportunities did not exist. Every day, I struggled to find food and water. There were no international aid organizations in the camp."

The same applies to Jordan camps. P9 (28, male), who lived in 2015 for two months in a camp in Jordan, reported similar impressions:

"I lived in an improvised shelter. I was just glad to escape the military conflict in Syria. However, life in the camp was devastating - no schools, no playgrounds, no food, no housing, simply nothing. Once I felt sick, but I could not find a doctor or medicine. I was just glad to leave the place."

Thus, qualitative research confirms the impressions from the quantitative section. Many Turkish camps provided reasonable living conditions, but less wealthy states such as Lebanon or Jordan failed to provide the same standards. 


\section{Conditions in EU camps}

All the participants of the sample came from Syria. Due to Greece's Mediterranean location and proximity to Turkey or the crisis region, all the interview partners stayed in a Greek camp. Thus, first-time arrivals in the EU usually happen by the sea, and very often, Greece is the destination for entering the EU.

According to the participants, the conditions in camps on the Greek islands were, again, absolutely devastating. None of the people I interviewed for the qualitative research had a positive impression about these camps. The contrary is the case. Some people even argued the conditions were at the same level or worse than in Lebanon or Jordan, and the Turkish camps were usually in better shape. People reported living in improvised shelters, no sanitation, no health care, and no education for children. International aid organizations and Greek state authorities were overwhelmed by the situation. There was a shortage of food and water, but sometimes local community members brought nutrition or clothes and toys for children. P2 (20, male) described the situation in the Greek camps as follows:

\footnotetext{
"It was a daily fight for survival - pure chaos and anarchy. For weeks I was sleeping on the street, and for one week, I had to survive with just a few chocolate bars and four bottles of water, during the summer and without any protection from the heat. I was starving and afraid not to survive. Aid workers could not provide sufficient nutrition and health care. I immediately fled from the camps when I had the chance."
}

A slightly better impression came from P7 (25, male), who observed little health care and nutrition. In his opinion, the living conditions were still bad, but he recognized the work of international aid workers:

"These people tried to do their best, but they simply had not the capabilities and resources to improve the situation significantly. The nutrition distribution did not work sufficiently. Other inhabitants of the camp taught children, and a few doctors checked people regularly."

However, it is worth mentioning that P7 lived in a camp in Lebanon before coming to Europe. Thus, he was already used to dire conditions in camps. In conclusion, the conditions on the Greek islands were not reasonably livable.

\section{The Journey to Europe}

Regarding their journey to Europe, almost all the participants had the same story to tell. All of them came to Greece by crossing the Mediterranean Sea, which is not surprising. Indeed, all 
of the participants engaged smugglers to manage their arrival in Europe. The prices and costs of going to the EU vary significantly from smuggler to smuggler - from free to several thousand EUR. Usually, people had to spend several hundreds of EUR. The smuggler's intention can explain the wide price ratio. Not all of them run a profit-orientated business model, but rather have a genuine interest in helping people, who are sometimes even friends, family members, or members from the same network of the refugees (see also table 16). Nonprofit-orientated smugglers usually asked for a lower price.

Nonetheless, most participants had a traumatic journey experience. The boats for crossing the Mediterranean Sea were too small and overcrowded. Sometimes the event took place at night, so the coast guards had a more difficult job stopping the crossing. Thus, arriving by sea to the EU is dangerous and life-threatening. Two examples illustrate this:

"We were on a boat with approximately 1,000 people, but the boat was conceptualized for maybe 200 or 300 people. The smuggler was one of our group, which is the reason why it was so cheap (100,- EUR each). The crossing happened in the middle of the night, and not all of us made it to the other side of the Mediterranean Sea. There were many waves; we felt sick and had no orientation. It was a wonder that we survived this trip." (P15, 20, female); (P16 18, female) - sisters

And:

"The price for crossing the Mediterranean Sea was incredibly low (100,- EUR), but I was with several hundred people on a boat that was designed for 50 people. I did not know the smuggler, and he put as many people as possible on the boat. It was reckless. I risked my life, and I thought I would have to die. Luckily, we made it to Greece, but at least three persons fell from the boat and died in the sea." (P8, 19, male)

The interviews confirm the observation that not all smugglers are ruthless people (see chapter 4.1.3). Some smugglers have good intentions, but 'black sheeps' exist, of course, too. At any rate, the crossing of the Mediterranean Sea is dangerous and life-threatening.

\section{Reasons for Leaving the Country of Origin/Syria}

All the participants gave the same reasons for leaving the country of origin. The outbreak of the civil war in Syria was the main reason. In this context, terrorism and (state) persecution (from the Assad regime) are factors as well. P1 (25, male) said: 
"I liked my life in Syria before the outbreak of the civil war. I worked as a barber, and I have never had the intention of leaving the country. However, the situation changed tremendously, and I decided to leave. I did not have a luxury life, but it was okay. I had friends and family in Syria. As a consequence of the armed conflict, I lost my flat and all my savings. I had to restart my whole life."

Of course, the civil war in Syria also had economic consequences, including the destruction of the whole infrastructure and high unemployment. Some of the participants also mentioned 'unemployment' as a push factor. Thus, 'unemployment' played a minor role. P17 (22, male) expressed it this way:

"The main reason for leaving Syria was, of course, the war. (...) Nevertheless, I lost everything, including my job in the oil business. I had no more reason to stay since I was not only struggling financially (no functional social-welfare system) but also risking my life every day."

Again, the results of the quantitative and qualitative research are almost identical. Armed conflicts are by far the main reason for people fleeing to Europe. Economic factors, such as unemployment, have only a small impact.

\section{Reasons for Coming to Germany/Europe}

In general, all participants were looking for a peaceful and secure destination, which makes Europe attractive. Another important aspect was the overall higher living standard in Germany compared to other countries. Therefore, one could argue that when people decide to leave their country of origin (for severe threats to their life or not), they are influenced by factors of attractiveness and aim to get to the destination which guarantees the highest living standard. However, 'higher living standard' cannot only be determined by economic factors. Even though economic factors are relevant, the majority said they played only a minor role in the semi-structured interviews.

Furthermore, this section produced two new findings regarding the so-called 'openborder policy' of Angela Merkel and family and networks. Every interview partner stressed the importance of fewer migration barriers. For example, P2 (20, male) said:

"I can only move to a destination that is accessible and where I am welcome. Germany always had the reputation of being a free, liberal, and open state. After refugees were welcome in Germany, immediately, everyone knew about the open border policy and wanted to go there." 
The other significant factor is the role of family and networks. Since many of the interview partners were still children or teenagers when they lived in camps and migrated to Germany, they came together with their family and friends or followed their networks. Of course, people preferring moving to places where they find (personal) networks:

"I already had family members and friends in Germany. Without a doubt, this was a major reason for me going to Germany. I wanted to be reunited with the people that are important to me." (P6, 24, male)

Hence, Germany's open border policy influenced migration decisions and was a decisive pull factor. The same applies to family and friends (networks).

\section{Stay Factors in the Camps}

It is one of the research questions of this dissertation if camps can decrease the push factors in the migration process to Europe. Although many people do not see any incentives for staying in the camps or would not have stayed under any circumstances in the camps, I found, again, little evidence for the hypothesis that camps can reduce push factors.

According to P3 (21, male), camps need to provide acceptable living conditions and a (long-term) prospects:

"If camps would provide proper living conditions, I would have considered staying. There are some things that I do not like in Germany, for example, the bad weather. Nonetheless, I want security, education, employment, and sufficient health care. I do not want to be worried about food and water supply or housing. If camps could offer prospects for me, my family, and friends, I might not have moved to Germany."

P10's response goes in a similar direction. He adds:

"I do not really feel at home in Germany. The culture and lifestyle are completely different. Under different circumstances, I think I might feel more comfortable in the south or southeast of Europe. However, in the camp was no prospects. If camps became small Syrian cities with significantly improved living conditions, I would consider living there."

In conclusion, camps are not a (long-term) solution. At the moment, camps fail to provide at least minimum standards. Nevertheless, acceptable living conditions and factors such as prospects, education, employment, sufficient health care, satisfactory nutrition, proper housing, and security have the potential to change the situation. Indeed, not all refugees and 
asylum seekers are willing to move back since they have already established their new life elsewhere, but this is also not the goal, nor should it be. In the framework of early anticipation of refugee movements and urbanization, camps can manage migrants' influx, specifically from the Middle East. Therefore, improved living conditions in camps are a convenient way to save lives without jeopardizing the EU's unity in the migration question.

\subsection{Conclusion}

In total, I conducted 192 fully-structured and 17 semi-structured interviews with asylum seekers and refugees in Germany. Even though everyone had his own story to tell, there are some findings and conclusions that we can derive from the interviews. The average age of the interview participants was very young, and the majority were male. Migration is a discipline of the youth and requires a lot of health, endurance, and resources. As people become older, they are less likely willing to move. In many cases, young males migrate first on very insecure routes and try later, after they have successfully migrated to their destination, to encourage their families and friends to follow them (network theory). Increased mobility and communication infrastructure fuel this development. The actual (mass) migration movements that have started in 2015 mainly originate from the Middle East and the African continent. By far, the biggest group of migrants are currently Syrian refugees in this context. Other countries, such as Iraq, Afghanistan, or Eritrea, are also profoundly affected by people's mass exodus. The main fleeing reasons for asylum seekers in Germany are wars, armed conflicts, and political persecution. In contradiction to nationalistic governments' claims in the EU economic reasons, there was a relevant pull factor, but not a significant push factor. Most of the migrants who moved to Germany had to face severe threats to their lives. Thus, people are seeking peace, stability, and (long-term) prospects in the EU.

According to the Dublin system and their Mediterranean geographic position, Greece and Italy are the most affected states in the EU by migration from the Middle East and Africa for first-time arrivals by sea, which is the most common way to enter the EU for fleeing persons. Hence, on their journey to Europe, migrants are forced to pay smugglers to cross the EU border. Outside of the EU, Syria's neighboring countries are the primary destination for refugees: Turkey, Lebanon, and Jordan. A large portion of refugees ended up living in camps in these countries. Consequently, the role of refugee camps is of extraordinary importance in terms of migration to Europe. The interviews aimed to shed light on the camps' living conditions by asking people about their personal experiences there. Moreover, the conducted 
research makes a comparison between non-EU and EU camps possible. Were camps able to soften the crisis? Did they stop or accelerate migration to the EU? Did camps improve the living conditions of people or not? The interviews provide a unique insight into the life of asylum seekers and refugees and their journey to Europe.

The findings of the study correspond to the research questions 'How does the devastating situation in the perceived reality of asylum seekers and refugees in camps (including undernourishment, poverty, disease, et cetera) affect migration movements to Europe?' and 'How does the camp experience [experiences gained in camps] contribute to refugees' and asylum seekers' decision-making process in the context of migration to Europe?'. The questionnaire's first 17 questions of the fully structured interviews are camp specific topics and evaluated the situation in the non-EU and EU camps in terms of nutrition, health care, education, labor market, income, spare-time activities, political participation, and crime rate. In both cases, the overall perception of the camps was overwhelmingly devastating. Indeed, there are exceptions, and the ratings vary from camp to camp and from country to country (Italy and Turkey usually received better grades). Still, most camps fail to provide at least minimum living standards for their inhabitants. Often, people find themselves under lockdown and have to survive somehow without proper accommodation, nourishment, and medical treatment. The push factors in the camps remain high, and even if people can enter the EU, their situation does not change tremendously. If people move from Turkish to Greek camps, the situation might become worse. Until this day, the EU has not found a solution to improving living conditions in camps, and member states are left alone with this issue. The other interview questions evaluated why people left the camps and under which circumstances they would have stayed in the camps.

Besides, I conducted additional 17 semi-structured interviews concerning conditions in non-EU camps, conditions in EU camps, the journey to Europe, reasons for leaving the country of origin/Syria, and reasons for coming to Germany/Europe and stay factors in the camps. These questions address, among others, the hypothesis of the research that people would not flee to Europe in significant numbers if the situation in refugee camps in the EU and outside of the EU (Middle East) were reasonably livable (reduce the push factors). The interviews show evidence that camps' appropriate living conditions can reduce the push factors and significantly impact migration decisions. Therefore, improving living conditions in refugee camps could be a long-term approach to stop (mass) migration movements to Europe by increasing migrants' life quality. In the past, the case of refugee camps has been 
widely ignored by the literature and researchers with some rare exceptions, such as the work of Fafo (2019a; 2019b). However, the research sample sizes are still too small since I had only limited financial and personal resources. Indeed, interviews and questionnaires with hundreds or thousands of people with camp experience should be the goal, as well as more actual field studies in the camps. A higher budget and more human resources would be a valuable contribution to the study of refugee camps, not only in the context of migration movements to Europe but worldwide. There is a further need for research. Hopefully, future scholars will get this opportunity and enhance the discussion with new findings. 


\section{Conclusion}

In 2015, the EU faced one of the biggest challenges in its history, with the influx of over one million refugees and asylum seekers from the Middle East and the African continent. The migration topic damaged unity and showed cracks in the European integration process. Whereas some member states in the North were willing to accept migrants, many others were not. For an extended period, especially the Mediterranean sea countries, namely Greece and Italy, missed European solidarity and had to deal alone with that issue. At the same time, the rise of the anti-migration movement has started everywhere in Europe. Since then, many things have changed, but migration remains a controversial and emotional topic for many people, even though migration to Europe has significantly decreased due to restrictive policy measures in recent years.

Now, in 2020, migration is still one of the most current topics in media, EU policies, and domestic political debates. This dissertation aimed to elaborate on the role of refugee camps in the context of migration to Europe, which is an oft-ignored issue in the literature. For that purpose, I developed a questionnaire and had 192 fully-structured and 17 semistructured interviews with asylum seekers and refugees in Germany. The main focus of the conversations was on the evaluation of living conditions in camps. How did they contribute to the 'migration crisis' in Europe?

Thus, the dissertation answers the following research questions: 'How does the devastating situation in the perceived reality of asylum seekers and refugees in camps (including undernourishment, poverty, disease, et cetera) affect migration movements to Europe?' and 'How does the camp experience [experiences gained in camps] contribute to refugees' and asylum seekers' decision-making process in the context of migration to Europe?'. The research results indicate that refugee camps' poor living conditions are an essential push factor and cause migration movements to Europe. Hence, the dissertation is built around the theory and hypothesis that reasonable living conditions in refugee camps in the EU and outside of the EU have the potential to reduce (mass) migration movements.

The first chapter of the dissertation is a comprehensive literature review in the field of migration studies. Over 100 years of theories are included in this section. After a short discourse of what migration theory is, the chapter explains from a theoretical standpoint why people move. The most influential methods in this regard are the neoclassical approach, migration, transitions, and development, the historical-structural approach, systems and 
networks, and the new economics of labor migration. All these theories are very much economics orientated and argue that people mainly move because of possible financial benefits. Armed conflicts, natural disasters, or other severe push factors played a minor role in migration studies for decades. The discipline of asylum seekers and refugee studies emerged over time and became more significant in the last 20 years. The aspiration and ability model (including drivers of migration) answers the questions 'Why and where do asylum seekers and refugees move?'. This approach is more flexible and comprehensive by considering various factors that affect primary asylum seekers and refugees (e.g., armed conflicts or political persecution). Severe threats to life and health are getting more attention. However, a comprehensive and coherent approach for refugee camps was missing, which is why I established the 'Push-Stay-Pull Model.' The chapter concludes with the current status of migration studies, future challenges, and some critical remarks.

The next chapter reviews migration in terms of EU policy implications, security and borders, and policy situations. First of all, the chapter defines legal and irregular migration before explaining the Common European Asylum System (CEAS), Schengen, counterterrorism and radicalization, organized crime and human trafficking, EU agencies, and the EU-Turkey deal. All essential EU migration policy agencies are summarized and evaluated. This section's main findings are that EU policy has become more restrictive in recent years, and agreements with non-EU countries have priority. The last part of the chapter includes the actual policy situation (growing populism and human rights), burden-sharing, and borders from a security standpoint. Thus, the current ongoing discussions in EU policy are discerningly reflected. The current debates show that reducing migration is more important than preserving human rights, and the lack of solidarity among EU member states remains a significant issue. All efforts for finding fair distribution and allocation solutions have failed so far, and refugee camps are almost entirely ignored in EU policies, except for some financial contribution from EU funds. In reality, some states are still left alone with asylum seekers and refugees (for example, Greece and Italy), which makes burden-sharing insufficient.

The following section is an in-depth analysis of non-EU and EU refugee camps. The selection of case studies consists of the countries most affected by asylum seekers and refugee movements from the Middle East and the African continent. Outside of the EU, Turkey, Lebanon, and Jordan are part of the analysis. In the EU, the focus is on camps in Greece and Italy. All camps are analyzed by the same pattern: figures, numbers, statistics, and funding requirements. Furthermore, each case study includes a full description of the refugee camps' 
situation in these countries, followed by comparisons between non-European camps, camps in the EU, and between non-European and EU camps. The analysis shows that some countries struggle more than others and that the living condition can vary from camp to camp significantly. Whereas Turkey can provide, overall, sufficient conditions in its camps, Lebanon and Jordan's situation is devastating. In the EU, Italian camps are in better shape than those in Greece. In the comparison between non-EU and EU camps, Turkey is even doing better than Greece. In general, the situation in camps depends on migrants' influx and the country's economic power. Other factors, such as early crisis anticipation or cooperation with international aid organizations, play a role as well. The chapter concludes with a discussion part about the conditions in camps. The connection between aid and conditions in camps is discussed, and the perspective of camps in terms of development and urbanization is explained. The chapter finishes with some recommendations and solutions on how the situation in the camps could be improved. This section shows that a new approach for camps is needed, and the improvement of living conditions is a promising way to prevent mass migration movements from happening.

The last chapter of the dissertation is the interview section. In total, I conducted 192 fully structured (quantitative research) and 17 semi-structured (qualitative research) interviews with asylum seekers and refugees in Germany. This section provides a comprehensive overview of asylum seekers' characteristics in Europe and their journeys, aspirations, and motivations. The interview findings confirm the devastating conditions in camps in- and outside of Europe and make them comparable. The vast majority of the interview partners evaluated the camps' situation in terms of nutrition, health care, education, job opportunities, income, security, political participation, and spare time activities negatively.

Additionally, I could not find any evidence for nationalistic European governments' claims that asylum seekers are not refugees but economic migrants. Hence, most people fled to Europe because of severe threats to their life and health. On the other hand, the study found evidence for the hypothesis that reasonable living conditions in refugee camps in the EU and outside of the EU have the potential to reduce (mass) migration movements. Since the interviewer asked why people leave the camps and under which circumstances they would have stayed, the responses indicate improved living conditions, long-term prospects, and security are a sustainable approach for reducing mass migration movements to Europe. 
Nevertheless, the dissertation has, of course, also some weaknesses and shortcomings. The study of the 'migration crisis' is still a relatively new field, and not many policy-makers and scholars have addressed the camps' situations since 2015. Access to available sources is limited or are out-dated. Another issue is the absence of field studies. Unfortunately, I was not able to visit any of the camps myself. The primary sources for the evaluation of the situation came from reports, journalists, and interviews. The example of Turkey shows that perceptions can be very different. Whereas the media coverage of Turkish camps was widely positive, the interviews revealed a different picture since there are many different camps. Different camps can lead to different experiences in the same country. A distinction between various camps of the same country might increase the quality of the research. Alternatively, there are many more camps that are worth studying. With sufficient funding, I would love to continue my research in this field. ${ }^{49}$

Regarding the interviews, the sample sizes could always be more significant; respectively, a representative study would be a desirable goal. There are probably more efficient ways to do interviews with more financial resources. Interview with asylum seekers and refugees from other European countries than Germany would also enhance the study, as well as interviews with aid workers in the camps and other experts.

The current research can be only a starting point for further research. There is always room for improvement, and I am quite sure that I have only scratched the surface of a field that is still barely covered by scholars. Migration movements have always existed, do exist, and will continue to exist. According to several studies, e.g., climate change will have a severe impact on migration worldwide in the future. Therefore, refugee camps' role needs to be globally reconsidered since camps are a sustainable approach to weaken forced displacement. The outbreak and spread of the Coronavirus Sars-CoV-2 also raise attention to security issues and how inhabitants in camps can be appropriately protected. Moreover, the consequences of pandemics on migration will very likely become an important discussion in migration studies.

\footnotetext{
${ }^{49}$ Beginning in September 2020, I have been working at the Leibniz Institute for East and Southeast European Studies in Regensburg (Germany) as a researcher and continuing my own research on migration.
} 
I hope I have enhanced the discussion in the field of migration and refugee camp studies with new ideas and concepts and that present and future scholars and students will benefit from my research.

Thank you very much for reading my dissertation. 


\section{Bibliography}

Acarturk, C., Konuk, E., Cetinkaya, M., Senay, I., Sijbrandij, M., Cuijpers, P. and Akter, T. (2015). EMDR for Syrian refugees with posttraumatic stress disorder symptoms: results of a pilot randomized controlled trial. European Journal of Psychotraumatology.

Achilli, L. (2015). Syrian Refugees in Jordan: a Reality Check. Migration Policy Centre. [online] Online: http://cadmus.eui.eu/bitstream/handle/1814/34904/MPC_201502_PB.pdf?sequence $=1 \&$ isAllowed=y [Accesed 21.03.2018]

Achilli, L. (2018). The "Good" Smuggler: The Ethics and Morals of Human Smuggling among Syrians. The ANNALS of the American Academy of Political and Social Science, Vol 676, Issue 1, 2018.

Adam, L. B. (2017). The EU-Turkey Deal One Year On: A Delicate Balancing Act. The International Spectator, Italian Journal of International Affairs, Volume 52, 2017 . Issue 4.

Ademmer, E., Barsbai, T., Lücke, M., and Stöhr, T. (2015). 30 Years of Schengen: Internal blessing, external curse? Kiel Policy Brief, No. 88, Kiel Institute for the World Economy (IfW), Kiel.

Ahmed, S., Castañeda, C., Fortier, A.-M., and Sheller, M. (eds.) (2003). Uprootings/Regroundings: Questions of Home and Migration. Oxford: Berg.

Ambrosini, M. (2020). The Local Governance of Immigration and Asylum: Policies of Exclusion as a Battleground. In: Ambrosini M., Cinalli M., Jacobson D. (eds) Migration, Borders and Citizenship. Migration, Diasporas and Citizenship. Palgrave Macmillan, Cham.

Ambrosini M., Cinalli M., Jacobson D. (2020). The Politics of Borders and the Borders of Politics: A Conceptual Framework. In: Ambrosini M., Cinalli M., Jacobson D. (eds) Migration, Borders and Citizenship. Migration, Diasporas and Citizenship. Palgrave Macmillan, Cham.

Amnesty International (2015). Lebanon 2015. [online] Online: https://www.amnesty.de/jahresbericht/2015/libanon\#section-10080 [Accessed 12.11.2017]

Ammar, W., Kdouh, O., Hammoud, R., Hamadeh, R., Harb, H., Ammar, Z., Atun, R., Christiani, D.A., and Zalloua, P. (2016). J Glob Health. 2016 Dec; 6(2): 020704. Published online 2016 Dec 14. DOI: 10.7189/jogh.06.020704.

Anadolu Agency (2019). Turkey: Syrians applaud conditions in refugee camps. [online] Online: https://www.aa.com.tr/en/turkey/turkey-syrians-applaud-conditions-inrefugee-camps/1652940\# [Accessed 16.02.2020]

Anderlini, J. (2020). Border Troubles: Medical Expertise in the Hotspots. In: Ambrosini M., Cinalli M., Jacobson D. (eds) Migration, Borders and Citizenship. Migration, Diasporas and Citizenship. Palgrave Macmillan, Cham.

Andrade, P. G. (2013). The Legal Feasibility of the EU's External Action on Legal Migration: The Internal and the External Intertwined. European Journal of Migration and Law. eISSN: 1571-8166. Print ISSN: 1388-364X.

Arango, J. (2004). Theories of International Migration. In D. Joly (ed.), International Migration and the New Millennium. Aldershot: Ashgate, 15-36.

Argomaniz, J. (2015). European Union Responses to Terrorist use of the Internet. Cooperation and Conflict 50 (2): 250-268.

ASGI (2020). Conditions in Receptions Facilities, Italy. Asylum Information Database. 
[online] Online: https://www.asylumineurope.org/reports/country/italy/receptionconditions/housing/conditions-reception-facilities [accessed 19.02.2020]

Baban, F, Ilcan, S. and Rygiel, K. (2015). Syrian refugees in Turkey: pathways to precarity, differential inclusion, and negotiated citizenship rights. Journal of Ethnic and Migration Studies, Volume 43, pages 41-57.

Barjaba, K. and King, R. (2005). Introducing and Theorising Albanian Migration, in King, R., Mai, N. and Schwandner-Sievers, S. (eds.), The New Albanian Migration, Brighton: Sussex Academic Press, 1-28.

Bakker, E. (2015). EU Counter-radicalization Policies: A Comprehensive and Consistent Approach? Intelligence and National Security, Volume 30, 2015 - Issue 2-3: A Decade of EU Counter-Terrorism and Intelligence: A Critical Assessment.

Barthel, F., and E. Neumayer (2015). Spatial Dependence in Asylum Migration. Journal of Ethnic and Migration Studies, 41(7): 1131-1151

Basch, L., Glick Schiller, N. and Szanton-Blanc, C. (eds.) (1994). Nations Unbound: Transnational Projects, Postcolonial Predicaments and Deterritorialized Nation-States. Amsterdam: Gordon and Breach.

Bauer, T., and K. Zimmermann (1998). Causes of International Migration: A Survey. In Crossing Borders: Regional and Urban Perspectives on International Migration. Edited by P. Gorter, P. Nijkamp, and J. Poot, pp. 95-127. Aldershot: Ashgate.

BBC (2019). Syria war: Turkey can't handle new 'refugee wave', says Erdogan. British Broadcasting Cooperation (BBC). [online] Online: https://www.bbc.com/news/worldeurope-50886120 [Accessed 17.02.2020]

Beech, H. and Hubbard, B. (2020). Unprepared for the Worst: World's Most Vulnerable Brace for Virus. The New York Times. [online] Online: https://www.nytimes.com/2020/03/26/world/asia/coronavirus-refugees-camps bangladesh.html [accessed 28.03.2020]

Ben Farhat, J., Blanchet, K., Juul Bjertrup, P. et al. (2018). Syrian refugees in Greece: experience with violence, mental health status, and access to information during the journey and while in Greece. BMC Med 16, 40 (2018).

Bertelsmann (2018). Demokratie unter Druck: Polarisierung und Repression nehmen weltweit zu. Bertelsmann. [online] Online: https://www.bertelsmannstiftung.de/de/themen/aktuelle-meldungen/2018/maerz/demokratie-unter-druckpolarisierung-und-repression-nehmen-weltweit-zu/ [Accessed 22.03.2018]

Berti, B. (2015). The Syrian Refugee Crisis: Regional and Human Security Implications.Strategic Assessment, Volume 17, No. 4.

Bjéren, G. (1997). Gender and Reproduction. In Hammar, T., Brochmann, G., Tamas, K. \& Faist, T. (eds.), International Migration, Immobility and Development.

Multidisciplinary Perspectives. Oxford: Berg, 219246.

Bjorgo T., (2005). Root Causes of Terrorism. Myths, Reality and Ways Forward. Abingdon: Routledge 2005, pp. 3-4.

Blunt, A. (2007). Cultural Geographies of Migration: Mobility, Transnationality and Diaspora. Progress in Human Geography, 31(4): 684-694.

Bonizzoni, P. (2020). The Border(s) Within: Formal and Informal Processes of Status Production, Negotiation and Contestation in a Migratory Context. In: Ambrosini M., Cinalli M., Jacobson D. (eds) Migration, Borders and Citizenship. Migration, Diasporas and Citizenship. Palgrave Macmillan, Cham.

Borjas, G.J. (1989). Economic Theory of International Migration. International Migration Review, 23(3): 457-485.

Börzel, T. and Risse, T. (2018). From the euro to the Schengen crises: European integration 
theories, politicization, and identity politics. Journal of European Public Policy Volume 25, 2018 - Issue 1: SI: THEORY MEETS CRISIS.

Bossong, R. (2014). EU Cooperation on Terrorism Prevention and Violent Radicalization: Frustrated Ambitions or New Forms of EU Security Governance? Cambridge Review of International Affairs 27 (1): 66-82.

Bosworth and Turnbull (2015). Immigration detention, punishment and the criminalization of migration. The Routledge Handbook on Crime and International Migration. Routledge. DOI: https://doi.org/10.4324/9780203385562.

Boyd, M. and Nowak, J. (2012). Social Networks and International Migration, in Martiniello, M. and Rath, J. (eds.). An Introduction to International Migration Studies. Amsterdam: Amsterdam University Press, 77-103.

Boyle, P., Halfacree, K. and Robinson, V. (1998). Exploring Contemporary Migration. London: Longman.

Brettell, C. B., and Hollifield, J. F. (eds.) (2008). Migration Theory. Talking Across Disciplines. New York: Routledge.

BAMF (2020). Aktuelle Zahlen (01/2020). Bundesamt für Migration und Flüchtlinge [online] Online:

https://www.bamf.de/SharedDocs/Anlagen/DE/Statistik/AsylinZahlen/aktuelle-zahlenjanuar-2020.html [Accessed 31.03.2020]

BPB (2020). Demografie von Asylsuchenden in Deutschland. Bundeszentrale für politische Bildung. [online] Online: https://www.bpb.de/gesellschaft/migration/flucht/zahlen-zuasyl/265710/demografie [Accessed 31.03.2020]

Burke et al. (2009). Warming increases the risk of civil war in Africa. PNAS 106 (49).

Burke, M., Hsiang, S. and Miguel, E. (2015). Climate and Conflict. Annual Review of Economics.

Cagaptay, S. (2014). The Impact of Syria's Refugees on Southern Turkey. Washington Institute for Near East Policy, Policy Focus 130.

Carling, J. (2002). Migration in the age of Involuntary Immobility: Theoretical Reflections and Cape Verdean Experiences. Journal of Ethnic and Migration Studies 28 (1): 542.

Carling, J. and Collins, F. (2018). Aspiration, desire and drivers of migration. Journal of Ethnic and Migration Studies, 44:6, 909-926.

Carling, J. and Schewel, K. (2018). Revisiting aspiration and ability in international migration, Journal of Ethnic and Migration Studies, 44:6, 945-963.

Carr, E. (1939). The twenty years' crisis, 1919-1939. Reissued with a new preface from Michael Cox. Palgrave Macmillan, London 2016, ISBN 978-1-349-95075-1.

Carrera, S., Cassarino, J. P., Qadim, E., Nora, Lahlou, Mehdi, Den Hertog and Leonhard (2016). EU-Morocco Cooperation on Readmission, Borders and Protection: A Model to Follow? CEPS Papers in Liberty and Security in Europe, 2016.

Cassarino, J.P. (2004). Theorising Return Migration: The Conceptual Approach to Return Migration Revisited. International Journal on Multicultural Societies, 6(2): 253-279.

Castles, S., Booth, H. and Wallace, T. (1984). Here for Good: Western Europe's New Ethnic Minorities. London: Pluto.

Castles, S. and Miller, M.J. (1993). The Age of Migration: International Population Movements in the Modern World. London: Macmillan.

Castles, S. (2000). Ethnicity and Globalization: From Migrant Worker to Transnational Citizen. SAGE Publications, 2000. University of Michigan.

Castles, S. and Delgado Wise, R. (eds) (2008). Migration and Development: Perspectives from the South. Geneva: International Organisation for Migration.

Castles, S. and Miller, M.J. (2009). The Age of Migration: International Population 
Movements in the Modern World. Basingstoke: Palgrave Macmillan (4th edition).

Castles, S. (2010). Understanding Global Migration: A Social Transformation Perspective. Journal of Ethnic and Migration Studies, 36(10): 1565-1586.

Ceccorulli, M. (2018). Back to Schengen: the collective securitisation of the EU free-border area. West European Politics Volume 42, 2019 - Issue 2: The European Union, Security Governance and Collective.

Chambers, I. (1994). Migrancy, Culture, Identity. London: Routledge.

Chatty, D. (2009) The Iraqi Refugees: The New Crisis in the Middle East. London: I. B. Tauris.

Chatty, D. (2010) Displacement and Dispossession in the Modern Middle East. Cambridge: Cambridge University Press.

Chatty, D. (2017). The duty to be generous (karam): Alternatives to rights-based asylum in the Middle East Lecture on Africa, Asia and the Middle East, 14 March 2017. Journal of the British Academy (5): 177-199.

Christides, G. and Lüdke, S. (2020). Im Ausnahmezustand. SPIEGEL ONLINE. [online Online: https://www.spiegel.de/politik/ausland/griechenland-reagiert-auf-fluechtlingelesbos-im-ausnahmezustand-a-5146e0ee-8725-4ff2-9a1f-875aab299a6f [Accessed 05.03.2020]

Cicero (2015). „Die Türkei hat ein großes Druckmittel in der Hand“. Cicero. [online] Online: https://web.archive.org/web/20151128183039/http://www.cicero.de/weltbuehne/masse nmigration-als-waffe-die-tuerkei-hat-ein-grosses-druckmittel-der-hand/60134 [Accessed 17.02.2020]

Ciervo A, Mancini F, di Berenardo F, Giammanco A, Vitale G, Dones P, et al. (2016). Louseborne relapsing fever in young migrants, Sicily, Italy, July-September 2015 [letter]. Emerg Infect Dis. 2016 Jan; 22(1): 152-153.

Cinalli M. and Jacobson D. (2020). From Borders to Seams: The Role of Citizenship. In: Ambrosini M., Cinalli M., Jacobson D. (eds) Migration, Borders and Citizenship. Migration, Diasporas and Citizenship. Palgrave Macmillan, Cham.

CNN (2019). Here are all the treaties and agreements Trump has abandoned. CNN. [online] Online: https://edition.cnn.com/2019/02/01/politics/nuclear-treaty-trump/index.html [Accessed 25.10.2020]

Cohen, R. (1987). The New Helots: Migrants in the International Division of Labour. Aldershot: Avebury.

Cohen, R. (1996). Introduction, in Cohen, R. (ed.) Theories of Migration. Cheltenham: Edward Elgar, xi-xvii.

Cohen, R. (2008). Global Diasporas: An Introduction. London: Routledge, 2nd edition.

Cohen, R. and Van Hear, N. (2019). Refugia Radical Solutions to Mass Displacement. Routledge 2019.

Collyer, M. (2007). In-between Places: Trans-Saharan Transit Migrants in Morocco and the Fragmented Journey to Europe. Antipode, 39(4), 620-635.

Compas (2020). Refugia: a new transnational polity in the making. COMPAS, School of Anthropology, University of Oxford. [online] Online: https://www.compas.ox.ac.uk/project/the-refugia-project/ [Accessed 25.10.2020]

Crenshaw, M. (1981). 'The Causes of Terrorism'. Comparative Politics 13/4 (1981) pp. 37999.

Crisp, J. and Jacobsen, S. (1998). Refugee camps reconsidered. Forced Migration review, No. 3, December 1998.

Cuthbert, O. (2020). Coronavirus: Jordan closes off Syrian refugee camps to contain virus. 
The National. [online] Online: https://www.thenational.ae/world/mena/coronavirusjordan-closes-off-syrian-refugee-camps-to-contain-virus-1.993381 [Accessed 28.03.2020]

Cwerner, S. (2001). The Times of Migration. Journal of Ethnic and Migration Studies, 27(1): 7-36.

Dalal, A. (2015). A Socio-economic Perspective on the Urbanisation of Zaatari Camp in Jordan. Migration Letters, Issue No. 3, 263-278.

Davenport, C., Moore, W. and Poe, S. (2003). Sometimes You Just Have to Leave: Domestic Threats and Forced Migration, 1964-1989. International Interactions, 29:1, $27-55$.

Debray, R. (2010). Eloge des frontières. Paris: Gallimard.

Dedja, S. (2012). Human Rights in the EU Return Policy: The Case of the EU-Albania Relations. European Journal of Migration and Law. eISSN: 1571-8166. Print ISSN: 1388-364X.

de Haas, H. (2010.) Migration transitions - A theoretical and empirical inquiry into the developmental drivers of international migration. International Migration Institute (IMI), Oxford Department of International Development (QEH), Paper 24.

De Luce, D. (2020). Stopping coronavirus spread in Syrian refugee camps is 'mission impossible,' Turkish ambassador says. NBC News. [online] Online: https://www.nbcnews.com/health/health-news/stopping-coronavirus-spread-syrianrefugee-camps-mission-impossible-says-turkish-n1153606 [Accessed 28.03.2020]

de Montlocs, M. and Kagwanja, P. (2000). Refugee Camps or Cities? The Socio-economic Dynamics of the Dadaab and Kakuma Camps in Northern Kenya. Journal of Refugee Studies, Volume 13, Issue 2, 1 June 2000, Pages 205-222.

De Nuzzo C. (2020). The Two Dimensions of the Border: An Empirical Study France-Italy. In: Ambrosini M., Cinalli M., Jacobson D. (eds) Migration, Borders and Citizenship. Migration, Diasporas and Citizenship. Palgrave Macmillan, Cham.

de Wenden, C.W. (2010). Irregular Migration in France. Irregular Migration in Europe Myths and Realities. Routledge. DOI: https://doi.org/10.4324/9781315589848.

de Wenden, C.W. (2020). Borders and Migrations: The Fundamental Contradictions. In: Ambrosini M., Cinalli M., Jacobson D. (eds) Migration, Borders and Citizenship. Migration, Diasporas and Citizenship. Palgrave Macmillan, Cham.

Dionigi, F. (2016). The Syrian refugee crisis in Lebanon: state fragility and social resilience. LSE Middle East Centre paper series (15). Middle East Centre, LSE, London, UK.

Drbohlav, D. and Medová, L. (2010). Czech Republic: Irregular Migration - 'Old Wine in New Bottles'. Irregular Migration in Europe Myths and Realities. Routledge. DOI: https://doi.org/10.4324/9781315589848.

Düvell, F. (2011). Paths into Irregularity: The Legal and Political Construction of Irregular Migration. European Journal of Migration and Law. eISSN: 1571-8166. Print ISSN: 1388-364X.

EFJ (2017). Environmental Justice Foundation. BEYOND BORDERS: Our changing climate - its role in conflict and displacement. EFJ. [online] Online:

https://ejfoundation.org/resources/downloads/BeyondBorders.pdf\#page=30\&zoom=au to,-158,37 [Accessed 28.01.2020]

Eisele, K. and Wiesbrock, A. (2011). Enhancing Mobility in the European Neighborhood Policy? The Cases of Moldova and Georgia. Review of Central and East European Law. eISSN: 1573-0352, Print ISSN: 0925-9880.

Engbersen, G. (2001). The Unanticipated Consequences of Panopticon Europe: Residence Strategies of Illegal Migrants, in V. Guiraudon and C. Joppke (eds.) Controlling a New Immigration World. London: Routledge, 222-246. 
El-Khatib, Z., Scales, D., Vearey, J. and Forsberg, B. (2013). Syrian refugees, between rocky crisis in Syria and hard inaccessibility to healthcare services in Lebanon and Jordan. Conflict and Health 2013, 7:18.

Ettinger, A. (2019). Principled realism and populist sovereignty in Trump's foreign policy. Cambridge Review of International Affairs, Volume 33, 2020 - Issue 3.

EC (2019a). Managing Migration EU Financial Support to Greece. European Commission. [online] Online: https://ec.europa.eu/home-affairs/sites/homeaffairs/files/what-wedo/policies/european-agenda-migration/201902_managing-migration-eu-financialsupport-to-greece_en.pdf [Accessed 18.02.2020]

EC (2019b). Managing Migration EU Financial Support to Italy European Commission. [online] Online: https://ec.europa.eu/home-affairs/sites/homeaffairs/files/what-wedo/policies/european-agenda-migration/201905_managing-migration-eu-financialsupport-to-italy_en.pdf [Accessed 19.02.2020]

EC (2020). Migration and Home Affairs. An official website of the European Union. European Commission. [online] Online: https://ec.europa.eu/homeaffairs/index_en [Accessed 15.02.2020]

European Parliament (2016). EU-TURKEY STATEMENT \& ACTION PLAN. European Parliament. [online] Online: www.europarl.europa.eu/legislative-train/theme-towardsa-new-policy-on-migration/file-eu-turkey-statement-action-plan [Accessed 15.02.2020]

Fafo (2019a). Syrian refugees in Jordan: better off than before but still vulnerable. Fafo. [online] Online: https://www.fafo.no/images/pub/2019/2019-Oct-Brief-Syrian-ref.pdf [Accessed 06.11.2020]

Fafo (2019b). The living conditions of Syrian refugees in Jordan Results from the 2017-2018 survey of Syrian refugees inside and outside camps. Fafo-report, 2019:04.

Faist, T. (1997). The Crucial Meso-Level. In T. Hammar, G. Brochmann, K. Tamas \& T. Faist (eds.), International Migration, Immobility and Development. Multidisciplinary Perspectives. Oxford: Berg, 187-218.

Faist, T. (2000). The Volume and Dynamics of International Migration and Transnational Spaces. Oxford: Oxford University Press.

Faist, T. (2010). Towards Transnational Studies: World Theories, Transnationalisation and Changing Institutions, Journal of Ethnic and Migration Studies, 36(10): 1665-1687.

Fakiolas, R. (2003). Regularising Undocumented Migrants in Greece: Procedures and Effects, Journal of Ethnic and Migration Studies, 29(3): 539-561.

Farah, R. (2006). PALESTINIAN REFUGEES. Interventions, 8:2, 228-252.

Fasani, F. (2010). The Quest for La Dolce Vita? Undocumented Migration in Italy. Irregular Migration in Europe Myths and Realities. Routledge. DOI: https://doi.org/10.4324/9781315589848.

Favell, A. (2008). Re-booting Migration Theory: Interdisciplinarity, Globality and Postdisciplinarity in Migration Studies, in C. B. Brettell, \& J. F. Hollifield (eds.), Migration Theory. Talking Across Disciplines. New York: Routledge, 259-278.

Fielding, T. (1992). Migration and Culture, in Champion, T. and Fielding,T. (eds.) Migration Processes and Patterns, Vol. 1: Research Progressand Prospects, London: Belhaven Press, 201-212.

Finnemore, M. (1996). National Interests in International Society. Cornell University Press, ISBN 978-0-8014-8323-3.

FitzGerald, D. D. and Arar, R. (2018). The Sociology of Refugee Migration, Annual Review of Sociology 2018 44:1, 387-406.

Frangieh, G. (2016). Relations Between UNHCR and Arab Governments: Memoranda of Understanding in Lebanon and Jordan. LSE Middle East Centre Collected Papers 6. 
Foucher, M. (2007). L'obsession des frontières. Paris: Perri.

FPRI (2014). Building resilience to conflict through food-security policies and programs.

FPRI. [online] Online:

http://ebrary.ifpri.org/utils/getfile/collection/p15738coll2/id/128136/filename/128347.

pdf [Accessed 28.01.2020]

Francis, A. (2015). Jordan's Refugee Crisis. CARNEGIE. [online] Online:

http://carnegieendowment.org/2015/09/21/jordan-s-refugee-crisis-pub-61338

[Accessed 12.11.2017]

Frank, A.G. (1969). Capitalism and Underdevelopment in Latin America. New York: Monthly Review Press.

Frank, A.G. (1978). Dependent Accumulation and Underdevelopment. London: Macmillan.

Frey, C. and Osborne, M. (2013). The Future of Employment: how susceptible are jobs to computerization? Oxford. [online] Online:

https://www.oxfordmartin.ox.ac.uk/downloads/academic/The_Future_of_Employment .pdf [accessed 13.11.2017]

Froebel, F., Heinrichs, J. and Kreye, O. (1980). The New International Division of Labour. Cambridge: Cambridge University Press.

Fussell, E. (2012). Space, Time, and Volition: Dimensions of Migration Theory, in M.R. Rosenblum and D.J. Tichenor (eds.) The Oxford Handbook of the Politics of International Migration. Oxford: Oxford University Press, 25-52.

Futo, P. (2010). Hungary: A Quantitative Overview of Irregular Migration. Irregular Migration in Europe Myths and Realities. Routledge.

Gall, C. (2019). Turkey's Radical Plan: Send a Million Refugees Back to Syria. The New York Times. [online] Online:

https://www.nytimes.com/2019/09/10/world/middleeast/turkey-syria-refugeeserdogan.html [Accessed 28.03.2020]

Gallup (2008). World Poll Questions. Washington, DC: Gallup.

Giliberti, L., and Queirolo Palmas, L. (2020). Solidarities in Transit on the French-Italian Border: Ethnographic Accounts from Ventimiglia and the Roya Valley. In: Ambrosini M., Cinalli M., Jacobson D. (eds) Migration, Borders and Citizenship. Migration, Diasporas and Citizenship. Palgrave Macmillan, Cham.

Glick Schiller, N., Basch, L., and Blanc-Szanton, C. (1992). Towards a Transnational Perspective on Migration: Race, Class, Ethnicity, and Nationalism Reconsidered. New York: Annals of the New York Academy of Sciences, vol. 645.

González-Enríquez, C. (2010). Spain: Irregularity as a Rule. Irregular Migration in Europe Myths and Realities. Routledge.

Goodman, S. and Kirkwood,S. (2019). "Political and media discourses about integrating refugees in the UK." European Journal of Social Psychology, 49, 7, (1456-1470).

Goss, J. and Lindquist, B. (1995). Conceptualising International Labor Migration: A Structuration Perspective, International Migration Review, 29(2): 317-351.

Göbel, A. (2019). Warum der EU-Türkei Deal nicht funktioniert. Deutschlandfunk. [online] Online: https://www.deutschlandfunk.de/fluechtlingslager-in-griechenland-warumder-eu-tuerkei-deal.795.de.html?dram:article_id=466600 [Accessed 18.02.2020]

Greenhill, K. (2010). Weapons of Mass Migration: Forced Displacement, Coercion, and Foreign Policy. Ithaca, NY, Cornell University Press, 2010, 342 p., ISBN : 978-08014-4871-3.

Grillmeier, F. (2020). "Die Kinder fragen, ob sie an dem Virus sterben werden". SPIEGEL ONLINE. [online] Online: https://www.spiegel.de/politik/ausland/corona-angst-auflesbos-die-kinder-fragen-ob-sie-an-dem-virus-sterben-werden-a-104f11f4-6be8-4632a504-c081a0de6f86 [Accessed 28.03.2020] 
Guild, E., Costello, C., Garlick, M., Moreno-Lax, V. and Carrera, S. (2015). Enhancing the Common European Asylum System and Alternatives to Dublin. Study for the European Parliament, LIBE Committee, 2015.

Guild, E., Groenendijk, C.A. et al. (2016). Internal border controls in the Schengen area. Is Schengen crisis-proof? European Pariliament. [online] Online: https://www.europarl.europa.eu/RegData/etudes/STUD/2016/571356/IPOL_STU(201 6)571356_EN.pdf [Accessed 25.03.2020]

Hadlock, L. (2017). 'Rising seas could result in 2 billion refugees by 2100 '. Phys.org. [online] Online: https://phys.org/news/2017-06-seas-result-billionrefugees.html [Accesed 28.01.2020]

Hage, G. (2005). A not so Multi-Sited Ethnography of a not so Imagined Community, Anthropological Theory, 5(4): 463-475.

Halabi, Z. (2004). Exclusion and identity in Lebanon's Palestinian refugee camps: a story of sustained conflict. Environment \& Urbanization, Vol. 16, No. 2.

Hammar, T., Brochmann, G., Tamas, K. and Faist, T. (eds.) (1997). International Migration, Immobility and Development. Multidisciplinary Perspectives. Oxford: Berg.

Hampshire, J. (2016). Speaking with one voice? The European Union's global approach to migration and mobility and the limits of international migration cooperation, Journal of Ethnic and Migration Studies, 42:4, 571-586.

Harris, J. R., and M. P. Todaro. (1970). Migration, unemployment and development: A two-sector analysis. American Economic Review 60:126-142.

Hatton, T. J. (2016). Refugees, Asylum Seekers, and Policy in OECD Countries. American Economic Review, 106 (5): 441-45; Hatton, Timothy J. (2017). Refugees and asylum seekers, the crisis in Europe and the future of policy, Economic Policy, Volume 32, Issue 91, July 2017, Pages 447-496.

Hatton, T. J., and J. G. Williamson (1998). The Age of Mass Migration: Causes and Economic Impact. New York: Oxford University Press.

Heck, G. and Hess, S. (2017). Tracing the Effects of the EU-Turkey Deal The Momentum of the Multi-layered Turkish Border Regime. Movements. Journal for Critical Migration and Border Regime Studies, Vol. 3, Issue 2/2017.

Heijer, M. D., Rijpma, J. and Spijkerboer, T. (2016). Coercion, prohibition, and great expectations: The continuing failure of the Common European Asylum System. 53 Common Market Law Review, Issue 3, pp. 607-642.

Herkes, G. (2018). The Janus-faced victimisation in human smuggling and human trafficking. THE JANUS-FACES OF CROSS-BORDER CRIME IN EUROPE. Eleven International Publishing, ISBN 978-94-6236-871-2.

Hermans, M.P.J., Kooistra, J., Cannegieter, S.C. et al. (2017). Healthcare and disease burden among refugees in long-stay refugee camps at Lesbos, Greece. Eur J Epidemiol 32, 851-854 (2017). https://doi.org/10.1007/s10654-017-0269-4.

Hilz W. (2007). Hans J. Morgenthau, Politics Among Nations: The Struggle for Power and Peace, New York 1948. In: Kailitz S. (eds) Schlüsselwerke der Politikwissenschaft. VS Verlag für Sozialwissenschaften.

Hollifield, J.F. (2008). The Politics of International Migration: How Can We Bring the State in? in Brettell, C. B., \& Hollifield, J. F. (eds.) Migration Theory. Talking Across Disciplines. New York: Routledge, 183-237.

Human Rights Watch (2019). Lebanon: Syrian Refugee Shelters Demolished. Human rights Watch [online] Online: https://www.hrw.org/news/2019/07/05/lebanon-syrianrefugee-shelters-demolished [Accessed 17.02.2020]

IAB (2016). IAB-Kurzbericht 24/2016. Institut für Arbeitsmarkt- und Berufsforschung der 
Bundesagentur für Arbeit. [online] Online:

http://doku.iab.de/kurzber/2016/kb2416.pdf [Accessed 17.05.2018]

İçduygu, A. (2015). Syrian Refugees in Turkey - The Long Road Ahead. Migration Policy Institute. [online] Online: file:///C:/Users/SEBAST 1/AppData/Local/Temp/TCMProtection-Syria.pdf [Accessed 20.03.2018]

ILO (2015). Access to Work for Syrian Refugees in Jordan: A Discussion Paper on Labour and Refugee Laws and Polices 11-12 (2015). International Labour Organization. [online] Online: https://data.unhcr.org/syrianrefugees/download.php?id=8919 [Accessed 17.10.2020]

Jakobeit, C. and Methmann, C. (2007). Klimaflüchtlinge - die verleugnete Katastrophe. Greenpeace. [online] Online: https://www.greenpeace.de/sites/www.greenpeace.de/files/klimafluechtlinge_endv_0. PDF [ Accessed 28.01.2020]

Jansen, C. (1969). Some Sociological Aspects of Migration, in Jackson, J.A. (ed.) Migration. Cambridge: Cambridge University Press, 60-73.

Jones, J.and Winterdyk, J. (2018). Introduction. Human Trafficking: Challenges and Opportunities for the 21st Century. Oñati Socio-legal Series [online], 8 (1), 1-10.

Kaplanoglou, G., and Rapanos, V. T. (2016). Evolutions in consumption inequality and poverty in Greece: The impact of the crisis and austerity policies. Review of Income and Wealth.,64, 105-126.

Kasparek, B. (2016). Complementing Schengen: The Dublin System and the European Border and Migration Regime. In: Bauder H., Matheis C. (eds) Migration Policy and Practice. Migration, Diasporas and Citizenship. Palgrave Macmillan, New York.

Katzenstein, P. (2005). A World of Regions: Asia and Europe in the American Imperium. Ithaca; London: Cornell University Press.

Kaufmann, V., Bergman, M.M. and Joye, D. (2004). Motility: mobility as capital. International Journal of Urban and Regional Research, 28(4): 745-756.

Kaunert, C. and Léonard, S. (2012). The development of the EU asylum policy: venueshopping in perspective. Journal of European Public Policy, 19:9, 1396-1413.

Keohane, R.O. (1984). After Hegemony : Cooperation and Discord in the World Political Economy. Princeton, N.J. :Princeton University Press, 1984.

Kfir, I., (2017). A Faustian Pact - Has the EU-Turkey Deal Undermined the Human Rights in Turkey and Threaten Its Own Security (June 12, 2017). Available at SSRN: https://ssrn.com/abstract=2985217 or http://dx.doi.org/10.2139/ssrn.2985217.

Kindleberger, C.P. (1967). Europe's Postwar Growth: The Role of Labor Supply. New York: Oxford University Press.

Kindleberger, C.P. (1973). The world in depression, 1929-1939. Berkeley: University of California Press.

King, R., Fielding, A. and Black, R. (1997). The International Migration Turnaround in Southern Europe, in King, R. and Black, R. (eds.) Southern Europe and the New Immigrations. Brighton: Sussex Academic Press, 1-25.

King, R. (2002). Towards a New Map of European Migration. International Journal of Population Geography, 8(2), pp. 89-106.

King, R. (2012). Theories and Typologies of Migration: an Overview and a Primer. Willy Brandt series of working papers in international Migration and ethnic Relations 3/12. Malmö Institute for Studies of Migration, Diversity and Welfare (MIM).

Kirişci, K. (2014). Syrian Refugees and Turkey's Challenges: Going beyond Hospitality. The Brookings Institution. [online] Online: http://madde14.org/english/images/0/0e/2014BrookingsSyriaKirisci.pdf [Accessed 20.03.2018] 
Knights, M. and King, R. (1998). The Geography of Bangladeshi Migration to Rome. International Journal of Population Geography, 4(4): 299-321.

Koser, K. (2007). Refugees, Transnationalism and the State. Journal of Ethnic and Migration Studies, 33(2): 233-254.

Kousoulis, A.A., Ioakeim-Ioannidou, M., and Economopoulos, K.P. (2016). Access to health for refugees in Greece: lessons in inequalities. Int J Equity Health 15, 122 (2016).

Kraler, A. and Hollomey, C. (2010). Austria: Irregular Migration - A Phenomenon in Transition. Irregular Migration in Europe Myths and Realities. Routledge. DOI: https://doi.org/10.4324/9781315589848.

Krasner, S.D. (1985). Structural Conflict: The Third World Against Global Liberalism. University of California Press, 1985.

Kritz, M., Lim, L.L., and Zlotnik, H. (eds.) (1992). International Migration Systems: A Global Approach. Oxford: Clarendon Press.

Kruse, I. and Trauner, F. (2008). EC Visa Facilitation and Readmission Agreements: A New Standard EU Foreign Policy Tool? European Journal of Migration and Law. eISSN: 1571-8166. Print ISSN: 1388-364X.

Kunz, E. (1981). Exile and Resettlement: Refugee Theory. International Migration Review, 15(1-2): 42-51.

Lambert, H. (2009). TRANSNATIONAL JUDICIAL DIALOGUE, HARMONIZATION AND THE COMMON EUROPEAN ASYLUM SYSTEM. Cambridge University Press, Volume 58, Issue 3 ,July 2009 , pp. 519-543.

Lavenex, S. (2016). Multilevelling EU external governance: the role of international organizations in the diffusion of EU migration policies. Journal of Ethnic and Migration Studies, 42:4, 554-570.

Lavenex, S. (2018). 'Failing Forward' Towards Which Europe? Organized Hypocrisy in the Common European Asylum System. Journal of Common Market Studies, Volume 56, Issue 5, July 2018, Pages 1195-1212.

Lee, E. S. (1966). A Theory of Migration. Demography Vol. 3, No. 1 (1966), pp. 47-57.

Lee, J. (2018). Syria's war: Inside Jordan's Zaatari refugee camp. Al Jazeera. [online] Online: https://www.aljazeera.com/indepth/inpictures/syria-war-jordan-zaatari-refugee-camp180326115809170.html [Accessed 17.02.2020]

Lehner, R. (2018). The EU - Turkey - 'deal': Legal Challenges and Pitfalls. International Migration, Volume57, Issue2, April 2019, Pages 176-185.

Léonard, S. (2009). The Creation of FRONTEX and the Politics of Institutionalisation in the EU External Borders Policy. JCER | Journal of Contemporary European Research, Vol 5 No 3 (2009), pp. 371-388.

Léonard, S. (2010). EU border security and migration into the European Union: FRONTEX and securitisation through practices. European Security, 19:2, 231-254.

Léonard, S. and Kaunert, C. (2019). The development of the Common European Asylum System (CEAS). Refugees, Security and the European Union. Routledge.

Lewis, W.A. (1954). Economic Development with Unlimited Supplies of Labour. Manchester School of Economic and Social Studies, 22: 139191.

Liempt, I. (2011). 'And then one day they all moved to Leicester': The Relocation of Somalis from the Netherlands to the UK Explained'. Population, Space and Place, 17(3): 254-266.

Lovec, M. (2017). Politics of the Schengen/Dublin System: The Case of the European Migrant and Refugee Crisis. In: Günay C., Witjes N. (eds) Border Politics. Springer, Cham.

Lucas, R.E.B. and Stark, O. (1985). Motivations to Remit: Evidence from Botswana. Journal 
of Political Economy, 93(5): 901-918.

Mabogunje, A. (1970). Systems Approach to a Theory of Rural-Urban Migration. Geographical Analysis, 2(1): 1-18.

MacDonald, J.S. and MacDonald, L.D. (1964). Chain Migration, Ethnic Neighbourhood Formation and Social Networks. Millbank Memorial Fund Quarterly, 42(1): 82-97.

Maher, S. (2018). Out of West Africa: Human Smuggling as a Social Enterprise. The ANNALS of the American Academy of Political and Social Science, Vol 676, Issue 1, 2018.

Mahler, S.J. and Pessar, P.R. (2006). Gender Matters: Ethnographers Bring Gender from the Periphery to the Core of Migration Studies, International Migration Review, 40(1): 2763.

Malmberg, G. (1997). Time and Space in International Migration, in Hammar, T., Brochmann, G., Tamas, K. \& Faist, T.(eds.), International Migration, Immobility and Development. Multidisciplinary Perspectives, Oxford: Berg, 21-48.

Manners, I. and Murray, P. (2016). "The End of a Noble Narrative?" Europe Integration Narratives after the Nobel Peace Prize. JCMS 2016 Volume 54. Number 1. Pp 202.

Marchetti, C. (2020). Cities of Exclusion: Are Local Authorities Refusing Asylum Seekers?. In: Ambrosini M., Cinalli M., Jacobson D. (eds) Migration, Borders and Citizenship. Migration, Diasporas and Citizenship. Palgrave Macmillan, Cham.

Marshall, T., Rapp, C.A., Becker, D.R., and Bond, G.R. (2008). Key factors for implementing supported employment. Psychiatric Services. 2008;59:886-892.

Martin, I. and Venturini, A. (2015). A comprehensive labour market approach to EU labour migration policy. Migration Policy Centre, Policy Briefs, 2015/07. Retrieved from Cadmus, European University Institute Research Repository, at: http://hdl.handle.net/1814/35743.

Martin, N. (2019). From Containment to Realpolitik and Back Again: A Realist Constructivist Analysis of Turkey-EU Relations and the Migration Issue. Journal of Common Market Studies (JCMS), Volume57, Issue 6, November 2019, Pages 1349-1365.

Martin, P. L. (1993). Trade and Migration: NAFTA and Agriculture. Vol. 30. Washington D.C.: Institute for International Economics.

Martin, P. L., and J. E. Taylor (1996). "The anatomy of a migration hump," in Development strategy, employment, and migration: Insights from models. Edited by J. E. e. Taylor, pp. 43-62. Paris: OECD, Development Centre.

Martiniello, M. and Rath, J. (eds.) (2012). An Introduction to International Migration Studies. Amsterdam: Amsterdam University Press.

Martins, B.O. and Ziegler, M. (2018). Counter-Radicalization as Counter-Terrorism: The European Union Case. In: Steiner K., Önnerfors A. (eds) Expressions of Radicalization. Palgrave Macmillan, Cham.

Massey, D. S. (1988). Economic Development and International Migration in Comparative Perspective. Population and Development Review 14:383-413.

Massey, D.S., Arango, J., Hugo, G., Kouaouci, A., Pellegrino, A. and Taylor, J.E. (1993). Theories of International Migration: A Review and Appraisal. Population and Development Review, 19(3): 431-466.

Massey, D.S., Arango, J., Hugo, G., Kouaouci, A., Pellegrino, A., and Taylor, J.E. (1998). Worlds in Motion. Understanding International Migration at the End of the Millenium. Oxford University Press.

Mattsson, C., Hammarén, N. and Odenbring, Y. (2016). Youth 'At Risk': A Critical Discourse Analysis of the European Commission's Radicalisation Awareness Network Collection of Approaches and Practices used in Education. Power and Education 8 (3): 251-265.Millennium. Oxford: Clarendon Press. 
McClelland, M. (2014). How to Build a Perfect Refugee Camp. The New York Times. [online] Online: https://www.nytimes.com/2014/02/16/magazine/how-to-build-aperfect-refugee-camp.html [Accessed 12.11.2017]

McNeill, W. \& Adams, R.S. (eds.) (1978). Human Migration: Patterns and Policies. Bloomington: Indiana University Press.

Melander, E. and Öberg, M. (2007). The Threat of Violence and Forced Migration: Geographical Scope Trumps Intensity of Fighting. Civil Wars, 9:2, 156-173.

Mengiste, T.A. (2018). Refugee Protections from Below: Smuggling in the Eritrea-Ethiopia Context. The ANNALS of the American Academy of Political and Social Science, Vol 676, Issue 1, 2018.

Miller, M. and Singh, V. (2020). Self-help tool helps Syrians deal with the trauma of war. CBS News. [online] Online: https://www.cbsnews.com/news/syrian-refugeesimportance-of-mental-health-aid-inside-zaatari-refugee-camp-in-middle-east/ [Accessed 28.03.2020]

Milton, D., Spencer, M. and Findley, M. (2013). Radicalism of the Hopeless: Refugee Flows and Transnational Terrorism. International Interactions, 39:5, 621-645.

Mitsilegas, V. (2014). Solidarity and Trust in the Common European Asylum System. CMS 2, 181-202 (2014).

Molter, A. (2016). „Selbst Sterben ist hier ein Problem“ - Zu Besuch in einem Flüchtlingscamp im Libanon. Heinrich Böll Stiftung. [online]. Online: https://www.boell.de/de/2016/02/19/selbst-sterben-ist-hier-ein-problem-ein-besuchden-syrischen-fluchtlingscamps-im-libanon [Accessed 12.11.2017]

Monar, J. (2010). The 'Area of Freedom, Security and Justice': 'Schengen' Europe, Opt-outs, Opt-ins and Associates. In: Dyson K., Sepos A. (eds) Which Europe?. Palgrave Studies in European Union Politics. Palgrave Macmillan, London.

Monitor (2019). Hilflos, obdachlos, chancenlos: Das Elend der Flüchtlinge in Italien. WDR, Westdeutscher Rundfunk. [online] Online:

https://www1.wdr.de/daserste/monitor/sendungen/fluechtlinge-italien-100.html [Accessed 20.02.2020]

Moore, W. H. and Shellman, S. M. (2007). Whither Will They Go? A Global Study of Refugees' Destinations, 1965-1995. International Studies Quarterly, Volume 51, Issue 4, December 2007, Pages 811-834.

Morawska, E. (2001). Gappy Immigration Control, Resourceful Migrants and Pendel Communities, in V. Guiraudon and C. Joppke (eds.) Controlling a New Immigration World. London: Routledge, 173-199.

Morawska, E. (2007). International Migration: Its Various Mechanisms and Different Theories that Try to Explain it. Malmö: Malmö University, Willy Brandt Series of Working Papers in International Migration and Ethnic Relations 1/07.

Morawska, E. (2012). Historical-Structural Models of International Migration, in Martiniello, M. and Rath, J. (eds.) An Introduction to International Migration Studies. Amsterdam: Amsterdam University Press, 55-75.

Morokvasic, M. (1984). Birds of passage are also women. International Migration Review, Jg. 18, Nr. 4, S. 886-907.

Musharbash, Y. (2017). Sie sitzen fest im Niemandsland. ZEIT ONLINE. [online] Online: http://www.zeit.de/politik/ausland/2017-04/fluechtlinge-jordanien-syrien-rukban fluechtlingscamp-wueste [Accessed 12.11.2017]

Müller, O. (2020). 'Solidarity Crime' at the Border: A Lesson from France. In: Ambrosini M., Cinalli M., Jacobson D. (eds) Migration, Borders and Citizenship. Migration, Diasporas and Citizenship. Palgrave Macmillan, Cham.

Myklebost, H. (1989). Migration of Elderly Norwegians to Spain. Norsk Geografisk 
Tidsskrift, 43(4): 191-213.

Myrdal, G. (1957). Rich Lands and Poor. New York: Harper and Row.

Neumayer, E. (2004). Asylum Destination Choice: What Makes Some West European

Countries More Attractive Than Others? European Union Politics, Volume 5 (2):

$155-180$.

Neumayer, E. (2005). Bogus Refugees? The Determinants of Asylum Migration to Western Europe. International Studies Quarterly, Volume 49, Issue 3, September 2005, Pages 389-409.

Nieswand, B. (2011). Theorizing Transnational Migration. The Status Paradox of Migration. New York: Routledge.

Norwegian Refugee Council (2008). Future floods of refugees. A comment on climate change, conflict and forced migration. Norwegian Refugee Council. [online] Online: http://www.migrationdrc.org/publications/resource_guides/Migration_and_Climate_C hange/Future_floods_of_refugees.pdf [Accessed 28.01.2020]

Nye, J.S. (1971). Peace in parts: integration and conflict in regional organization. Boston: Little, Brown, 1971.

Oomen B., and Leenders E. (2020). Symbolic Laws, Street-Level Actors: Everyday Bordering in Dutch Participation Declaration Workshops. In: Ambrosini M., Cinalli M., Jacobson D. (eds) Migration, Borders and Citizenship. Migration, Diasporas and Citizenship. Palgrave Macmillan, Cham.

Özden, Ş. (2013). Syrian Refugees in Turkey. MPC Research Report 2013/05. [online] Online: http://cadmus.eui.eu/bitstream/handle/1814/29455/MPC-RR2013\%2005.pdf?sequence $=1 \&$ isAllowed $=y$ [Accessed 20.03.2018]

Paardekooper B., de Jong J. T. V. M. and Hermanns, J. M. A. (1999). The Psychological Impact of War and the Refugee Situation on South Sudanese Children in Refugee Camps in Northern Uganda: An Exploratory Study. The Journal of Child Psychology and Psychiatry and Allied Disciplines, Volume 40, Issue 4 May 1999, pp. 529-536.

Papadopoulou, A. (2004). Smuggling into Europe: Transit Migrants in Greece. Journal of Refugee Studies, Volume 17, Issue 2, June 2004, Pages167-184, https://doi.org/10.1093/jrs/17.2.167.

Papastergiadis, N. (2000). The Turbulence of Migration. London: Routledge.

Passaris, C. (1989). Immigration and the Evolution of Economic Theory. International Migration 27: 525-542.

Patton, M. (2002). Qualitative research and evaluation methods. 3rd Sage Publications; Thousand Oaks, CA: 2002.

Paul, R. (2013). Limits of the competition state? The cultural political economy of European labor migration policies. Critical Policy Studies Volume 6, 2012 - Issue 4, Pages 379401.

Paul, S. (2018). Climate Change and the Process of Migration to Europe. Corvinus Journal of International Affairs, Vol 3, No 1 (2018), 13-26.

Paul, S. (2019). The Implications of Devastating Conditions in Refugee Camps on the European Migration Crisis. Köz-Gazdaság - Review of Economic Theory and Policy, 13(3), 204-221.

PCC (2014). Climate Change 2014: Impacts, Adaptation, and Vulnerability. Part A: Global and Sectoral Aspects. Contribution of Working Group II to the Fifth Assessment Report of the Intergovernmental Panel on Climate Change [Field, C.B., V.R. Barros, D.J. Dokken, K.J. Mach, M.D. Mastrandrea, T.E. Bilir, M. Chatterjee, K.L. Ebi, Y.O. Estrada, R.C. Genova, B. Girma, E.S. Kissel, A.N. Levy, S. MacCracken, P.R. Mastrandrea, and L.L. White (eds.)]. Cambridge University Press, Cambridge, United 
Kingdom and New York, NY, USA, 1132 pp. [online] Online: https://ipccwg2.gov/AR5/report/full-report/ [Accessed 28.01.2020]

Perez, S.A. and Matsaganis, M. (2018). The Political Economy of Austerity in Southern Europe. New Political Economy, 23:2, 192-207.

Pessar, P.R. and Mahler, S.J. (2003). Transnational Migration: Bringing Gender. International Migration Review, 37(3): 812-846.

Petersen, W. 1958. A General Typology of Migration. American Sociological Review 23: 256-266.

Petras, E. (1981). The Global Labour Market in the Modern World Economy, in Kritz, M.M., Keely, C.B. and Tomasi, S.M. (eds.) Global Trends in Migration: Theory and Research on International Population Movements. New York: Center of Migration Studies, 44-63.

Petrova, S. (2017). Illuminating austerity: Lighting poverty as an agent and signifier of the Greek crisis. European Urban and Regional Studies, vol. 25, 4: pp. 360-372.

Piore, M.J. (1979). Birds of Passage: Migrant Labour and Industrial Societies. New York: Cambridge University Press.

Poon, J. (2016). EU-Turkey Deal: Violation of, or Consistency with, International Law? European Papers, Vol. 1, 2016, No 3, pp. 1195-1203.

Portes, A. (1999). Towards a New World - The Origin and Effects of Transnational Activities. Ethnic and Racial Studies, 22(2): 465-477.

Portes, A., Guarnizo, L.E. and Landolt, P. (1999). The Study of Transnationalism: Pitfalls and Promises of an Emergent Research Field. Ethnic and Racial Studies, 22(2): 217-237.

Portes, A. (2010). Migration and Social Change: Some Conceptual Reflections. Journal of Ethnic and Migration Studies, 36(10): 15371563.

Potts, L. (1990). The World Labour Market: A History of Migration. London: Zed Books.

Pouplier, R. (2020). "Dann wären wir geliefert". SPIEGEL ONLINE. [online] Online: https://www.spiegel.de/politik/ausland/corona-angst-im-fluechtlingslager-auf-lesboskein-wasser-kein-abstand-keine-chance-a-e5036fac-c22d-48ef-a266-c444fa088a5a [Accessed 28.03.2020]

Provera, M. (2015). The Criminalisation of Irregular Migration in the European Union. CEPS Liberty and Security in Europe No. 80/2015.

Putz, A. (2013). Syrische Flüchtlinge im Libanon verkaufen Organe. SPIEGEL ONLINE. [online] Online: http://www.spiegel.de/gesundheit/diagnose/organhandel-syrischefluechtlinge-im-libanon-verkaufen-ihre-nieren-a-932573.html [Accessed 17.05.2018]

Rainey, V. (2015). Lebanon: No formal refugee camps for Syrians. Al Jazeera. [online] Online: http://www.aljazeera.com/news/2015/03/lebanon-formal-refugee-campssyrians-150310073219002.html [Accessed 12.11.2017]

Ranis, G., and J. H. C. Fei. 1961. A theory of economic development. American Economic Review 51:533-565.

Raitio, J. (2011). A Few Remarks to Evaluate the Dublin System and the Asylum Acquis. In: Goudappel F., Raulus H. (eds) The Future of Asylum in the European Union. T.M.C. Asser Press, The Hague.

Rapport, N. and Dawson, A. (eds.) (1998). Migrants of Identity: Perceptions of Home in a World of Movement. Oxford: Berg.

Ravenstein, E.G. (1885). The Laws of Migration. Journal of the Royal Statistical Society, XLVIII, Part 2 (June, 1885), 167-227. Also Reprint No. S-482 in the "Bobbs-Merrill Series in the Social Sciences."

Ravenstein, E.G. (1889). The Laws of Migration. Journal of the Royal Statistical Society, LII (June, 1889), 241-301. Also Reprint No. S-483 in the "Bobbs-Merrill Series in the Social Sciences." 
Reitano, T. (2015). A Perilous but Profitable Crossing: The Changing Nature of Migrant Smuggling through sub-Saharan Africa to Europe and EU Migration Policy (20122015). The European Review of Organised Crime 2(1), 2015, 1-23 ISSN: 2312-1653.

Reslow, N. (2010). Migration and Development? An Assessment of Recent EU Initiatives'. Journal of Contemporary European Research. Volume 6, Issue 1, pp. 3-21.

Reslow, N. (2012). Deciding on EU External Migration Policy: The Member States and the Mobility Partnerships. Journal of European Integration, Volume 34, 2012, Pages 223239.

Richmond, A. (1988). Sociological Theories of International Migration: The Case of Refugees. Current Sociology, 36(2): 7-25.

Rink, D., Couch, C., Haase, A., Krzysztofik, R., Nadolu, B., and Rumpel, P. (2014). The governance of urban shrinkage in cities of post-socialist Europe: policies, strategies and actors. Urban Research \& Practice, 7:3, 258-277

Rostow, W.W. (1960). The Stages of Economic Growth. Cambridge: Cambridge University Press.

Rummel, R.J. (1976). Understanding Conflict and War: Vol. 2 The Conflict Helix. Sage Publications.

Sahlool, Z., Sankri-Tarbichi, A., and Kherallah, M. (2012). Evaluation report of health care services at the Syrian refugee camps in Turkey. Ncbi.nlm.nih.gov. [online] Online: https://www.ncbi.nlm.nih.gov/pmc/articles/PMC3507073/ [Accessed 20.03.2018]

Sales, R. (2007). Understanding Immigration and Refugee Policy. Contradictions and Continuities. Bristol: The Policy Press.

Saliba, I. (2016a). Refugee Law and Policy: Lebanon. Library of Congress. Loc.gov. [online] Online: https://www.loc.gov/law/help/refugee-law/lebanon.php\#_ftn5 [Accessed 17.10.2020]

Saliba, I. (2016b). Refugee Law and Policy: Jordan. Library of Congress. Loc.gov. [online] Online: https://www.loc.gov/law/help/refugee-law/jordan.php [accessed 17.10.2020]

Salloum, R. (2015). Von Behörden schikaniert, von Schleusern geködert. SPIEGEL ONLINE. [online] Online: http://www.spiegel.de/politik/ausland/syrische-fluechtlinge-imlibanon-schikaniert-und-gekoedert-a-1050780.html [Accessed 12.11.2017]

Salt, J. (1992). Migration Processes among the Highly Skilled in Europe. International Migration Review, 26(3): 484-505.

Samers, M. (2010). Migration. London: Routledge.

Saroufim, M. (2014). Ongoing Epidemic of Cutaneous Leishmaniasis among Syrian Refugees, Lebanon. Emerg. Infec. Dis. 2014 Oct; 20(10): 1712-1715.

Scheffran, J. et al. (2012). Climate change, human security and violent conflict. Challenges for Societal Stability. Hexagon Series on Human and Environmental Security. Springer. DOI: 10.1007/978-3-642-28626-1.

Schimmelfenning, F. (2018). European integration (theory) in times of crisis. A comparison of the euro and Schengen crises. Journal of European Public Policy Volume 25, 2018 - Issue 7: Best Papers from the European Union Studies Association 2017 Biennial Conference.

Schleussner et al. (2016). Armed-conflict risks enhanced by climate-related disasters in ethnically fractionalized countries. PNAS 113 (33).

Schiff, M. (1994). How Trade, Aid, and Remittances Affect International Migration. Policy Research Working Paper 1376. Washington: World Bank, International Economics Department.

Schmoll, C., Thiollet, H., and de Wenden, C.W. (2015). Migrations en méditerranée. Paris: CNRS Editions.

Scipioni, M. (2018). Failing forward in EU migration policy? EU integration after the 2015 
asylum and migration crisis. Journal of European Public Policy Volume 25, 2018 Issue 9, Pages 1357-1375.

Sedgwick, M. (2010). The Concept of Radicalization as a Source of Confusion. Terrorism and Political Violence 22 (4): 479-494.

Selby, J., Dahi, O., Förhlich, C., and Hulme, M. (2017). Climate change and the Syrian civil war revisited. Political Geography Volume 60, September 2017, Pages 232-244.

Sharara, S. and Kanj, S. (2014). War and Infectious Diseases: Challenges of the Syrian Civil War. PLOS Pathogens, Volume 10.

Shear, M. and Kanno-Youngs, Z. (2019).Trump Slashes Refugee Cap to 18,000, Curtailing U.S. Role as Haven. The New York Times. [online] Online: https://www.nytimes.com/2019/09/26/us/politics/trump-refugees.html [Accessed 25.10.2020]

Silvey, R. (2006). Geographies of Gender and Migration: Spatializing Social Difference. International Migration Review, 40(1): 64-81.

Sirin, S. and Sirin, L. (2015). The Educational and Mental Health Needs of Syrian Refugee Children. Migration Policy Institute.

Sirkeci, I. (2009). Transnational mobility and conflict. Migration Letters, 6(1), 3-14.

Sirkeci, I., Cohen, J. H., and Yazgan, P. (2012). Turkish culture of migration: Flows between Turkey and Germany, socio-economic development and conflict. Migration Letters, 9(1), 33-46.

Sjaastad, L.A. (1962). The Costs and Returns of Human Migration. Journal of Political Economy, 70(1): 80-93.

Skeldon, R. (1977). The Evolution of Migration Patterns during Urbanization in Peru, Geographical Review, 67(4): 394-411.

Skeldon, R. (1990). Population mobility in developing countries: A reinterpretation. London: Belhaven press.

Skeldon, R. (1997). Migration and development: A global perspective. Essex: Longman.

Smeets, S. and Beach, D. (2019). When success is an orphan: informal institutional governance and the EU-Turkey deal. West European Politics, Volume 43, 2020 Issue 1.

Sotiris, C. and DeMond, S.M. (2017). Refugee Flows and Volunteers in the Current Humanitarian Crisis in Greece. Journal of Applied Security Research, Volume 12, 2017.

Standing, G. (2011). The Precariat: The New Dangerous Class. London: Bloomsbury Academic.

Stark, O. (1991). The Migration of Labor. Cambridge, Mass.: Basil Blackwell.

Stark, O. and Bloom, D.E. (1985). The New Economics of Labour Migration. American Economic Review, 75(2): 173-178.

Statista (2020a). Griechenland: Staatsverschuldung von 1980 bis 2018 und Prognosen bis 2024. Statista. [online] Online:

https://de.statista.com/statistik/daten/studie/167459/umfrage/staatsverschuldung-vongriechenland/ [Accessed 08.06.2020]

Statista (2020b). Anzahl der Asylanträge (Erstanträge) in Deutschland nach Bundesländern In den Jahren 2018 und 2019. Statista. [online] Online: https://de.statista.com/statistik/daten/studie/671759/umfrage/asylantraege-indeutschland-nach-bundeslaendern/ [Accessed 22.06.2020]

Statista (2020c). Anzahl der Asylanträge (Erstanträge) in Deutschland nach Bundesländern im Jahr 2020. Statista. [online] Online: https://de.statista.com/statistik/daten/studie/451902/umfrage/asylantraege-indeutschland-nach-bundeslaendern/ [Accessed 22.06.2020] 
Stefanelli P, Neri A, Vacca P, Picicco D, Daprai L, Mainardi G, et al. (2017). Meningococci of serogroup X clonal complex 181 in refugee camps, Italy. Emerg Infect Dis. 2017 May; 23(5): 870-872.

Suter, B. (2012). Tales of Transit: Sub-Saharan African Migrants' Experiences in Istanbul. Malmö: Malmö Studies in International Migration and Ethnic Relations no. 11, and Linköping Studies in Art and Science no. 561.

Tagesschau (2019). Regierung will Flüchtlingslager schließen. Tagesschau [online] Online: https://www.tagesschau.de/ausland/griechenland-fluechtlingslager-101.html [Accessed 18.02.2020]

Tagesschau (2020). Wer hat den Flüchtlingsdeal gebrochen? Tagesschau. [online] Online: https://www.tagesschau.de/faktenfinder/eu-tuerkei-fluechtlingsabkommen-109.html [Acessed 27.03.2020]

Tallmadge, R. and Gitter, R. J. (2018). The Determinants of Human Trafficking in the European Union. Journal of Human Trafficking, Volume 4, 2018 - Issue 2.

Tawil, M. (2006). A doctorate dissertation submitted to the Faculty of Spatial Planning at Dortmund University as a partial fulfilment of the requirements of the award of the degree Dr. Ing. Refugee Camps in Jordan: Options for Urban Redevelopment.

Taylor J. E., Filipski, M.J., Alloush, M., Gupta, A., Valdes, R. and Gonzalez-Estrada, E. (2016). Economic impact of refugees. PNAS July 5, 2016113 (27) 7449-7453; first published June 20, 2016.

Tétényi, A., Barczikay, T. and Szent-Iványi, B. (2018). Refugees, not Economic Migrants Why do Asylum-Seekers Register in Hungary? International Migration IOM, Volume 57, 323-340.

Tétényi A. (2020). Economic Insecurity. In: Romaniuk S., Thapa M., Marton P. (eds) The Palgrave Encyclopedia of Global Security Studies. Palgrave Macmillan, Cham.

The Guardian (2015). UN agencies 'broke and failing' in face of ever-growing refugee crisis. The Guardian. [online] Online: https://www.theguardian.com/world/2015/sep/06/refugee-crisis-un-agencies-brokefailing [Accessed 17.05.2018]

The Guardian (2020a). Overtourism in Europe's historic cities sparks backlash. The Guardian. [online]. Online: https://www.theguardian.com/world/2020/jan/25/overtourism-ineurope-historic-cities-sparks-backlash [Accessed 24.10.2020]

The Guardian (2020b). UN calls for urgent evacuation of Lesbos refugee camp. The Guardian. [online] Online: https://www.theguardian.com/globaldevelopment/2020/feb/11/un-calls-for-urgent-evacuation-of-lesbos-refugee-camp [Accessed 19.02.2020]

The Time (2020). UN Calls For 'Emergency Measures' to Improve Conditions in Greek Refugee Camps, Amid Overcrowding and Risk of Disease Outbreaks. The Time. [online] Online: https://time.com/5781936/lesbos-greece-refugee-camps-dangerous/ [Accessed 19.02.2020]

Thielemann, E. (2018). Why Refugee Burden-Sharing Initiatives Fail: Public Goods, Free-Riding and Symbolic Solidarity in the EU. JCMS 2018 Volume 56. Number 1. pp. 63-82.

Thielemann, E. and Hobolth, M. (2016). Trading numbers vs. rights? Accounting for liberal and restrictive dynamics in the evolution of asylum and refugee policies. Journal of Ethnic and Migration Studies, 42:4, 643-664.

Thielemann, E. and Zaun, N. (2018). Escaping Populism - Safeguarding Minority Rights: Non-majoritarian Dynamics in European Policy-making*. JCMS 2018 Volume 56. Number 4. pp. 906-922.

Thomas, W.I. and Znaniecki, F. (1918-1920). The Polish Peasant in Europe and America. 
Boston: William Badger.

Thornton, L. (2014). "EU Asylum Policy: Reception Conditions for Asylum Seekers" in Lewis, T. Report on coherence of human rights policy making in EU Institutions and other EU agencies and bodies (September 2014), pp. 105-111.

Tilly, C. (1990). Transplanted Networks. In V. Yans-McLaughlin (Ed.), Immigration Reconsidered: History, Sociology and Politics. New York: Oxford University Press, 79-95.

Todaro, M. P. 1969. A model of labor migration and urban unemployment in less-developed countries. American Economic Review 59:138-148.

Todaro, M. P., and L. Maruszko. 1987. Illegal migration and US immigration reform: A conceptual framework. Population and development review 13:101-114.

Toole, M., et al. (1988). The Association Between Inadequate Rations, Undernutrition Prevalence, and Mortality in Refugee Camps: Case Studies of Refugee Populations in Eastern Thailand, 1979-1980, and Eastern Sudan, 1984-1985. Journal of Tropical Pediatrics, Volume 34, Issue 5, 1 October 1988, Pages 218-224.

Topçu, Ö. (2015). Man möchte vor Wut schreien, betrachtet man den EUFlüchtlingsstreit von der Türkei aus. Zwei Millionen Syrer leben hier. Viele Türken helfen, andere protestieren. ZEIT ONLINE. [online] Online: http://www.zeit.de/politik/ausland/2015-05/fluechtlingsdebatte-europa-tuerkei-hilfesyrien [Accessed 12.11.2017]

Trauner, F. (2016). Asylum policy: the EU's 'crises' and the looming policy regime failure. Journal of European Integration Volume 38, 2016 - Issue 3: EU Policies in Times of Crisis.

Triandafyllidou, A. (2010). Irregular Migration in Europe in the Early 21st Century. Irregular Migration in Europe Myths and Realities. Routledge. DOI: https://doi.org/10.4324/9781315589848.

Triandafyllidou, A. (2018). Migrant Smuggling: Novel Insights and Implications for Migration Control Policies. The ANNALS of the American Academy of Political and Social Science, Volume 676 Issue 1, March 2018.

Tsapenko, I. P. (2017). Regionalization of Migration. Outlines of global transformations: politics, economics, law, Center for Crisis Society Studies.

Tunaboylu, S. and Alpes, J. (2017). The EU-Turkey deal: what happens to people who return to Turkey? Forced Migration Review, FMR 54.

UN (2015). Conditions of Syrian refugees in Lebanon worsen considerably, UN reports. United Nations. [online] Online: http://www.un.org/apps/news/story.asp?NewsID=52893\#.WVRJQ4VOJPY [Accessed 12.11.2017]

UN (2019a). World Population Prospects 2019. Department of Economic and Social Affairs, Population Division (2019). Volume I: Comprehensive Tables (ST/ESA/SER.A/426).

UN (2019b). The number of international migrants reaches 272 million, continuing an upward trend in all world regions, says UN. United Nations. [online] Online:

https://www.un.org/development/desa/en/news/population/international-migrantstock-2019.html [Accessed 28.01.2020]

UNDP (2009). Human Development Report. Overcoming barriers: human mobility and Mobility. UNDP. [online] Online:

http://hdr.undp.org/sites/default/files/reports/269/hdr_2009_en_complete.pdf [Accessed 17.05.2018]

UNHCR (1951, 1967). Convention and Protocol Relating to the Status of Refugees. [online] Online: https://www.unhcr.org/3b66c2aa10.html [accessed: 27.12.2019]

UNHCR (2010). Submission by the United Nations High Commissioner for Refugees for the 
Office of the High Commissioner for Human Rights' Compilation Report - Universal Periodic Review: The Republic of Lebanon 2 (Apr. 2010). UNHCR. [online] Online: http://lib.ohchr.org/HRBodies/UPR/Documents/Session9/LB/UNHCR_HighCommissi onerforRefugees.pdf [Accessed 17.10.2020]

UNHCR (2017a). Syrian Regional Refugee Response. UNHCR. [online] Online: https://data2.unhcr.org/en/situations/syria/location/113 [Acessed 12.11.2017]

UNHCR (2017b). Syrian Regional Refugee Response. UNHCR. [online] Online: https://data2.unhcr.org/en/situations/syria/location/71 [Accessed 12.11..2017]

UNHCR (2017c). Syrian Regional Refugee Response. UNHCR. [online] Online: https://data2.unhcr.org/en/situations/syria/location/36 [Accessed 12.11.2017]

UNHCR (2018). 'Refugees' and 'Migrants' Frequently Asked Questions (FAQs). UNHCR. [online] Online: https://www.refworld.org/docid/56e81c0d4.html [Accessed 27.12.2019]

UNHCR (2019a). Internally Displaced People. UNHCR. [online] Online: https://www.unhcr.org/internally-displaced-people.html [Accessed 27.12.2019]

UNHCR (2019b). Asylum Seekers. UNHCR. [online] Online: https://www.unhcr.org/asylum-seekers.html [Accessed 27.12.2019]

UNHCR (2019c). UNHCR Turkey: Syrian Refugee Camps and Provincial Breakdown of Syrian Refugees Registered in South East Turkey. UNHCR. [online] Online: https://reliefweb.int/sites/reliefweb.int/files/resources/71510.pdf [Accessed 16.02.2020]

UNHCR (2019d). Syria Regional Refugee Response. UNHCR. [online] Online: https://data2.unhcr.org/en/situations/syria/location/71 [Accessed 17.02.2020]

UNHCR (2019e). Fact Sheet Greece. UNHCR. [online] Online: http://reporting.unhcr.org/sites/default/files/UNHCR\%20Greece\%20Fact\%20Sheet $\% 2$ 0-\%20December\%202019.pdf [Accessed 18.02.2020]

UNHCR (2019f). Greece must act to end dangerous overcrowding in island reception centres, EU support crucial. UNHCR. [online] Online: https://www.unhcr.org/news/briefing/2019/10/5d930c194/greece-must-act-enddangerous-overcrowding-island-reception-centres-eu.html [Accessed 18.02.2020]

UNHCR (2019g). Italy November 2019. UNHCR. [online] Online: https://data2.unhcr.org/en/documents/download/73119 [Accessed 19.02.2020]

UNHCR (2019h). The Refugee Brief - 10 July 2019. UNHCR. [online] Online: https://www.unhcr.org/refugeebrief/the-refugee-brief-10-july-2019/ [Accessed 19.02.2020]

UNHCR (2020a). Figures at a Glance. UNHCR. [online] Online: https://www.unhcr.org/figures-at-a-glance.html [Accessed 28.01.2020]

UNHCR (2020b). Syria Regional Refugee Response. UNHCR. [online] Online: https://data2.unhcr.org/en/situations/syria/location/113 [Accessed 17.02.2020]

UNHCR (2020c). Syria Regional Refugee Response. UNHCR. [online] Online: https://data2.unhcr.org/en/situations/syria/location/36 [Accessed 17.02.2020]

UNHCR (2020d). Syria Regional Refugee Response. UNHCR. [online] Online: https://data2.unhcr.org/en/situations/syria/location/36 [Accessed 17.02.2020]

UHNCR (2020e). Mediterranean situation. UNHCR. [online] Online: https://data2.unhcr.org/en/situations/mediterranean/location/5205 [Accessed 19.02.2020]

Urry, J. (2000). Sociology beyond Society: Mobilities for the 21 st Century. London: Routledge.

Urry, J. (2007). Mobilities. Cambridge: Polity.

Van Hear, N. (2010). Theories of Migration and Social Change. Journal of Ethnic and 
Migration Studies, 36(10): 1531-1536.

Van Hear, N. (2018). Refugia: Answering the Critics. The New Humanitarian. The New Humanitarian. [online] Online: https://deeply.thenewhumanitarian.org/refugees/community/2018/10/29/refugiaanswering-the-critics [Accessed 25.10.2020]

Van Hear, N., Bakewell, O. and Long, K. (2018). Push-pull plus: reconsidering the drivers of migration. Journal of Ethnic and Migration Studies, 44(1):1-18.

Vertovec, S. (1999). Conceiving and Researching Transnationalism. Ethnic and Racial Studies, 22(2): 447-462.

Vertovec, S. (2004). Migrant Transnationalism and Modes of Transformation. International Migration Review, 38(4): 970-1001.

Vohra, A. (2019). Lebanon Is Sick and Tired of Syrian Refugees. Foreign Policy.com. [online] Online: https://foreignpolicy.com/2019/07/31/lebanon-is-sick-and-tired-ofsyrian-refugees/ [Accessed 17.02.2020]

Vollmer, B. (2011). Policy Discourses on Irregular Migration in the EU - 'Number Games' and 'Political Games'. European Journal of Migration and Law. eISSN: 1571-8166. Print ISSN: 1388-364X.

Wallerstein, I. (1974). The Modern World-System: Capitalist Agriculture and the Origins of the European World-Economy in the Sixteenth Century. New York: Academic Press.

Wallerstein, I. (1979). The Capitalist World Economy. Cambridge: Cambridge University Press.

Wallis, E. (2019). Italy's largest migrant 'welcome center' in Sicily to close within the year. Infomigrants. [online] Online: https://www.infomigrants.net/en/post/14821/italy-slargest-migrant-welcome-center-in-sicily-to-close-within-the-year [Accessed 19.02.2020]

Waltz, K. N. (1959). Man, the state, and war: A theoretical analysis. New York: Columbia University Press.

Watenpaugh, K.D. (2016). Bread from Stones - The Middle East and the Making of Modern Humanitarianism. University of California Press.

Wendt, A. (1992). Anarchy is what States Make of it: The Social Construction of Power Politics. International Organization, Vol. 46, No. 2 (Spring, 1992), pp. 391-425.

Wendt, A. (1999). Social theory of international politics. Cambridge, UK: Cambridge University Press.

Werrell and Femia (2015). Fragile States. The Nexus of Climate Change, State Fragility and Migration. Angle Journal. [online] Online: https://anglejournal.com/article/2015-11fragile-states-the-nexus-of-climate-change-state-fragility-and-migration [Accessed 28.01.2020]

WFP (2015).10 Fakten über syrische Flüchtlinge in der Türkei. World Food Programme. [online] Online: http://de.wfp.org/artikel/10-fakten-ueber-syrische-fluechtlinge-dertuerkei [Accessed 12.11.2017]

WFP (2019). 10 Facts about Syrian Refugee Crisis in Jordan. World Food Program. [online] Online: https://www.wfpusa.org/stories/10-facts-about-the-syrian-refugee-crisis-injordan/ [Accessed 17.02.2020]

White, B. T., Haysom, S. and Davey, E. (2013). Refugees, host states and displacement in the Middle East: an enduring challenge. Humanitarian Exchange (59), pp. 20-22.

White, P. and Woods, R. (eds.) (1980). The Geographical Impact of Migration. London: Longman.

Wimmer, A. and Glick Schiller, N. (2003). Methodological Nationalism, the Social Sciences, and the State of Migration: An Essay in Historical Epistemology. International Migration Review, 37(3): 576-610. 
World Bank (2018a). Nearly Half the World Lives on Less than \$5.50 a Day. World Bank. [online] Online: https://www.worldbank.org/en/news/pressrelease/2018/10/17/nearly-half-the-world-lives-on-less-than-550-a-day [25.11.2020]

World Bank (2018b). Groundswell: Preparing for Internal Climate Migration. World Bank. [online] Online: https://openknowledge.worldbank.org/handle/10986/29461 [Accessed 28.01.2020]

Wunderlich, D. (2012). The limits of external governance: implementing EU external migration policy. Journal of European Public Policy Volume 19, 2012 - Issue 9, Pages 1414-1433.

Zaun, N. (2016). Why EU asylum standards exceed the lowest common denominator: the role of regulatory expertise in EU decision-making. Journal of European Public Policy Volume 23, 2016 - Issue 1.

ZDF (2020). "Kann man nicht mit Griechenland vergleichen". Zweites Deutsches Fernsehen. [online] Online: https://www.zdf.de/nachrichten/politik/fluechtlinge-tuerkei-duevell100.html [Accessed 16.02.2020]

ZEIT ONLINE. Caritas fordert sofortige Hilfe für Geflüchtete in Griechenland. ZEIT ONLINE. [online] Online: https://www.zeit.de/politik/ausland/2019-12/griechischefluechtlingslager-caritas-hilfswerk-ngo-unterstuetzung-forderung [Accessed 18.02.2020]

Zeldin, W. (2016). Refugee Law and Policy: Turkey. Library of Congress. Loc.gov. [online] Online: https://www.loc.gov/law/help/refugee-law/turkey.php\#_ftnref31 [Accessed 17.10.2020]

Zelinsky, W. (1971). The Hypothesis of the Mobility Transition. Geographical Review, 61(2): 219-249.

Zelinsky, W. (1983). The Impasse of Migration Theory: A Sketch Map for Potential Escapees, in Morrison, P. (ed.) Population Movements: Their Forms and Functions in Urbanization and Development. Liège: Ordina, 19-46.

Zhang, S. X., Sanchez, G. E. and Achilli, L. (2018). Crimes of Solidarity in Mobility: Alternative Views on Migrant Smuggling. The ANNALS of the American Academy of Political and Social Science, Vol 676, Issue 1, 2018.

Zweig, S. (1982). Le Monde d'hier. Souvenirs d'un Européen. Paris: Belfond. 


\section{Appendices}

\subsection{Appendix 1: Interview-Questionaire (English)}

\section{Refugee \& Aslyum Seekers Survey \\ Situation in Refugee Camps \\ Questionnaire}

\section{ASSESSING SITUATION OF PEOPLE, WHO HAVE BEEN LIVING IN REFUGEE CAMPS}

Thank you for agreeing to take this survey. The survey is being done by Sebastian Paul (Ph.D. candidate in International Relations at the Corvinus University of Budapest) and is part of his final Ph.D. thesis.

The purpose of the survey is to collect information from refugees or asylum seekers, who have been living for a certain period of time in refugee camps, before and/or after coming to Europe, in order to get a more comprehensive overview about the living conditions there.

All of the answers you provide in this survey will be kept confidential. No identifying information will be provided to the Corvinus University of Budapest or any other institution. The survey data will be reported in a summary fashion only and will not identify any individual person.

This survey will take about 10-15 minutes to complete.

\section{PERSONAL DATA}

\section{Age:}

Gender (f/m):

Citizenship:

\section{Profession:}

Q1:

Were you in a refugee camp before coming to the EU?
A) Yes
B) No

Q2:

In which country was the refugee camp located where you lived before coming to the EU? Please circle all that apply. (only answer if Q1 is 'Yes')
A) Turkey
B) Lebanon
C) Jordan
D) Syria
E) Other Country

Q3:

Were you in a refugee camp after entering the EU? 

A) Yes
B) $\mathrm{No}$

\section{Q4:}

In which country was the refugee camp located, where you lived after entering the EU? Please circle all that apply. (only answer if Q3 is 'Yes')
A) Greece
B) Italy
C) Spain
D) Hungary
E) Other Country

Q5:

Why did you choose a camp in the countries from Q2 \& Q4? Please circle all that apply.

Q2: Non-EU country

\begin{tabular}{|l|l|l|l|l|}
\hline A) & B) & C) & D) & E) \\
\hline Security & $\begin{array}{l}\text { Accessibility of } \\
\text { the country }\end{array}$ & $\begin{array}{l}\text { I was sent to the } \\
\text { camp }\end{array}$ & $\begin{array}{l}\text { Higher living } \\
\text { standard }\end{array}$ & Others \\
\hline & & & \\
\hline
\end{tabular}

Q4: EU country

\begin{tabular}{|l|l|l|l|l|}
\hline A) & B) & C) & D) & E) \\
\hline Security & $\begin{array}{l}\text { Accessibility of } \\
\text { the country }\end{array}$ & $\begin{array}{l}\text { I was sent to the } \\
\text { camp }\end{array}$ & $\begin{array}{l}\text { Higher living } \\
\text { standard }\end{array}$ & Others \\
\hline & & & \\
\hline
\end{tabular}

Q6:

For how long did you stay in the refugee camp(s) named in Q2 \& Q4?

Q2: Non-EU country

\begin{tabular}{|l|l|l|}
\hline A) & B) & C) \\
\hline Less than one year & $\begin{array}{l}\text { More than one year, but less } \\
\text { than three years }\end{array}$ & Three years or more \\
\hline & & \\
\hline
\end{tabular}

Q4: EU country

\begin{tabular}{|l|l|l|}
\hline A) & B) & C) \\
\hline Less than one year & $\begin{array}{l}\text { More than one year, but less } \\
\text { than three years }\end{array}$ & Three years or more \\
\hline & & \\
\hline
\end{tabular}

Q7:

How would you evaluate the nutrition situation (food \& water supply) in the camp(s) in Q2 \& Q4?

Q2: Non-EU country 


\begin{tabular}{|l|l|l|l|l|}
\hline Very good & Good & Sufficient & Insufficient & Very bad \\
\hline & & & & \\
\hline
\end{tabular}

Q4: EU country

\begin{tabular}{|l|l|l|l|l|}
\hline Very good & Good & Sufficient & Insufficient & Very bad \\
\hline & & & & \\
\hline
\end{tabular}

Q8:

How would you evaluate the health care situation (medicine, doctors, equipment, etc.) in the camp(s) in Q2 \& Q4?

Q2: Non-EU country

\begin{tabular}{|l|l|l|l|l|}
\hline Very good & Good & Sufficient & Insufficient & Very bad \\
\hline & & & & \\
\hline
\end{tabular}

Q4: EU country

\begin{tabular}{|l|l|l|l|l|}
\hline Very good & Good & Sufficient & Insufficient & Very bad \\
\hline & & & & \\
\hline
\end{tabular}

Q9:

How would you evaluate the educational situation in the camp(s) in Q2 \& Q4?

Q2: Non-EU country

\begin{tabular}{|l|l|l|l|l|}
\hline Very good & Good & Sufficient & Insufficient & Very bad \\
\hline & & & & \\
\hline
\end{tabular}

Q4: EU country

\begin{tabular}{|l|l|l|l|l|}
\hline Very good & Good & Sufficient & Insufficient & Very bad \\
\hline & & & & \\
\hline
\end{tabular}

Q10:

Were there schools or other institutions, especially for children in the camp(s) in Q2 \& Q4?

Q2: Non-EU country
A) Yes
B) No

Q4: EU country
A) Yes
B) $\mathrm{No}$

Q11:

Were there any job opportunities in the camp(s) in Q2 \& Q4?

Q2: Non-EU country
A) Yes
B) Yes, but in not in my field of work 
C) No

Q4: EU country
A) Yes
B) Yes, but in not in my field of work
C) No

\section{Q12:}

Did you receive any income during your time in the camp(s) in Q2 \& Q4? If yes, how much?

Q2: Non-EU country
A) No income
B) Less than 100 EUR per month
C) More than 100 EUR per month, but less than 200 EUR per month
D) More than 200 EUR per month, but less than 300 EUR per month
E) More than 300 EUR per month, but less than 400 EUR per month
F) More than 400 EUR per month, but less than 500 EUR per month
G) More than 500 EUR per month

Q4: EU country
A) No income
B) Less than 100 EUR per month
C) More than 100 EUR per month, but less than 200 EUR per month
D) More than 200 EUR per month, but less than 300 EUR per month
E) More than 300 EUR per month, but less than 400 EUR per month
F) More than 400 EUR per month, but less than 500 EUR per month
G) More than 500 EUR per month

\section{Q13:}

How would you evaluate the opportunities for free time activities in the camp(s) in Q2 \& Q4?

Q2: Non-EU country

\begin{tabular}{|l|l|l|l|l|}
\hline Very good & Good & Sufficient & Insufficient & Very bad \\
\hline & & & & \\
\hline
\end{tabular}

Q4: EU country

\begin{tabular}{|l|l|l|l|l|}
\hline Very good & Good & Sufficient & Insufficient & Very bad \\
\hline & & & & \\
\hline
\end{tabular}

\section{Q14:}

Were there any forms of political participation in the camp(s) in Q2 \& Q4?

Q2: Non-EU country
A) Yes
B) No

Q4: EU country
A) Yes
B) No

Q15:

How was the security situation (high or low crime rate) in the camp(s) in Q2 \& Q4? 
Q2: Non-EU country

\begin{tabular}{|l|l|l|l|l|}
\hline A) & B) & C) & D) & E) \\
\hline $\begin{array}{l}\text { Very high crime } \\
\text { rate }\end{array}$ & High crime rate & $\begin{array}{l}\text { Normal crime } \\
\text { rate }\end{array}$ & Low crime rate & $\begin{array}{l}\text { Very low crime } \\
\text { rate }\end{array}$ \\
\hline & & & \\
\hline
\end{tabular}

Q4: EU country

\begin{tabular}{|l|l|l|l|l|}
\hline A) & B) & C) & D) & E) \\
\hline $\begin{array}{l}\text { Very high crime } \\
\text { rate }\end{array}$ & High crime rate & $\begin{array}{l}\text { Normal crime } \\
\text { rate }\end{array}$ & Low crime rate & $\begin{array}{l}\text { Very low crime } \\
\text { rate }\end{array}$ \\
\hline & & & \\
\hline
\end{tabular}

Q16:

Why did you leave the camp(s) in Q2 \& Q4? Please circle all that apply.

Q2: Non-EU country
A) Poor living conditions
B) Seeking a better life in the host country
C) Seeking a better life in the EU
D) Others

Q4: EU country
A) Poor living conditions
B) Seeking a better life in the host country
C) Seeking a better life in another EU country
D) Others

Q17:

Under which circumstances would you have stayed in the camp(s) in Q2 \& Q4? Please circle all that apply.

Q2: Non-EU country
A) Long-term prospects in the country
B) Higher satisfaction of basic human needs (water, food, medicine, etc.)
C) I would not have stayed under any circumstances
D) Other

Q4: EU country
A) Long-term prospects in the country
B) Higher satisfaction of basic human needs (water, food, medicine, etc.)
C) I would not have stayed under any circumstances
D) Other

Q18:

What was the (major) reason for you leaving the country of your origin? Please circle all that apply.
A) (Civil) War or Armed Conflict(s)
B) Political Persecution 
C) Discrimination

D) Natural Disasters

E) Economic Reasons / Poverty

F) Climate change-related reason

G) Seeking a higher living standard in the EU

H) Other

Q19:

What was the main reason for you coming to the EU? Please circle all that apply.
A) Peaceful and secure environment
B) Political stability
C) Human rights (open and free society)
D) Cultural aspects
E) Higher living standard
F) Others

Q20:

What was the country where you entered the EU for the first time?
A) Greece
B) Italy
C) Spain
D) Bulgaria
E) Hungary
F) Another country

Q21:

How did you arrive in the EU?
A) By land
B) By sea
C) By airplane
D) Other

Q22:

Did you pay any smugglers in order to enter the EU?
A) Yes
B) No

Q23:

Did/do you have any intention of going back to your country of origin?
A) Yes
B) No
C) I do not know yet

I appreciate your response. I am seeking to get a better understanding of the situation of people living in camps. Thank you for your time. 


\subsection{Appendix 2: Interview-Questionaire (German)}

\section{Umfrage mit Flüchtlingen und Asylsuchenden \\ über die Situation in Flüchlingslagern \\ Umfrage}

\section{BEWERTUNG DER LEBENSBEDINGUNGEN VON MENSCHEN, DIE IN FLÜCHTLINGSLAGERN GELEBT HABEN}

Vielen Dank, dass Sie zustimmen, an dieser Umfrage teilzunehmen. Die Umfrage wurde von Sebastian Paul (Doktorand an der Corvinus Universität in Budapest im Studienfach International Relations) erstellt und ist ein wesentlicher Bestandteil seiner Doktorarbeit.

Das Ziel dieser Umfrage besteht darin, Informationen über Flüchtlinge und Asylsuchende zu sammeln, die für einen bestimmten Zeitraum auf ihrer Reise nach Europa in einem Flüchtlingslager gelebt haben, um einen umfassenden Überblick über die dortigen Lebensbedigungen zu erhalten.

Alle Antworten, die im Zuge dieser Umfrage gegeben warden, werden vertraulich behandelt. Keine Informationen, die Rückschlüsse auf die Identität eines Umfrageteilnehmers zulassen, werden an die Corvinus Universität oder an irgendeine andere Insitution weitergegeben. Die Umfrageergebnisse werden lediglich in einer zusammenfassenden Form verarbeitet.

Es dauert ca. 10-15 Minuten, um die Umfrage abzuschließen.

\section{PERSÖNLICHE DATEN}

\section{Alter: \\ Geschlecht (w/m): \\ Staatsbürgerschaft: \\ Beruf/Ausbildung:}

Q1:

Waren Sie in einem Flüchtlingslager, bevor Sie in die EU eingereist sind?
A) Ja
B) Nein

\section{Q2:}

In welchen Land befindet sich das Flüchtlingslager, in dem Sie gelebt haben, bevor Sie in die EU eingereist sind? Kreuzen Sie bitte alle zutreffenden Antworten an. (antworten Sie bitte nur, wenn Ihre Antwort auf Frage 1 „Ja“ ist)
A) Türkei
B) Libanon
C) Jordanien
D) Syrien
E) Ein anderes Land

Q3:

Waren Sie in einem Flüchtlingslager, nachdem Sie in die EU eingereist sind?
A) $\mathrm{Ja}$
B) Nein 
Q4:

In welchen Land befindet sich das Flüchtlingslager, in dem Sie gelebt haben, nachdem Sie in die EU eingereist sind? Kreuzen Sie bitte alle zutreffenden Antworten an. (antworten Sie bitte nur, wenn Ihre Antwort auf Frage 3 „Ja“ ist)
A) Griechenland
B) Italien
C) Spanien
D) Ungarn
E) Ein anderes Land

Q5:

Warum haben Sie ein Flüchtlingslager aus Q2 \& Q4 ausgewählt? Kreuzen Sie bitte alle zutreffenden Antworten an.

Q2: Nicht-EU-Land

\begin{tabular}{|l|l|l|l|l|}
\hline A) & B) & C) & D) & E) \\
\hline Sicherheit & $\begin{array}{l}\text { Erreichbarkeit } \\
\text { des Landes }\end{array}$ & $\begin{array}{l}\text { Ich wurde in das } \\
\text { Lager geschickt }\end{array}$ & $\begin{array}{l}\text { Höherer } \\
\text { Lebensstandard }\end{array}$ & Andere Gründe \\
\hline & & & & \\
\hline
\end{tabular}

Q4: EU-Land

\begin{tabular}{|l|l|l|l|l|}
\hline A) & B) & C) & D) \\
\hline Sicherheit & $\begin{array}{l}\text { Erreichbarkeit } \\
\text { des Landes }\end{array}$ & $\begin{array}{l}\text { Ich wurde in das } \\
\text { Lager geschickt }\end{array}$ & $\begin{array}{l}\text { Höherer } \\
\text { Lebensstandard }\end{array}$ & Andere Gründe \\
\hline & & & \\
\hline
\end{tabular}

Q6:

Für wie lange sind Sie in einem der Flüchtlingslager aus Q2 \& Q4 geblieben?

Q2: Nicht-EU-Land

\begin{tabular}{|l|l|l|}
\hline A) & B) & C) \\
\hline Weniger als 1 Jahr & $\begin{array}{l}\text { Mehr als 1 Jahr, aber } \\
\text { weniger als 3 Jahre }\end{array}$ & 3 Jahre oder mehr \\
\hline & & \\
\hline
\end{tabular}

Q4: EU-Land

\begin{tabular}{|l|l|l|}
\hline A) & B) & C) \\
\hline Weniger als 1 Jahr & $\begin{array}{l}\text { Mehr als 1 Jahr, aber } \\
\text { weniger als 3 Jahre }\end{array}$ & 3 Jahre oder mehr \\
\hline & & \\
\hline
\end{tabular}

Q7:

Wie würden Sie die Versorgung mit Lebensmitteln (Essens- und Wasserversorgung) in den Flüchtlingslagern aus Q2 \& Q4 bewerten?

Q2: Nicht-EU-Land 


\begin{tabular}{|l|l|l|l|l|}
\hline Sehr gut & Gut & Zufriedenstellend & Unzureichend & Sehr schlecht \\
\hline & & & & \\
& & & & \\
\hline
\end{tabular}

Q4: EU-Land

\begin{tabular}{|l|l|l|l|l|}
\hline Sehr gut & Gut & Zufriedenstellend & Unzureichend & Sehr schlecht \\
\hline & & & & \\
& & & & \\
\hline
\end{tabular}

Q8:

Wie würden Sie Gesundheitsversorgung (Medikamente, Ärzte, Ausstattung, etc.) in den Flüchtlingslagern aus Q2 \& Q4 bewerten?

Q2: Nicht-EU-Land

\begin{tabular}{|l|l|l|l|l|}
\hline Sehr gut & Gut & Zufriedenstellend & Unzureichend & Sehr schlecht \\
\hline & & & & \\
\end{tabular}

Q4: EU-Land

\begin{tabular}{|l|l|l|l|l|}
\hline Sehr gut & Gut & Zufriedenstellend & Unzureichend & Sehr schlecht \\
\hline & & & & \\
& & & & \\
\hline
\end{tabular}

Q9:

Wie würden Sie die Bildungssituation in den Flüchtlingslagern aus Q2 \& Q4 bewerten?

Q2: Nicht-EU-Land

\begin{tabular}{|l|l|l|l|l|}
\hline Sehr gut & Gut & Zufriedenstellend & Unzureichend & Sehr schlecht \\
\hline & & & & \\
\hline
\end{tabular}

Q4: EU-Land

\begin{tabular}{|l|l|l|l|l|}
\hline Sehr gut & Gut & Zufriedenstellend & Unzureichend & Sehr schlecht \\
\hline & & & & \\
\hline
\end{tabular}

\section{Q10:}

Gab es Schulen oder andere Bildungseinrichtung für Kinder in den Flüchtlingslagern aus Q2 \& Q4?

Q2: Nicht-EU-Land
A) $\mathrm{Ja}$
B) Nein

Q4: EU-Land
A) Ja
B) Nein

\section{Q11:}

Gab es irgendwelche Möglichkeiten zur Ausübung einer beruflichen Tätigkeit in den Flüchtlingslagern aus Q2 \& Q4?

Q2: Nicht-EU-Land 

A) $\mathrm{Ja}$
B) Ja, aber nicht in meinem Arbeitsbereich
C) Nein

Q4: EU-Land
A) $\mathrm{Ja}$
B) Ja, aber nicht in meinem Arbeitsbereich
C) Nein

\section{Q12:}

Haben Sie während Ihrer Zeit in den Flüchtlingslagern aus Q2 \& Q4 irgendein Einkommen bezogen? Wenn ja, wie hoch?

Q2: Nicht-EU-Land
A) Kein Einkommen
B) Weniger als 100 EUR im Monat
C) Mehr als 100 EUR im Monat, aber weniger als 200 EUR im Monat
D) Mehr als 200 EUR im Monat, aber weniger als 300 EUR im Monat
E) Mehr als 300 EUR im Monat, aber weniger als 400 EUR im Monat
F) Mehr als 400 EUR im Monat, aber weniger als 500 EUR im Monat
G) Mehr als 500 EUR im Monat

Q4: EU-Land
A) Kein Einkommen
B) Weniger als 100 EUR im Monat
C) Mehr als 100 EUR im Monat, aber weniger als 200 EUR im Monat
D) Mehr als 200 EUR im Monat, aber weniger als 300 EUR im Monat
E) Mehr als 300 EUR im Monat, aber weniger als 400 EUR im Monat
F) Mehr als 400 EUR im Monat, aber weniger als 500 EUR im Monat
G) Mehr als 500 EUR im Monat

\section{Q13:}

Wie würden Sie die Möglichkeiten zur Ausübung von Freizeitaktivitäten in den

Flüchtlingslagern aus Q2 \& Q4 bewerten?

Q2: Nicht-EU-Land

\begin{tabular}{|l|l|l|l|l|}
\hline Sehr gut & Gut & Zufriedenstellend & Unzureichend & Sehr schlecht \\
\hline & & & & \\
& & & & \\
\hline
\end{tabular}

Q4: EU-Land

\begin{tabular}{|l|l|l|l|l|}
\hline Sehr gut & Gut & Zufriedenstellend & Unzureichend & Sehr schlecht \\
\hline & & & & \\
& & & & \\
\hline
\end{tabular}

Q14:

Gab es irgendwelche Formen der politischen Teilhabe in den Flüchtlingslagern aus Q2 \& Q4?

Q2: Nicht-EU-Land
A) $\mathrm{Ja}$
B) Nein

Q4: EU-Land 

A) $\mathrm{Ja}$
B) Nein

\section{Q15:}

Wie würden Sie die Sicherheitslage (hohe oder niedrige Kriminalitätsrate) in den Flüchtlingslagern aus Q2 \& Q4 bewerten?

Q2: Nicht-EU-Land

\begin{tabular}{|l|l|l|l|l|}
\hline A) & B) & C) & D) & E) \\
\hline $\begin{array}{l}\text { Sehr hohe } \\
\text { Kriminalitätsrate }\end{array}$ & $\begin{array}{l}\text { Hohe } \\
\text { Kriminalitätsrate }\end{array}$ & $\begin{array}{l}\text { Durchschnittliche } \\
\text { Kriminalitätsrate }\end{array}$ & $\begin{array}{l}\text { Niedrige } \\
\text { Kriminalitätsrate }\end{array}$ & $\begin{array}{l}\text { Sehr niedrige } \\
\text { Kriminalitätsrate }\end{array}$ \\
\hline & & & & \\
\hline
\end{tabular}

Q4: EU-Land

\begin{tabular}{|l|l|l|l|l|}
\hline A) & B) & C) & D) & E) \\
\hline $\begin{array}{l}\text { Sehr hohe } \\
\text { Kriminalitätsrate }\end{array}$ & $\begin{array}{l}\text { Hohe } \\
\text { Kriminalitätsrate }\end{array}$ & $\begin{array}{l}\text { Durchschnittliche } \\
\text { Kriminalitätsrate }\end{array}$ & $\begin{array}{l}\text { Niedrige } \\
\text { Kriminalitätsrate }\end{array}$ & $\begin{array}{l}\text { Sehr niedrige } \\
\text { Kriminalitätsrate }\end{array}$ \\
\hline & & & & \\
\hline
\end{tabular}

\section{Q16:}

Warum haben Sie die Flüchtlingslager aus Q2 \& Q4 verlassen? Kreuzen Sie bitte alle zutreffenden Antworten an.

Q2: Nicht-EU-Land
A) Schleche Lebensbedigungen
B) Auf der Suche nach einem besseren Leben im Aufnahmeland
C) Auf der Suche nach einem besseren Leben in der EU
D) Andere Gründe

Q4: EU-Land
A) Schleche Lebensbedigungen
B) Auf der Suche nach einem besseren Leben im Aufnahmeland
C) Auf der Suche nach einem besseren Leben in der EU
D) Andere Gründe

\section{Q17:}

Unter welchen Umständen wären Sie in einem der Flüchtlingslager aus Q2 \& Q4 geblieben? Kreuzen Sie bitte alle zutreffenden Antworten an.

Q2: Nicht-EU-Land
A) Langfristige Perspektive im Aufnahmeland
B) Höhere Befriedigung von grundlegenden menschlichen Bedürfnissen (Wasser, Essen, Medizin, etc.)
C) Ich wäre unter keinerlei Umständen geblieben
D) Andere Umstände

Q4: EU-Land
A) Langfristige Perspektive im Aufnahmeland
B) Höhere Befriedigung von grundlegenden menschlichen Bedürfnissen (Wasser, Essen, Medizin, etc.)


C) Ich wäre unter keinerlei Umständen geblieben

D) Andere Umstände

\section{Q18:}

Was war für Sie die Hauptursache, warum Sie Ihr Herkunftsland verlassen haben? Kreuzen Sie bitte alle zutreffenden Antworten an.
A) Bürgerkrieg oder bewaffnete Konflikte
B) Politische Verfolgung
C) Diskriminierung
D) Naturkatastrophe(n)
E) Wirtschaftliche Gründe / Armut
F) Ursachen, die mit der Klimaerwärmung zusammenhängen
G) Auf der Suche nach einem höheren Lebensstandard in der EU
H) Andere Ursachen

\section{Q19:}

Was war für Sie der Hauptgrund in die EU zu kommen? Kreuzen Sie bitte alle zutreffenden Antworten an.
A) Friedliches und sicheres Umfeld
B) Politische Stabilität
C) Menschenrechte (offene und freie Gesellschaften)
D) Kulturelle Aspekte
E) Höherer Lebensstandard
F) Andere Gründe

Q20:

Was war das erste EU-Land, das Sie betreten haben?
A) Griechenland
B) Italien
C) Spanien
D) Bulgarien
E) Ungarn
F) Ein anderes EU-Land

Q21:

Wie haben Sie die EU erreicht?
A) Über den Landweg
B) Über den Seeweg
C) Mit einem Flugzeug
D) Auf eine andere Art und Weise

\section{Q22:}

Haben Sie Menschenschleuser auf Ihrem Weg in die EU bezahlt?
A) $\mathrm{Ja}$
B) Nein

Q23:

Hatten oder haben Sie die Absicht jemals in Ihr Herkunfsland zurückzukehren? 

A) Ja
B) Nein
C) Ich weiß es noch nicht

Ich weiß Ihre Antworten sehr zu schätzen. Ich erhoffe mir dadurch, ein besseres Verständnis für die Situation von Menschen in Flüchtlingslagern zu bekommen. Vielen Dank für Ihre Zeit.

\subsection{List of the Semi-structured Interviews and Notes}

\begin{tabular}{|c|c|c|c|c|}
\hline \multicolumn{5}{|c|}{ Qualitative Research - Notes } \\
\hline Participant & $\begin{array}{l}\text { Date and place } \\
\text { of the interview }\end{array}$ & $\begin{array}{l}\text { Duration of the } \\
\text { interview }\end{array}$ & $\begin{array}{l}\text { Age and } \\
\text { gender }\end{array}$ & Profession \\
\hline P1 & $\begin{array}{l}21^{\text {st }} \text { of May, } \\
\text { Skype (online) }\end{array}$ & $\begin{array}{l}27 \text { minutes and } \\
36 \text { seconds }\end{array}$ & 25 , male & Barber \\
\hline Notes & $\begin{array}{r}\text { Conditions in nor } \\
\text { - The person li } \\
\text { - The person h } \\
\text { for } 50 \text { people } \\
\text { - Safe and secu } \\
\text { - Sufficient foc } \\
\text { - Reasonable c } \\
\text { institutions; } \\
\text { Turkish orgar } \\
\text { - Outside of th } \\
\text { Conditions in EU } \\
\text { - } \quad \text { The perso } \\
\text { (2015) } \\
\text { - The condi } \\
\text { - It it was a d } \\
\text { - Almost no } \\
\text { - No health } \\
\text { - No housin } \\
\text { - Aid organ } \\
\text { The Journey to E }\end{array}$ & \multicolumn{2}{|c|}{$\begin{array}{l}\text { Conditions in non-EU camps } \\
\text { - The person lived in a Turkish camp for } 2 \text { years }(2013-2015) \\
\text { - The person had to share the room with } 3 \text { other people; shared toilets } \\
\text { for } 50 \text { people } \\
\text { - Safe and secure camps } \\
\text { - Sufficient food and water supply } \\
\text { - Reasonable conditions; playgrounds for children and educational } \\
\text { institutions; sufficient health care; international aid organization plus } \\
\text { Turkish organizations } \\
\text { - Outside of the camps, people had to live on the streets }\end{array}$} & $\begin{array}{l}\text { - 2015) } \\
\text {; shared toilets } \\
\text { educational } \\
\text { ganization plus } \\
\text { reek islands } \\
\text { helmed }\end{array}$ \\
\hline
\end{tabular}




\begin{tabular}{|c|c|c|c|c|}
\hline & \multicolumn{4}{|c|}{$\begin{array}{l}\text { - Paid smugglers; only 500,- EUR; not local community } \\
\text { - Crossed the Mediterranean Sea to Europe } \\
\text { - Life-threatening journey; } 200 \text { people on one small boat } \\
\text { - Brought to camps by Greek state authorities } \\
\text { Why did you leave Syria? } \\
\text { - Civil war, terrorism, Assad } \\
\text { Why did you come to Germany/Europe? } \\
\text { - Safe and secure environment } \\
\text { - Higher living standard } \\
\text { - Open borders; Merkel } \\
\text { - Family and friends } \\
\text { - The economic situation played only a minor role } \\
\text { Under which circumstances would you have stayed in the camps? } \\
\text { - Under no circumstances }\end{array}$} \\
\hline $\mathrm{P} 2$ & $\begin{array}{l}21^{\text {st }} \text { of May, } \\
\text { Skype (online) }\end{array}$ & $\begin{array}{l}34 \text { minutes and } \\
12 \text { seconds }\end{array}$ & 20, male & Student \\
\hline Notes & $\begin{array}{l}\text { Conditions in } \\
\text { - The person } \\
\text { - The person } \\
\text { for } 100 \text { peo } \\
\text { - Safe and se } \\
\text { - Sufficient } \\
\text { - Reasonable } \\
\text { institutions } \\
\text { Turkish or } \\
\text { - Outside of } \\
\text { Conditions in } \\
\text { - The per } \\
\text { (2015) } \\
\text { - The con } \\
\text { - Alt was a }\end{array}$ & $\begin{array}{l}\text { U camps } \\
\text { d in a Turkish ca } \\
\text { to share the roo } \\
\text { camps } \\
\text { and water suppl } \\
\text { ditions; playgro } \\
\text { ficient health ca } \\
\text { ations } \\
\text { lived for } 6 \text { montl } \\
\text { amps } \\
\text { ons were absolut } \\
\text { y fight for survi } \\
\text { utrition and wat }\end{array}$ & $\begin{array}{l}\text { for } 6 \text { mo } \\
\text { with } 7 \text { oth } \\
\text { is for chil } \\
\text { internatio } \\
\text { o live on t } \\
\text { n a camp } \\
\text { devastati }\end{array}$ & $\begin{array}{l}\text { 15) } \\
\text {; shared toilets } \\
\text { educational } \\
\text { ganization plus } \\
\text { reek islands } \\
\text { rates }\end{array}$ \\
\hline
\end{tabular}




\begin{tabular}{|c|c|c|c|c|}
\hline & \multicolumn{4}{|c|}{$\begin{array}{l}\text { - No health care, no education for children } \\
\text { - No housing; people lived in improvised shelters } \\
\text { - Aid organizations and the Greek state were overwhelmed } \\
\text { The Journey to Europe } \\
\text { - Paid smugglers; only 800,- EUR; not local community } \\
\text { - Crossed the Mediterranean Sea to Europe } \\
\text { - Life-threatening journey; } 300 \text { people on one small boat } \\
\text { - Came in a group to the camps } \\
\text { Why did you leave Syria? } \\
\text { - Civil war, terrorism, Assad } \\
\text { Why did you come to Germany/Europe? } \\
\text { - Safe and secure environment } \\
\text { - Higher living standard } \\
\text { - Open borders; Merkel } \\
\text { - Family and friends } \\
\text { - The economic situation played only a minor role } \\
\text { Under which circumstances would you have stayed in the camps? } \\
\text { - Under no circumstances }\end{array}$} \\
\hline P3 & $\begin{array}{l}21^{\text {st }} \text { of May, } \\
\text { Skype (online) }\end{array}$ & $\begin{array}{l}32 \text { minutes and } \\
48 \text { seconds }\end{array}$ & 21, male & Student \\
\hline Notes & $\begin{array}{l}\text { Conditions in no } \\
\text { - The person } \\
\text { - No real acce } \\
\text { - Unsafe and } \\
\text { - Almost no f } \\
\text { - Devastating } \\
\text { institutions } \\
\text { doctors); no } \\
\text { - People had } \\
\text { Conditions in E } \\
\text { - The pers } \\
\text { (2015) }\end{array}$ & $\begin{array}{l}\text { U camps } \\
\text { d in a camp in L } \\
\text { nodation or hous } \\
\text { ecure camps; terı } \\
\text { and water supp } \\
\text { ing conditions; } \\
\text { children; no heal } \\
\text { ernational aid or } \\
\text { ve and sleep in i } \\
\text { amps } \\
\text { lived for } 6 \text { montl }\end{array}$ & $\begin{array}{l}\text { anon for } 3 \\
\text { facilities } \\
\text { sm; crime } \\
\text { laygrounc } \\
\text { care (no n } \\
\text { izations } \\
\text { rovised sl } \\
\text { n a camp }\end{array}$ & $\begin{array}{l}\text { (2015) } \\
\text { educational } \\
\text { and only a few } \\
\text { reek islands }\end{array}$ \\
\hline
\end{tabular}




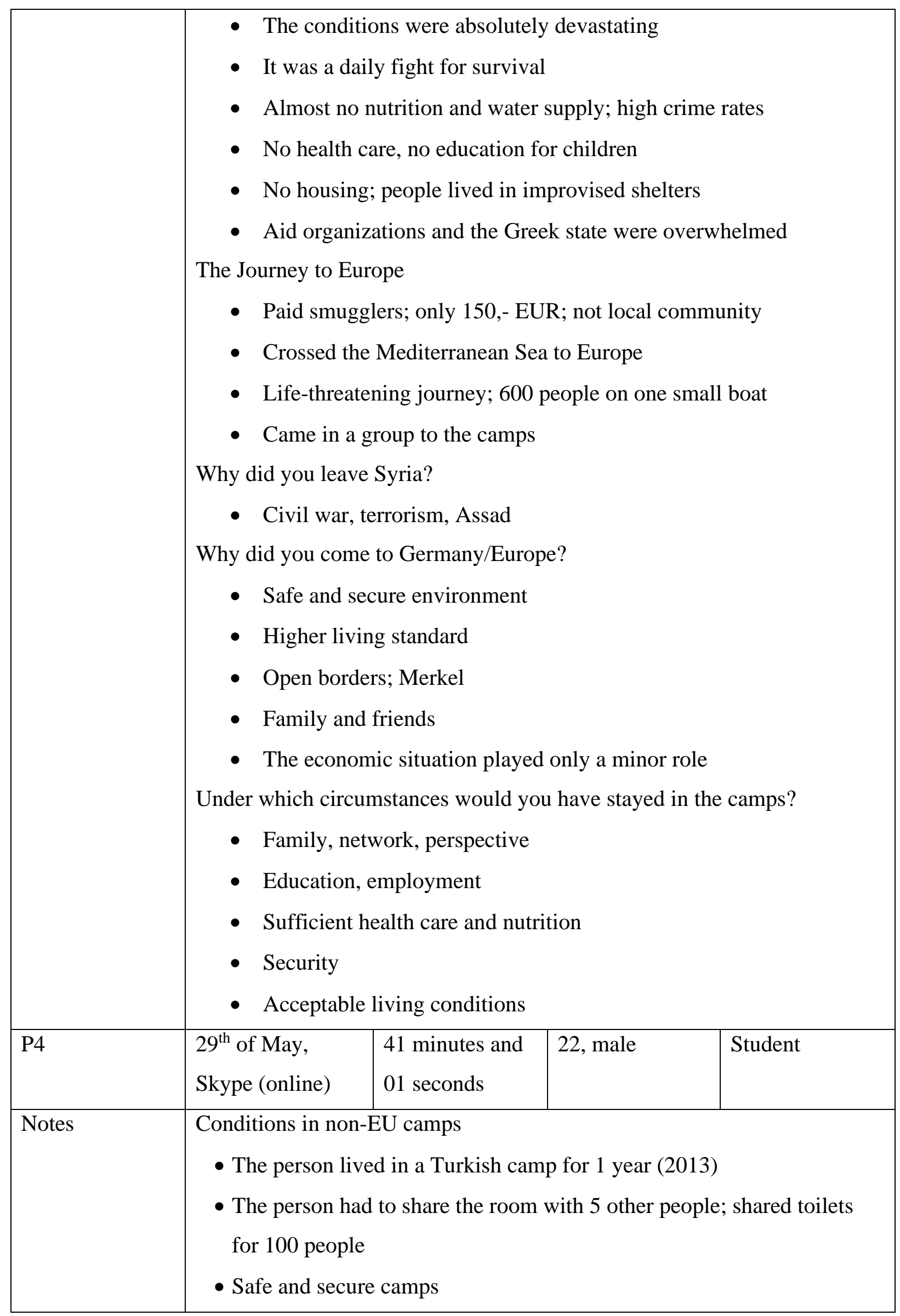




\begin{tabular}{|c|c|c|c|c|}
\hline & \multicolumn{4}{|c|}{$\begin{array}{l}\text { The Journey to Europe } \\
\text { - Paid smugglers; only 200,- EUR; local community } \\
\text { - Crossed the Mediterranean Sea to Europe } \\
\text { - Life-threatening journey; } 400 \text { people on one small boat } \\
\text { - Brought to camps by Greek state authorities } \\
\text { Why did you leave Syria? } \\
\text { - Civil war, terrorism, Assad } \\
\text { Why did you come to Germany/Europe? } \\
\text { - Safe and secure environment } \\
\text { - Higher living standard } \\
\text { - Open borders; Merkel } \\
\text { - Family and friends } \\
\text { - The economic situation played only a minor role } \\
\text { Under which circumstances would you have stayed in the camps? } \\
\text { - Under no circumstances }\end{array}$} \\
\hline P5 & $\begin{array}{l}29^{\text {th }} \text { of May, } \\
\text { Skype (online) }\end{array}$ & $\begin{array}{l}29 \text { minutes and } \\
55 \text { seconds }\end{array}$ & 29 , male & Barber \\
\hline Notes & Conditions in $n$ & U camps & & $(2015)$ \\
\hline
\end{tabular}


- No real accommodation or housing facilities

- Unsafe and insecure camps; terrorism; crime

- Almost no food and water supply

- Devastating living conditions; no playgrounds and no educational institutions for children; no health care (no medicines and only a few doctors); no international aid organizations

- People had to live and sleep in improvised shelters

Conditions in EU camps

- The person lived for 6 months in a camp on the Greek islands (2015)

- The conditions were absolutely devastating

- It was a daily fight for survival

- Almost no nutrition and water supply; high crime rates

- No health care, no education for children

- No housing; people lived in improvised shelters

- Aid organizations and the Greek state were overwhelmed

The Journey to Europe

- Paid smugglers; only 200,- EUR; local community

- Crossed the Mediterranean Sea to Europe

- Life-threatening journey; 400 people on one small boat

- Brought to camps by Greek state authorities

Why did you leave Syria?

- Civil war, terrorism, Assad

Why did you come to Germany/Europe?

- Safe and secure environment

- Higher living standard

- Open borders; Merkel

- The economic situation played only a minor role

Under which circumstances would you have stayed in the camps?

- Family, network, perspective

- Education, employment

- Sufficient health care and nutrition 


\begin{tabular}{|c|c|c|c|c|}
\hline \multirow[b]{2}{*}{ P6 } & \multicolumn{4}{|c|}{$\begin{array}{l}\text { - Security } \\
\text { - Acceptable living conditions }\end{array}$} \\
\hline & $\begin{array}{l}3^{\text {rd }} \text { of June, Skype } \\
\text { (online) }\end{array}$ & $\begin{array}{l}35 \text { minutes and } \\
39 \text { seconds }\end{array}$ & 24, male & Unemployed \\
\hline Notes & 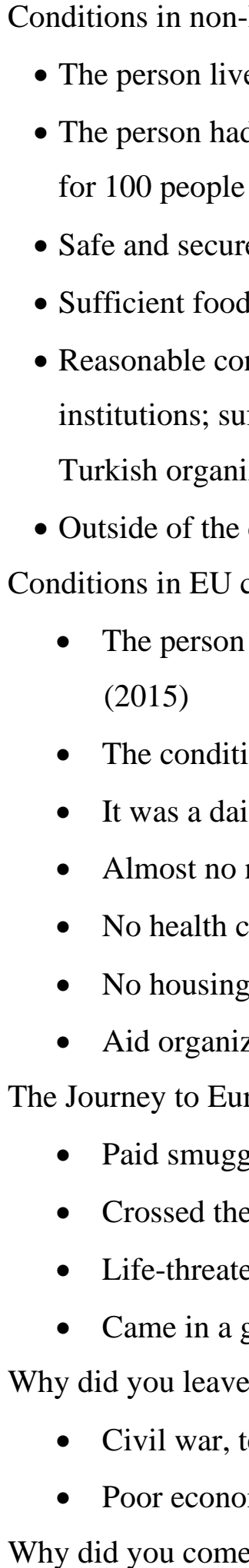 & $\begin{array}{l}\text { U camps } \\
\text { d in a Turkish can } \\
\text { to share the room } \\
\text { camps } \\
\text { and water supply } \\
\text { ditions; playgrour } \\
\text { ficient health care } \\
\text { ations } \\
\text { amps, people had } \\
\text { amps } \\
\text { lived for } 3 \text { months } \\
\text { ny, high unemplo } \\
\text { to Germany/Euro } \\
\text { roup to the camps } \\
\text { Syria? } \\
\text { y fight for surviva } \\
\text { utrition and water } \\
\text { are, no education } \mathrm{f} \\
\text { people lived in in } \\
\text { ations and the Gre } \\
\text { ope } \\
\text { aring journey; } 350 \\
\text { lediterranean Se }\end{array}$ & $\begin{array}{l}\text { for } 2 \text { yea } \\
\text { vith } 8 \text { othe } \\
\text { ls for chilc } \\
\text { internatior } \\
\text { live on t } \\
\text { n a camp } \\
\text { devastatir } \\
\text { tont Europe } \\
\text { eople on c } \\
\text { uptate we } \\
\text { rovised children } \\
\text { orovis }\end{array}$ & $\begin{array}{l}\text {-2014) } \\
\text {; shared toilets } \\
\text { educational } \\
\text { ganization plus } \\
\text { reek islands } \\
\text { boat } \\
\text { rates }\end{array}$ \\
\hline
\end{tabular}




\begin{tabular}{|c|c|c|c|c|}
\hline & \multicolumn{4}{|c|}{$\begin{array}{l}\text { - Safe and secure environment } \\
\text { - Higher living standard } \\
\text { - Open borders; Merkel } \\
\text { - Family and friends } \\
\text { - The economic situation played a significant role } \\
\text { Under which circumstances would you have stayed in the camps? } \\
\text { - Family, network, perspective } \\
\text { - Education, employment } \\
\text { - Sufficient health care and nutrition } \\
\text { - Security } \\
\text { - Acceptable living conditions }\end{array}$} \\
\hline P7 & $\begin{array}{l}3^{\text {rd }} \text { of June, Skype } \\
\text { (online) }\end{array}$ & $\begin{array}{l}34 \text { minutes and } \\
22 \text { seconds }\end{array}$ & 25, male & Farmer \\
\hline Notes & \multicolumn{4}{|c|}{$\begin{array}{l}\text { Conditions in non-EU camps } \\
\text { - The person lived in a camp in Lebanon for } 6 \text { months (2015) } \\
\text { - No real accommodation or housing facilities } \\
\text { - Unsafe and insecure camps; terrorism; crime } \\
\text { - Almost no food and water supply } \\
\text { - Devastating living conditions; no playgrounds and no educational } \\
\text { institutions for children; no health care (no medicines and only a few } \\
\text { doctors); no international aid organizations } \\
\text { - People had to live and sleep in improvised shelters } \\
\text { Conditions in EU camps } \\
\text { - The person lived for } 3 \text { months in a camp on the Greek islands } \\
\text { (2015) } \\
\text { - The conditions were insufficient } \\
\text { - Sufficient nutrition and water supply; high crime rates } \\
\text { - Some housing opportunities, but many people lived in improvised } \\
\text { - } \text { shelters } \\
\text { condid organizations and Greek state authorities improved living }\end{array}$} \\
\hline
\end{tabular}




\begin{tabular}{|c|c|c|c|c|}
\hline & \multicolumn{4}{|c|}{$\begin{array}{l}\text { The Journey to Europe } \\
\text { - Paid smugglers; } 1,200,- \text { EUR; not local community } \\
\text { - Crossed the Mediterranean Sea to Europe } \\
\text { - Life-threatening journey; } 300 \text { people on one small boat } \\
\text { - Came in a group to the camps } \\
\text { Why did you leave Syria? } \\
\text { - Civil war, terrorism, Assad } \\
\text { - Poor economy, high unemployment } \\
\text { Why did you come to Germany/Europe? } \\
\text { - Safe and secure environment } \\
\text { - Higher living standard } \\
\text { - Open borders; Merkel } \\
\text { - The economic situation played only a minor role } \\
\text { Under which circumstances would you have stayed in the camps? } \\
\text { - Sufficient health care and nutrition } \\
\text { - Security } \\
\text { - Acceptable living conditions }\end{array}$} \\
\hline P8 & $\begin{array}{l}3^{\text {rd }} \text { of June, Skype } \\
\text { (online) }\end{array}$ & $\begin{array}{l}42 \text { minutes and } \\
03 \text { seconds }\end{array}$ & 19, male & Student \\
\hline Notes & $\begin{array}{l}\text { Conditions in non-E } \\
\text { - The person live } \\
\text { - The person had } \\
\text { for } 100 \text { people } \\
\text { - Safe and secure } \\
\text { - Sufficient food } \\
\text { - Reasonable con } \\
\text { institutions; suf } \\
\text { Turkish organiz } \\
\text { - Outside of the } \\
\text { Conditions in EU c } \\
\text { - The person } \\
\text { (2015) }\end{array}$ & $\begin{array}{l}\text { U camps } \\
\text { d in a Turkish ca } \\
\text { to share the roon } \\
\text { camps } \\
\text { and water supply } \\
\text { ditions; playgrou } \\
\text { ficient health car } \\
\text { ations } \\
\text { amps, people ha } \\
\text { lived for } 6 \text { month }\end{array}$ & $\begin{array}{l}\text { for } 6 \mathrm{mo} \\
\text { vith } 4 \text { oth } \\
\text { is for chil } \\
\text { internatio } \\
\text { o live on } t \\
\text { n a camp }\end{array}$ & $\begin{array}{l}\text { 15) } \\
\text {; shared toilets } \\
\text { educational } \\
\text { rganization plus } \\
\text { reek islands }\end{array}$ \\
\hline
\end{tabular}




\begin{tabular}{|c|c|c|c|c|}
\hline & \multicolumn{4}{|c|}{$\begin{array}{l}\text { - } \text { - The conditions were insufficient } \\
\text { - Little health care, little education for children } \\
\text { - Some housing opportunities, but many people lived in improvised } \\
\text { shelters } \\
\text { - } \text { Aid organizations and Greek state authorities improved living } \\
\text { The Journey to Europe } \\
\text { - } \quad \text { Paid smugglers; only } 100,- \text { EUR; not local community } \\
\text { - Crossed the Mediterranean Sea to Europe } \\
\text { - Life-threatening journey; } 500 \text { people on one small boat } \\
\text { - Brought to camps by Greek state authorities } \\
\text { Why did you leave Syria? } \\
\text { - Civil war, terrorism, Assad } \\
\text { Why did you come to Germany/Europe? } \\
\text { - Safe and secure environment } \\
\text { - Family and friends }\end{array}$} \\
\hline P9 & $\begin{array}{l}15^{\text {st }} \text { of June, } \\
\text { Skype (online) }\end{array}$ & $\begin{array}{l}39 \text { minutes and } \\
08 \text { seconds }\end{array}$ & 28, male & Unemployed \\
\hline Notes & $\begin{array}{l}\text { Conditions in no } \\
\text { - The person } \\
\text { - No real acco } \\
\text { - Unsafe and } \\
\text { - Almost no f } \\
\text { - Devastating } \\
\text { institutions } \\
\text { doctors); no } \\
\text { - People had t } \\
\text { Conditions in E } \\
\text { - The pers }\end{array}$ & $\begin{array}{l}\text { EU camps } \\
\text { d in a camp in J } \\
\text { nodation or hous } \\
\text { ecure camps; terr } \\
\text { and water supp }\end{array}$ & $\begin{array}{l}\text { an for } 2 \mathrm{~m} \\
\text { facilities } \\
\text { sm; crime } \\
\text { laygroun } \\
\text { care (no } \mathrm{n} \\
\text { lizations }\end{array}$ & $\begin{array}{l}\text { 015) } \\
\text { educational } \\
\text { and only a few } \\
\text { reek islands }\end{array}$ \\
\hline
\end{tabular}




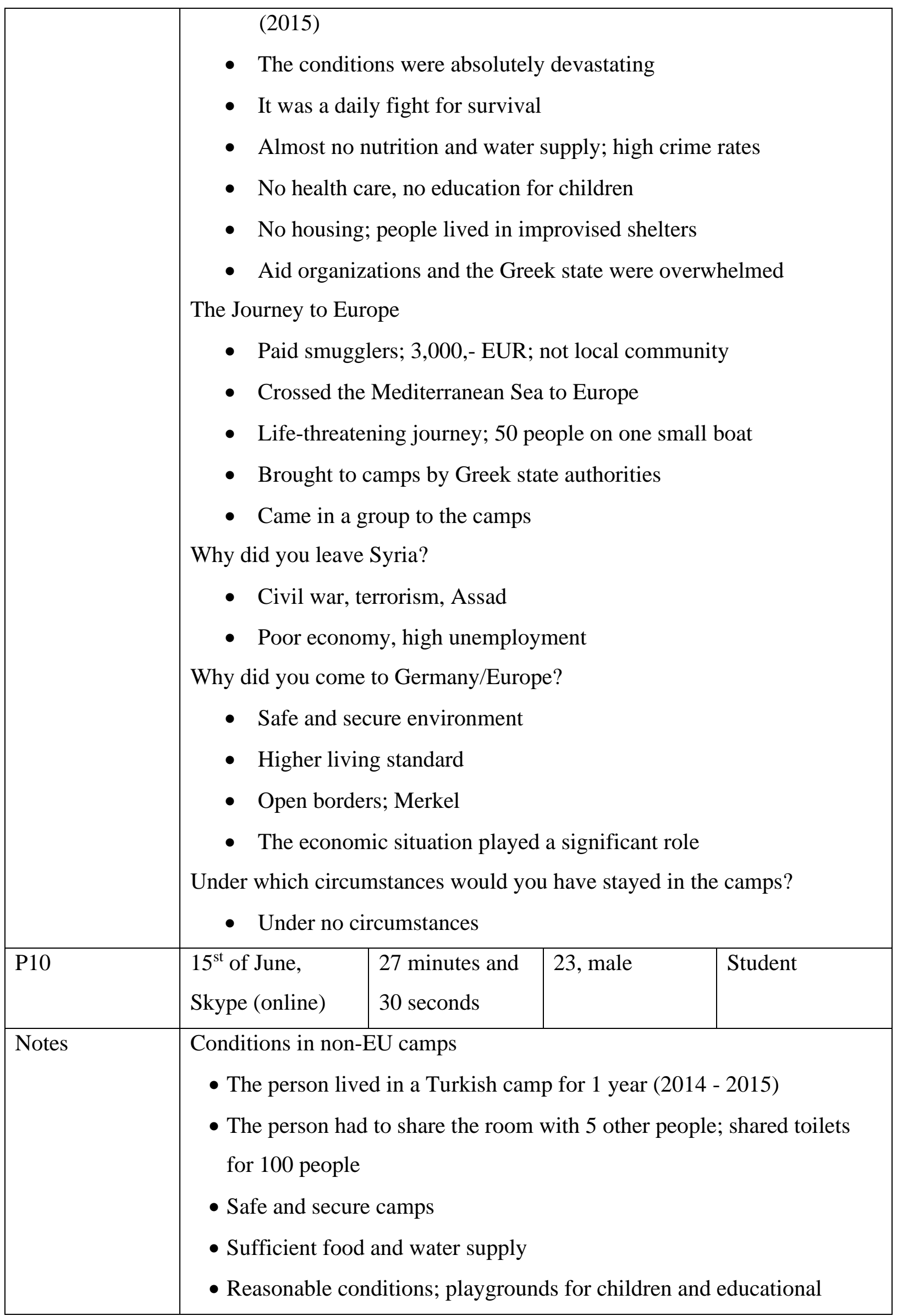




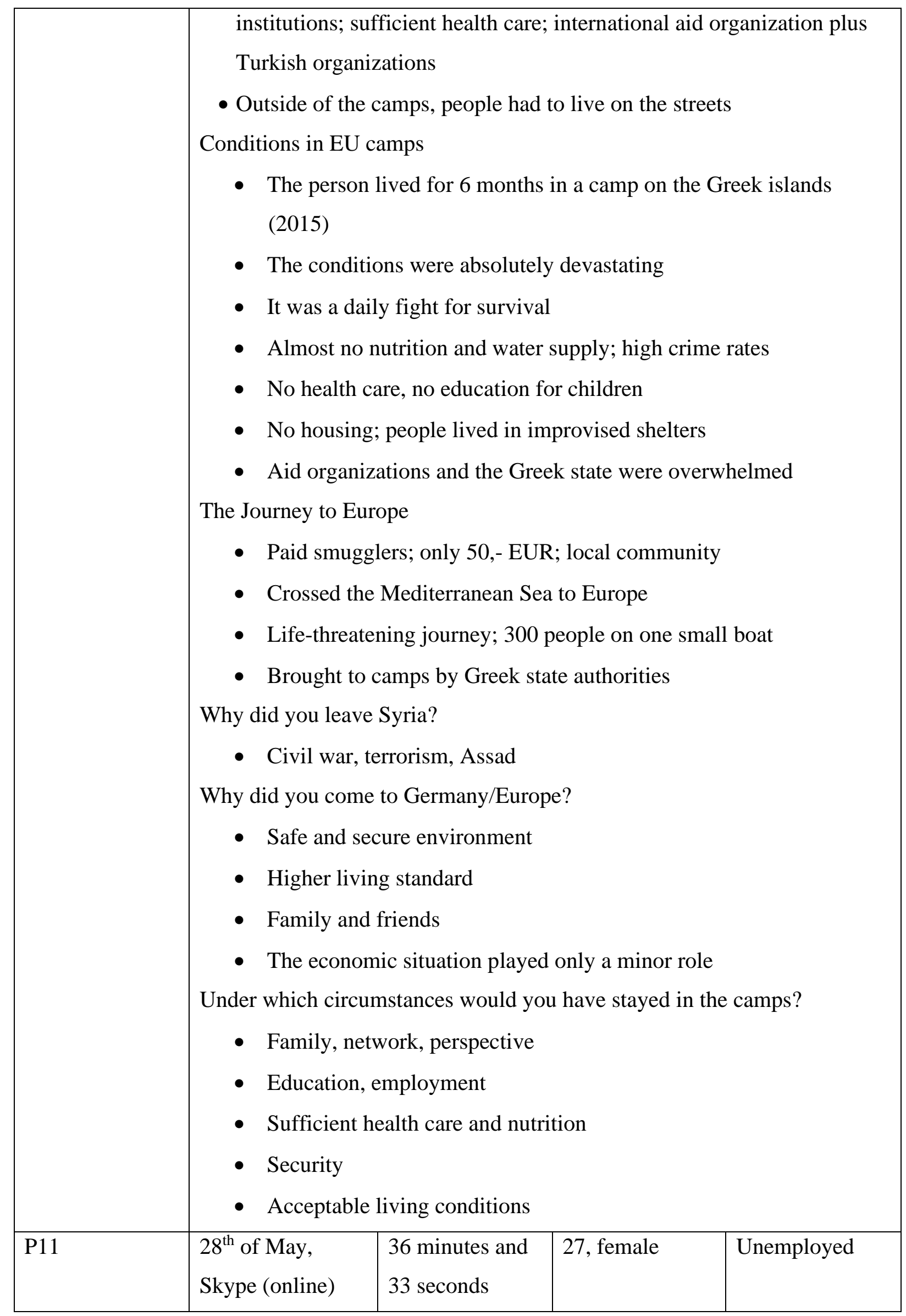




\begin{tabular}{|c|c|}
\hline Notes & 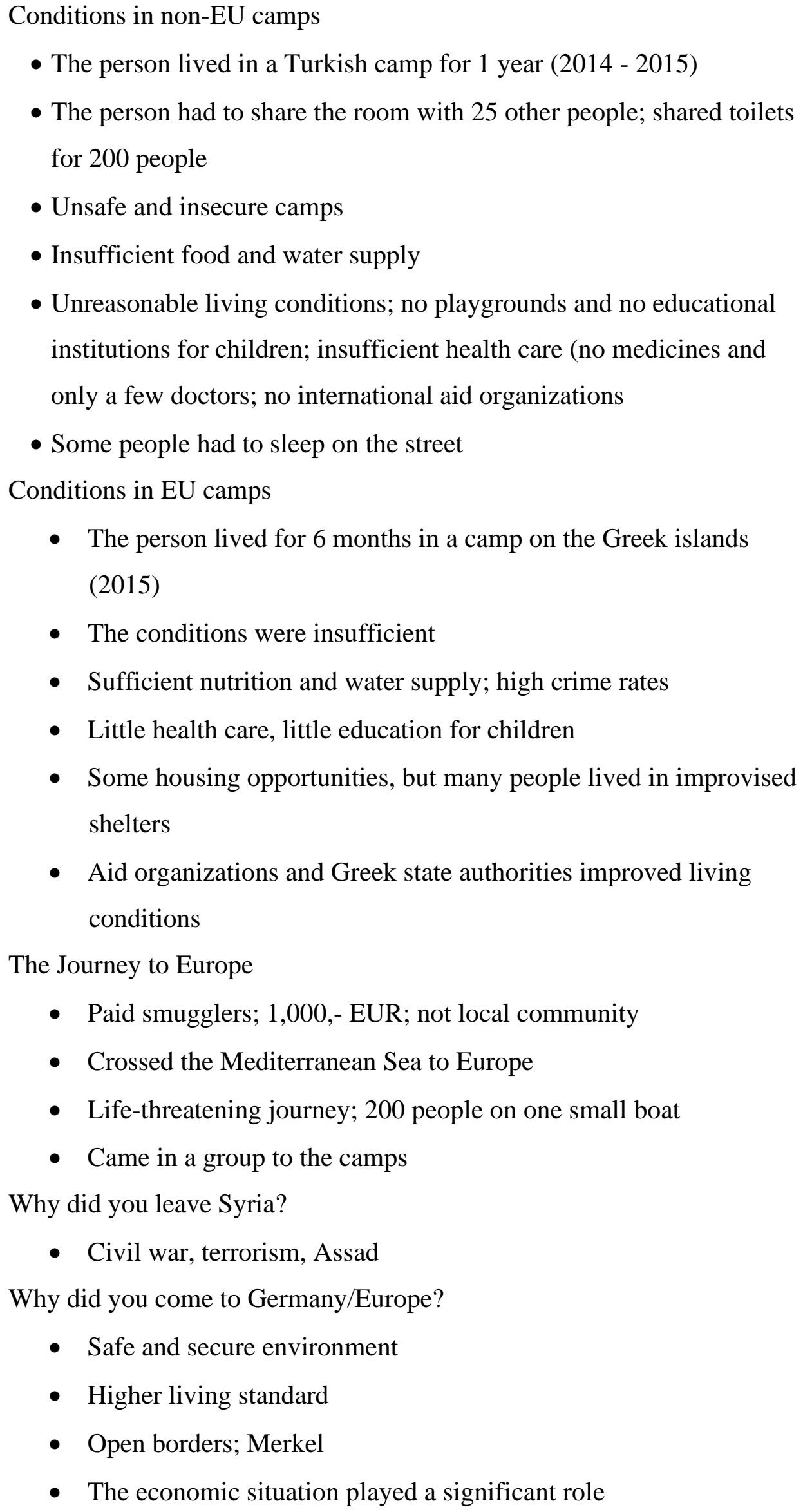 \\
\hline
\end{tabular}




\begin{tabular}{|c|c|c|c|c|}
\hline \multirow[b]{2}{*}{$\mathrm{P} 12$} & \multicolumn{4}{|c|}{$\begin{array}{l}\text { Under which circumstances would you have stayed in the camps? } \\
\text { - Sufficient health care and nutrition } \\
\text { - Security } \\
\text { - Acceptable living conditions }\end{array}$} \\
\hline & $\begin{array}{l}4^{\text {th }} \text { of July, Skype } \\
\text { (online) }\end{array}$ & $\begin{array}{l}42 \text { minutes and } \\
53 \text { seconds }\end{array}$ & 26, male & Unemployed \\
\hline Notes & 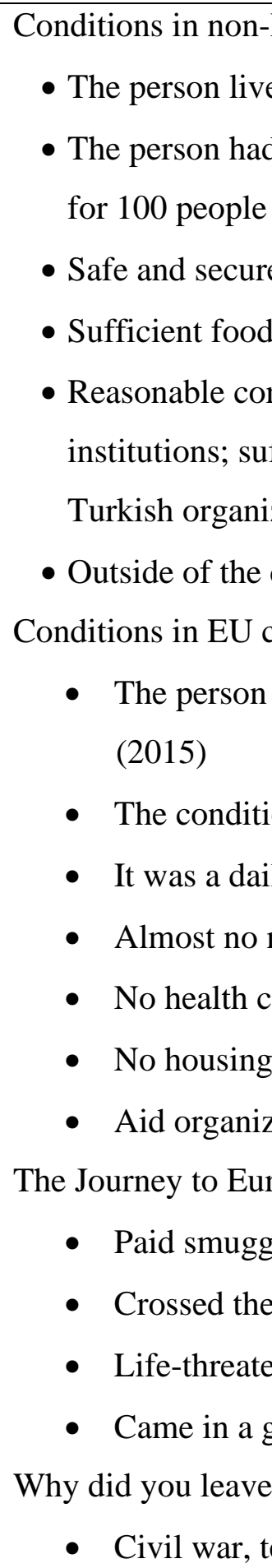 & $\begin{array}{l}\text { U camps } \\
\text { d in a Turkish ca } \\
\text { to share the roon } \\
\text { camps } \\
\text { and water supply } \\
\text { ditions; playgrou } \\
\text { ficient health car } \\
\text { ations } \\
\text { amps, people hac } \\
\text { amps } \\
\text { ived for } 3 \text { month } \\
\text { nins were absolute } \\
\text { roup to the camp } \\
\text { Syria? } \\
\text { rrorism, Assad for surviv } \\
\text { utrition and wate } \\
\text { Mediterranean } S \\
\text { people lived in i } \\
\text { ations and the Gr } \\
\text { ope } \\
\text { ers; for free; loca } \\
\text { arion }\end{array}$ & $\begin{array}{l}\text { for } 6 \text { mo } \\
\text { vith } 8 \text { othe } \\
\text { in for child } \\
\text { internation } \\
\text { live on tl } \\
\text { n a camp c } \\
\text { devastatin } \\
\text { to Europe } \\
\text { eople on o } \\
\text { r children } \\
\text { provised s } \\
\end{array}$ & $\begin{array}{l}\text { 15) } \\
\text {; shared toilets } \\
\text { educational } \\
\text { ganization plus } \\
\text { reek islands } \\
\text { boat } \\
\text { hates }\end{array}$ \\
\hline
\end{tabular}




\begin{tabular}{|c|c|c|c|c|}
\hline & \multicolumn{4}{|c|}{$\begin{array}{l}\text { - Poor economy, high unemployment } \\
\text { Why did you come to Germany/Europe? } \\
\text { - Safe and secure environment } \\
\text { - Higher living standard } \\
\text { - Open borders; Merkel } \\
\text { - Family and friends } \\
\text { - The economic situation played only a minor role } \\
\text { Under which circumstances would you have stayed in the camps? } \\
\text { - Under no circumstances }\end{array}$} \\
\hline P13 & $\begin{array}{l}13^{\text {th }} \text { of July, } \\
\text { Skype (online) }\end{array}$ & $\begin{array}{l}31 \text { minutes and } \\
41 \text { seconds }\end{array}$ & 22 , male & \\
\hline Notes & \multicolumn{4}{|c|}{$\begin{array}{l}\text { Conditions in non-EU camps } \\
\text { - The person lived in a Turkish camp for } 1 \text { year (2014) } \\
\text { - The person had to share the room with } 50 \text { other people; shared toilets } \\
\text { for } 500 \text { people } \\
\text { - Unsafe and insecure camps } \\
\text { - Insufficient food and water supply } \\
\text { - Unreasonable living conditions; no playgrounds and no educational } \\
\text { institutions for children; insufficient health care (no medicines and } \\
\text { only a few doctors; no international aid organizations } \\
\text { - Some people had to sleep on the street } \\
\text { Conditions in EU camps } \\
\text { - The person lived for } 6 \text { months in a camp on the Greek islands } \\
\text { (2015) } \\
\text { - The conditions were insufficient } \\
\text { - Sufficient nutrition and water supply; high crime rates } \\
\text { - Little health care, little education for children } \\
\text { - Some housing opportunities, but many people lived in improvised } \\
\text { - } \text { shelters } \\
\text { Thid organizations and Greek state authorities improved living } \\
\text { conditions }\end{array}$} \\
\hline
\end{tabular}




\begin{tabular}{|c|c|c|c|c|}
\hline & \multicolumn{4}{|c|}{$\begin{array}{l}\text { - Paid smugglers; } 1,400,- \text { EUR; not local community } \\
\text { - Crossed the Mediterranean Sea to Europe } \\
\text { - Life-threatening journey; } 100 \text { people on one small boat } \\
\text { - Came in a group to the camps } \\
\text { Why did you leave Syria? } \\
\text { - Civil war, terrorism, Assad } \\
\text { Why did you come to Germany/Europe? } \\
\text { - Safe and secure environment } \\
\text { - Higher living standard } \\
\text { - Open borders; Merkel } \\
\text { - The economic situation played a significant role } \\
\text { Under which circumstances would you have stayed in the camps? } \\
\text { - Under no circumstances }\end{array}$} \\
\hline P14 & $\begin{array}{l}13^{\text {th }} \text { of July, } \\
\text { Skype (online) }\end{array}$ & $\begin{array}{l}29 \text { minutes and } \\
57 \text { seconds }\end{array}$ & 27, male & Farmer \\
\hline Notes & $\begin{array}{l}\text { Conditions in } \\
\text { - The person } \\
\text { - The person } \\
\text { for } 500 \text { peo } \\
\text { - Unsafe and } \\
\text { - Insufficien } \\
\text { - Unreasonal } \\
\text { institutions } \\
\text { only a few } \\
\text { - Some peop } \\
\text { Conditions in } 5 \\
\text { - The per } \\
\text { (2015) } \\
\text { - The con } \\
\text { - It was a } \\
\text { - Nlmost }\end{array}$ & $\begin{array}{l}\text { UU camps } \\
\text { d in a Turkish ca } \\
\text { to share the roo } \\
\text { ecure camps } \\
\text { d and water sup } \\
\text { ving conditions; } \\
\text { children; insuffic } \\
\text { ors; no internatic } \\
\text { ad to sleep on the } \\
\text { amps } \\
\text { lived for } 6 \text { montl } \\
\text { ons were absolut } \\
\text { y fight for survi } \\
\text { utrition and wat } \\
\text { are, no education }\end{array}$ & $\begin{array}{l}\text { for } 2 \text { yea } \\
\text { with } 50 \text { otl } \\
\text { playgrou } \\
\text { t health c } \\
\text { reet aid orga } \\
\text { n a camp } \\
\text { devastati } \\
\text { r children }\end{array}$ & $\begin{array}{l}\text { - 2015) } \\
\text { le; shared toilets } \\
\text { no educational } \\
\text { nedicines and } \\
\text { reek islands } \\
\text { rates }\end{array}$ \\
\hline
\end{tabular}




\begin{tabular}{|c|c|c|c|c|}
\hline & \multicolumn{4}{|c|}{$\begin{array}{l}\text { - No housing; people lived in improvised shelters } \\
\text { - Aid organizations and the Greek state were overwhelmed } \\
\text { The Journey to Europe } \\
\text { - Paid smugglers; } 2,000,- \text { EUR; not local community } \\
\text { - Crossed the Mediterranean Sea to Europe } \\
\text { - Life-threatening journey; } 100 \text { people on one small boat } \\
\text { - Brought to camps by Greek state authorities } \\
\text { Why did you leave Syria? } \\
\text { - Civil war, terrorism, Assad } \\
\text { Why did you come to Germany/Europe? } \\
\text { - Safe and secure environment } \\
\text { - Higher living standard } \\
\text { - The economic situation played only a minor role } \\
\text { Under which circumstances would you have stayed in the camps? } \\
\text { - Sufficient health care and nutrition } \\
\text { - Security } \\
\text { - Acceptable living conditions }\end{array}$} \\
\hline P15 & $\begin{array}{l}11^{\text {th }} \text { of August, } \\
\text { Skype (online) }\end{array}$ & $\begin{array}{l}43 \text { minutes and } \\
24 \text { seconds }\end{array}$ & 20, female & Student \\
\hline Notes & $\begin{array}{r}\text { Conditions in } n \\
\text { - The person } \\
\text { - The person } \\
\text { for } 100 \text { peo } \\
\text { - Safe and se } \\
\text { - Sufficient } \mathrm{f} \\
\text { - Reasonable } \\
\text { institutions } \\
\text { Turkish org } \\
\text { - Outside of } \\
\text { Conditions in } \mathrm{E} \\
\text { - The per } \\
\text { - The con }\end{array}$ & $\begin{array}{l}\text { UU camps } \\
\text { d in a Turkish ca } \\
\text { to share the roo } \\
\text { camps } \\
\text { and water suppl }\end{array}$ & $\begin{array}{l}\text { for } 6 \text { mont } \\
\text { vith } 7 \text { other } \\
\text { s for childr }\end{array}$ & $\begin{array}{l}\text { 15) } \\
\text {; shared toilets } \\
\text { educational } \\
\text { rganization plus } \\
\text { s } \\
\text { eek islands (2015) }\end{array}$ \\
\hline
\end{tabular}




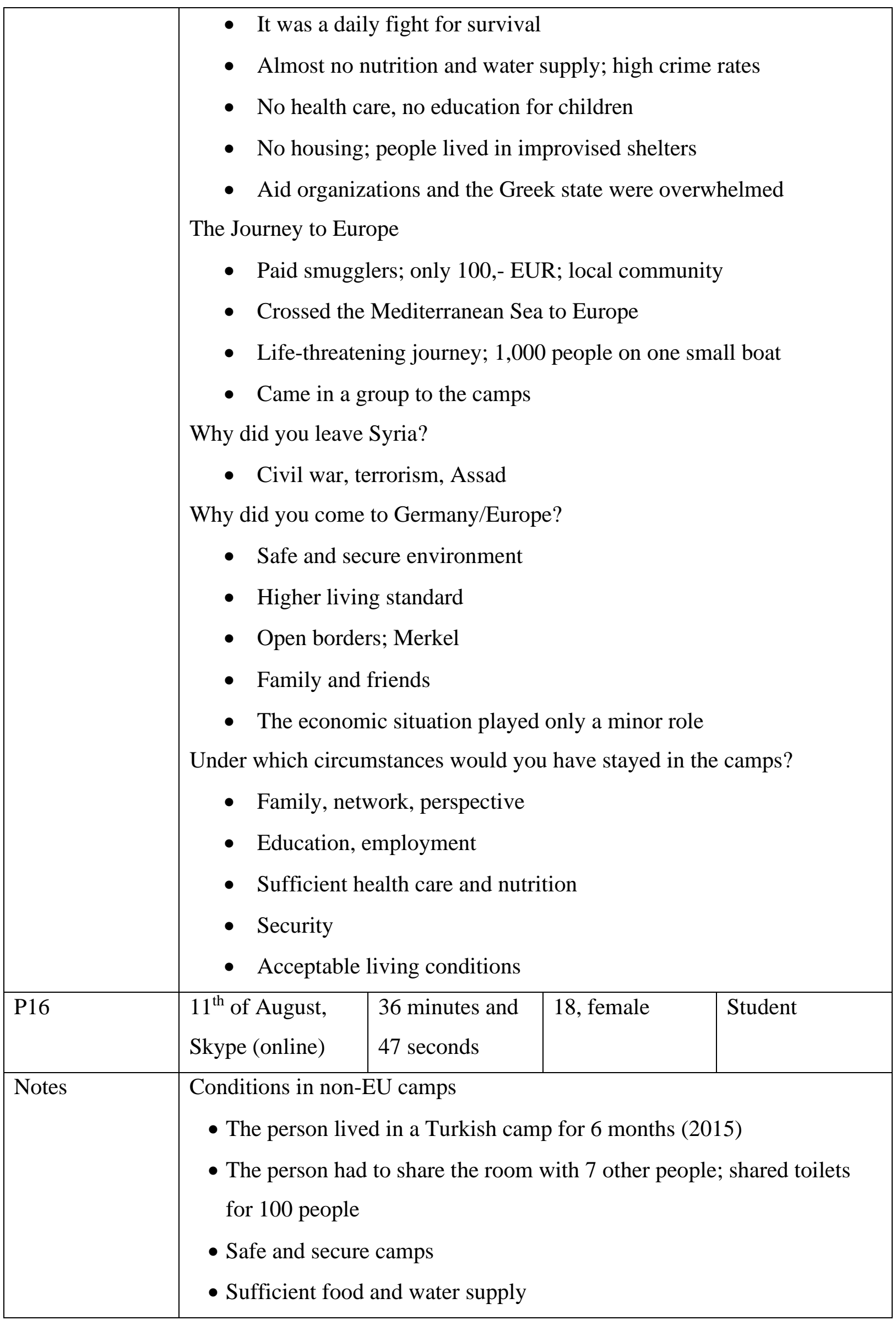




\begin{tabular}{|c|c|c|c|c|}
\hline & 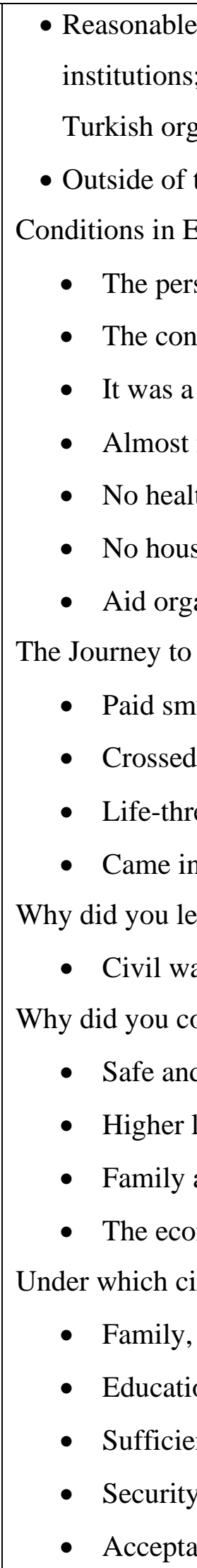 & 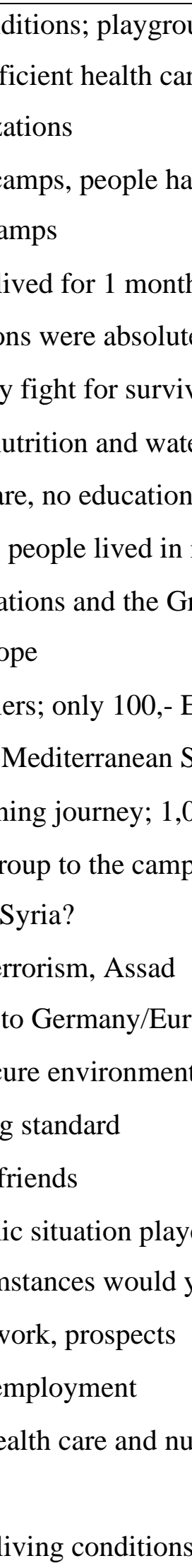 & $\begin{array}{l}\text { ds for child } \\
\text { internatior } \\
\text { to live on t } \\
\text { a camp o } \\
\text { devastatir } \\
\text { supply; hig } \\
\text { phildren } \\
\text { provised st } \\
\text { R; lote we } \\
\text { tion } \\
\text { to Europe } \\
\text { people on }\end{array}$ & $\begin{array}{l}\text { educational } \\
\text { rganization plus } \\
\text { s } \\
\text { eek islands (2015) } \\
\text { rates } \\
\text { helmed } \\
\text { all boat }\end{array}$ \\
\hline P17 & $\begin{array}{l}25^{\text {th }} \text { of August, } \\
\text { Skype (online) }\end{array}$ & $\begin{array}{l}38 \text { minutes and } \\
28 \text { seconds }\end{array}$ & 22, male & Unemployed \\
\hline
\end{tabular}




\begin{tabular}{|c|c|}
\hline Notes & 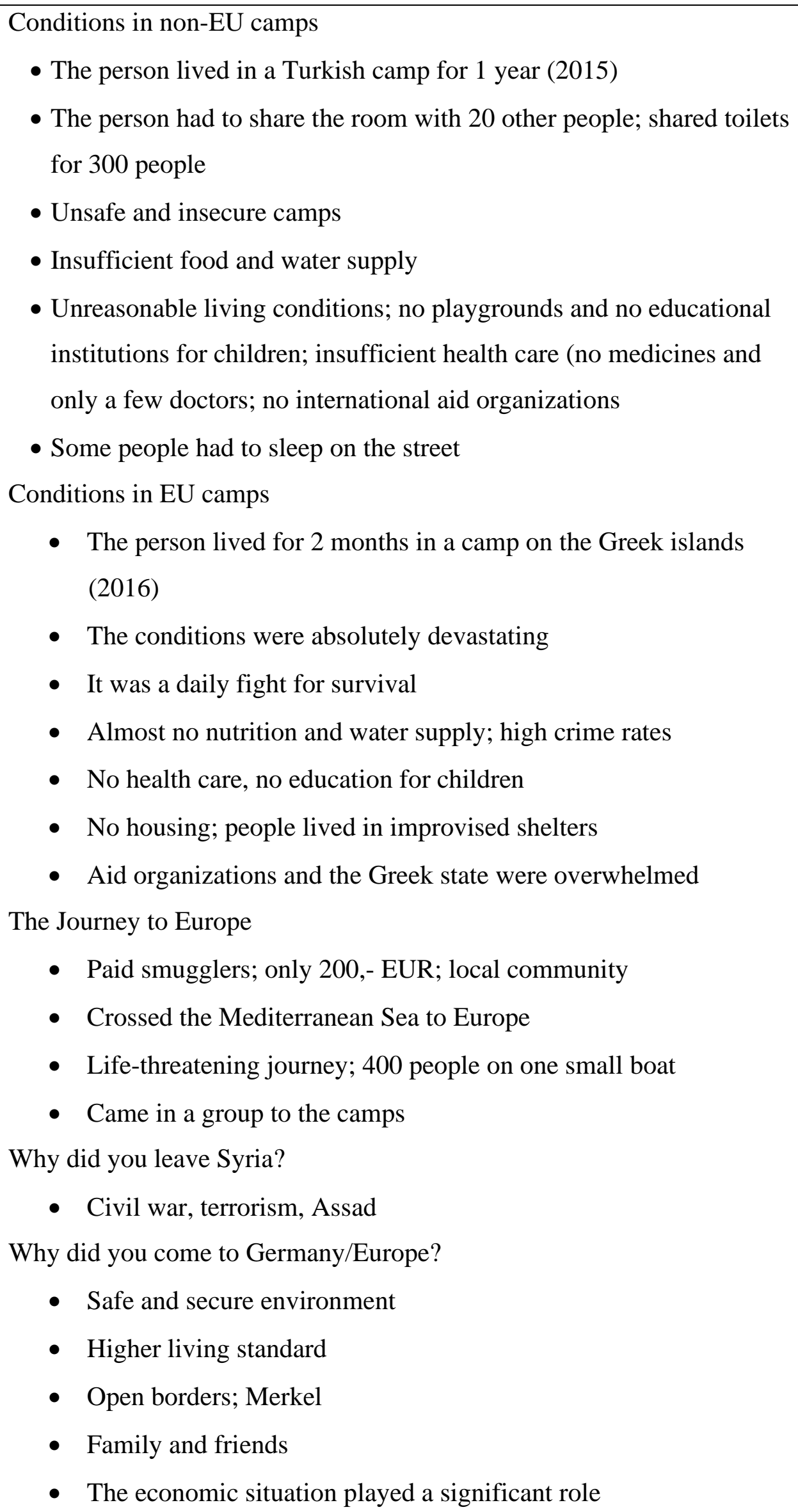 \\
\hline
\end{tabular}




\begin{tabular}{|l|l|}
\hline Under which circumstances would you have stayed in the camps? \\
- Family, network, prospects \\
- Education, employment \\
- Sufficient health care and nutrition \\
- Acceptable living conditions
\end{tabular}

